\title{
Transition to literacy
}

Citation for published version (APA):

Willems, G. (2017). Transition to literacy: the cognitive challenges underlying emergent reading in children at familial risk for dyslexia. [Doctoral Thesis, Maastricht University]. Datawyse / Universitaire Pers Maastricht. https://doi.org/10.26481/dis.20171123gw

\section{Document status and date:}

Published: 01/01/2017

DOI:

10.26481/dis.20171123gw

Document Version:

Publisher's PDF, also known as Version of record

\section{Please check the document version of this publication:}

- A submitted manuscript is the version of the article upon submission and before peer-review. There can be important differences between the submitted version and the official published version of record.

People interested in the research are advised to contact the author for the final version of the publication, or visit the DOI to the publisher's website.

- The final author version and the galley proof are versions of the publication after peer review.

- The final published version features the final layout of the paper including the volume, issue and page numbers.

Link to publication

\footnotetext{
General rights rights.

- You may freely distribute the URL identifying the publication in the public portal. please follow below link for the End User Agreement:

www.umlib.nl/taverne-license

Take down policy

If you believe that this document breaches copyright please contact us at:

repository@maastrichtuniversity.nl

providing details and we will investigate your claim.
}

Copyright and moral rights for the publications made accessible in the public portal are retained by the authors and/or other copyright owners and it is a condition of accessing publications that users recognise and abide by the legal requirements associated with these

- Users may download and print one copy of any publication from the public portal for the purpose of private study or research.

- You may not further distribute the material or use it for any profit-making activity or commercial gain

If the publication is distributed under the terms of Article $25 \mathrm{fa}$ of the Dutch Copyright Act, indicated by the "Taverne" license above, 

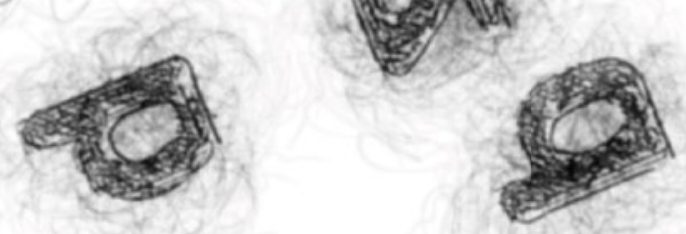

: senesy

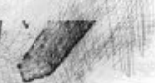

\title{
TRANSITION TO LITERACY
}

the cognitive challenges underlying emergent reading

1. gnitive

\author{
in children
}

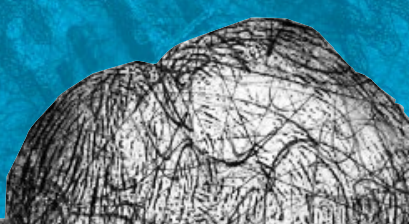
at familial risk

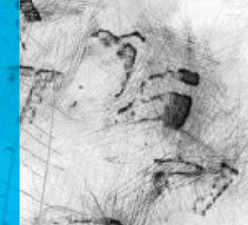

(x)

(2)

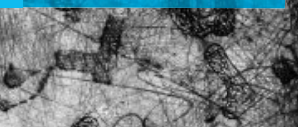

ans.

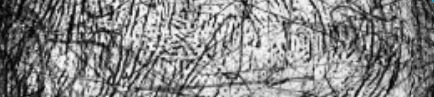

\section{for dyslexia}

है $c+(x=6$

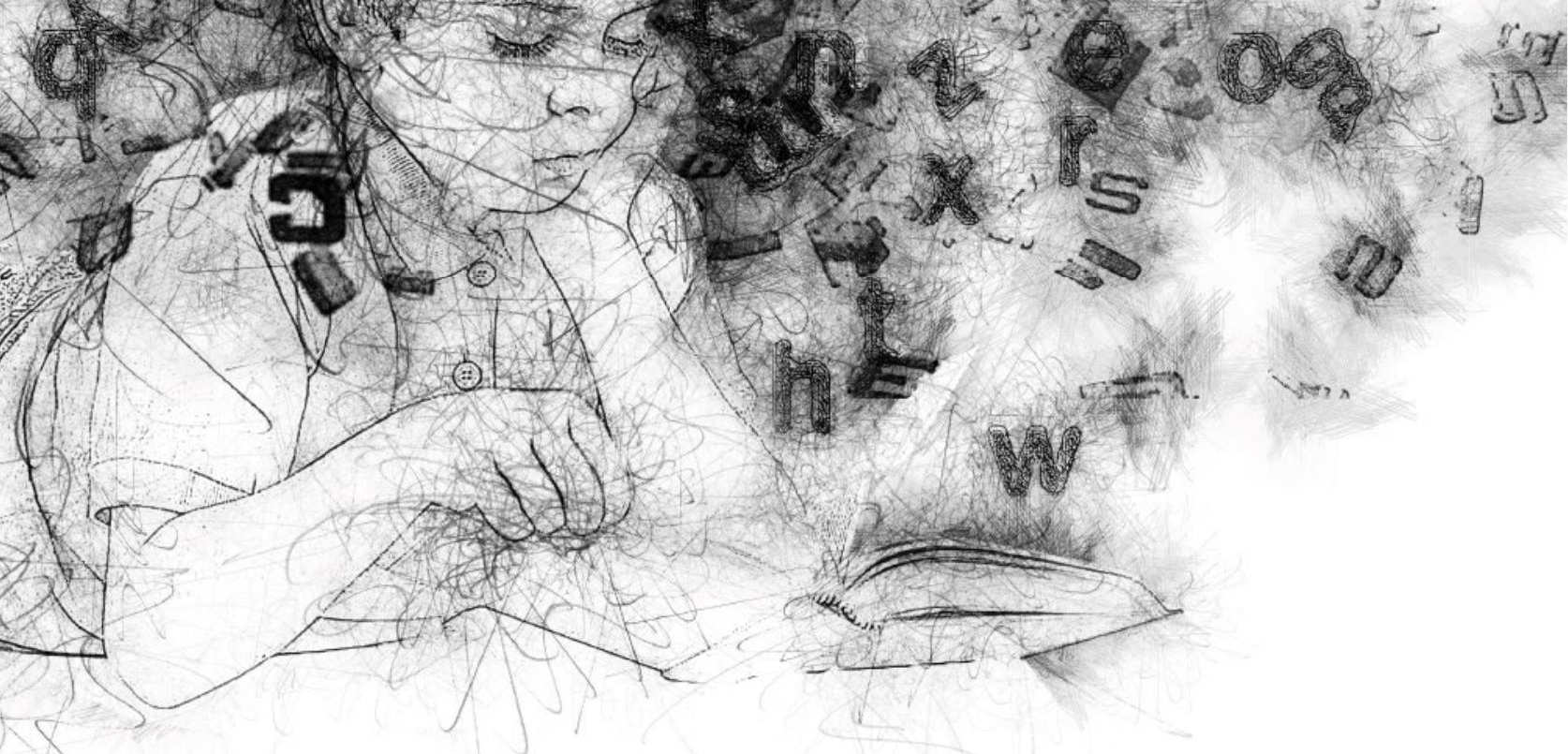

Gonny Willems 



\section{Transition to literacy:}

\section{The cognitive challenges underlying}

\section{emergent reading in children at \\ familial risk for dyslexia}

Gonny Willems 
(C) G. Willems, Maastricht 2017

ISBN: 978-94-6295-737-4

Cover design Robert Nijboer, Oburon Design

Production: Datawyse | Universitaire Pers Maastricht 


\title{
Transition to literacy:
}

\section{The cognitive challenges underlying}

\author{
emergent reading in children at \\ familial risk for dyslexia
}

\begin{abstract}
Proefschrift
Ter verkrijging van de graad van doctor aan de Universiteit Maastricht op gezag van de Rector Magnificus, Prof. dr. Rianne M. Letschert, volgens het besluit van het College van Decanen, in het openbaar te verdedigen op donderdag 23 november 2017 om 12.00 uur

door
\end{abstract}

Gonny Willems

Geboren op 24 oktober 1981 te Hoensbroek 


\section{Promotor}

Prof. dr. B. Jansma

\section{Copromotors}

Dr. A. A. Vaessen, Arnhem

Dr. S. Asteriadis

\section{Beoordelingscommissie}

Prof. dr. S.A. Kotz, (Voorzitter)

Prof. dr. G. Schülte-Korne, University of Munich, D.

Dr. M. Bonte

Dr. J. Tijms, Universiteit van Amsterdam 


\section{TABLE OF CONTENT}

$\begin{array}{ll}\text { CHAPTER 1: } \quad \text { GENERAL INTRODUCTION } & 7\end{array}$

CHAPTER 2: INVESTIGATION OF THE CAUSALITY BETWEEN PHONOLOGICAL AWARENESS 57 DEFICITS AND EMERGING READING DEFICITS IN CHILDREN AT FAMILIAL RISK FOR DYSLEXIA

CHAPTER 3: PHONOLOGICAL-ORTHOGRAPHIC ASSOCIATION DEFICITS IN KINDERGARTEN 87 AND GRADE 1 BEST PREDICT READING OUTCOME IN CHILDREN AT FAMILIAL RISK FOR DYSLEXIA

CHAPTER 4: COGNITIVE AND FAMILIAL RISK EVIDENCE CONVERGED: A DATA-DRIVEN IDENTIFICATION OF DISTINCT AND HOMOGENEOUS SUBTYPES WITHIN THE HETEROGENEOUS SAMPLE OF READING DISABLED CHILDREN

CHAPTER 5: SUMMARY 

CHAPTER 1

GENERAL INTRODUCTION 


\section{PROLOGUE}

Reading is a complex cognitive process that involves the mastery of interpreting a set of printed arbitrary artefacts or symbols for the use of acquiring meaning from a written linguistic message. The ability to read forms the foundation of literacy. While spoken language is acquired spontaneously from birth before reading acquisition starts, becoming literate and mastering a written language system needs intensive and explicit instruction. It has therefore always been assumed that the development of written language builds on the spoken language system. In line with this rationale, it is indeed unlikely that evolution prepared the human brain for such a recent cultural invention by developing a specialized literacy module. Instead, reading is proposed to profit from already evolutionary anchored cognitive visual and spoken language domains (e.g., Liberman, Shankweiler, Fischer, \& Carter, 1974) and related expert brain regions of interest such as the 'Visual Word Form Area' located in the left lateral occipital-temporal sulcus and centred on the mid-fusiform gyrus, which is considered to be the most relevant for fast visual word recognition (Dehaene et al., 2010; McCandliss, Cohen, \& Dehaene, 2003). In this context, it is interesting that amongst the majority of children, of whom most learn to read with relative ease, there is a group of developmental dyslexic children that struggle with acquiring adequate literacy skills, consequent upon a genetic predisposition (e.g., Pennington \& Olson, 2008; Schumacher, Hoffmann, Schmael, Schulte-Körne, \& Nöthen, 2007). Learning to read and write fluently is a necessity for every child in today's modern information-based society. Consequences of a reading deficit can extend far beyond difficulties with literacy alone. Dyslexic readers, for example, may suffer secondary emotional and behavioural problems such as low self-esteem, frustration or motivation difficulties which subsequently challenges their academic, social or economic success (e.g., Bosman \& Braams, 2005; Glazzard, 2010; Ingesson, 2007). Unfortunately, reading failure or dyslexia is usually only diagnosed behaviourally at the time that poor reading skills have already been established, usually indicated by a two-year gap between a child's chronological age and his or her reading age. In a relatively transparent orthography like Dutch, this is usually not before the age of 9 or third grade (Blomert, 2005). In an attempt to help the weakest $10 \%$ of struggling readers as early as grade 1 and/or grade 2 , the Dutch National Dyslexia Protocol recently introduced a strict referral criteria for this weakest group: a pupil with three consecutive e-scores on a Dutch standardized Three-Minute reading test (i.e., bottom 10\%) is referred by their school to get a formal diagnostics investigation at a 
Dyslexia Institute (Gijsel, Scheltinga, van Druenen, \& Verhoeven, 2011a; Gijsel, Scheltinga, van Druenen, \& Verhoeven, 2011b). Nevertheless, the opportunities to minimize, let alone prevent, the above mentioned primary and secondary negative effects within the current school system, are currently still fairly limited for many struggling readers. The need for more effective and precisely targeted diagnostic and intervention efforts, is however eminent. A promising way forward to develop such early identification and intervention attempts is to focus attention on the literacy development of children with a familial risk to develop subsequent severe reading problems, even before they learn to read. Accordingly, it will be possible to identify and assist these children that struggle with reading acquisition at an earlier age than is currently the case. The present thesis therefore focuses on understanding the cognitive deficit pattern underlying reading failure in at-risk children during the early steps of literacy acquisition. The thesis outline starts with the current general introduction of the research objectives of the present thesis, followed by a discussion of the most pertinent concepts of reading development and necessary research lines (present chapter). Subsequently, a number of empirical studies of the present thesis are provided. In chapter 2 and 3, we focus on the transition from being pre-literate in kindergarten to acquiring basic literacy skills in grade 1 and explore relevant precursors of reading development during these basic literacy acquisition stages. Dutch children start primary school with two years of kindergarten before entering grade 1 around the age of seven years old at which point explicit reading instruction starts. In chapter 4, we focus on children with reading fluency problems early on in grade 2 to 4 . Finally, the present thesis is completed with an overall summary and discussion to elucidate its main findings and conclusions (chapter 5 and chapter 6 , respectively).

\subsection{RESEARCH AIMS AND THESIS OUTLINE}

So far, identification and prevention efforts were mainly guided by an abundant literature and overall consensus over many years that phonological awareness (PA), or a child's ability to recognize, identify or manipulate sound units in orally presented words (e.g., Ramus et al., 2003; Wagner, Torgesen, \& Rashotte, 1994), is the main vulnerability marker in dyslexia. In addition, PA is generally assumed to be causally related to reading development (e.g., Rack, 1994; Snowling, 2000; Vellutino, Fletcher, Snowling, \& Scanlon, 2004; Wagner \& Torgesen, 1987). 
Nevertheless, direct evidence supporting that difficulties with PA actually precede reading difficulties, or that PA is necessary before letters can be linked to sounds such that reading ability can develop, is still lacking (Castles \& Coltheart, 2004 , p. 78). Interestingly, empirical evidence that PA and reading ability show strong interactive influences (Morais, Cary, Alegria, \& Bertelson, 1979; Perfetti, Beck, Bell, \& Hughes, 1987), has hardly influenced the status of PA as the main cause of reading failure in the generally assumed phonological deficit theory (Frith, 1986; Rack, 1994; Snowling, 1981, 2000; Stanovich \& Siegel, 1994; Vellutino, et al., 2004). Other researchers incorporate such an interaction, proposing a reciprocal causality between reading and PA skills. They postulate that phonological awareness supports reading acquisition and that awareness of single phonemes, or phonemic awareness specifically, develops mainly as a consequence of learning to read (for reviews see Castles \& Coltheart, 2004; Ziegler \& Goswami, 2005). Illiterates for instance show severe phonemic awareness problems and only start to show some phonemic awareness insights after basic literacy training (Morais, Bertelson, Cary, \& Alegria, 1986). A subsequent study refined these results further and revealed that the development of phonemic awareness in illiterates and semi-literates showed a strong dependency on alphabetic acquisition (De Santos Loureiro, Willadino Braga, Souza, Queiroz, \& Dellatolas, 2004; Landgraf et al., 2012). At the same time, results showed that their phonological awareness and phonological processing skills other than awareness (i.e., 'phonological insensitivity' involving access or retrieval of larger speech segments in phonological working memory tasks, rhyme identification and phonological lexical processing) were unrelated to their limited knowledge of letters and words. Since the bidirectional influence between PA and reading skills is already in effect in established readers, studying a PA-reading relationship in this group obviously cannot result in the possibility to decide on causal matters. However, by exploring pre-reading children in kindergarten, before the start of explicit literacy instruction, this reciprocal influence between reading and underlying PA deficits can be avoided, and only then can decisive, causal evidence be provided. The study described in chapter 2 focuses on kindergarten and grade 1 children, with and without a familial risk of dyslexia, and aims to establish evidence for the directionality of the PA-reading relationship by addressing the following basic claims of the phonological awareness deficit theory of dyslexia: 
1. Is a phonological awareness deficit characteristic for a familial dyslexia risk?

2. Is a phonological awareness deficit causally linked to a reading deficit?

3. Is 'phonological insensitivity' linked to a reading deficit?

Another issue which remains to be established is the still elusive claim that a PA deficit directly influences the development of a reading deficit by causing 'unstable' letter-speech sound correspondences (Snowling, 2000; Vellutino, et al., 2004 for review). If so, kindergarten children with a familial risk for subsequent reading disability showing a PA deficit before learning to read are also expected to show a letter-speech sound association deficit. It is however also possible that such a deficit in learning letter-speech sound associations constitutes a specific problem for at-risk children in kindergarten, independent of the presence of phonological problems. Thus, the study described in chapter 2 also aims to answer the following research questions:

4. Is a phonological awareness deficit causing later reading deficits by causing 'unstable' or otherwise poor letter-speech sound associations?

5. Can children at-risk for dyslexia at pre-reading age be differentiated from control subjects on the basis of their letter-speech sound learning ability on a training specifically designed to accurately teaching these associations?

Next to phonological awareness, reading researchers also explored the possible use of other reading-related vulnerability markers characteristic of reading failure. This is not surprising, given the multi-dimensional nature of reading and the heterogeneous composition of the reading disabled population. Previous predictor studies for instance identified that adequate skills in rapidly and accurately naming well-known visual symbols such as letters and objects (i.e., rapid automatized naming, or RAN) as well as fluent processing and understanding the relationships between letters and speech-sounds (i.e., letter-speech sound efficiency, or LS) are both important markers of normal reading development (e.g., Adams, 1990; Berninger, Abbott, Thomson, \& Raskind, 2001; Kirby, Georgiou, Martinussen, \& Parrila, 2010; Landerl et al., 2013; 
Scarborough, 1989, 1990; Snowling, Gallagher, \& Frith, 2003). Predicting success in subsequent reading might however not necessarily be the same as predicting poor reading outcome. For instance, although kindergarten PA is found to be a good predictor of subsequent successful reading, several studies showed that having a limited appreciation of the phonological structure of spoken language prior to reading does not necessarily imply that these children turn out to be poor readers (e.g., Ehri, 1998; Wimmer, Landerl, Linortner, \& Hummer, 1991; Wimmer \& Schurz, 2010). So far, the knowledge on early kindergarten predictors of reading outcome in children at risk of dyslexia is still scarce, especially in more transparent orthographies. These languages have clear often one-on-one letter-speech sound correspondences and regular spelling rules such as Finnish being the most transparent European language and Italian and Dutch that are considered fairly transparent. The few at-risk studies that identified early cognitive readingrelated markers such as PA, RAN and LS processing as relevant kindergarten predictors were mainly conducted in opaque orthographies (Cardoso-Martins \& Pennington, 2004; Elbro, Borstrøm, \& Petersen, 1998; Gallagher, Frith, \& Snowling, 2000; Pennington \& Lefly, 2001; Petersen \& Elbro, 1999; Scarborough, 1989, 1990; Snowling, et al., 2003; Thompson et al., 2015), although a few at-risk studies also researched children learning to read in a transparent orthography (Boets et al., 2010; Puolakanaho et al., 2008; Puolakanaho et al., 2007; Torppa, Lyytinen, Erskine, Eklund, \& Lyytinen, 2010). Learning to read in an opaque or deep orthography, like English or Danish, with not just one-on-one but numerous possible letterspeech sound mappings, is much more effortful and time-consuming than learning to read in a relative transparent orthography (Seymour, Aro, \& Erskine, 2003; Wentink \& Verhoeven, 2003). Consequently, the predictive role of important reading-related markers might differ between these orthographies, especially during the early stages of reading acquisition (for an overview see Share, 2008). Finally, it is important to examine possible predictors of future reading outcome over a period of time, as their prognostic value might change as a function of developmental maturation and school experience (e.g., Muter, Hulme, Snowling, \& Stevenson, 2004; Pennington \& Lefly, 2001; Vaessen \& Blomert, 2010; Wagner et al., 1997; Wesseling \& Reitsma, 2000). The research described in chapter 3 focuses on children with and without a familial history of dyslexia, learning to read in the relatively transparent Dutch orthography, and investigates the underlying deficit pattern predictive of future reading outcome in these children. The main aim of this research is to add to the rather limited research on early predictors of reading outcome in transparent orthographies, and increase current 
understanding on relevant, early kindergarten and grade 1 predictors of subsequent reading in Dutch. We also investigate whether predictors vary as a function of at-risk status in this orthography. Chapter 3 further investigates the following research questions:

6. Are kindergarten $P A, R A N$ and $L S$ knowledge important predictors of subsequent grade 1 and 2 reading ability in at-risk children learning to read in a relatively transparent orthography?

7. Does the emerging correlation pattern after kindergarten differ as a result of acquiring basic literacy skills in grade 1 (i.e., grade 1 prediction of subsequent grade 2 reading fluency)?

8. Is the correlation pattern found in children at-risk for a deficient reading development comparable to the pattern found in their normally developing peers without such a familial predisposition?

In the last and forth chapter, we focus on identifying relevant subtypes of poor reading within a large sample of children struggling with reading fluency early on in grade 2 to 4 . The heterogeneity of poor readers has puzzled reading researchers for years, resulting in numerous classification studies attempting to identify more homogeneous subtypes within this mixed population. These classification studies widely differ in their approach, which often resulted in equally variable classification profiles. While some studies for instance focus on poor reading fluency skills, others focus on reading comprehension ability. Also, several studies include a pure population of reading impaired children, while others focus on children suffering from a wide variety of learning disabilities amongst which dyslexia, arithmetic problems, and attention deficits. Another difference is the variation in statistical approaches for such classification, either being pre-defined and top-down, or data-driven and bottom-up. These previous studies demonstrated the possibility to find distinct subtypes, but there is to our knowledge no study yet that took into account major advances in the genetic underpinnings of reading disability. One of these findings is that dyslexia is highly heritable and runs in families (e.g., Grigorenko, 2004; Pennington, 1990; Pennington \& Olson, 2008; Peterson \& Pennington, 2015). The aim of the study described in chapter 4 was to establish coherent and distinct subtypes of poor reading based on theoretically relevant reading-related measures (PA, RAN, LS processing and VWM) in addition to general cognitive skills (i.e., non-verbal IQ and vocabulary), and, subsequently, 
investigate whether these subtypes can be distinguished based on familial risk and environmental risk factors (e.g., socio-economic status, school reading performance level and comorbidity factors). To this aim, we adopted a data-driven classification approach, which provides the opportunity to explore distinct subtypes without making a priori assumptions on the nature and number of emerging subtypes and thus not being limited by any theoretical constraints beyond the included clustering variables. The questions that will be addressed in chapter 4 are:

9. Can a data-driven classification based on the cognitive reading-related vulnerability markers $P A, R A N, L S$ processing and verbal working memory differentiate distinct and coherent cognitive deficit profiles within a large and heterogeneous sample of grade 2 to 4 poor readers?

10. Are possible emerging cognitive deficit patterns underlying different types of poor reading distinguishable based on familial risk influences, environmental risk influences or a combination?

\subsection{HOW CHILDREN LEARN TO READ}

In the Netherlands, primary school starts at the age of four and lasts for eight years. During the first two years that are called kindergarten, no formal reading instruction is provided and no emphasis is placed on systematically learning about letter-speech sound correspondences. Yet, some attention is paid to emergent literacy skills and knowledge of letters by means of storytelling, rhyming games or songs that induce children to become at least aware of the segments in spoken language. In the third year of primary school (i.e., first grade), the year most children turn seven, formal reading instruction starts. Primary schools choose a reading method out of a selection of reading instructions that are updated regularly and reinforced by Dutch government. During the initial phase of reading instruction these methods concentrate on developing phonological awareness by means of exercises that require analysing and blending of written words. There is also a large emphasis on explicit phonetics instruction, a way of reading education that stresses the acquisition of letter-sound correspondences and their use in reading and spelling (Reitsma \& Verhoeven, 1990), a crucial step in the development of subsequent 
fluent reading skills (Ehri, 2005; Frith, 1985; Ziegler \& Goswami, 2005). The mastery of these initial steps of literacy acquisition builds on the existence of a writing system, also called a script. A script represents meaning, either by means of logograms, which are single written symbols representing a complete word (for instance in the logographic script Chinese), or by means of arbitrary and abstract representations such as letters, consonants or syllables (i.e., an alphabetical script). Like most modern orthographies, the Dutch orthography is an alphabetical writing system, with an alphabet consisting out of 26 letters; 6 vowels and 20 consonants. So, a child first has to learn about the alphabet and acquire understanding that words and syllables in spoken language consist out of sounds that map onto this limited amount of letters (i.e., the alphabetical principle; Liberman, Shankweiler, \& Liberman, 1989). In a perfectly consistent alphabet like Finnish, each letter and phoneme correspond bi-directionally; a speaker can predict the pronunciation of a word given its spelling, and a writer can predict the spelling of a word given its pronunciation (e.g., Caravolas, Lervåg, Defior, Málková, \& Hulme, 2013; Seymour, et al., 2003). In a highly inconsistent or opaque alphabet like English, there are many speech sounds represented by more than one letter and the other way around (e.g., Caravolas, et al., 2013; Seymour, et al., 2003). On this continuum from highly consistent to highly opaque orthographies, Dutch can be classified as a fairly consistent orthography in which a large part of letters and speech sounds correspond in a one-on-one fashion (Reitsma \& Verhoeven, 1990; Wentink \& Verhoeven, 2003). However, there are some inconsistencies to this one-to-one relation indicated by the fact that the 26 letters of the Dutch alphabet are not sufficient to sound out all phonemes existing in spoken language and therefore 36 basic graphemes (corresponding to single phonemes as well as several combined phonemes or diphthongs like /oe/ or /eu/) are introduced to first grade children. Although the Dutch orthography is fairly consistent, it takes young children approximately a year to accurately master these letterspeech sound relations and with this a tool to decode and encode an almost infinite amount of words (Blomert \& Vaessen, 2009; Seymour, et al., 2003; present thesis chapter 2). As a result, most Dutch children are able to read some simple, consistent words by the end of first grade, although reading still relies heavily on an effortful and slow decoding process (Seymour, et al., 2003; Wentink \& Verhoeven, 2003; present thesis chapter 2 and 3). As an effect of large amounts of reading practice, children's word decoding skills improve, resulting in the ability to identify written words more accurately and fluently over time. As a consequence of growing accurate and automatic decoding, the phonological representation of a written word is directly 
linked to its orthographic form in established readers (e.g., Adams, 1990; Ehri, 1998, 2000; Jorm \& Share, 1983; Share, 1999). Thus, when a child develops from the initial stages of reading to becoming a proficient and fluent reader, a shift is made from a slow phonological decoding strategy to automatic direct whole word identification and reading fluency (for an overview see Ehri, 2005).

\subsection{THE HETEROGENEITY OF READING FAILURE AND THE HISTORY OF DEFINING DYSLEXIA}

Although learning how to read is an effortful process for many years and it is not an innate cognitive skill, only a small proportion of children fail to master this process successfully. More specifically, around $10 \%$ of Dutch school children struggle with learning to read and write adequately and turn out to be poor readers at the end of primary school (Blomert, 2005). Of these poor readers, around $40 \%$ will be diagnosed with developmental dyslexia, which results in an epidemiological estimate of approximately 4\% (Blomert, 2005; for similar results in other orthographies see Badian, McAnulty, Duffy, \& Als, 1990; Børstrom \& Elbro, 1997; Byrne, Shankweiler, \& Hine, 2008; Shaywitz, Shaywitz, Fletcher, \& Escobar, 1990). Please note that the present thesis will focus on this type of developmental dyslexia, from here on named dyslexia, and not on the fairly rare form of acquired dyslexia, which is usually the result of some type of brain trauma. Dyslexia is considered to be the most prevalent developmental disorder acknowledged by the Western world and in the Netherlands approximately 640.000 individuals are affected in the general population, around 40.000 children in primary schools and yearly incidence of new dyslexia diagnoses tallying up to 7000 children (Blomert \& Vaessen, 2008). Given the multi-dimensional nature of reading, requiring a host of sensory, perceptual, linguistic abilities and intellectual capacities, it is not surprising that poor readers constitute a heterogeneous group with variable impairments in a broad range of domains, likely to emerge from equally variable cognitive and/or biological sources. Consequently, answering the challenging question how to define and research the disability has been greatly debated.

Historically, a reading-specific learning disability in adults was first reported on in the second half of the nineteenth century by Berkhan (1985) and later coined 'Dyslexia' by Berlin (1887). In 1896, a physician named Morgan published a report in the British Medical Journal titled 'Congenital Word Blindness' to describe the case of a fourteen-year-old boy that, despite 
adequate intellectual capacities and development in other domains, was not able to learn to read adequately (Morgan, 1896). Other terms traditionally used to refer to reading failure where, for instance, 'Word Blindness' (Kussmaul, 1877), 'Strephosymbolia' (Orton, 1925), and 'Reading Retardation' (Rutter \& Yule, 1975). Over 75 years ago, (Schonell, 1935) first differentiated between two distinct types of poor readers, namely, specific reading disability/retardation, or dyslexia, and general reading disability also called general backward reading (Rutter \& Yule, 1975), or garden-variety poor reading (Gough \& Tunmer, 1986; Stanovich, 1988). (Rutter \& Yule, 1975) proposed the idea to define dyslexia according to a discrepancy between the intellectual capacities of a child and their expected reading performance. Nevertheless, the IQ-achievement discrepancy criterion was challenged from its inception and discarded over the past two decades due to a lack of evidence for reliably distinguishing different types of poor readers in terms of for instance long-term prognosis or response to intervention (for a review see Stanovich \& Siegel, 1994; Stuebing et al., 2002; Vellutino, Scanlon, \& Lyon, 2000). Alternative pre-defined categories of different poor reading profiles were based on either being characterized by a specific word decoding deficit or a more general word decoding and comprehension deficit, i.e., the 'simple view of reading' (Gough \& Tunmer, 1986). This brief historical overview clearly indicates that the classification field of reading failure is by no means a new one. Although these early decades of reading research have not led to a uniform definition of dyslexia, they significantly contributed to the ongoing debate on what constitutes reading failure and supported at least the possibility of distinguishing between specific types of reading disability.

\subsection{DEFINITION OF DEVELOPMENTAL DYSLEXIA}

Despite the ongoing debate on how to define dyslexia, it is currently agreed upon that dyslexia is characterized by serious and persistent difficulties in literacy skills, mainly inaccurate and influent word recognition, inadequate spelling skills and poor decoding abilities (Hulme \& Snowling, 2016; Lyon, Shaywitz, \& Shaywitz, 2003). One of the major challenges to come to an accurate, uniform definition of dyslexia has been agreeing on the source of the disability. As mentioned, the predominant aetiological view of dyslexia postulates it to result from a phonological deficit (e.g., Rack, 1994; Snowling, 2000; Vellutino, et al., 2004). Nevertheless, 
other reading-related cognitive factors, mostly complementary to phonological difficulties, were explored as possible causes as well. For instance, visual and magnocellular deficits (Lovegrove, 1996; Stein, 2001; Stein \& Walsh, 1997), cerebellar deficits (Nicolson et al., 1999; Nicolson, Fawcett, \& Dean, 2001), rapid naming deficits (Bowers \& Ishaik, 2003; Wolf \& Bowers, 1999) and rapid auditory processing deficits (Tallal, 1980; Tallal, Miller, \& Fitch, 1993; Temple et al., 2000). Therefore, over the last years, researchers opted for a working definition of dyslexia to agree upon for future research, since such a working definition does not require any causal explanation of the condition. Proposed definitions of dyslexia for example are:

(DSM-V): Decoding difficulty or dyslexia is defined as difficulty with mastering the relationships between spelling patterns of words and their pronunciation. Dyslexic children read inaccurately and slow and experience spelling problems and their literacy problems are indicated to arise from a phonological (speech sound) deficit (This newer version of the DSM decouples a decoding impairment (or dyslexia) from reading comprehension impairment. It is remarkable and counter opposed by many dyslexia experts that dyslexia and other types of learning disorders like dyscalculia are no longer considered as discrete entities by DMS-V, but instead collectively are categorized under specific learning disabilities) (DSM-V: American Psychiatric Association, 2013). For a review on the limitations of this 'categorical' approach to learning disorders see (Snowling \& Hulme, 2012).

(British Dyslexia Institution): Dyslexia is best described as a combination of abilities and difficulties that affect the learning process in one or more of reading, spelling, and writing. Accompanying weaknesses may be identified in areas of speed of processing, short-term memory, sequencing and organization, auditory and/or visual perception, spoken language and motor skills. It is particularly related to mastering and using written language, which may include alphabetic, numeric and musical notation. Some dyslexics have outstanding creative skills. Others have strong oral skills. Some have no outstanding talents. They all have strengths. Dyslexia can occur despite normal intellectual ability and teaching. It is independent of socioeconomic or language background (BDA: The Dyslexia Handbook, 2002).

(International Dyslexia Association): Dyslexia is a specific learning disability that is neurobiological in origin. It is characterized by difficulties with accurate and/or fluent word 
recognition and by poor spelling and decoding abilities. These difficulties typically result from a deficit in the phonological component of language that is often unexpected in relation to other cognitive abilities and the provision of effective classroom instruction. Secondary consequences may include problems in reading comprehension and reduced reading experience that can impede growth of vocabulary and background knowledge (IDA: About dyslexia, 2002).

Overall, dyslexia is defined as a specific learning disability, characterized by literacy difficulties that are often unexpected considering general intellectual capacities, normal sensory functioning and educational opportunities. Moreover, dyslexic and more generally impaired poor readers, both within and beyond the literacy domain (e.g., low intellectual capacity, poor mathematics, sensory deficits, low socio-economic or other environmental disadvantages), are considered to be distinct categories of poor reading. Results from neuroimaging and genetic studies (e.g., Grigorenko, 2001; Pennington \& Olson, 2008; Schumacher, et al., 2007; Williams \& O'Donovan, 2006) have added to the definition of dyslexia indicating that specific learning disability has a neurobiological origin with a strong genetic predisposition to develop reading impairment. Taking into account this predisposition of family risk factors when classifying distinct poor reader subtypes within the heterogeneous poor reader population (present thesis, chapter 4), will not only promote the possibility of more precise diagnostic and intervention efforts targeted to the specific needs of each cognitive subtype, but will also create straightforward possibilities to unravel behavioural, biological origins of possible subtypes.

\subsection{FAMILIAL RISK AND GENETICS OF DYSLEXIA}

The recent discoveries on the genetic basis of dyslexia have their origins in the beginning of the twentieth century when dyslexia was first described in several case studies as a reading disability that reoccurred in families (Thomas, 1905, reviewed by Pennington, 1990). Around 50 years later, (Hallgren, 1950) carried out the first formal genetic epidemiological and large-scale family study that provided considerable evidence for the familial and heritable character of this learning disability. Especially the last two decades substantially contributed to our present understanding of the neurobiological and genetic basis of dyslexia (Grigorenko, 2001; McGrath, Smith, \& Pennington, 2006; Pennington \& Olson, 2008; Schumacher, et al., 2007; Williams \& 
O'Donovan, 2006). First, studies indicated a higher risk to develop reading disability among relatives with at least one dyslexic member in their family compared to the general population (Pennington \& Olson, 2008). More specific, the prevalence of dyslexia in children at familial risk is estimated to be around 40\% to 50\% (Borstrøm \& Elbro, 1997; Byrne et al., 2006; Byrne, et al., 2008; Lyytinen et al., 2006; Pennington \& Lefly, 2001; Puolakanaho, et al., 2007), which is 10 times the population prevalence. Since at-risk children share both genes and life style habits and environmental factors with their relatives, a gene-environment interaction might be at play. Although having a family history of dyslexia is one of the strongest risk factors of the disorder (e.g., Snowling, et al., 2003; Thompson, et al., 2015), it should not be considered a pure genetic component (Byrne et al., 2009; Christopher et al., 2015; Williams \& O'Donovan, 2006). The strongest evidence dissecting heritability and shared family environment comes from twin studies (Christopher, et al., 2015; Pennington \& Olson, 2008; Plomin, Reiss, Hetherington, \& Howe, 1994; Rutter \& Silberg, 2002), comparing the concordance of a trait in monozygotic twin pairs (i.e., identical or one-egg) with that in heterozygote twin pairs (i.e., fraternal or two-egg). Both types of twin pairs have a similar shared family environment, while the degree of relatedness is larger in monozygotic than in heterozygote twins. Twin studies investigating the heritability of dyslexia, for example, showed that the concordance rate for monozygotic twins is estimated at $80 \%$, whereas this is less than $50 \%$ for heterozygote twins (Pennington \& Olson, 2008). Next to the fact that dyslexia is both heritable and runs in families, the most recent breakthrough on the genetic underpinnings of dyslexia has been the discovery of several candidate susceptible genes for dyslexia. Molecular studies have established a link between the genetic predisposition for dyslexia and the DCDC2 gene (Centanni et al., 2016; Meng et al., 2005) and the KIAA0319 gene (D'Souza et al., 2016; Paracchini et al., 2008) on chromosome 6 (Grigorenko, Wood, Meyer, \& Pauls, 2000), and the DYX1C1 gene on chromosome 15 (Taipale et al., 2003; Tran et al., 2013). Furthermore, genetic studies have indicated the existence of at least two possible aetiologies for the poor reading skills of the heterogeneous sample of reading disabled children: a primarily genetic, specific impaired type with adequate general cognitive capacities and a more generally impaired environmentally influences type (Castles, Datta, Gayan, \& Olson, 1999; Friend, DeFries, \& Olson, 2008; Knopik et al., 2002; Olson, Wise, Conners, Rack, \& Fulker, 1989; Rack \& Olson, 1993; Wadsworth, Olson, \& DeFries, 2010; Wadsworth, Olson, Pennington, \& DeFries, 2000). Interestingly, neuroimaging results corroborated the existence of these two types of childhood reading failure amongst young adults followed 
prospectively and longitudinally from the age of five onward: one primarily genetic poor reader type with higher IQ and a more generally impaired type characterized with lower IQ and influenced most by environmental risk factors as indicated by a trend to attend more disadvantaged schools (Shaywitz \& Shaywitz, 2005). While the first subtype showed relative under activation in posterior neural systems located in the superior temporal and the occipitaltemporal regions during real word reading, the later subtype showed activated posterior systems during real word reading. More and more established becomes the view that familial risk for dyslexia is one of the key predictors of future reading problems (Lyytinen et al., 2001; Puolakanaho, et al., 2008; Scarborough, 1989, 1990; Thompson, et al., 2015). Perhaps even more important, this increased familial risk for subsequent literacy problems can be identified early on in the development of a child, even before they have learned to read and write. Consequently, research focused on pre-literate at-risk children might find useful cognitive precursors and lead to early identification of dyslexia (present thesis, chapter 3) as well as the possibility to alleviate or even prevent primary and secondary (e.g., behavioral or emotional) difficulties related to impaired reading development. Moreover, it creates the opportunity to investigate potential interaction of cognitive and biological factors of reading failure before the reciprocal influence of reading comes into play.

\subsection{IDENTIFICATION OF READING DISABILITY: UNDERLYING COGNITIVE VULNERABILITY MARKERS}

The exact relation between genes and brain functions and whether different genes explain the variety of reading and spelling phenotypes is still unknown (Berninger \& Richards, 2010). Investigating a gene-behavior relation is a challenge as the concordance between a child's genetic make-up (genotype) and his or her cognitive reading and reading-related abilities or behavioral traits (phenotype) does not reflect a straightforward correspondence (Fischer \& DeFries, 2002). The way dyslexia is clinically defined, as a specific impairment in reading with otherwise normal general cognitive ability and opportunity, seems too simplistic and generalized, not being able to differentiate between distinct, coherent aetiologies with possibly different biological origins within this heterogeneous and complex trait. A way forward is to focus on the identification of 'vulnerability markers' that make it possible to parse behavioral 
risk factors into more coherent, distinct cognitive phenotypes of the disability (Gooch, Snowling, \& Hulme, 2011; Moll, Loff, \& Snowling, 2013; Pennington, 1997; Skuse, 2001) and are intended as a simpler indicator regarding causal factors that may be related to the disorder (Gottesman \& Gould, 2003). Phonological awareness, rapid naming, letter-speech sound processing and verbal working memory have been proposed as potential, behavioral vulnerability or dyslexia-related cognitive markers.

THE ROLE OF EMERGENT PHONOLOGICAL AWARENESS. Phonological awareness (PA) is often seen as the critical element or the sine qua non of successful reading acquisition (e.g., Share, 1995), and it is therefore not surprising that it is proposed to be the most important vulnerability marker in reading children (Berninger et al., 2006; Berninger \& Richards, 2010; Snowling, 2008). Good PA characterizes normally developing readers and poor PA is seen as the core deficit in dyslexia (Adams, 1990; Frith, Wimmer, \& Landerl, 1998; Landerl, et al., 2013; Liberman, et al., 1989; Moll, et al., 2013; Ramus, 2003; Snowling, 2000; Stanovich, 1988; Vellutino, et al., 2004). In addition, phonological skills are found to correlate with word recognition skills (for a review see Grigorenko, 2001; Ramus, 2006). Both impaired and unimpaired familial at-risk children show phonological processing problems, although perhaps differing in severity (Bruck, 1992; Lyytinen, et al., 2006; Puolakanaho, et al., 2008; Snowling, 2008; Wilson \& Lesaux, 2001). PA is considered one of the most important predictors of reading development in opaque orthographies like English (e.g., Bradley \& Bryant., 1983; CardosoMartins \& Pennington, 2004; Goswami \& Bryant, 1990; Torgesen, Wagner, \& Rashotte, 1994; Torgesen, Wagner, Rashotte, Burgess, \& Hecht, 1997) as well as in more transparent orthographies, although to a lesser extent (Bigozzi, Tarchi, Pinto, \& Accorti Gamannossi, 2015; de Jong \& van der Leij, 1999; Georgiou, Parrila, \& Papadopoulos, 2008; Harris \& Giannouli, 1999; Holopainen, Ahonen, \& Lyytinen, 2001; Landerl \& Wimmer, 2008; Vaessen, Gerretsen, \& Blomert, 2009; Wimmer \& Schurz, 2010; Ziegler et al., 2010). Interestingly, some studies on transparent languages indicate that PA is not a relevant predictor of reading (Georgiou, Parrila, et al., 2008; Mann \& Wimmer, 2002). This might be explained by the more consistent one-toone mappings of letters and sounds found in more transparent orthographies, naturally promoting higher PA levels given the reciprocal influence between reading and PA development (Morais, et al., 1986; Morais, et al., 1979; Perfetti, et al., 1987). However, several cross-language studies comparing a range of orthographies varying in script depth (i.e., the level of 
transparency of phoneme to symbol mapping), indicate that PA is an important predictor across all orthographies as long as adequate measures of PA are involved (Caravolas, et al., 2013; Caravolas et al., 2012; Ehri, Nunes, Stahl, \& Willows, 2001; Furnes \& Samuelsson, 2011; Vaessen et al., 2010; Ziegler, et al., 2010). Phonological awareness starts to emerge when children learn to understand and use spoken language, years before children acquire written language. From this point onward, the development of PA follows a continuum of complexity on which a child gradually learns to understand that spoken alphabetical language can be broken down into smaller and smaller speech segments. The main rational here is as follows: since letters represent speech sounds in alphabetical languages, children first need to become aware of the fact that spoken language and in particular words and syllables can be segmented into individual speech sounds, before being able to unlock the intricate process of matching these speech sounds to their written counterparts and then learn how to read (Gough \& Tunmer, 1986; Mattingly, 1972)

Before the start of formal reading education, children usually show an adequate performance on phonological awareness tasks involving larger speech segments such as words or syllables (e.g., on rhyming tasks). In a next step, children must become aware of the individual phonemes in spoken words and thus develop some phonemic awareness before being able to learn the correspondences between letters and these phonemes and subsequently learn to read. This view thus assumes that PA is not only the main predictor of reading in established readers, it also assumes that phonemic awareness plays a causal and preceding role in the acquisition of reading skills (e.g., Adams, 1990; Goswami \& Bryant, 1990; Snowling, 2000; Vellutino, et al., 2004; Wagner \& Torgesen, 1987). There has however to date been no direct evidence for this latter claim of a causal role of PA in reading. Instead, many researchers question whether phonological awareness actually does represent a distinct set of spoken language skills that (a) precede and (b) directly influence the acquisition of reading skills (for an excellent overview of pros and cons see Castles \& Coltheart, 2004; Ziegler \& Goswami, 2005). Moreover, the idea that phonology and reading are two sides of the same coin, showing a reciprocal relationship, with PA enhancing reading skills and vice versa (Ehri, 1989, 2000; Morais, et al., 1986; Morais, et al., 1979; Perfetti, et al., 1987), has hardly influenced this assumed but never proven causal role of PA in reading development. Instead, phonological awareness of the smallest units of sounds, namely phonemes, also called phonemic awareness, might actually only develop in close relation with or even as a consequence of learning to read and write, 
instead of being a causal precursor of reading (Castles \& Coltheart, 2004; Wimmer, et al., 1991; Ziegler \& Goswami, 2005; present thesis, chapter 2). In support, studies indicate that although pre-reading children might have a limited appreciation of the phonemic structure of spoken language before learning to read, they do not turn out to be poor readers later on (Ehri, 1989; Scarborough, 1998; Wimmer, et al., 1991; Ziegler \& Goswami, 2005). For instance, (Wimmer, et al., 1991) revealed a floor performance in the majority of non-reading children aged 6-to-7-years on a phonological vowel substitution task in kindergarten, while after a few months of reading instruction, most children demonstrated a near ceiling performance on this task as well as a normal reading development. Moreover, illiterates exhibit difficulties on task requiring the manipulation of single phonemes (Lukatela, Carello, Shankweiler, \& Liberman, 1995; Morais, et al., 1979) and only start to show some phonemic awareness after a basic literacy training (Morais, et al., 1986). We will investigate the exact nature of this potential causal relationship in children with a familial risk to develop reading problems, before the start of reading instruction and in first grade (chapter 2). Moreover, when investigating the cognitive development of children at-familial risk for reading failure (chapter 3 ) as well as of already established poor readers (chapter 4), it is indispensable to include a measure of phonological awareness.

RAPID AUTOMATIZED NAMING OF FAMILIAR STIMULI. The ability to name a series of visual symbols, such as objects, pictures, letters or digits as quickly as possible with a minimal amount of error, also known as rapid automatized naming (RAN), is a reading-related marker of literacy acquisition that some researchers suggest is equally important as phonological skills. Over forty years ago, the influential work of Denckla and Rudel (1976a, 1976b) already indicated a significant relationship between children's naming speed ability and their reading development and slower naming speed in dyslexic readers compared to normal readers or other non-dyslexic poor readers. Since then, extensive research has been done, indicating that variations in naming speed ability in kindergarten and primary school children are a strong predictor of future reading ability. This holds true especially for more transparent orthographies like Dutch (e.g., Brizzolara et al., 2006; de Jong \& van der Leij, 1999; Georgiou, Das, \& Hayward, 2008; Kirby, et al., 2010; Landerl \& Wimmer, 2008; Lepola, Poskiparta, Laakkonen, \& Niemi, 2005; Puolakanaho, et al., 2008; Vaessen, et al., 2009; Wimmer, 1993; Wimmer, Mayringer, \& Landerl, 2000) but also in more opaque orthographies (e.g., Allor, 2002; Caravolas, et al., 2013; Clarke, Hulme, \& Snowling, 2005; Compton, 2003; McBride-Chang \& Manis, 1996; Neuhaus \& Swank, 2002; 
Savage \& Frederickson, 2005; Torgesen, et al., 1997; Wagner, et al., 1994), although often to a lesser extent (e.g., Kirby, et al., 2010; Landerl, et al., 2013; Vaessen, et al., 2010). In transparent orthographies reading is usually measured by means of fluency tasks, while in opaque orthographies most emphasis lies on reading accuracy measures. The fact that both RAN and reading fluency are operationalized with speeded measures may partially explain why the RANreading relationship is usually identified as a more significant in more transparent than in opaque orthographies (Georgiou, Parrila, \& Papadopoulos, 2016; Kirby, et al., 2010; Vaessen, et al., 2010; but also see Landerl et al., 2013 indicating RAN to be an equally strong predictor across orthographies). Also, object and colour naming tasks have been found suitable for predicting subsequent literacy skills especially in preliterate children, while alphanumerical RAN tasks have shown the strongest and most persistent relationship to reading development in established readers (Brizzolara, et al., 2006; Vaessen, et al., 2009; Wimmer, 1993).

The unique role of both RAN and PA in reading acquisition of reading disabled children has led Wolf and Bowers to formulate the double-deficit hypothesis of dyslexia (i.e., Bowers \& Wolf, 1993; Wolf, 1997; Wolf \& Bowers, 1999; Wolf, Bowers, \& Biddle, 2000). They propose the existence of three subtypes that can be characterized by the presence, the absence or a combination of the two core deficits in phonology and naming speed. This later, double-deficit subtype is expected to show the most severe form of dyslexia as compared to the single naming or single phonological subtype, since the two deficits are expected to be independent and additive. Nevertheless, inconsistent and equivocal results surrounding the double-deficit hypothesis led reading researchers to question whether a RAN deficit is actually independent from a PA deficit, or whether the two deficits are merely different manifestations of the same, single underlying deficit in the phonological domain. Objectives have for instance been that some studies indicate a more modest or sometimes even absent contribution of RAN to reading accuracy and speed in for instance both Dutch and English orthographies (e.g., Patel, Snowling, \& de Jong, 2004; Torgesen, et al., 1994) or the fact that several researchers failed to show the additive influence of a double PA-RAN deficit resulting in increased severity of reading and spelling problems (Ackerman, Holloway, Youngdahl, \& Dykman, 2001; Wimmer, et al., 2000) contrasting the findings of others (Lovett, Steinbach, \& Frijters, 2000; Manis, Doi, \& Bhadha, 2000). Finally, one of the assumptions of the double-deficit theory predicts the existence of a RAN-only reading impaired subtype was not supported by several researchers (Pennington, Cardoso-Martins, Green, \& Lefly, 2001; Vaessen et al., 2009; the present thesis, chapter 3). 
(Pennington, et al., 2001) for example only found 1 child within a sample of 71 dyslexic readers that exhibited poor naming skills in the absence of phonological difficulties. Vaessen and colleagues (2009) did identify a small group of dyslexic readers with RAN problems in the absence of phonological problems, but since this was only $5 \%$ of the participants included, the authors concluded that a RAN deficit couldn't be considered as a second independent core deficit in dyslexia as predicted by the double-deficit theory. Instead they proposed that speeded naming tasks are mainly speeded phonological processing tasks, which have a unique and additional quality of measuring efficient and fast cross-modal matching of visual and phonological codes, also important in speeded reading fluency tasks. In contrast, a cluster analysis by (Morris et al., 1998) did yield a subtype with rather mild RAN problems in the absence of PA problems, in addition to several other non-impaired and impaired subtypes characterized by a variety of phonological, rapid naming and verbal working memory problems. Also, (King, Giess, \& Lombardino, 2007) showed a RAN-only dyslexic subtype, next to a PA-only impaired subtype and a subtype reflecting a double deficit in both domains. Taken together, these observations indicate that the debate on the independence of rapid naming and phonological awareness is far from closed. It is clear, however, that there is a unique and strong (predictive) association between RAN and reading failure (de Jong \& van der Leij, 1999; McBride-Chang \& Manis, 1996; Puolakanaho, et al., 2008; Vaessen, et al., 2009; Wolf \& Bowers, 1999; Wolf, et al., 2000). Moreover, twin studies show that RAN deficits in dyslexics are significantly heritable (Byrne, et al., 2006; Davis et al., 2001; Gayan \& Olson, 2001; van Bergen, de Jong, Maassen, \& van der Leij, 2014) and both at-risk impaired as well as at-risk non-impaired children exhibit RAN difficulties, although the latter often less severe (Boets, et al., 2010; Pennington \& Lefly, 2001; Puolakanaho, et al., 2008). RAN is thus a useful vulnerability marker to include when investigating the cognitive development of children at-familial risk for reading failure (chapter 2 and 3 ) as well as for looking for distinct subtypes of poor reading in already established readers (chapter 4).

LETTER KNOWLEDGE AND THE MASTERY OF LETTER-SPEECH SOUND ASSOCIATIONS. Learning the important correspondences between letters and speech sounds is considered a primary building block for successful reading development in an alphabetical orthography (Ehri, 2005; Frith, 1985; Scarborough, 1989). Moreover, early letter-speech sound knowledge in kindergarten children at familial risk for dyslexia is one of the most important predictors of 
reading outcome in both opaque orthographies (Fox, 1994; Frith, 1985; Gallagher, et al., 2000; Pennington \& Lefly, 2001; Scarborough, 1989, 1990; Snowling, 1980; Vellutino, et al., 2004) as well as in transparent orthographies (de Jong \& van der Leij, 1999; Lyytinen et al., 2004a; Lyytinen et al., 2004b; Puolakanaho, et al., 2008). Also, both impaired and unimpaired at-risk children were found to demonstrate slow acquisition of letter speech sound knowledge (Puolakanaho, et al., 2008; Snowling, et al., 2003). One of the studies of the present thesis focusing on pre-reading children at-risk for dyslexia, however shows, that knowledge of letter names prior to the start of reading instruction was not a primary candidate to account for reading deficits developing during the first months of grade 1 (chapter 2). Instead, we found that learning letter names and learning to associate and integrate letters and speech sounds are different processes, and specifically the later seems directly linked to the development of reading deficits. More specifically, a core group of pre-reading at-risk children demonstrated severe problems in letter-speech sound learning on a training specifically designed to do so. Older, already established dyslexic readers, demonstrated a significantly slower performance on letter-speech sound pair processing than their normally developing peers over all six primary school grades (Blomert \& Vaessen, 2008, summarized in Blomert, 2011). In other words, while normal readers demonstrated a decrease in LS processing speed (i.e., faster, more automated LS coupling) up to the end of primary school, impaired readers showed a premature halting after grade 3 , indicating persistent problems to efficiently map letters and speech sounds. This protracted development of automated letter-speech sound mapping in dyslexic readers cannot be explained by insufficient knowledge of the letter-speech sound pairs, since both normal and poor readers accomplish reasonable knowledge of what letter belongs to which speech sound within a year of reading acquisition in both transparent as well as opaque orthographies (Aarnoutse, van Leeuwe, \& Verhoeven, 2000; Blomert \& Vaessen, 2009; Seymour, et al., 2003; Ziegler \& Goswami, 2005). Neuroimaging studies also showed an extended development of letter-speech sound integration and letter sensitivity at neural level over many years, even though children master complete knowledge of which letter belongs to which speech sound within a year of reading instruction (Blau et al., 2010; Blau, Van Atteveldt, Ekkebus, Goebel, \& Blomert, 2009; Brem et al., 2010; Froyen, Bonte, Van Atteveldt, \& Blomert, 2009; Froyen, Van Atteveldt, Bonte, \& Blomert, 2008; Zaric et al., 2015). For example, a combined electrophysiological (ERP) and functional magnetic resonance imaging (fMRI) study by (Brem, et al., 2010) revealed that, although non-reading kindergarten children knew some letters at a 
behavioural level, no such letter sensitivity in brain activation was revealed. After an intense computerized training specifically focused on letter-speech sound correspondences, this behavioural learning effect did show a significant visual print sensitivity effect on neural level. It is possible that these changes were driven by acquiring letter-speech sound knowledge as the authors suggested, or merely reflecting increased exposure to letters (McCandliss, 2010).. Another ERP study by Froyen et al. (2009) revealed that while adult fluent readers showed early and automated cross-modal integration of letters and speech sounds within $150 \mathrm{~ms}$ after stimulus onset (Froyen, et al., 2008), 11-year-old- normal readers revealed EEG signals sensitive to early automation only after four years of reading instruction and needed a relatively larger time window to do so, as reflected in latency shifts in the EEG effects compared to controls. At that point, dyslexic readers did not show any signs of early automated letter-speech sound integration but rather late letter-speech sound association activation patterns similar to normal reading grade 1 children (Froyen, Willems, \& Blomert, 2011). A series of fMRI studies corroborate that despite full mastery of letter knowledge, both dyslexic children and adults showed diminished brain activity in areas functionally associated to cross-modal integration, while processing isolated speech sounds or letter-speech sound pairs (Blau, et al., 2010; Blau, et al., 2009). Even more interesting, these dyslexic individuals showed similar brain activation for congruent and incongruent letter-speech sound pairs, while normal readers showed immediate suppressed activity for non-existing (incongruent) letter-speech sound pairs. These data suggest the dyslexic children do not differentiate between congruent and congruent stimuli pairs, whereas normal readers do that automatically. Recently, neuroimaging results indicated that this reduced LS matching activity show mild improvements after intensive letter-speech sound training (Zaric, et al., 2015), supporting the idea that observed suppression in regions of interest indeed are related to the deficit and that this deficit can be treated, and the treatment effect can quantified by fMRI. Taken together, these neuroimaging studies convincingly demonstrate that full and automatic letter-speech sound integration at a neural level, a skill necessary for fluent reading, takes years to develop in normal readers. Moreover, a cross-modal association deficit is found in dyslexic readers who fail to develop fully automated integration of corresponding letter-speech sounds at a neural level up to adulthood. Thus, efficiency of letterspeech sound processing seems to be a highly relevant vulnerability marker to include when researching the initial phases of reading development (chapter 2 and 3 ) as well as in later phases 
when abnormal letter-speech sound integration was indicated to remain a manifestation of poor reading in established readers (chapter 4).

VERBAL WORKING MEMORY. Although traditionally PA, RAN and LS knowledge have been the primary candidate cognitive markers investigated in the field of reading, several researchers have focused their attention on more fundamental skills such as verbal working memory to look for alternative theories to interpret the cognitive basis of dyslexia (e.g., Beneventi, Tønnessen, Ersland, \& Hugdahl, 2010; Berninger, et al., 2006; Georgiou, Das, et al., 2008; Goswami et al., 2002; Jeffries \& Everatt, 2004; Menghini, Finzi, Carlesimo, \& Vicari, 2011; Tijms, 2004). The concept of verbal working memory (VWM) is simply defined as a limited capacity system used to store information from a variety of sources for a short period of time for further processing or manipulation (Baddeley, 1995; Baddeley \& Hitch, 1974; Eriksson, Vogel, Lansner, Bergström, \& Nyberg, 2015; Gathercole \& Baddeley, 1993; Logie \& Cowan, 2015). There have been many reports on working memory deficits in dyslexic readers, such as reduced working memory span as compared to controls matched on age and reading level (for reviews see Elbro, 1996; Menghini, et al., 2011; Pickering, 2012; Snowling, 2000; Wagner \& Torgesen, 1987). Dyslexic children as well as dyslexic adults are also found to perform poorer on verbal learning tasks such as story recall (Felton \& Brown, 1990; O'Neill \& Douglas, 1991), non-word repetition (De Bree, Rispens, \& Gerrits, 2007; de Bree, Wijnen, \& Gerrits, 2010; Snowling, 1981; Snowling, Goulandris, Bowlby, \& Howell, 1986), paired-associated learning (Elbro \& Jensen, 2005; Kalashnikova \& Burnham, 2016; Vellutino, Scanlon, \& Spearing, 1995; Vellutino, Steger, DeSetto, \& Phillips, 1975) and list learning (Douglas \& Benezra, 1990; Felton, Wood, Brown, Campbell, \& Harter, 1987; Jeffries \& Everatt, 2003). Although it is generally agreed upon that deficiency in working memory characterizes dyslexia, there has been considerable debate and uncertainty about mechanisms underlying these difficulties. Ever since the influential work by (Vellutino, 1979) demonstrating that dyslexic readers perform inferior specifically on tasks processing information with a verbal component, but not on tasks involving non-verbal material, it has been suggested that the working memory deficit in dyslexia is a verbal deficit confined to phonological material, and thus stemming from the same root as the generally accepted phonological deficit of dyslexia (e.g., Fletcher, 1985; Jeffries \& Everatt, 2004; Kibby, Marks, Morgan, \& Long, 2004; Liberman \& Shankweiler, 1985; Menghini, et al., 2011; Tijms, 2004). Indeed, reports indicate a strong correlation between verbal working memory and phonological 
processing (e.g., Baddeley, 1995). When looking at the current, dominant view of working memory that conceptualizes it as a central executive with two supporting systems, a phonological loop dedicated to short-term storage of verbal information and a sketchpad for storage of visuospatial information (Baddeley, 2003a, 2003b, 2007), it is the former system that is thought to be affected in dyslexia. However, an opposing view indicates the working memory deficit to be a more general impairment involving both visuo-object and visuospatial material as well as verbal information, thus challenging the view that dyslexia is a pure phonological deficit (De Jong, 1998, 2006; Menghini, et al., 2011; Smith-Spark \& Fisk, 2007) and expecting more widespread deficiencies in the above proposed working memory model by Baddeley. Despite the ongoing discussion on whether a uniform core PA deficit explains the poor working memory skills specifically in the verbal domain in dyslexic children, researchers argued that there exists a link between efficient working memory processing of at least verbal material and the cognitive profiles of dyslexia since VWM is found to uniquely explain variance in reading outcome in poor readers, even after correcting for PA levels (e.g., Georgiou, Das, et al., 2008; McCallum et al., 2006). Affirming that VWM is a useful vulnerability marker of reading disability are findings of a genetic component identified for VWM in dyslexic readers (e.g., Byrne, et al., 2006). Moreover, a VWM deficit is shared by genetically at-risk children with impaired reading skills and at-risk children with non-impaired reading skills (e.g., Pennington \& Lefly, 2001). Especially in early reading acquisition, when word decoding is still a slow and effortful process and conversion of letter-speech sound correspondences are not yet automatic or error-free, working memory capacity is especially important (e.g., Baddeley, 1992; Gathercole \& Baddeley, 1993). To be able to figure out the meaning of written text, a beginning reader heavily relies on the graphemephoneme conversion rules, connecting letters to their corresponding speech-sounds, while holding the phonological information active in memory for each executive part of a word or sentence. Thus, especially in beginning readers, reading relies heavily on the processing and storage of phonological information and deficits in VWM may influence the efficiency of reading acquisition in children with a genetic predisposition for reading failure. Therefore, the present thesis will include verbal, phonological measures of working memory when exploring the cognitive dynamics of reading acquisition in poor readers with and without a familial history of dyslexia (chapter 2, 3, 4). 


\subsection{LITERACY DEVELOPMENT AND THE INFLUENCE OF ENVIRONMENTAL RISK FACTORS}

As mentioned, familial history of dyslexia is a definite, highly important risk factor for the development of reading failure (e.g., Pennington \& Olson, 2008; Snowling, et al., 2003; Thompson, et al., 2015) although it cannot be considered a pure genetic trait due to a geneenvironment interplay (Byrne, et al., 2006; Gayan \& Olson, 2001; Grigorenko, 2001; Molfese, Modglin, \& Molfese, 2003; Olson, et al., 1989). Dyslexic parents may indeed transfer the biological basis in their genes to their children (for genes susceptible to dyslexia, see above), but they do more. For instance, dyslexic parents themselves generally read less frequently by themselves or to their children (e.g., Wadsworth et al., 2000, but also see Elbro, et al., 1998; Gallagher, et al., 2000; Wadsworth, et al., 2010), provide fewer books in their home (Byrne et al., 2013; Elbro, et al., 1998; Scarborough, 1990; Snowling, 2000) and have less positive attitudes towards reading (Leinonen et al., 2001). A poorer socio-economic status (SES) of a family (e.g., defined by parental education, social neighbourhood status and/or family income) is also an important potential risk facilitator in the study of reading disability and results showed that poorer SES resulted in inferior initial reading scores and succeeding slower growth in reading acquisition (Aikens \& Barbarin, 2008; Cheadle, 2008). Other environmental factors also influencing this observed difference are for instance parental educational involvement (e.g., Cheadle, 2008), richness of home literacy environment (e.g., Aikens \& Barbarin, 2008) and school performance level influencing student reading outcome (e.g., Connor, Crowe, \& Meadows, 2009; Foorman et al., 2006). (Snowling, et al., 2003) suggest that such environmental influences in reading impaired families clearly impacts the range and severity of symptoms as well as the spectrum of the reading impairment and correlated reading-related deficits. Indeed, environmental aspects are found to impose both risk and protective influences within the highly heterogeneous and multifactorial aetiology of reading impairment (Molfese, et al., 2003; Snowling, et al., 2003). Consequently, reading researchers proposed the existence of at least two possible aetiologies for childhood reading disabilities: a primarily genetic, specific impaired type with problems mainly confined to the reading domain and a more generally impaired and environmentally influenced type affected also beyond the reading domain in for instance more general cognitive abilities (Castles, et al., 1999; Rack \& Olson, 1993; Shaywitz \& Shaywitz, 2005; Wadsworth, et al., 2000). Interestingly, the exact nature of the influence of varying environmental as well as genetic risk factors is found to vary across different components of 
literacy skills. For example, early print and letter deficiencies are more influenced by environmental factors such as SES (e.g., Byrne, et al., 2006; Samuelsson et al., 2005), while inferior rapid naming skills are more related to genetic risk (Gayan \& Olson, 2001; Petrill, Deater-Deckard, Thompson, DeThorne, \& Schatschneider, 2006; Samuelsson, et al., 2005). It follows from this short discussion on environmental influences in reading failure that when looking for distinct cognitive subtypes of poor reading, differences in the amount of geneticenvironmental influence can occur between poor reading subtypes and measures of both familial risk factors as well as important environmental risk factors such as SES and parental education should be included (chapter 4).

To conclude this general outline of the research objectives of the present thesis and the introduction of its most pertinent concepts, the specific goals of the current thesis are shortly recapitulated. The present thesis aims to contribute to the understanding of cognitive deficit patterns underlying reading disability in children at familial risk for dyslexia during the early steps of reading development. The following chapters will firstly focus on the initial stages of literacy acquisition in kindergarten and grade 1 when children evolve from being pre-literate to establishing basic reading skills (chapter 2 and 3 ) and secondly, we focus on a large sample of established poor readers found to struggle significantly with reading fluency early on in grade 2 to 4 (chapter 4). In conclusion, the main findings and their implications are summarized and discussed (chapter 5). 


\section{REFERENCES}

Aarnoutse, C., van Leeuwe, J., \& Verhoeven, L. (2000). Ontwikkeling van beginnende geletterdheid [development of beginning literacy]. Pedagogische Studiën, 77, 307 - 325.

Ackerman, P. T., Holloway, C. A., Youngdahl, P. L., \& Dykman, R. A. (2001). The double-deficit theory of reading disability does not fit all. Learning Disabilities Research \& Practice, 16(3), 152-160. doi: 10.1111/0938-8982.00016.

Adams, M. J. (1990). Beginning to Read: Thinking and Learning about Print. Cambridge, Massachusetts: The MIT Press.

Aikens, N. L., \& Barbarin, O. (2008). Socioeconomic differences in reading trajectories: The contribution of family, neighborhood, and school contexts. Journal of Educational Psychology, 100(2), 235. doi: 10.1037/0022-0663.100.2.235.

Allor, J. H. (2002). The relationships of phonemic awareness and rapid naming to reading development. Learning Disability Quarterly, 25(1), 47-57. doi: 10.2307/1511190.

American Psychiatric Association. (2013). Diagnostic and Statistical Manual of Mental Disorders (5th ed., text rev.). Washington, DC: American Psychiatric Association.

Baddeley, A. D. (1992). Working memory. Science, 255(5044), 556-559. doi: 10.1126/science.1736359.

Baddeley, A. D. (1995). Working memory. In M. S. Gazzaniga (Ed.), The Cognitive Neurosciences (pp. 755-764). Cambridge MA, US: MIT: Press.

Baddeley, A. D. (2003a). Working memory and language: An overview. Journal of communication disorders, 36(3), 189-208.

Baddeley, A. D. (2003b). Working memory: looking back and looking forward. Nature reviews neuroscience, 4(10), 829-839.

Baddeley, A. D. (2007). Working memory, thought, and action. Oxford, UK: Oxford University Press.

Baddeley, A. D., \& Hitch, G. J. (1974). Working memory. The psychology of learning and motivation, 8, 47-89. doi: 10.1016/S0079-7421(08)60452-1.

Badian, N. A., McAnulty, G. B., Duffy, F. H., \& Als, H. (1990). Prediction of dyslexia in kindergarten boys. Annals of Dyslexia, 40(1), 152-169. doi: 10.1007/BF02648146. 
Beneventi, H., Tønnessen, F. E., Ersland, L., \& Hugdahl, K. (2010). Working Memory Deficit in Dyslexia: Behavioral and fMRI Evidence. International Journal of Neuroscience, 120(1), 51-59. doi: 10.3109/00207450903275129.

Berkhan, O. (1985). Über die Störung der Schriftsprache bei Halbidioten und ihre Ähnlichkeit mit dem Stammeln [About the disorder of written language of half-idiots and their similarity with dislaia. Archiv für Psychiatrie und Nervenkrankenheiten, 16, 78-86.

Berlin, R. (1887). Eine besondere Art der Wortblindheit [A specific kind of word blindness]. Wiesbaden, Germany: J. F. Berg-man.

Berninger, V. W., Abbott, R. D., Thomson, J., Wagner, R., Swanson, H. L., Wijsman, E. M., \& Raskind, W. (2006). Modeling Phonological Core Deficits Within a Working Memory Architecture in Children and Adults With Developmental Dyslexia. Scientific Studies of Reading, 10(2), 165-198. doi: 10.1207/s1532799xssr1002_3.

Berninger, V. W., Abbott, R. D., Thomson, J. B., \& Raskind, W. H. (2001). Language Phenotype for Reading and Writing Disability: A Family Approach. Scientific Studies of Reading, 5(1), 59-106. doi: 10.1207/s1532799xssr0501_3.

Berninger, V. W., \& Richards, T. (2010). Inter-relationships among behavioral markers, genes, brain and treatment in dyslexia and dysgraphia. Future neurology, 5(4), 597-617. doi: 10.2217/fnl.10.22.

Bigozzi, L., Tarchi, C., Pinto, G., \& Accorti Gamannossi, B. (2015). Predicting Dyslexia in a Transparent Orthography From Grade 1 Literacy Skills: A Prospective Cohort Study. Reading \& Writing Quarterly, 1-20.

Blau, V., Reitler, J., Van Atteveldt, N., Gerretsen, P., Seitz, J., Goebel, R., \& Blomert, L. (2010). Deviant processing of letters and speech sounds as proximate cause of reading failure: an fMRI study of dyslexic children. Brain, 133(3), 868-879. doi: 10.1093/brain/awp308.

Blau, V., Van Atteveldt, N., Ekkebus, M., Goebel, R., \& Blomert, L. (2009). Reduced neural integration of letters and speech sounds links phonological and reading deficits in adult dyslexia. Current Biology, 19(6), 503-508. doi: 10.1016/j.cub.2009.01.065.

Blomert, L. (2005). Dyslexie in Nederland - theorie, praktijk en beleid [Dyslexia in The Netherlands - theory, practice and policy]. Amsterdam: Nieuwezijds Publishers.

Blomert, L., \& Vaessen, A. (2008). Verantwoorde protocollen voor dyslexie diagnostiek en behandeling. Amsterdam: Nieuwezijds. 
Blomert, L., \& Vaessen, A. (2009). 3DM: Cognitieve analyse van lezen en spellen [3DM: Cognitive analysis of reading and spelling]. Amsterdam: Boom test publishers BV.

Boets, B., Smedt, B., Cleuren, L., Vandewalle, E., Wouters, J., \& Ghesquiere, P. (2010). Towards a further characterization of phonological and literacy problems in Dutch-speaking children with dyslexia. British Journal of Developmental Psychology, 28(1), 5-31. doi: $10.1348 / 026151010 \times 485223$.

Borstrøm, I., \& Elbro, C. (1997). Prevention of dyslexia in kindergarten: effects of phoneme awareness training with children of dyslexic parents. In C. Hulme, \& M. Snowling (Ed.), Dyslexia: Biology, cognition, and intervention (pp. 235-253). London: Whurr Publishers.

Børstrom, I., \& Elbro, C. (1997). Prevention of dyslexia in kindergarten: effects of phoneme awareness training with children of dyslexic parents. In C. Hulme, \& M. Snowling (Ed.), Dyslexia: Biology, cognition, and intervention (pp. 235-253). London: Whurr Publishers.

Bosman, A., \& Braams, T. (2005). Depressie en angst bij basisschoolleerlingen met dyslexie. Tijdschrift voor orthopedagogiek, 44, 213-223.

Bowers, P. G., \& Ishaik, G. (2003). RAN's contribution to understanding reading disabilities. In S. Graham, H. Swanson \& K. R. Lee Harris (Eds.), Handbook of learning disabilities (pp. 140157). New York, US: Guilford Press.

Bowers, P. G., \& Wolf, M. (1993). Theoretical links among naming speed, precise timing mechanisms and orthographic skill in dyslexia. Reading and Writing, 5(1), 69-85. doi: 10.1007/BF01026919.

Bradley, L., \& Bryant., P. E. (1983). Categorizing sounds and learning to read - a causal connection. Nature, 301, 419-421. doi: 10.1038/301419a0

Brem, S., Bach, S., Guttorm, T. K., Martin, E., Lyytinen, H., Brandeis, D., \& Richardson, U. (2010). Brain sensitivity to print emerges when children learn letter-speech sound correspondences. proceedings of the national academy of sciences of the United States of America, 107(17), 7939-7944. doi: 10.1073/pnas.0904402107.

Brizzolara, D., Chilosi, A., Cipriani, P., Di Filippo, G., Gasperini, F., Mazzotti, S., . . Zoccolotti, P. (2006). Do phonologic and rapid automatized naming deficits differentially affect dyslexic children with and without a history of language delay? A study of Italian dyslexic children. Cognitive and Behavioral Neurology, 19(3), 141-149. doi: 10.1097/01.wnn.0000213902.59827.19. 
Bruck, M. (1992). Persistence of dyslexics' phonological awareness deficits. Developmental Psychology, 28(5), 874-886. doi: 10.1037/0012-1649.28.5.874.

Byrne, B., Coventry, W. L., Olson, R. K., Samuelsson, S., Corley, R., Willcutt, E. G., . . DeFries, J. C. (2009). Genetic and environmental influences on aspects of literacy and language in early childhood: Continuity and change from preschool to Grade 2. Journal of Neurolinguistics, 22(3), 219-236.

Byrne, B., Olson, R. K., Samuelsson, S., Wadsworth, S. J., Corley, R., DeFries, J. C., \& Willcutt, E. (2006). Genetic and environmental influences on early literacy. Journal of Research in Reading, 29(1), 33-49. doi: 10.1111/j.1467-9817.2006.00291.x.

Byrne, B., Shankweiler, D., \& Hine, D. W. (2008). Reading development in children at risk for dyslexia. In M. Mody \& K. Silliman (Eds.), Brain, Behavior and Learning in Language and Reading disorders (pp. 240-270). New York, US: Guilford Press.

Byrne, B., Wadsworth, S. J., Boehme, K., Talk, A. C., Coventry, W. L., Olson, R. K., . . Corley, R. (2013). Multivariate genetic analysis of learning and early reading development. Scientific Studies of Reading, 17(3), 224-242. doi: 10.1080/10888438.2011.654298.

Caravolas, M., Lervåg, A., Defior, S., Málková, G. S., \& Hulme, C. (2013). Different patterns, but equivalent predictors, of growth in reading in consistent and inconsistent orthographies. Psychological science, 0956797612473122 . doi: 10.1177/0956797612473122.

Caravolas, M., Lervag, A., Mousikou, P., Efrim, C., Litavsky, M., Onochie-Quintanilla, E., . . . Hulme, C. (2012). Common patterns of prediction of literacy development in different alphabetic orthographies. Psychological Science, 23(6), 678-686. doi: 10.1177/0956797611434536.

Cardoso-Martins, C., \& Pennington, B. F. (2004). The relationship between phoneme awareness and rapid serial naming skills and literacy acquisition: The role of developmental period and reading ability. Scientific Studies of Reading, 8, 27-52. doi: 10.1207/s1532799xssr0801_3.

Castles, A., \& Coltheart, M. (2004). Is there a causal link from phonological awareness to success in learning to read? Cognition, 91(1), 77-111. doi: 10.1016/S0010-0277(03)00164-1.

Castles, A., Datta, H., Gayan, J., \& Olson, R. K. (1999). Varieties of Developmental Reading Disorder: Genetic and Environmental Influences. Journal of Experimental Child Psychology, 72(2), 73-94. doi: 10.1006/jecp.1998.2482. 
Centanni, T. M., Booker, A. B., Chen, F., Sloan, A. M., Carraway, R. S., Rennaker, R. L., . . Kilgard, M. P. (2016). Knockdown of Dyslexia-Gene Dcdc2 Interferes with Speech Sound Discrimination in Continuous Streams. The Journal of Neuroscience, 36(17), 4895-4906.

Cheadle, J. E. (2008). Educational investment, family context, and children's math and reading growth from kindergarten through the third grade. Sociology of Education, 81(1), 1-31. doi: $10.1177 / 003804070808100101$.

Christopher, M. E., Hulslander, J., Byrne, B., Samuelsson, S., Keenan, J. M., Pennington, B. F., . . Olson, R. K. (2015). Genetic and environmental etiologies of the longitudinal relations between prereading skills and reading. Child development, 86(2), 342-361.

Clarke, P., Hulme, C., \& Snowling, M. J. (2005). Individual differences in RAN and reading: A response timing analysis. Journal of Research in Reading, 28(2), 73-86. doi: 10.1111/j.1467-9817.2005.00255.x.

Compton, D. L. (2003). Modelling the relationship between growth in rapid naming speed and growth in decoding skill in first-grade children. Journal of Educational Psychology, 95(2), 225-239. doi: 10.1037/0022-0663.95.2.225.

Connor, C. M., Crowe, E. C., \& Meadows, J. G. (2009). Instruction, student engagement, and reading skill growth in Reading First classrooms. The Elementary School Journal, 109(3), 221-250. doi: 10.1086/592305.

D'Souza, S., Backhouse-Smith, A., Thompson, J., Slykerman, R., Marlow, G., Wall, C., . . Waldie, K. E. (2016). Associations Between the KIAA0319 Dyslexia Susceptibility Gene Variants, Antenatal Maternal Stress, and Reading Ability in a Longitudinal Birth Cohort. Dyslexia, 22(4), 379-393.

Davis, C. J., Gayán, J., Knopik, V. S., Smith, S. D., Cardon, L. R., Pennington, B. F., . . Defries, J. C. (2001). Etiology of Reading Difficulties and Rapid Naming: The Colorado Twin Study of Reading Disability. Behavior Genetics, 31(6), 625-635. doi: 10.1023/a:1013305730430.

De Bree, E., Rispens, J., \& Gerrits, E. (2007). Non-word repetition in Dutch children with (a risk of) dyslexia and SLI. Clinical Linguistics \& Phonetics, 21(11-12), 935-944.

de Bree, E., Wijnen, F., \& Gerrits, E. (2010). Non-word repetition and literacy in Dutch children at-risk of dyslexia and children with SLI: results of the follow-up study. Dyslexia, 16(1), 36-44.

De Jong, P. F. (1998). Working Memory Deficits of Reading Disabled Children. Journal of Experimental Child Psychology, 70(2), 75-96. doi: 10.1006/jecp.1998.2451. 
De Jong, P. F. (2006). Understanding normal and impaired reading development: A working memory perspective. Working memory and education, 33-60.

de Jong, P. F., \& van der Leij, A. (1999). Specific contributions of phonological abilities to early reading acquisition: results from a Dutch latent variable longitudinal study. Journal of Educational Psychology, 91(3), 450-476. doi: 10.1037/0022-0663.91.3.450.

De Santos Loureiro, C., Willadino Braga, L., Souza, L. d. N., Queiroz, E., \& Dellatolas, G. (2004). Degree of illiteracy and phonological and metaphonological skills in unschooled adults. Brain and Language, 89(3), 499-502. doi: 10.1016/j.bandl.2003.12.008.

Dehaene, S., Pegado, F., Braga, L. W., Ventura, P., Nunes Filho, G., Jobert, A., . . Cohen, L. (2010). How learning to read changes the cortical networks for vision and language. Science, 330(6009), 1359-1364. doi: 10.1126/science.1194140.

Denckla, M. B., \& Rudel, R. G. (1976a). Naming of object-drawings by dyslexic and other learning disabled children. Brain and language, 3, 1-15. doi: 10.1016/0093-934X(76)90001-8.

Denckla, M. B., \& Rudel, R. G. (1976b). Rapid "automatized" naming (R.A.N): Dyslexia differentiated from other learning disabilities. Neuropsychologia, 14(4), 471-479. doi: 10.1016/0028-3932(76)90075-0.

Douglas, V. I., \& Benezra, E. (1990). Supraspan verbal memory in attention deficit disorder with hyperactivity normal and reading-disabled boys. Journal of Abnormal Child Psychology, 18(6), 617-638.

Ehri, L. C. (1989). The development of spelling knowledge and its role in reading acquisition and reading disability. Journal of Learning Disabilities, 22(6), 356. doi: 10.1177/002221948902200606.

Ehri, L. C. (1998). Grapheme-phoneme knowledge is essential to learning to read words in English. In J. L. Metsala \& L. C. Ehri (Eds.), Word recognition in beginning literacy (pp. 340). Mahwah, NJ, US: Lawrence Erlbaum Associates Publishers.

Ehri, L. C. (2000). Learning to read and learning to spell: Two sides of a coin. Topics in Language Disorders, 20(3), 19-36. doi: 10.1097/00011363-200020030-00005.

Ehri, L. C. (2005). Development of sight word reading: Phases and findings. In M. J. Snowling \& C. Hulme (Eds.), The Science of Reading: A Handbook (pp. 135-154). Oxford: Blackwell publishing. 
Ehri, L. C., Nunes, S. R., Stahl, S. A., \& Willows, D. M. (2001). Systematic phonics instruction helps students learn to read: Evidence from the National Reading Panel's meta-analysis. Review of educational research, 71(3), 393-447. doi: 10.3102/00346543071003393.

Elbro, C. (1996). Early linguistic abilities and reading development: A review and a hypothesis. Reading and Writing, 8(6), 453-485. doi: 10.1007/BF00577023.

Elbro, C., Borstrøm, I., \& Petersen, D. K. (1998). Predicting dyslexia from kindergarten. The importance of distinctness of phonological representations of lexical items. Reading Research Quarterly, 33(1), 36-60. doi: 10.1598/RRQ.33.1.3.

Elbro, C., \& Jensen, M. N. (2005). Quality of phonological representations, verbal learning, and phoneme awareness in dyslexic and normal readers. Scandinavian Journal of Psychology, 46(4), 375-384.

Eriksson, J., Vogel, E. K., Lansner, A., Bergström, F., \& Nyberg, L. (2015). Neurocognitive architecture of working memory. Neuron, 88(1), 33-46.

Felton, R. H., \& Brown, I. S. (1990). Phonological processes as predictors of specific reading skills in children at risk for reading failure. Reading and Writing: An Interdisciplinary Journal, 2(1), 39-59. doi: 10.1007/BF00383373.

Felton, R. H., Wood, F. B., Brown, I. S., Campbell, S. K., \& Harter, M. R. (1987). Separate verbal memory and naming deficits in attention deficit disorder and reading disability. Brain and Language, 31(1), 171-184. doi: 10.1016/0093-934X(87)90067-8.

Fischer, S. E., \& DeFries, J. C. (2002). Developmental dyslexia: genetic dissection of a complex cognitive trait. Nature Reviews Neuroscience, 3(10), 767-780. doi: 10.1038/nrn936.

Fletcher, J. M. (1985). External validation of learning disability subtypes. In B. P. Rourke (Ed.), Neuropsychology of learning disabilities: Essentials of subtype analysis (pp. 187-211). New York: Guilford Press.

Foorman, B. R., Schatschneider, C., Eakin, M. N., Fletcher, J. M., Moats, L. C., \& Francis, D. J. (2006). The impact of instructional practices in grades 1 and 2 on reading and spelling achievement in high poverty schools. Contemporary Educational Psychology, 31(1), 129. doi: 10.1016/j.cedpsych.2004.11.003.

Fox, E. (1994). Grapheme-phoneme correspondence in dyslexic and matched control readers. British Journal of Psychology, 85(1), 41-53. doi: 10.1111/j.2044-8295.1994.tb02507.x. 
Friend, A., DeFries, J. C., \& Olson, R. K. (2008). Parental education moderates genetic influences on reading disability. Psychological Science, 19(11), 1124-1130. doi: 10.1111/j.14679280.2008.02213.x.

Frith, U. (1985). Beneath the surface of developmental dyslexia. In K. E. Patterson, J. C. Marshhall \& M. Coltheart (Eds.), Surface Dyslexia (pp. 301-322). London: Erlbaum.

Frith, U. (1986). A developmental framework for developmental dyslexia. Annals of Dyslexia, 36, 69-81. doi: 10.1007/BF02648022.

Frith, U., Wimmer, H., \& Landerl, K. (1998). Differences in phonological recoding in German- and English-speaking children. Scientific Studies of Reading, 2, 31-54. doi: 10.1207/s1532799xssr0201_2.

Froyen, D., Bonte, M., Van Atteveldt, N., \& Blomert, L. (2009). The long road to automation: neurocognitive development of letter-speech sound processing. Journal of Cognitive Neuroscience, 21, 567-580. doi: 10.1162/jocn.2009.21061.

Froyen, D., Van Atteveldt, N., Bonte, M., \& Blomert, L. (2008). Cross-modal enhancement of the MMN to speech-sounds indicates early and automatic integration of letters and speechsounds. Neuroscience Letters, 430(1), 23-28. doi: 10.1016/j.neulet.2007.10.014.

Froyen, D., Willems, G., \& Blomert, L. (2011). Evidence for a specific cross-modal association deficit in dyslexia: an electrophysiological study of letter-speech sound processing. Developmental Science, 14(4), 635-648. doi: 10.1111/j.1467-7687.2010.01007.x.

Furnes, B., \& Samuelsson, S. (2011). Phonological awareness and rapid automatized naming predicting early development in reading and spelling: results from a cross-linguistic longitudinal study. Learning and Individual Differences, 21, 85-95. doi: 10.1016/j.lindif.2010.10.005.

Gallagher, A., Frith, U., \& Snowling, M. J. (2000). Precursors of literacy-delay among children at genetic risk of dyslexia. Journal of Child Psychology \& Psychiatry, 41(2), 203-213. doi: 10.1111/1469-7610.00601.

Gathercole, S. E., \& Baddeley, A. D. (1993). Working memory and language: Lawrence Erlbaum Associates, Inc.

Gayan, J., \& Olson, R. K. (2001). Genetic and Environmental Influences on Orthographic and Phonological Skills in Children With Reading Disabilities. Developmental Neuropsychology, 20(2), 483-507. doi: 10.1207/s15326942dn2002_3. 
Georgiou, G. K., Das, J. P., \& Hayward, D. V. (2008). Comparing the contribution of two tests of working memory to reading in relation to phonological awareness and rapid naming speed. Journal of Research in Reading, 31(3), 302-318. doi: 10.1111/j.14679817.2008.00373.x.

Georgiou, G. K., Parrila, R., \& Papadopoulos, T. C. (2008). Predictors of word decoding and reading fluency across languages varying in orthographic consistency. Journal of Educational Psychology, 100, 566-580. doi: 10.1037/0022-0663.100.3.566.

Georgiou, G. K., Parrila, R., \& Papadopoulos, T. C. (2016). The anatomy of the RAN-reading relationship. Reading and Writing, 1-23.

Gijsel, M., Scheltinga, F., van Druenen, M., \& Verhoeven, L. (2011a). Protocol Leesproblemen en Dyslexie voor groep 3. Nijmegen: Expertisecentrum Nederlands.

Gijsel, M., Scheltinga, F., van Druenen, M., \& Verhoeven, L. (2011b). Protocol Leesproblemen en Dyslexie voor groep 4. Nijmegen: Expertisecentrum Nederland.

Glazzard, J. (2010). The impact of dyslexia on pupils' self-esteem. Support for Learning, 25(2), 6369.

Gooch, D., Snowling, M. J., \& Hulme, C. (2011). Time perception, phonological skills and executive function in children with dyslexia and/or ADHD symptoms. The Journal of Child Psychology and Psychiatry, 52(2), 195-203. doi: 10.1111/j.14697610.2010.02312.x.

Goswami, U., \& Bryant, P. (1990). Phonological skills and learning to read. Hove, UK: Lawrence Erlbaum.

Goswami, U., Thomson, J., Richardson, U., Stainthorp, R., Hughes, D., Rosen, S., \& Scott, S. K. (2002). Amplitude envelope onsets and developmental dyslexia: A new hypothesis. Proceedings of the National Academy of Sciences, 99(16), 10911-10916. doi: 10.1073/pnas.122368599.

Gottesman, I. I., \& Gould, T. D. (2003). The endophenotype concept in psychiatry: etymology and strategic intentions. American Journal of Psychiatry, 160(4), 636-645. doi: 10.1176/appi.ajp.160.4.636.

Gough, P. B., \& Tunmer, W. E. (1986). Decoding, reading, and reading disability. Remedial and Special Education, 7, 6-10. doi: 10.1177/074193258600700104. 
Grigorenko, E. L. (2001). Developmental Dyslexia: An Update on Genes, Brains, and Environments. Journal of Child Psychology and Psychiatry, 42(1), 91-125. doi: 10.1111/1469-7610.00704.

Grigorenko, E. L. (2004). Genetic bases of developmental dyslexia: A capsule review of heritability estimates. Enfance, 56(3), 273-288.

Grigorenko, E. L., Wood, F. B., Meyer, M. S., \& Pauls, D. L. (2000). Chromosome 6p influences on different dyslexia-related cognitive processes: further confirmation. The American Journal of Human Genetics, 66(2), 715-723. doi: 10.1086/302755.

Hallgren, B. (1950). Specific dyslexia (congenital word-blindness): a clinical and genetic study. Acta Psychiatrica et Neurologica, 65, 1-287.

Harris, M., \& Giannouli, V. (1999). Learning to read and spell in Greek: The importance of letter knowledge and morphological awareness. Learning to read and write: A cross-linguistic perspective, 4, 51-70.

Holopainen, L., Ahonen, T., \& Lyytinen, H. (2001). Predicting delay in reading achievement in a highly transparent language. Journal of Learning Disabilities, 34(5), 401-413. doi: 10.1177/002221940103400502.

Hulme, C., \& Snowling, M. J. (2016). Reading disorders and dyslexia. Current Opinion in Pediatrics, 28(6), 731-735.

Ingesson, S. G. (2007). Growing up with dyslexia interviews with teenagers and young adults. School Psychology International, 28(5), 574-591.

International Dyslexia Association. (2002). About dyslexia. Wellington, New Zealand: International Dyslexia Association.

Jeffries, S., \& Everatt, J. (2003). Differences between dyspraxics and dyslexics in sequence learning and working memory. Dyspraxia Foundation Professional Journal, 2, 12-21.

Jeffries, S., \& Everatt, J. (2004). Working memory: its role in dyslexia and other specific learning difficulties. Dyslexia, 10(3), 196-214. doi: 10.1002/dys.278.

Jorm, A. F., \& Share, D. L. (1983). Phonological recoding and reading acquisition. Applied Psycholinguistics, 4, 103-147. doi: 10.1017/S0142716400004380.

Kalashnikova, M., \& Burnham, D. (2016). Novel Word Learning, Reading Difficulties, and Phonological Processing Skills. Dyslexia, 22(2), 101-119. 
Kibby, M. Y., Marks, W., Morgan, S., \& Long, C. J. (2004). Specific Impairment in Developmental Reading Disabilities: A Working Memory Approach. Journal of Learning Disabilities, 37(4), 349-363. doi: 10.1177/00222194040370040601.

King, W. M., Giess, S. A., \& Lombardino, L. J. (2007). Subtyping of children with developmental dyslexia via bootstrap aggregated clustering and the gap statistic: comparison with the double-deficit hypothesis. International Journal of Language \& Communication Disorders, 42(1), 77-95. doi: 10.1080/13682820600806680.

Kirby, J. R., Georgiou, G. K., Martinussen, R., \& Parrila, R. (2010). Naming speed and reading: From prediction to instruction. Reading Research Quarterly, 45(3), 341-362.

Knopik, V., Smith, S., Cardon, L., Pennington, B. F., Gayan, J., Olson, R. K., \& DeFries, J. C. (2002). Differential Genetic Etiology of Reading Component Processes as a Function of IQ. Behavior Genetics, 32(3), 181-198. doi: 10.1023/A:1016069012111.

Kussmaul, A. (1877). Diseases of the nervous system and disturbances of speech. In H. v. Z. E. J. A. M. (Trans.) (Ed.), Cyclopedia of the practice of medicine (pp. 770-778). New York: William Wood.

Landerl, K., Ramus, F., Moll, K., Lyytinen, H., Leppänen, P., Lohvansuu, K., . . Bruder, J. (2013). Predictors of developmental dyslexia in European orthographies with varying complexity. Journal of Child Psychology and Psychiatry, 54(6), 686-694.

Landerl, K., \& Wimmer, H. (2008). Development of word reading fluency and spelling in a consistent orthography: an 8-year follow-up. Journal of Educational Psychology, 100, 150-161. doi: 10.1037/0022-0663.100.1.150.

Landgraf, S., Beyer, R., Hild, I., Schneider, N., Horn, E., Schaadt, G., . . van der Meer, E. (2012). Impact of phonological processing skills on written language acquisition in illiterate adults. Developmental cognitive neuroscience, 2, S129-S138.

Leinonen, S., Müller, K., Leppänen, P., Aro, M., Ahonen, T., \& Lyytinen, H. (2001). Heterogeneity in adult dyslexic readers: Relating processing skills to the speed and accuracy of oral text reading. Reading and Writing, 14(3-4), 265-296. doi: 10.1023/A:1011117620895.

Lepola, J., Poskiparta, E., Laakkonen, E., \& Niemi, P. (2005). Development of and Relationship Between Phonological and Motivational Processes and Naming Speed in Predicting Word Recognition in Grade 1. Scientific Studies of Reading, 9(4), 367-399. doi: 10.1207/s1532799xssr0904_3. 
Liberman, I. Y., \& Shankweiler, D. (1985). Phonology and the problems of learning to read and write. Remedial and Special Education, 6(6), 8-17. doi: 10.1177/074193258500600604.

Liberman, I. Y., Shankweiler, D., \& Liberman, A. M. (1989). The alphabetic principle and learning to read. Paper presented at the Meeting of the International Academy for Research on Learning Disabilities, Oct, 1986, Northwestern U, Evanston, IL, US.

Liberman, I. Y., Shankweiler, D. P., Fischer, F. W., \& Carter, B. (1974). Explicit syllable and phoneme segmentation in the young child. Journal of Experimental Child Psychology, 18, 201-212. doi: 10.1016/0022-0965(74)90101-5.

Logie, R. H., \& Cowan, N. (2015). Perspectives on working memory: introduction to the special issue. Memory \& cognition, 43(3), 315-324.

Lovegrove, B. (1996). Dyslexia and a transient/magnocellular pathway deficit: The current situation and future directions. Australian Journal of Psychology, 48(3), 167-171. doi: $10.1080 / 00049539608259525$.

Lovett, M. W., Steinbach, K. A., \& Frijters, J. C. (2000). Remediating the core deficits of developmental reading disability: a double-deficit perspective. Journal of Learning Disabilities, 33(4), 334-358. doi: 10.1177/002221940003300406.

Lukatela, K., Carello, C., Shankweiler, D., \& Liberman, I. Y. (1995). Phonological awareness in illiterates: Observations from Serbo-Croatian. Applied Psycholinguistics, 16, 463-488. doi: $10.1017 /$ S0142716400007487.

Lyon, G. R., Shaywitz, S. E., \& Shaywitz, B. A. (2003). A definition of dyslexia. Annals of Dyslexia, 53, 1-14. doi: 10.1007/s11881-003-0001-9.

Lyytinen, H., Ahonen, T., Eklund, K., Guttorm, T., Kulju, P., Laakso, M. L., . . Viholainen, H. (2004a). Early Development of Children at Familial Risk for Dyslexia: Follow-up from Birth to School Age. Dyslexia, 10(3), 146-178. doi: 10.1002/dys.274.

Lyytinen, H., Ahonen, T., Eklund, K., Guttorm, T. K., Laakso, M. L., Leinonen, S., . . Viholainen, H. (2001). Developmental pathways of children with and without familial risk for dyslexia during the first years of life. Developmental Neuropsychology, 20(2), 535-554. doi: 10.1207/S15326942DN2002_5.

Lyytinen, H., Aro, M., Eklund, K., Erskine, J., Guttorm, T., Laakso, M. L., . . Richardson, U. (2004b). The development of children at familial risk for dyslexia: birth to early school age. Annals of Dyslexia, 54(2), 184-220. doi: 10.1007/s11881-004-0010-3. 
Lyytinen, H., Erskine, J., Tolvanen, A., Torppa, M., Poikkeus, A., \& Lyytinen, P. (2006). Trajectories of reading development: A follow-up from birth to school age of children with and without risk for dyslexia. Merrill-Palmer Quarterly, 52(3), 514-546. doi: 10.1353/mpq.2006.0031.

Manis, F. R., Doi, L. M., \& Bhadha, B. (2000). Naming speed, phonological awareness, and orthographic knowledge in second graders. Journal of Learning Disabilities, 33, 325-333, 374. doi: $10.1177 / 002221940003300405$.

Mann, V. A., \& Wimmer, H. (2002). Phoneme awareness and pathways into literacy: A comparison of German and American children. Reading and Writing: An Interdisciplinary Journal, 15, 653-682. doi: 10.1023/A:1020984704781.

Mattingly, I. G. (1972). Reading, the linguistic process, and linguistic awareness: ERIC.

McBride-Chang, C., \& Manis, F. R. (1996). Structural invariance in the associations of naming speed, phonological awareness, and verbal reasoning in good and poor readers: A test of the double deficit hypothesis. Reading and Writing: An Interdisciplinary Journal, 8(4), 323-339. doi: 10.1007/BF00395112.

McCallum, R. S., Bell, S. M., Wood, M. S., Below, J. L., Choate, S. M., \& McCane, S. J. (2006). What Is the Role of Working Memory in Reading Relative to the Big Three Processing Variables (Orthography, Phonology, and Rapid Naming)? Journal of Psychoeducational Assessment, 24(3), 243-259. doi: 10.1177/0734282906287938.

McCandliss, B. D. (2010). Educational neuroscience: The early years. Proceedings of the National Academy of Sciences of the Univted States of America, 107(18), 8049-8050. doi: 10.1073/pnas.1003431107.

McCandliss, B. D., Cohen, L., \& Dehaene, S. (2003). The visual word form area: Expertise for reading in the fusiform gyrus. Trends in Cognitive Sciences, 7(7), 293-299.

McGrath, L. M., Smith, S. D., \& Pennington, B. F. (2006). Breakthroughs in the search for dyslexia candidate genes. Trends in Molecular Medicine, 12(7), 333-341. doi: 10.1016/j.molmed.2006.05.007.

Meng, H., Smith, S. D., Hager, K., Held, M., Liu, J., Olson, R. K., . . . O'Reilly-Pol, T. (2005). DCDC2 is associated with reading disability and modulates neuronal development in the brain. Proceedings of the national academy of sciences of the united states of america, 102(47), 17053-17058. doi: 10.1073/pnas.0508591102. 
Menghini, D., Finzi, A., Carlesimo, G. A., \& Vicari, S. (2011). Working memory impairment in children with developmental dyslexia: is it just a phonological deficity? Developmental Neuropsychology, 36(2), 199-213. doi: 10.1080/87565641.2010.549868.

Molfese, V. J., Modglin, A., \& Molfese, D. L. (2003). The Role of Environment in the Development of Reading Skills A Longitudinal Study of Preschool and School-Age Measures. Journal of learning disabilities, 36(1), 59-67. doi: 10.1177/00222194030360010701.

Moll, K., Loff, A., \& Snowling, M. J. (2013). Cognitive endophenotypes of dyslexia. Scientific Studies of Reading, 17(6), 385-397. doi: 10.1080/10888438.2012.736439.

Morais, J., Bertelson, P., Cary, L., \& Alegria, J. (1986). Literacy training and speech segmentation. Cognition, 24, 45-64. doi: 10.1016/0010-0277(86)90004-1.

Morais, J., Cary, L., Alegria, J., \& Bertelson, P. (1979). Does awareness of speech as a sequence of phones arise spontaneously? Cognition, 7, 323-331. doi: 10.1016/0010-0277(79)90020-9

Morgan, W. P. (1896). A Case of Congenital Word Blindness. British Medical Journal, II, 178.

Morris, R. D., Stuebing, K. K., Fletcher, J. M., Shaywitz, S. E., Lyon, G. R., Shankweiler, D. P., . . Shaywitz, B. A. (1998). Subtypes of reading disability: Variability around a phonological core. Journal of Educational Psychology, 90(3), 347-373. doi: 10.1037/00220663.90.3.347.

Muter, V., Hulme, C., Snowling, M. J., \& Stevenson, J. (2004). Phonemes, rimes, vocabulary, and grammatical skills as foundations of early reading development: Evidence from a longitudinal study. Developmental Psychology, 4O(5), 665-680. doi: 10.1037/00121649.40.5.665.

Neuhaus, G. F., \& Swank, P. R. (2002). Understanding the relations between RAN letter subtest components and word reading in first-grade students. Journal of Learning Disabilities, 35(2), 158-174. doi: 10.1177/002221940203500206.

Nicolson, R. I., Fawcett, A. J., Berry, E. L., Jenkins, I. H., Dean, P., \& Brooks, D. J. (1999). Association of abnormal cerebellar activation with motor learning difficulties in dyslexic adults. The Lancet, 353(9165), 1662-1667. doi: 10.1016/S0140-6736(98)09165-X.

Nicolson, R. I., Fawcett, A. J., \& Dean, P. (2001). Dyslexia, development and the cerebellum. Trends in Neurosciences, 24(9), 515-516. doi: 10.1016/S0166-2236(00)01923-8.

O'Neill, M. E., \& Douglas, V. I. (1991). Study strategies and story recall in attention deficit disorder and reading disability. Journal of Abnormal Child Psychology, 19(6), 671-692. doi: 10.1007/BF00918906. 
Olson, R. K., Wise, B., Conners, F., Rack, J., \& Fulker, D. (1989). Specific deficits in component reading and language skills: Genetic and environmental influences. Journal of Learning Disabilities., 22, 339-348. doi: 10.1177/002221948902200604.

Orton, S. (1925). Word-blindness in school children. Archives of Neurology and Psychiatry, 14, 581-615.

Paracchini, S., Steer, C., Buckingham, L., Morris, A., Ring, S., Scerri, T., . . Golding, J. (2008). Association of the KIAA0319 dyslexia susceptibility gene with reading skills in the general population. American Journal of Psychiatry, 165(12), 1576-1584. doi: 10.1176/appi.ajp.2008.07121872.

Patel, T. K., Snowling, M. J., \& de Jong, P. F. (2004). A cross-linguistic comparison of children learning to read in English and Dutch. Journal of Educational Psychology, 96, 785-797. doi: 10.1037/0022-0663.96.4.785.

Pennington, B. F. (1990). The genetics of dyslexia. Journal of Child Psychology and Psychiatry, 31(2), 193-201. doi: 10.1111/j.1469-7610.1990.tb01561.x.

Pennington, B. F. (1997). Using genetics to dissect cognition. American Journal of Human Genetics, 60(1), 13-16.

Pennington, B. F., Cardoso-Martins, C., Green, P. A., \& Lefly, D. L. (2001). Comparing the phonological and double deficit hypotheses for developmental dyslexia. Reading and Writing: An Interdisciplinary Journal, 14, 707-755. doi: 10.1023/A:1012239018038.

Pennington, B. F., \& Lefly, D. L. (2001). Early reading development in children at family risk for dyslexia. Child Development, 72(3), 816-833. doi: 10.1111/1467-8624.00317.

Pennington, B. F., \& Olson, R. K. (2008). Genetics of Dyslexia. The Science of Reading: A Handbook, 453-472. doi: 10.1002/9780470757642.ch24.

Perfetti, C. A., Beck, I., Bell, L. C., \& Hughes, C. (1987). Phonemic knowledge and learning to read are reciprocal: a longitudinal study of first grade children. Merill-Palmer Quarterly, 33(3), 283-319. .

Petersen, D. K., \& Elbro, C. (1999). Pre-school prediction and prevention of dyslexia: A longitudinal study with children of dyslexic parents. In T. Nunes (Ed.), Learning to read: An integrated view from research and practice (pp. 133-154). Dordrecht: Kluwer.

Peterson, R. L., \& Pennington, B. F. (2015). Developmental dyslexia. Annual review of clinical psychology, 11, 283-307. 
Petrill, S. A., Deater-Deckard, K., Thompson, L. A., DeThorne, L. S., \& Schatschneider, C. (2006). Genetic and Environmental Effects of Serial Naming and Phonological Awareness on Early Reading Outcomes. Journal of Educational Psychology, 98(1), 112-121. doi: 10.1037/0022-0663.98.1.112.

Pickering, S. J. (2012). 2 Working memory in dyslexia. Working memory and neurodevelopmental disorders, 7.

Plomin, R., Reiss, D., Hetherington, E. M., \& Howe, G. W. (1994). Nature and nurture: genetic contributions to measures of the family environment. Developmental Psychology, 30(1), 32. doi: 10.1037/0012-1649.30.1.32.

Puolakanaho, A., Ahonen, T., Aro, M., Eklund, K., Leppänen, P., Poikkeus, A., . . Lyytinen, H. (2008). Developmental Links of Very Early Phonological and Language Skills to Second Grade Reading Outcomes: Strong to Accuracy but Only Minor to Fluency. Journal of Learning Disabilities, 41(4), 353-370. doi: 10.1177/0022219407311747.

Puolakanaho, A., Ahonen, T., Aro, M., Leppanen, P. H. T., Tolvanen, A., Lyytinen, H., . . Eklund, K. (2007). Very early phonological and language skills: Estimating individual risk of reading disability. Journal of Child Psychology and Psychiatry, 48, 923-931. doi: 10.1111/j.1469-7610.2007.01763.x.

Rack, J. P. (1994). Dyslexia: The Phonological Deficit Hypothesis. In A. J. F. a. R. I. Nicolson (Ed.), Dyslexia in Children: Multidisciplinary perspectives. London: Harvester Wheatsheaf.

Rack, J. P., \& Olson, R. K. (1993). Phonological Deficits, IQ, and Individual Differences in Reading Disability: Genetic and Environmental Influences. Developmental Review, 13(3), 269278. doi: 10.1006/drev.1993.1013.

Ramus, F. (2003). Developmental dyslexia: specific phonolical deficit or general sensorimotor dysfunction? Current Opinion in Neurobiology, 13, 212-218. doi: 10.1016/S09594388(03)00035-7.

Ramus, F. (2006). Genes, brain, and cognition: A roadmap for the cognitive scientist. Cognition, 101(2), 247-269. doi: 10.1016/j.cognition.2006.04.003.

Ramus, F., Rosen, S., Dakin, S. C., Day, B. L., Castellote, J. M., White, S., \& Frith, U. (2003). Theories of developmental dyslexia: Insights from a multiple case study of dyslexic adults. Brain: A Journal of Neurology, 126(4), 841-865. doi: 10.1093/brain/awg076.

Reitsma, P., \& Verhoeven, L. T. (1990). Acquisition of reading in Dutch (Vol. 9): Mouton de Gruyter. 
Rutter, M., \& Silberg, J. (2002). Gene-environment interplay in relation to emotional and behavioral disturbance. Annual review of psychology, 53(1), 463-490. doi: 10.1146/annurev.psych.53.100901.135223.

Rutter, M., \& Yule, W. (1975). The concept of specific reading retardation. Journal of Child Psychology and Psychiatry, 16, 181-197. doi: 10.1111/j.1469-7610.1975.tb01269.x.

Samuelsson, S., Byrne, B., Quain, P., Wadsworth, S., Corley, R., DeFries, J. C., . . Olson, R. K. (2005). Environmental and genetic influences on prereading skills in Australia, Scandinavia, and the United States. Journal of Educational Psychology, 97(4), 705-722. doi: 10.1037/0022-0663.97.4.705.

Savage, R., \& Frederickson, N. (2005). Evidence of a highly specific relationship between rapid automatic naming of digits and text-reading speed. Brain and Language, 93, 152-159. doi: 10.1016/j.bandl.2004.09.005.

Scarborough, H. S. (1989). Prediction of reading disability from familial and individual differences. Journal of Educational Psychology, 81(1), 101-108. doi: 10.1037/00220663.81.1.101.

Scarborough, H. S. (1990). Very early language deficits in dyslexic children. Child Development, 61, 1728-1743. doi: 10.2307/1130834.

Scarborough, H. S. (1998). Predicting the future achievement of second graders with reading disabilities: Contributions of phonemic awareness, verbal memory, rapid naming, and IQ. Annals of Dyslexia, 48(1), 115-136. doi: 10.1007/s11881-998-0006-5.

Schonell, F. J. (1935). Diagnostic tests for specific reading retardation. Journal of Child Psychiatry, 16, 181-197.

Schumacher, J., Hoffmann, P., Schmael, C., Schulte-Körne, G., \& Nöthen, M. M. (2007). Genetics of dyslexia: the evolving landscape. Journal of Medical Genetics, 44(5), 289-297. doi: 10.1136/jmg.2006.046516.

Seymour, P., Aro, M., \& Erskine, J. (2003). Foundation literacy acquisition in European orthographies. British Journal of Psychology, 94(2), 143-174. doi: $10.1348 / 000712603321661859$.

Share, D. L. (1995). Phonological recoding and self-teaching: sine qua non of reading acquisition. Cognition, 55, 151-218. doi: 10.1016/0010-0277(94)00645-2. 
Share, D. L. (1999). Phonological recoding and orthographic learning: A direct test of the selfteaching hypothesis. Journal of Experimental Child Psychology, 72, 95-129. doi: 10.1006/jecp.1998.2481.

Share, D. L. (2008). On the Anglocentricities of current reading research and practice: The perils of overreliance on an 'outlier' orthography. Psychological Bulletin, 134, 584-615. doi: 10.1037/0033-2909.134.4.584.

Shaywitz, S. E., \& Shaywitz, B. A. (2005). Dyslexia (Specific Reading Disability). Biological Psychiatry, 57(11), 1301-1309. doi: 10.1016/j.biopsych.2005.01.043.

Shaywitz, S. E., Shaywitz, B. A., Fletcher, J. M., \& Escobar, M. D. (1990). Prevalence of reading disability in boys and girls. Results of the Connecticut Longitudinal Study. The Journal of the American Medical Association, 264(8), 998-1002. doi: 10585988.

Skuse, D. H. (2001). Endophenotypes and child psychiatry. The British Journal of Psychiatry, 178(5), 395-396. doi: 10.1192/bjp.178.5.395.

Smith-Spark, J. H., \& Fisk, J. E. (2007). Working memory functioning in developmental dyslexia. Memory, 15(1), 34-56. doi: 10.1080/09658210601043384.

Snowling, M. J. (1980). The development of grapheme-phoneme correspondence in normal and dyslexic readers. Journal of Experimental Child Psychology, 29(2), 294-305. doi: 10.1016/0022-0965(80)90021-1.

Snowling, M. J. (1981). Phonemic deficits in developmental dyslexia. Psychological research, 43(2), 219-234. doi: 10.1007/BF00309831.

Snowling, M. J. (2000). Dyslexia. Oxford: Blackwell Publishers.

Snowling, M. J. (2008). Specific disorders and broader phenotypes: the case of dyslexia. The Quarterly Journal of Experimental Psychology, 61(1), 142-156. doi: 10.1080/17470210701508830.

Snowling, M. J., Gallagher, A., \& Frith, U. (2003). Family risk of dyslexia is continuous: individual differences in the precursors of reading skill. Child Development, 74(2), 358-373. doi: 10.1111/1467-8624.7402003.

Snowling, M. J., Goulandris, N., Bowlby, M., \& Howell, P. (1986). Segmentation and speech perception in relation to reading skill: A developmental analysis. Journal of Experimental Child Psychology, 41(3), 489-507. doi: 10.1016/0022-0965(86)90006-8. 
Snowling, M. J., \& Hulme, C. (2012). Annual Research Review: The nature and classification of reading disorders-a commentary on proposals for DSM-5. Journal of Child Psychology and Psychiatry, 53(5), 593-607. doi: 10.1111/j.1469-7610.2011.02495.x.

Staff, B. D. A., Johnson, M., Peer, L., \& Association, B. D. (2002). Dyslexia Handbook 2002: British Dyslexia Association.

Stanovich, K. E. (1988). Explaining the differences between dyslexic and the garden-variety poor reader. The phonological-core varibale-difference model. Journal of Learning Disabilities, 21, 590-612. doi: 10.1177/002221948802101003.

Stanovich, K. E., \& Siegel, L. S. (1994). Phenotypic performance profile of children with reading disabilities: A regression-based test of the phonological-core-variable-difference model. Journal of Educational Psychology, 86, 24-53. doi: 10.1037//0022-0663.86.1.24.

Stein, J. (2001). The magnocellular theory of developmental dyslexia. Dyslexia, 7(1), 12-36. doi: 10.1002/dys.186.

Stein, J., \& Walsh, V. (1997). To see but not to read; the magnocellular theory of dyslexia. Trends in Neurosciences, 20(4), 147-152. doi: citeulike-article-id:1074841.

Stuebing, K. K., Fletcher, J. M., LeDoux, J. M., Lyon, G. R., Shaywitz, S. E., \& Shaywitz, B. A. (2002). Validity of IQ-Discrepancy Classifications of Reading Disabilities: A Meta-Analysis. American Educational Research Journal, 39(2), 469-518. doi: 10.3102/00028312039002469.

Taipale, M., Kaminen, N., Nopola-Hemmi, J., Haltia, T., Myllyluoma, B., Lyytinen, H., . . HannulaJouppi, K. (2003). A candidate gene for developmental dyslexia encodes a nuclear tetratricopeptide repeat domain protein dynamically regulated in brain. Proceedings of the National Academy of Sciences, 100(20), 11553-11558. doi: 10.1073/pnas.1833911100.

Tallal, P. (1980). Auditory temporal perception, phonics, and reading disabilities in children. Brain and Language, 9(2), 182-198. doi: 10.1016/0093-934X(80)90139-X.

Tallal, P., Miller, S., \& Fitch, R. H. (1993). Neurobiological basis of speech: a case for the preeminence of temporal processing. Annals of the New York academy of sciences, 682(1), 27-47. doi: 10.1111/j.1749-6632.1993.tb22957.x.

Temple, E., Poldrack, R. A., Protopapas, A., Nagarajan, S., Salz, T., Tallal, P., . . Gabrieli, J. D. E. (2000). Disruption of the neural response to rapid acoustic stimuli in dyslexia: Evidence 
from functional MRI. Proceedings of the National Academy of Sciences, 97(25), 1390713912. doi: 10.1073/pnas.240461697.

Thompson, P. A., Hulme, C., Nash, H. M., Gooch, D., E., H. T., \& Snowling, M. J. (2015). Developmental dyslexia: predicting individual risk. Journal of Child Psychology and Psychiatry, 56(9), 976-987.

Tijms, J. (2004). Verbal memory and phonological processing in dyslexia. Journal of Research in Reading, 27, 300-310. doi: 10.1111/j.1467-9817.2004.00233.x.

Torgesen, J. K., Wagner, R. K., \& Rashotte, C. A. (1994). Longitudinal studies of phonological processing and reading. Journal of Learning Disabilities, 27, 276-291. doi: 10.1177/002221949402700503.

Torgesen, J. K., Wagner, R. K., Rashotte, C. A., Burgess, S. R., \& Hecht, S. A. (1997). Contributions of phonological awareness and rapid automatic naming ability to the growth of wordreading skills in second- to fifth-grade children. Scientific Studies of Reading, 1(2), 161185. doi: $10.1207 / s 1532799 x s s r 0102 \_4$.

Torppa, M., Lyytinen, P., Erskine, J., Eklund, K., \& Lyytinen, H. (2010). Language development, literacy skills, and predictive connections to reading in Finnish children with and without familial risk for dyslexia. Journal of learning disabilities.

Tran, C., Gagnon, F., Wigg, K. G., Feng, Y., Gomez, L., Cate-Carter, T. D., . . Lovett, M. W. (2013). A family-based association analysis and meta-analysis of the reading disabilities candidate gene DYX1C1. American Journal of Medical Genetics Part B: Neuropsychiatric Genetics, 162(2), 146-156.

Vaessen, A., Bertrand, D., Tóth, D., Csépe, V., Faísca, L., Reis, A., \& Blomert, L. (2010). Cognitive development of fluent word reading does not qualitatively differ between transparent and opaque orthographies. Journal of Educational Psychology, 102, 827-842. doi: 10.1037/a0019465.

Vaessen, A., \& Blomert, L. (2010). Long term cognitive dynamics of fluent reading development. Journal of Experimental Child Psychology, 105, 213-231. doi: 10.1016/j.jecp.2009.11.005.

Vaessen, A., Gerretsen, P., \& Blomert, L. (2009). Naming problems do not reflect a second, independent core deficit in dyslexia: 'Double deficits' explored. Journal of Experimental Child Psychology, 103, 202-221. doi: 10.1016/j.jecp.2008.12.004. 
van Bergen, E., de Jong, P. F., Maassen, B., \& van der Leij, A. (2014). The Effect of Parents' Literacy Skills and Children's Preliteracy Skills on the Risk of Dyslexia. Journal of Abnormal Child Psychology, 42(7), 1187-1200. doi: 10.1007/s10802-014-9858-9.

Vellutino, F. R. (1979). Dyslexia: Theory and research. Cambridge, MA: MIT Press.

Vellutino, F. R., Fletcher, J. M., Snowling, M. J., \& Scanlon, D. M. (2004). Specific reading disability (dyslexia): what have we learned in the past four decades? Journal of Child Psychology and Psychiatry, 45(1), 2-40. doi: 10.1046/j.0021-9630.2003.00305.x.

Vellutino, F. R., Scanlon, D. M., \& Lyon, G. R. (2000). Differentiating Between Difficult-toRemediate and Readily Remediated Poor Readers More Evidence Against the IQAchievement Discrepancy Definition of Reading Disability. Journal of Learning Disabilities, 33(3), 223-238. doi: 10.1177/002221940003300302.

Vellutino, F. R., Scanlon, D. M., \& Spearing, D. (1995). Semantic and phonological coding in poor and normal readers. Journal of experimental child psychology, 59(1), 76-123.

Vellutino, F. R., Steger, J. A., DeSetto, L., \& Phillips, F. (1975). Immediate and delayed recognition of visual stimuli in poor and normal readers. Journal of Experimental Child Psychology, 19(2), 223-232. doi: 10.1016/0022-0965(75)90086-7.

Wadsworth, S. J., Olson, R. K., \& DeFries, J. C. (2010). Differential genetic etiology of reading difficulties as a function of IQ: an update. Behavior Genetics, 40(6), 751-758. doi: 10.1007/s10519-010-9349-x.

Wadsworth, S. J., Olson, R. K., Pennington, B. F., \& DeFries, J. C. (2000). Differential Genetic Etiology of Reading Disability as a Function of IQ. Journal of Learning Disabilities, 33(2), 192-199. doi: 10.1177/002221940003300207.

Wagner, R. K., \& Torgesen, J. K. (1987). The nature of phonological processing and its causal role in the acquisition of reading skills. Psychological Bulletin, 101, 192-212. doi: 10.1037/0033-2909.101.2.192.

Wagner, R. K., Torgesen, J. K., \& Rashotte, C. A. (1994). Development of reading-related phonological processing abilities: New evidence of bidirectional causality from a latent variable longitudinal study. Developmental Psychology, 30, 73-87. doi: 10.1037/00121649.30.1.73.

Wagner, R. K., Torgesen, J. K., Rashotte, C. A., Hecht, S. A., Barker, T. A., Burgess, S. R., . . Garon, T. (1997). Changing relations between phonological processing abilities and word-level 
reading as children develop from beginning to skilled readers: a 5-year longitudinal study. Developmental Psychology, 33(3), 468-479. doi: 10.1037/0012-1649.33.3.468.

Wentink, H., \& Verhoeven, L. (2003). Protocol leesproblemen en dyslexie [protocol reading problems and dyslexia]. Nijmegen: Expertisecentrum Nederlands.

Wesseling, R., \& Reitsma, P. (2000). The transient role of explicit phonological recoding for reading acquisition. Reading and Writing, 13, 313-336. doi: 10.1023/A:1026432502088.

Williams, J., \& O'Donovan, M. C. (2006). The genetics of developmental dyslexia. European Journal of Human Genetics, 14(6), 681-689. doi: 10.1038/sj.ejhg.5201575.

Wilson, A. M., \& Lesaux, N. K. (2001). Persistence of Phonological Processing Deficits in College Students with Dyslexia Who Have Age-Appropriate Reading Skills. Journal of Learning Disabilities, 34(5), 394-400. doi: 10.1177/002221940103400501.

Wimmer, H. (1993). Characteristics of developmental dyslexia in a regular writing system. Applied Psycholinguistics, 14, 1-33. doi: 10.1017/S0142716400010122.

Wimmer, H., Landerl, K., Linortner, R., \& Hummer, P. (1991). The relationship of phonemic awareness to reading acquisition: more consequence than precondition but still important. Cognition, 4O(3), 219-249. doi: 10.1016/0010-0277(91)90026-Z.

Wimmer, H., Mayringer, H., \& Landerl, K. (2000). The double-deficit hypothesis and difficulties in learning to read a regular orthography. Journal of Educational Psychology, 92(4), 668680. doi: 10.1037/0022-0663.92.4.668.

Wimmer, H., \& Schurz, M. (2010). Dyslexia in regular orthographies: manifestation and causation. Dyslexia, 16(4), 283-299.

Wolf, M. (1997). A provisional, integrative account of phonological and naming-speed deficits in dyslexia: Implications for diagnosis and intervention. In B. A. Blachman \& A. Benita (Eds.), Foundations of reading acquisition and dyslexia: Implications for early intervention (pp. 67-92). Mahwah, NY: Lawrence Erlbaum Associates.

Wolf, M., \& Bowers, P. G. (1999). The double-deficit hypothesis for the developmental dyslexias. Journal of Educational Psychology, 91(3), 415-438. doi: 10.1037/0022-0663.91.3.415.

Wolf, M., Bowers, P. G., \& Biddle, K. (2000). Naming-speed processes, timing, and reading: A conceptual review. Journal of Learning Disabilities, 33(4), 387-407. doi: 10.1177/002221940003300409. 
Zaric, G., Fraga Gonzalez, G., Tijms, J., van der Molen, M. W., Blomert, L., \& Bonte, M. (2015). Crossmodal deficit in dyslexic children: practice affects the neural timing of letterspeech sound integration. Front Hum Neurosci, 9, 369. doi: 10.3389/fnhum.2015.00369.

Ziegler, J. C., Bertrand, D., Tóth, D., Csépe, V., Reis, A., Faísca, L., \& ...Blomert, L. (2010). Orthographic Depth and its impact on universal predictors of reading: a cross-language investigation. Psychological Science, 21, 551-559. doi: 2010-09433-018.

Ziegler, J. C., \& Goswami, U. (2005). Reading acquisition, developmental dyslexia, and skilled reading across languages: a psycholinguistic grain size theory. Psychological Bulletin, 131(1), 3-29. doi: 10.1037/0033-2909.131.1.3. 


\section{CHAPTER 2}

INVESTIGATION OF THE CAUSALITY BETWEEN PHONOLOGICAL AWARENESS DEFICITS AND EMERGING READING DEFICITS IN CHILDREN AT FAMILIAL RISK FOR DYSLEXIA

\section{This chapter is based on:}

Blomert, L., \& Willems, G. (2010) ${ }^{1}$. Is there a causal link from a phonological awareness deficit to reading failure in children at familial risk for dyslexia? Dyslexia: An International Journal of Research and Practise, 16(4), 300-317, doi: 10.1002/dys.405.

\footnotetext{
${ }^{1}$ Please be referred to the Author contribution statement at the end of this chapter for a clarification of the responsibilities of both authors in this work.
} 


\section{ABSTRACT}

The knowledge that reading and phonological awareness are mainly reciprocally related has hardly influenced the status of a phonological awareness deficit as the main cause of a reading deficit in dyslexia. Because direct proofs for this theory are still lacking we investigated children at familial risk for dyslexia in kindergarten and first grade. The familial risk was genuine; $40 \%$ developed reading deficits in first grade. However, we did not find any relationship between a phonological awareness or other phonological processing deficits in kindergarten and reading deficits in first grade. Finally, we did not find evidence for the claim that a phonological awareness deficit assumedly causes a reading deficit via 'unstable' or otherwise corrupted letter-speech sound associations. Although earlier research indicated letter knowledge as another significant determinant of later reading deficits, we found no support for this claim. Letter knowledge learning and learning to associate and integrate letters and speech sound are different processes and only problems in the latter process seem directly linked to the development of a reading deficit. The nature of this deficit and the impact it might have on multisensory processing in the whole reading network presents a major challenge to future reading and dyslexia research. 


\subsection{INTRODUCTION}

There never has been a cognitive skill other than phonological awareness, which has so widely, frequently and consistently been associated with reading acquisition and reading failure during the last quarter of a century. This statement is such a truism that it would probably qualify as the worst opening sentence ever, if there was not also something deeply troubling about this state of affairs. Despite an abundant literature stressing the causal role of phonological awareness in learning to read (e.g., Adams, 1990; Goswami, 2000; Torgesen, Wagner, \& Rashotte, 1994; Wagner \& Torgesen, 1987), there still is no convincing proof that phonological awareness represents a distinct set of spoken language skills that (a) precede and (b) directly influence the process of reading acquisition (Castles \& Coltheart, 2004, p. 78). Furthermore, there is an equally widespread literature concerning the other side of the same coin, stating that a deficit in phonological awareness is the main cause of reading failure in specific developmental disorders like dyslexia (e.g., Snowling, 2000; Torgesen et al., 1999; Vellutino, Fletcher, Snowling, \& Scanlon, 2004). It may not come as a surprise that also in this case the way how this phonological awareness deficit assumedly causes reading deficits still remains to be established. Although the arguments about pros and cons of the above theories have already been excellently reviewed elsewhere (e.g., Castles \& Coltheart, 2004; Ziegler \& Goswami, 2005), we introduce here the basic theoretical controversies in a nutshell to prepare the ground for our present study, which focuses not only on the direct claims of the phonological awareness deficit theory, but also explicitly on its most critical but still elusive indirect claim, i.e. that a phonological awareness deficit is presumably causing reading deficits by causing 'unstable' letter-sound associations (e.g., for a review see Snowling, 2000; Vellutino et al., 2004).

Phonological awareness refers to the ability to manipulate the sounds of one's spoken language (Mattingly, 1972). The basic argument for situating phonological awareness in a central position at the start of early reading acquisition runs as follows: In alphabetic languages letters represent speech sounds and a child therefore has to become aware that speech and more particularly words and syllables can be segmented into speech sounds, before they can be linked to letters or letter strings (Gleitman \& Rozin, 1977; Liberman, 1973; Liberman, Shankweiler, Fischer, \& Carter, 1974; Mattingly, 1972); hence the primacy of phonological, and more particularly, phonemic awareness. Interestingly, this view has been contested almost from its inception by an alternative theory posing that phonemic awareness is mainly a consequence 
of learning to read and not a necessary precursor. It was shown that illiterates, like dyslexics, exhibit phonemic awareness problems on tasks requiring them to segment individual phonemes (Morais, Cary, Alegria, \& Bertelson, 1979) and only start to show phonemic awareness insights after a basic literacy training (Morais, Bertelson, Cary, \& Alegria, 1986). This insight was further refined by revealing that e.g. phonological sensitivity and rhyme identification were relatively preserved in illiterates and semi-literates and not related to their limited knowledge of letters and words, whereas only phonemic awareness revealed a strong dependency on alphabetic acquisition (De Santos Loureiro, Willadino Braga, Souza, Queiroz, \& Dellatolas, 2004). Wimmer, Landerl, Linortner, and Hummer (1991) have convincingly shown that most 6- to 7-year-old children were not able to segment words into phonemes before reading instruction, but most of them did show clear phonemic awareness after several months of reading instruction. Speech perception research indeed showed an absence of any peaks in the phonemic discrimination functions of categorical phoneme perception in pre-school children at familial risk for dyslexia, but also for those without a risk (e.g., Boets, Wouters, Van Wieringen, \& Ghesquiere, 2007). Nevertheless, this does not imply that phonemic awareness can only result from reading experience (as claimed by Ziegler \& Goswami, 2005), since children can easily learn isolated phonemes without knowing the corresponding letters (Castles, Coltheart, Wilson, Valpied, \& Wedgwood, 2009; Hulme, Caravolas, Málková, \& Brigstocke, 2005, the present study). Further research revealed a strong reciprocal relationship between learning to read and the development of phonemic awareness (e.g., Perfetti, Beck, Bell, \& Hughes, 1987) with the addition that the influence of phonological awareness was less important in transparent orthographies than in opaque orthographies (Mann \& Wimmer, 2002). Recent research however shows that this interpretation is biased due to the incompatibility of the used measurement parameters; in transparent orthographies speed of reading is often compared with accuracy of phonological awareness and in opaque orthographies accuracy of phonological awareness and reading is standard. If speeded phonological awareness tasks are used, reading and phonological awareness remain reciprocally related over many years also in transparent orthographies (Vaessen \& Blomert, 2010). Furthermore, two recent studies also established that phonological awareness is strongly related to reading development in probably all alphabetic orthographies. The first study revealed that phonological awareness was important in all included orthographies, but the degree of orthographic transparency systematically modulated the weight of phonological contributions to reading (Ziegler et al., 2010) and the second study 
found that the cognitive dynamics of reading development did not differ between opaque and transparent orthographies, but the degree of transparency modulated the rate of reading development (Vaessen et al., 2010).

In summary, the emergence and development of phonological awareness is intrinsically linked to reading development over many years in all alphabetic orthographies, but is not the causal precursor of reading development. Although Wimmer et al. (1991) added that some basic phonological sensitivity was probably necessary to start to learn to read, we are not aware that the nature and type of influence of this initial phonological sensitivity have ever been clarified. The original basic claim that phonological awareness is necessary before letters can be linked to sounds is nevertheless very much alive in the reading research literature (e.g., see for examples Castles \& Coltheart, 2004).

To investigate the assumed primacy of phonological awareness in learning to read as directly as possible, Castles et al. (2009) trained letter awareness to one group of pre-literate children and phonemic awareness to another without revealing any of the correspondences between letters and speech sounds. Phonemic awareness training was successful, whereas letter awareness learning was somewhat less successful. After these trainings, all children received a letter-speech sound correspondence training. The results revealed that neither prior letter awareness nor prior speech sound awareness training directly assisted the subsequent learning of phoneme-grapheme associations in preliterate children. Phonemic awareness can thus be successfully taught without knowing the corresponding letters. But more important for present purposes, letter-sound correspondences can thus be learned in the absence of phonemic awareness for the speech sounds involved and the case for a causal link from phonological awareness to success in learning to read therefore seems ever more elusive.

Since the learning of letter-speech sound correspondences is the quintessence of learning to read (Ehri, 2005) and phonological awareness is not required to learn them (Castles et al., 2009), is it then plausible, that a phonological awareness deficit constitutes the main cause of reading failure? Even if phonological awareness is not the causal agent of reading acquisition, it can of course not be excluded that phonological awareness deficits may still cause reading problems. It is therefore indicated to investigate the primacy of possible distal and proximal causes, respectively phonological awareness and learning of letter-speech sound relations deficits, in reading failure. Since there is already an abundant literature on the assumed causal role of phonological awareness in dyslexia (e.g., for a review see Vellutino et al., 
2004), we will in the following concentrate on the widely assumed but never seriously tested assumption that a phonological awareness deficit causes reading deficits through poor lettersound associations.

Direct behavioural studies of letter-speech sound learning are scarce (e.g., Hardy, Smythe, Stennet, \& Wilson, 1972), but early studies did already show that mastery of lettersound associations still increased up into secondary education (Calfee, 1969). Recent electrophysiological brain studies confirmed this extended development by showing that, contrary to common expectation, normal readers need many years to automate 'simple' letterspeech sound correspondences, despite ceiling accuracy on behavioural letter knowledge tasks from first grade onwards (Froyen, Bonte, Van Atteveldt, \& Blomert, 2009). Although adult readers showed early and automatic crossmodal integration of letters and speech sounds within 150 ms (Froyen, Van Atteveldt, Bonte, \& Blomert, 2008), 11-year-old normal readers revealed the first signs of such automation only after four years of reading instruction, but they also still needed a relatively large time window to do so. On the contrary, their dyslexic peer's brain responses did not show any evidence of letter speech sound integration even after four years of reading education. The absence of early integration and only weak late association processes resembled the weak association effects between letters and speech sounds found in normal reading first graders (Froyen, Willems, \& Blomert, 2011). This extended automation process of the cross-modal integration of letters and speech sounds has recently been attributed to the special neural status of letter-sound pairs as audiovisual objects (Blomert \& Froyen, 2010), i.e., letter-speech sound pairs uniquely combine properties of natural and arbitrary unfamiliar audiovisual objects.

There are a few early behavioural studies claiming that dyslexics might have specific problems mastering letter-speech sound conversions (e.g., Fox, 1994; Snowling, 1980), but these studies mainly investigated pseudoword recognition and did not directly address the learning of letter-speech sound correspondences. Since it is not unreasonable to assume that dyslexic children and adults who are already reading will use already acquired visual word recognition skills to also deal with pseudowords, it is not clear if poor pseudo word reading should be attributed to poor reading skills or directly to poor letter-sound association skills. The finding that word and pseudoword reading remained highly correlated over six years of primary school reading development together with the finding that phonological awareness contributed substantially to both over the same period (Vaessen \& Blomert, 2010) favours the former 
interpretation. So, paired associate pseudoword learning might only very indirectly reveal insights in letter-speech sound processing.

A recent series of neuroimaging (fMRI) studies with dyslexic children and adults directly addressed letter-speech sound association in the brains of dyslexics without the use of a potentially interfering task; subjects did not have to do anything other than watch letters and listen to speech sounds (Blau et al., 2010; Blau, Van Atteveldt, Ekkebus, Goebel, \& Blomert, 2009). The results revealed as expected diminished brain activity for processing isolated speech sounds, but more importantly also reduced activation in well-defined posterior temporal brain areas when processing letters-speech sound pairs, despite full letter knowledge mastery. The most interesting observation was that dyslexic children and adults showed similar brain activation for existing and non-existing letter-speech sound pairs, whereas all normal readers immediately suppressed the activity for the letter-speech sound pair that did not exist in the subject's native orthography. So there might be more symmetry between the proximal causes of successful and impaired learning to read, than between the distal causes.

The problem of course is that these recent brain and early behavioural studies are ultimately not decisive in causal matters, because of the reciprocal relationship between reading problems and the underlying deficits. A test of the claim that phonological awareness deficits cause reading deficits then has to prevent reciprocal influences by investigating children who do not read yet, but who will develop dyslexia in the future. Since $40 \%$ of children with a familial risk will develop dyslexia (Byrne, Shankweiler, \& Hine, 2008), they pose as the best candidates for such an investigation. Furthermore, since about $30 \%$ of pre-literate risk children turn up as training resisters in kindergarten training studies of reading-related cognitive functions (e.g., Brown \& Felton, 1990; Torgesen et al., 1999; Vellutino et al., 1996; Whiteley, Smith, \& Connors, 2007), resistance to training may reveal a characteristic problem of risk children.

\section{THE PRESENT STUDY}

The present study investigates the basic claims that have been made in the name of the phonological deficit theory of dyslexia (see below) in children at familial risk for dyslexia in kindergarten and in first grade. Wagner and Torgesen (1987) described three classes of phonological processing related to reading; phonological awareness, phonological recoding in lexical access and phonetic recoding in working memory. Since we investigated pre-literate children we focused on the spoken language equivalents of these processes: phonological 
awareness, phonological lexical processing and phonological working memory. All children were first assessed in kindergarten and poor readers were identified in first grade. The following basic claims of the phonological awareness deficit theory of dyslexia were investigated:

1. Is a phonological awareness deficit characteristic for a familial dyslexia risk? Hypothesis 1: The percentage of familial risk children estimated to become dyslexic will exhibit phonological awareness problems in kindergarten.

2. Is a phonological awareness deficit causally linked to a reading deficit?

Hypothesis 2: Risk children showing a phonological awareness deficit in kindergarten will develop a reading deficit in first grade.

3. Is 'phonological insensitivity' linked to a reading deficit?

Hypothesis 3: Risk children showing poor phonological processing, other than awareness, in kindergarten will develop a reading deficit in first grade.

4. Is a phonological awareness deficit causing later reading deficits by causing unstable or otherwise poor letter- speech sound associations?

Hypothesis 4: Risk children showing a phonological awareness deficit in kindergarten will also show a letter-speech sound association deficit.

Next to these specific hypotheses we investigated whether reading-related cognitive deficits develop concurrently with the emergence of reading deficits in first grade. In addition we evaluated the possibility that letter-sound association learning constitutes a specific problem for risk children in kindergarten by examining the effects of a training focused on letter-sound learning. 


\subsection{METHODS}

\section{PARTICIPANTS}

The kindergarten sample consisted of 100 children, 53 (26 girls) with a dyslexic family member and 47 (26 girls) without a risk for dyslexia. Presence or absence of familial risk status was verified via a parental questionnaire concerning reading problems in the family. Furthermore, $70 \%$ of the Risk children had a sibling with a diagnosis of dyslexia from a specialized dyslexia institute. Eight children dropped out of the study in first grade. So, the total included sample in first grade was 92 children: 48 risk (23 girls) and 44 non-risk (22 girls). All children were native speakers without hearing problems or any neurological or sensory abnormalities. Informed consent from the parents and children and permission from the Ethical Committee of the Faculty of Psychology \& Neuroscience was obtained.

To investigate potential learning deficits we also conducted a training study focused on letter-sound learning in kindergarten. Roughly half the children of the sample were randomly assigned to the training condition, whereas the others only participated in the assessments. Thirteen Control children assigned to training did not start the training, but did participate in the measurements. This lead in effect to a training study sample of 32 trained risk, 21 untrained risk, 10 trained controls and 37 untrained controls.

\section{ASSESSMENT}

To control for third-factor explanations of group differences, all children were assessed for general non-verbal intelligence (RAVEN, Raven \& Court, 1998) and receptive vocabulary (RAKIT, Bleichrodt, Drenth, Zaal, \& Resing, 1988). Furthermore, the following reading-related cognitive skills were assessed (3 DM, Blomert \& Vaessen, 2009, unless indicated otherwise):

Reading fluency: number of correct words and pseudowords read aloud in 90 seconds, expressed in average speed per correct item in milliseconds.

Phonological Awareness 1 (PA-blend): blend an incomplete number of verbally presented phonemes or phoneme strings into a word (TVK, Van Bon \& Hoekstra, 1982).

Phonological Awareness 2 (PA-phon.del.): delete a phoneme from an auditory presented pseudoword and pronounce the resulting pseudoword (e.g. 'dauk' minus/d/).

Phonological Lexical Processing (PLP, access/retrieval): correctly pronounce a perceived auditory presented word in which parts were deleted (non-standard task). 
Phonological Working Memory (PWM): repeat a sequence of auditory presented items in the same order: words in kindergarten and speech sounds and syllables in first grade (nonstandard task).

Letter Knowledge (LK): correctly name or sound out visual presented letters (nonstandard task).

Letter-Speech Sound Identification (LSSI): correctly match an auditory speech sound to one out of four visually presented letters.

Letter-Speech Sound Discrimination (LSSD): make a same/different decision for congruent and incongruent letter -speech sound pairs.

Note: The phonemic blending task in kindergarten was motivated because the pilot study with 10 risk and 10 control children revealed floor performance for the phoneme deletion task in kindergarten.

\section{PROCEDURES}

All children were evaluated twice; in kindergarten and in first grade after half a year of reading instruction. All tests were administered individually, in a fixed order and in a quiet room in two sessions of 40-50 min. All tests were computerized with the exception of general nonverbal intelligence, receptive vocabulary and PA-blending.

Training: The computerized training presented to some of the children consisted of a series of exercises in which an orthographic item (i.e. a letter or a string of letters) and a number of orthographic distracter items were presented visually on the screen. Simultaneously, an auditory item (i.e. a single speech sound or a string of speech sounds) was presented auditory via high quality headphones. Children had to correctly match the corresponding letter(s) and speech sound(s). The letters taught were high frequency consonants (e.g. k, p, w), short vowels (e.g. a, e, i), long vowels (e.g. aa, ee, uu) and digraphs (e.g. eu, ui, ou). In case of an incorrect answer, positive feedback was provided by demonstrating which letter correctly corresponded to the speech sound. Moreover, the number of distracters increased and the presentation speed decreased as a function of individual success (for a description of the original training see Hintikka, Aro, \& Lyytinen, 2005, for an elaborate description of the Dutch language adaption of the training, see Appendix 1 of the present thesis). Children trained individually without parental help at home in a quiet room, 3-4 times a week each time 10 min over an average period of 10 weeks. Duration of training $(F(40)=0.84, p>0.05)$ and performance level reached $(F(40)=0.57$, 
$p>0.05)$ did not differ between groups: risk children trained on average 8,4 $\mathrm{hr}(\mathrm{SD}=2.2)$ and reached level $35.8(S D=21.1)$ out of 76 levels and control children trained $8.0 \mathrm{hr}(\mathrm{SD}=2.3)$ and reached 31.6 levels $(S D=17.8)$.

\subsection{RESULTS}

In kindergarten, Risk and Control children did not differ in Age, $F(1,96)=0.31, p>0.05$, respective mean age values in months were 70 (4.90) and 71 (4.97); in General Intelligence, $F(1,96)=4.01, p>0.05$, respective standard scores were 6.7 (1.9) and 6.3 (2.3), or in Receptive Vocabulary, $F(1,96)=1.00, p>0.05$, respective standard scores were $18.3(5.9)$ and $16.2(5.2)$. Moreover, the majority of Risk and Control children were non-readers in kindergarten; respective number of correctly read CVC words were 2.06 (4.58) and 3.11 (4.84) and there was no group difference, $F(1,96)=0.59, p>0.05$. In first grade, all Risk and Control children had reached full mastery of Letter Knowledge. Therefore, this variable was dropped from the analysis in first grade. Test Performance in Kindergarten and First Grade Performances of Risk and Control children were compared by means of a one-way ANOVA for each kindergarten dependent variable (i.e. LK, LSS-I, LSS-D, PA-blend, PLP, and PWM) and each grade 1 dependent variable (i.e. LSS-I, LSS-D, PA-blend, PLP, PWM, PA-phon.del., and Reading Fluency). See Table 1 for the descriptive values in kindergarten and grade 1 per dependent variable per group.

In kindergarten, Risk and Control groups did not differ on any measure; LK, $F(1,98)=$ $0.29, p>0.05$; LSSI, F(1,98) $=0.88, p>0.05$; LSSD, F(1, 98) $=0.03, p>0.05$; PA-blend, $\mathrm{F}(1,98)=$ $0.25, p>0.05 ;$ PLP, $F(1,98)=0.20, p>0.05 ;$ PWM, $F(1,98)=0.79, p>0.05$. In grade 1 , Risk children were outperformed by control children on Reading Fluency, $F(1,91)=16.7, p<0.01$, LSSI, $F(1,91)=6.78, p<.05$, LSSD, $F(1,91)=4.66, p<0.05$, and PA-phon.del., $F(1,91)=9.46, p<$ 0.01 . There was no significant difference between Risk and Control children on PA-blend, F(1, $91)=3.57, p>0.05, \operatorname{PLP}, \mathrm{F}(1,91)=0.46, p>0.05$ and $\mathrm{PWM}, \mathrm{F}(1,91)=0.56, p>0.05$. 
Table 1. Average raw scores kindergarten and first grade

\begin{tabular}{lllll}
\hline & Kindergarten & & Grade 1 \\
\hline & Risk $\mathrm{n}=53$ & Control $\mathrm{n}=47$ & Risk $\mathrm{n}=48$ & Control $\mathrm{n}=44$ \\
\hline LK & $10.36(6.14)$ & $9.7(5.99)$ & Ceiling & Ceiling \\
LSSI & $16.57(6.28)$ & $15.43(5.81)$ & $38.51(7.01)$ & $41.77(4.81)^{*}$ \\
LSSD & $36.72(7.70)$ & $34.45(8.22)$ & $70.88(14.78)$ & $76.75(11.09)^{*}$ \\
PA-blend & $18.17(3.95)$ & $17.74(4.53)$ & $22.29(2.37)$ & $23.34(3.03)$ \\
PLP & $21.89(5.13)$ & $21.47(4.17)$ & $29.20(3.89)$ & $29.68(3.0)$ \\
PWM & $24.77(5.40)$ & $23.79(5.73)$ & $29.00(4.60)$ & $29.70(3.89)$ \\
PA-phon.del & Floor & Floor & $8.02(6.45)$ & $12.24(5.44)^{* *}$ \\
Read (correct/sec) & - & - & $0.39(0.23)$ & $0.62(0.31)^{* *}$ \\
\hline
\end{tabular}

Note: LK, letter knowledge; LSSI, letter-speech sound identification; LSSD, letter-speech sound discrimination; PA-blend, phonological awareness-phoneme blending; PLP, phonological lexical processing; PWM, phonological working memory; Phonological Awareness-phoneme deletion. Chance level: LSSI kindergarten $=8$; first grade $=11$, LSSD kindergarten $=27$; first grade $=45$. Significance level: ${ }^{*} p$ $<0.05, * * p<0.01$.

\section{TESTING THE PHONOLOGIC DEFICIT HYPOTHESES}

In kindergarten, the Poor performance criterion in kindergarten was based on raw scores and corresponded to scores that were one standard deviation below the mean raw score of the total sample. In first grade, the Poor performance criterion was classified in terms of standardized norm scores and corresponded to scores that were one standard deviation below the mean norm score, i.e. <16th percentile rank norm score of each test. (See Table 2 for a summary of the results). Proportions of Poor performers in the Risk and Control group will be compared by means of a Chi-square test, unless the proportion per cell is less than five, then we will use a Fisher's Exact test. The individual differences analysis revealed that there was a significant larger proportion of Poor readers in first grade in the Risk group than in the Control group; $44 \%$ Risk (21 out of 48 ) and $9 \%$ Control (4 out of 44 ), $X^{2}(1,96)=13.94, p<0.01$. The results of the individual performance analysis are summarized in Table 2. 
Table 2. Individual poor performers in kindergarten and first grade

\begin{tabular}{|c|c|c|c|c|c|c|c|c|c|}
\hline \multicolumn{2}{|c|}{ Kindergarten } & \multicolumn{8}{|c|}{ First grade reading performance } \\
\hline & & \multicolumn{4}{|c|}{ Risk $n=48$} & \multicolumn{4}{|c|}{ Control $n=44$} \\
\hline & & \multicolumn{2}{|c|}{ Poor $n=21$} & \multicolumn{2}{|c|}{ Normal $n=27$} & \multicolumn{2}{|c|}{ Poor $n=4$} & \multicolumn{2}{|c|}{ Normal $n=40$} \\
\hline & & $\mathrm{n}$ & $\%$ & $\mathrm{n}$ & $\%$ & $\mathrm{n}$ & $\%$ & $\mathrm{n}$ & $\%$ \\
\hline \multirow[t]{2}{*}{ LK } & Poor & 6 & 13 & 2 & 4 & 1 & 2 & 8 & 18 \\
\hline & Normal & 15 & 31 & 25 & 52 & 3 & 7 & 32 & 73 \\
\hline \multirow[t]{2}{*}{ LSSI } & Poor & 5 & 10 & 2 & 4 & 1 & 2 & 5 & 11 \\
\hline & Normal & 16 & 33 & 25 & 52 & 3 & 7 & 35 & 80 \\
\hline \multirow[t]{2}{*}{ LSSD } & Poor & 2 & 4 & 0 & 0 & 2 & 5 & 5 & 11 \\
\hline & Normal & 19 & 40 & 27 & 56 & 2 & 5 & 35 & 80 \\
\hline \multirow[t]{2}{*}{ PA-blend } & Poor & 4 & 8 & 3 & 6 & 0 & 0 & 4 & 9 \\
\hline & Normal & 17 & 35 & 24 & 50 & 4 & 9 & 36 & 82 \\
\hline \multirow[t]{2}{*}{ PLP } & Poor & 3 & 6 & 4 & 8 & 1 & 2 & 6 & 14 \\
\hline & Normal & 18 & 38 & 23 & 48 & 3 & 7 & 34 & 77 \\
\hline \multirow[t]{2}{*}{ PWM } & Poor & 1 & 2 & 3 & 6 & 2 & 5 & 8 & 18 \\
\hline & Normal & 20 & 42 & 24 & 50 & 2 & 5 & 32 & 73 \\
\hline
\end{tabular}

Note: LK, letter knowledge; LSSI, letter-speech sound identification; LSSD, letter-speech sound discrimination; PA-blend, phonological awareness-phoneme blending; PLP, phonological lexical processing; PWM, phonological working memory.

\section{IS A PHONOLOGICAL AWARENESS DEFICIT CHARACTERISTIC FOR RISK OF DYSLEXIA?}

The results showed that in total only $14 \%$ (7 out of 48 ) of all risk children did show a phonological awareness deficit (phoneme blending) in kindergarten. Since 44\% (21 out of 48) of all risk children developed a reading deficit in first grade, the question narrows to: Is a phonological deficit characteristic for risk children who develop dyslexia? Only 19\% (4 out of 21) of the risk children who developed a reading deficit in first grade exhibited a phonological awareness deficit in kindergarten. None of the $9 \%$ Control children who showed reading difficulties in first grade ( 4 out of 44 ) showed a phonological awareness deficit in kindergarten ( 0 
out of 4). The proportions poor readers with phonological deficits in risk and control group did not differ ( $p=1.0$; Fischer Exact).

\section{IS A PHONOLOGICAL AWARENESS DEFICIT CAUSALLY LINKED TO A READING DEFICIT?}

A strong causal interpretation of this hypothesis predicts that all risk children with phonological awareness deficits in kindergarten will become reading disabled. The individual results showed that $57 \%$ (4 out of 7 ) of risk children with a kindergarten phonological awareness deficit will develop a reading deficit. This small group however only constituted $8 \%$ (4 out of 48 ) of all Risk children. Furthermore, $81 \%$ (17 out of 21 ) of the risk children who effectively developed a reading deficit in first grade showed normal phonological awareness in kindergarten. As for control children, none of the children with poor kindergarten PA showed first-grade reading difficulties (0 out of 4). This proportion did not differ significantly from the proportion in the Risk group ( $p=0.19$; Fischer Exact).

\section{IS A 'PHONOLOGICAL INSENSITIVITY' LINKED TO A READING DEFICIT?}

A strong interpretation of this hypothesis predicts that all risk children with phonological sensitivity deficits (working memory and lexical processing) will become reading disabled. The individual results showed that $43 \%$ ( 3 out of 7 ) of the risk children who showed poor phonological lexical processing in kindergarten did show a reading deficit in first grade. However, this small group only represented $6 \%$ (3 out of 48 ) of the Risk children. Moreover, $86 \%$ (18 out of 21) of the risk children who effectively developed a reading deficit in first grade showed normal phonological lexical processing in kindergarten. As for control children, $14 \%$ (1 out of 7) of the children with poor phonological lexical processing in kindergarten showed firstgrade reading difficulties. This proportion did not differ significantly from the proportion in the Risk group ( $p=0.56$, Fischer Exact).

The individual results also showed that $25 \%$ ( 1 out of 4 ) of Risk children with poor phonological working memory in kindergarten developed a reading deficit. In the Controls this was 20\% ( 2 out of 10); meaning that these proportions did not differ between groups ( $p=1.0$, Fischer Exact). In summary, this means that 95\% (20 out of 21) of the risk children, who developed a reading deficit, revealed normal working memory skills in kindergarten. 


\section{IS A PHONOLOGICAL AWARENESS DEFICIT LINKED TO A LETTER-SOUND ASSOCIATION DEFICIT?}

If a phonological awareness deficit causes reading deficits by corrupting letter-sound associations than a strong interpretation of this hypothesis predicts that all risk children exhibiting phonological deficits in kindergarten and reading deficits in first grade will also show letter-sound deficits in kindergarten. The individual results showed that $50 \%$ ( 2 out of 4 ) of the risk children with a phonological awareness and reading deficit also revealed a letter-speech sound processing (identification and/or discrimination) deficit in kindergarten. This constituted only $4 \%$ ( 2 out of 48 ) of the risk group. None of the Control children had a phonological awareness and reading deficit and they therefore drop out for this comparison. Furthermore, there was a weak non-significant relation (Pearson correlations) between poor phonological awareness and poor letter-sound processing in the risk children as a group in kindergarten; $r=$ 0.23 for LSSI and 0.028 for LSSD (controls $r=0.27$ and $r=0.22$, respectively).

\section{CONCURRENT RELATIONSHIP BETWEEN READING AND COGNITIVE DEFICITS IN FIRST GRADE}

There was a concurrent relationship between phonological awareness (phoneme deletion) and reading performance in first grade, overall $r=0.64, p<0.01$, in the risk group $r=$ $0.61, p<0.01$ and in the control group $r=0.57, p<0.01$. Furthermore $67 \%$ (14 out of 21 ) of all risk children with a reading deficit also showed poor PA-phoneme deletion performance in first grade. The two control children with a reading deficit also showed poor phoneme deletion performance ( 2 out of 2 ) and the proportions did not differ between groups (Fischer exact: $p=$ 1.0). Figure 1 summarizes the poor performers in grade 1 and the proportion of these who were poor readers.

\section{IS A DEFICIT IN LEARNING LETTER-SOUND ASSOCIATIONS CHARACTERISTIC FOR DYSLEXIA RISK?}

To investigate potential learning deficits, we compared the trained and untrained Risk and Control groups on the following reading-related variables: LK, LSSI, LSSD, and PA-blend. To correct for initial variability at pre-test within the groups, ANCOVA's corrected for pre-test differences (i.e. covariate) were carried out on the post-test scores with the variables Risk and Training as between-subject factors. Letter Knowledge (LK): A main effect of training, with the trained children outperforming the untrained children, $\mathrm{F}(1,95)=25.17, p<0.01, r=0.46$, but no effect of Group, $\mathrm{F}(1,95)=0.92, p=0.34, r=0.10$ and no Group $\times$ Training interaction $\mathrm{F}(1,95)=$ $0.76, p=0.38, r=0.09$. 


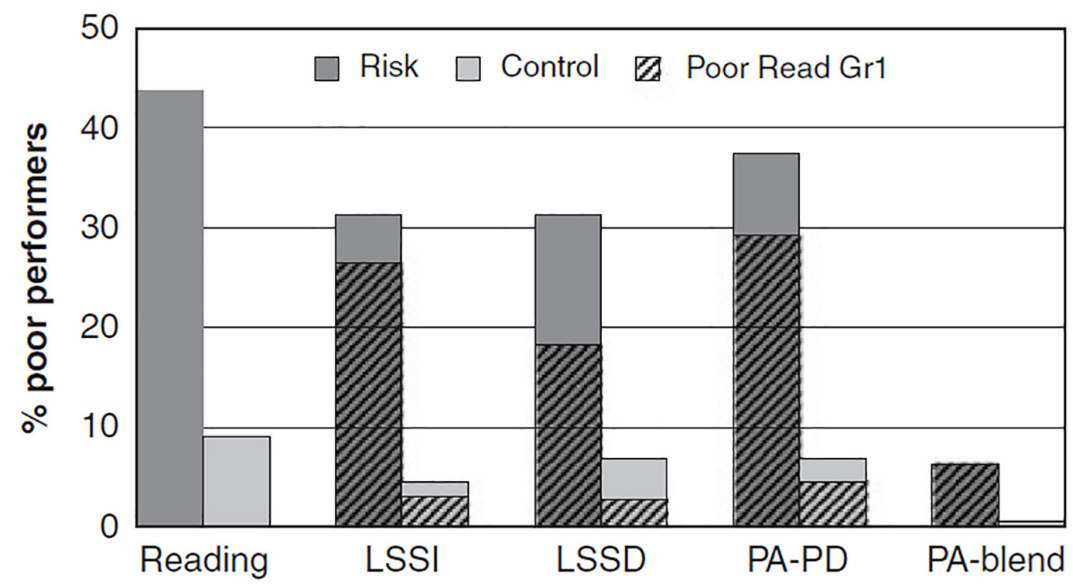

Figure 1. First-grade poor performers and poor readers: LSSI = Letter-Speech Sound Identification, LSSD = Letter-Speech Sound Discrimination, PA-blend = Phonological Awareness-phoneme blending, PA-PD = Phonological Awareness-phoneme deletion. Hatched area = proportion of poor performers, who also were poor readers.

Letter-Speech Sound Identification (LSSI): An interaction between Group and Training, $F(1,95)=6.24, p=0.01, r=0.25$. Separate analyses showed a main effect of Training in the Control group, $\mathrm{F}(1,44)=21.17, p<0.01, r=0.57$, but no effect in the Risk group, $\mathrm{F}(1,50)=0.70, p$ $=0.39, r=0.12$.

Letter-Speech Sound Discrimination (LSSD): A Group $x$ Training interaction, $F(1,95)=$ 4.63, $p=0.03, r=0.18$. Separate analyses showed a main effect of Training in the Control group, $\mathrm{F}(1,44)=13.25, p<0.01, r=0.48$, but not in the Risk group, $\mathrm{F}(1,50)=0.88, p=0.35, r=0.11$.

Phonological Awareness (PA-blend): No Training effect, $\mathrm{F}(1,93)=2.71, p=0.10, r=0.17$, no group effect, $\mathrm{F}(1,93)=0.01, p=0.92, r=0.01$ and no interaction, $\mathrm{F}(1,93)=0.35, p=0.55, r=$ 0.06 . 
Training resisters were identified by their individual responses to training. The criterion for gain was based on the combined average gain for the untrained Risk and Control children (AVG). The Resister criterion for LSS and also PA performance was defined as no gain over and beyond the improvements made by untrained children: poor $=<$ AVG. Gain calculations for LK were unreliable, since some children already knew most letters and this variable thus dropped out of the individual performance analysis. The summary of the training resisters in Figure 2 illustrates the proportions of training resisters who became poor reader. The results of the individual gain analysis showed that $38 \%$ (12 out of 32 ) of the trained Risk children showed no gain on LSSI and $28 \%$ (9 out of 32 ) revealed no gain on LSSD, whereas all Control gained on LSSI and only one of the trained control children (1 out of 10) did not gain on LSSD. It is interesting that $47 \%$ (15 out of 32 ) of the trained Risk and also $50 \%$ of the trained Control children (5 out of 10) exhibited no gain on PA. In summary more than a third of the Risk children showed letterspeech sound association learning problems, whereas all Controls improved immediately after training. In contrast, half of all children (risk and control) did not improve in phonological awareness. This leads then to the final question from the training study; was this specific learning problem related to a later reading deficit in first grade? From the $38 \%$ Risk training resisters (12 out of 32 , expressed in LSSI performance) $25 \%$ (3 out of 12) developed a reading deficit, whereas $40 \%$ of the training responders ( 8 out of 20 ) also developed a reading deficit. These proportions did not differ between groups ( $p=0.465$; Fisher exact). From the $28 \%$ Risk training resisters (9 out of 32, expressed in LSSD) 33\% (3 out of 9) developed a reading deficit, whereas $39 \%$ (9 out of 23 ) of the training responders also developed a reading deficit. These proportions did not differ between groups ( $p=0.10$; Fisher exact). 


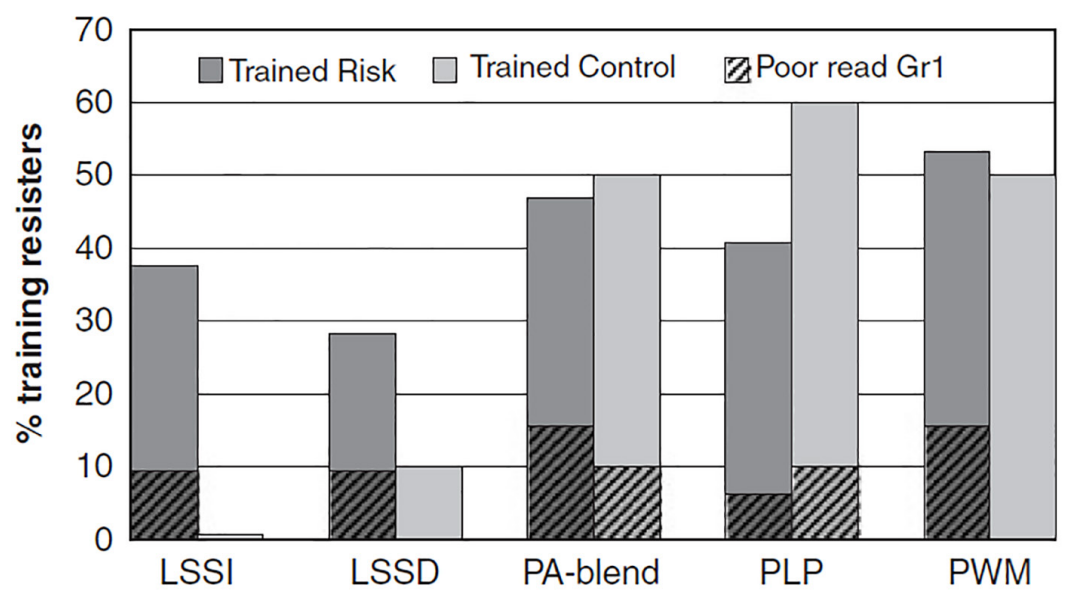

Figure 2. Training resisters in kindergarten and poor reading in first grade: $L S S I=$ Letter-Speech Sound Identification, LSSD = Letter-Speech Sound Discrimination, PA-blend $=$ Phonological Awareness-phoneme blending, PLP = Phonological Lexical Processing, PWM = Phonological Working Memory. Hatched area = proportion of training resisters, who became poor readers in grade 1. 


\subsection{DISCUSSION}

This study investigated the widely accepted, but still unproven, theory that there is a causal link from a phonological awareness deficit to a reading deficit in dyslexia. As the theory does not explain how this might happen, it is often assumed that a phonological awareness deficit may reside in poor phonological representations, which then lead to 'unstable' or otherwise poor letter-speech sound associations (e.g., Snowling, 2000). Since the reciprocal nature of phonological awareness and reading will not allow an unbiased evaluation of causes and consequences, we followed pre-literate children with a familial risk for dyslexia from kindergarten to first grade. The main results showed, first, that the subject selection was effective: In close agreement with the existing literature we found that $44 \%$ of the children with a familial risk for dyslexia developed a reading deficit in first grade, whereas only $9 \%$ of the control children did so. This cohort of poor readers set the stage for an exploration of the claims of the phonological deficit theory of reading failure in dyslexia. Since this theory is cast in terms of deficits, a pre-caution is needed. Since previous studies (Castles et al., 2009; Wimmer et al., 1991) and the present study showed that normally developing pre-literate children in general do not exhibit phonemic awareness before learning to read it does not seem adequate to label the absence of it a deficit. However, the use of a control group and standardized test instruments for relevant tasks allowed classifying significantly lower than normal performance on spoken language phonological (awareness) tasks. For consistency reasons we will thus refer to deficits in case of poor test performance.

The results revealed no support for the theory that a preceding phonological awareness deficit caused the reading deficit in the risk children, since only a very small proportion of the risk children exhibited phonological awareness problems in kindergarten and only part of these children developed a reading deficit. Furthermore, $80 \%$ of all risk children who did develop a reading deficit did not reveal a phonological awareness deficit in kindergarten. Since a phonological awareness deficit and a letter-sound association deficit only rarely co-occurred in the same individuals, there was also no support for the assumption that 'unstable' letter-sound associations 'explain' the reading problems of children with a phonological deficit. The finding that only very few risk children exhibited deficits in other potentially relevant phonological processes, like working memory and lexical processing deficits, did not provide an interpretation for the suggestion by Wimmer et al. (1991), that a certain level of phonological 'sensitivity' 
probably is necessary to start to learn to read. The large majority of risk children who effectively developed reading deficits in first grade did perform in the normal range on all included phonological processing tasks in kindergarten. In summary, the results of this study with familial risk children did not support the phonological (awareness) deficit theory of dyslexia; more precisely, the results render this theory rather unlikely.

On the contrary, the present results showed that reading-related cognitive deficits start to emerge only after the start of reading acquisition and develop in close relation with a developing reading deficit; i.e. only the children with a reading deficit (whether risk or control) in first grade did develop a phonological awareness deficit in first grade. Our results are thus fully in line with earlier research findings with illiterates (e.g., Morais et al., 1986; Morais et al., 1979) and beginning readers (e.g., Mann \& Wimmer, 2002; Wimmer et al., 1991) described in the introduction. However, since this earlier research mainly established that phonological awareness is probably a consequence of learning to read, it was still possible that a phonological awareness deficit caused reading deficits in dyslexia. The present results, however, do not support this theoretical possibility.

This interpretation also impacts on a variant of the phonological awareness deficit theory, which assumes a second independent rapid naming deficit in dyslexia next to the phonological awareness deficit (for an overview, see Wolf, Bowers, \& Biddle, 2000), because a recent study revealed that rapid naming deficits are not independent from a phonological deficit (Vaessen, Gerretsen, \& Blomert, 2009). This study showed that speeded naming tasks are mainly speeded phonological processing tasks, but with an, for present purposes, interesting addition: the naming task requires fast cross-modal matching of visual symbols and phonological codes. This seems to imply that rapid naming tasks are sensitive to phonological processing in the context of the fast audiovisual integration of letters and speech sounds. The plausibility of a letter-sound association deficit was raised by several brain studies, indicating persistent anomalies in letter-speech sound integration in dyslexic children and even in adults (Blau et al., 2010; Blau et al., 2009; Froyen, Van Atteveldt, Bonte, \& Blomert, 2007; Froyen et al., 2011; see introduction). Some studies have indeed advanced letter knowledge as another strong predictor of later reading problems of familial risk children (Lyytinen et al., 2006; Scarborough, 1990). However, our present results did not confirm these findings since our risk children did not differ from the controls in letter knowledge in kindergarten (see for similar results, Carroll \& Snowling, 2004). Furthermore, they showed similar letter knowledge improvement as controls after 
training (see for similar results, Byrne et al., 2008) and reached ceiling on letter knowledge like the controls within half a year of reading instruction in first grade. In contrast to these letter knowledge results, we found that a substantial part of the risk children did not profit from a kindergarten letter-sound training, whereas letter-speech sound association skills improved in all control children. There was however only a weak relationship between this letter-sound learning problem in kindergarten and reading deficits in first grade. This may mean that preschool letter-speech sound learning problems are not relevant for later reading development or are relevant, but effects can only be found over extended periods of time, because of the slowly developing automation of these associations even in normal readers (Froyen et al., 2009). Given that normally developing readers in a relatively transparent orthography like Dutch only showed the first signs of automatic letter-sound integration after four years of reading instruction (Froyen et al., 2009) reinforces our interpretation that half a year of reading instruction was probably too short to fully reveal the impact of a letter-sound association learning problem. Support for this argument was very recently found when we conducted a follow-up in second grade with the children, who participated in the present study. Kindergarten letter-speech sound association skills were a good predictor for risk and control reading performance in first grade, but turned out to be the best predictor of reading in second grade only for the risk children (chapter 3, present thesis). Another Dutch longitudinal study with risk children indeed showed that reading problems of a substantial group of risk children only emerged in second grade (van Otterloo \& van der Leij, 2009). A longitudinal study of English speaking familial risk children reported that risk children showed poorer non-word reading skills than the non-risk control children and the authors concluded that six-year-old risk children showed significant deficits in grapheme-phoneme skills (Snowling, Gallagher, \& Frith, 2003). However, since most (risk and control) children were hardly able to read non-words, this may primarily point to the severe opaqueness of letter-sound relationship in the English orthography (Share, 2008). The fact that a substantial part of these risk children did not develop reading deficits reiterates that non-word reading probably is not the best measure of letter-sound association skills and further indicates that more direct research of letter-speech sound processing in opaque orthographies is needed.

In summary, letter-speech sound association learning problems seem to be characteristic for a core of pre-school risk children in a relatively transparent orthography, independent of a phonological awareness problem, and independent of the letters they ' $k n o w$ '. 
Since anomalous letter-sound processing was also revealed in the brains of already reading dyslexic children and adults (Blau et al., 2010; Blau et al., 2009), it is intriguing to ask in how far this problem of mapping and integrating phonological and orthographic elements cascades through the reading network during development. In addition, it is interesting to note that the results also confirm the findings by Castles et al. (2009) that preschoolers can learn letterspeech sound correspondences in the absence of measurable phonemic awareness. There may thus indeed be more symmetry between the proximal causes of successful and impaired learning to read, than there has ever been between its assumedly distal causes, i.e. phonological awareness and phonological awareness deficits. In conclusion we did not find any evidence for the claim that phonological awareness deficits cause reading deficits. Instead, we found that problems in learning letter-speech sound associations and integration characterize children at familial risk for dyslexia. The nature of this deficit and the impact it has on multisensory processing in the whole reading network present a major challenge to future reading and dyslexia research. 


\section{ACKNOWLEDGEMENTS}

The authors thank the children and their parents for their cooperation, all assistants for testing the children, Hanne Poelmans for helping to conduct the training study and dr. Anniek Vaessen and two reviewers for helpful comments on the manuscript. We thank RID: Regional Institutes of Dyslexia and IWAL: Clinical Institutes for Dyslexia, both The Netherlands, for helping to recruit risk children. A part of the data from the training study were collected under the umbrella of the Marie Curie Excellence grant MCEXT-CE-2004-014203 (coordinator prof. Ulla Richardson) and were included here with permission. 


\section{AUTHOR CONTRIBUTION STATEMENT}

Both authors contributed to the conception and design of this work. G.W. moreover designed, wrote code for, developed stimuli for and implemented the Dutch version of the Graphogame training programme employed in this study (See Appendix 1). G.W. was responsible for all data collection, the training aspects, and the coordination with all stakeholders involved in the project (i.e., children, parents, schools, research assistants, and dyslexia institutes). G.W. analysed the output data and wrote the manuscript. L.B., as principle investigator, supervised the project by providing conceptual advice (e.g., discussion of results and implications) and commented on the manuscript in all stages. L.B., acted as corresponding author during the publication procedure. 


\section{REFERENCES}

Adams, M. J. (1990). Beginning to Read: Thinking and Learning about Print. Cambridge, Massachusetts: The MIT Press.

Blau, V., Reitler, J., Van Atteveldt, N., Gerretsen, P., Seitz, J., Goebel, R., \& Blomert, L. (2010). Deviant processing of letters and speech sounds as proximate cause of reading failure: an fMRI study of dyslexic children. Brain, 133(3), 868-879. doi: 10.1093/brain/awp308.

Blau, V., Van Atteveldt, N., Ekkebus, M., Goebel, R., \& Blomert, L. (2009). Reduced neural integration of letters and speech sounds links phonological and reading deficits in adult dyslexia. Current Biology, 19(6), 503-508. doi: 10.1016/j.cub.2009.01.065.

Bleichrodt, N., Drenth, P. D., Zaal, J. N., \& Resing, W. C. M. (1988). RAKIT: Revisie Amsterdamse Kinder Intelligentie Test [revision Amsterdam Children Intelligence Test]. Lisse: Swets \& Zeitlinger.

Blomert, L., \& Froyen, D. (2010). Multi-sensory learning and learning to read. International journal of psychophysiology, 77(3), 195-204.

Blomert, L., \& Vaessen, A. (2009). 3DM: Cognitieve analyse van lezen en spellen [3DM: Cognitive analysis of reading and spelling]. Amsterdam: Boom test publishers BV.

Boets, B., Wouters, J., Van Wieringen, A., \& Ghesquiere, P. (2007). Auditory processing, speech perception and phonological ability in pre-school children at high-risk for dyslexia: A longitudinal study of the auditory temporal processing theory. Neuropsychologia, 45(8), 1608-1620. doi: 10.1016/j.neuropsychologia.2007.01.009.

Brown, I. S., \& Felton, R. H. (1990). Effects of instruction on beginning reading skills in children at risk for reading disability. Reading and Writing, 2(3), 223-241.

Byrne, B., Shankweiler, D., \& Hine, D. W. (2008). Reading development in children at risk for dyslexia. In M. Mody \& K. Silliman (Eds.), Brain, Behavior and Learning in Language and Reading disorders (pp. 240-270). New York, US: Guilford Press.

Calfee, R. C. (1969). Pronunciation of Synthetic Words with Predictable and Unpredictable Letter-Sound Correspondences. Technical Report No. 71.

Carroll, J. M., \& Snowling, M. J. (2004). Language and phonological skills in children at high risk of reading difficulties. Journal of Child Psychology and Psychiatry, 45(3), 631-640. doi: 10.1111/j.1469-7610.2004.00252.x. 
Castles, A., \& Coltheart, M. (2004). Is there a causal link from phonological awareness to success in learning to read? Cognition, 91(1), 77-111. doi: 10.1016/S0010-0277(03)00164-1.

Castles, A., Coltheart, M., Wilson, K., Valpied, J., \& Wedgwood, J. (2009). The genesis of reading ability: What helps children learn letter-sound correspondences? Journal of Experimental Child Psychology, 104(1), 68-88.

De Santos Loureiro, C., Willadino Braga, L., Souza, L. d. N., Queiroz, E., \& Dellatolas, G. (2004). Degree of illiteracy and phonological and metaphonological skills in unschooled adults. Brain and Language, 89(3), 499-502. doi: 10.1016/j.bandl.2003.12.008.

Ehri, L. C. (2005). Development of sight word reading: Phases and findings. In M. J. Snowling \& C. Hulme (Eds.), The Science of Reading: A Handbook (pp. 135-154). Oxford: Blackwell publishing.

Fox, E. (1994). Grapheme-phoneme correspondence in dyslexic and matched control readers. British Journal of Psychology, 85(1), 41-53. doi: 10.1111/j.2044-8295.1994.tb02507.x.

Froyen, D., Bonte, M., Van Atteveldt, N., \& Blomert, L. (2009). The long road to automation: neurocognitive development of letter-speech sound processing. Journal of Cognitive Neuroscience, 21, 567-580. doi: 10.1162/jocn.2009.21061.

Froyen, D., Van Atteveldt, N., Bonte, M., \& Blomert, L. (2007). The long road to automaticity: Development of letter - speech sound integration in normal and dyslexic readers. Paper presented at the Annual Meeting SSSR, Prague.

Froyen, D., Van Atteveldt, N., Bonte, M., \& Blomert, L. (2008). Cross-modal enhancement of the MMN to speech-sounds indicates early and automatic integration of letters and speechsounds. Neuroscience Letters, 430(1), 23-28. doi: 10.1016/j.neulet.2007.10.014.

Froyen, D., Willems, G., \& Blomert, L. (2011). Evidence for a specific cross-modal association deficit in dyslexia: an electrophysiological study of letter-speech sound processing. Developmental Science, 14(4), 635-648. doi: 10.1111/j.1467-7687.2010.01007.x.

Gleitman, L. R., \& Rozin, P. (1977). The structure and acquisition of reading I: Relations between orthographies and the structure of language. Toward a psychology of reading, 1-54.

Goswami, U. (2000). Phonological representations, reading development and dyslexia: towards a cross-linguistic theoretical framework. Dyslexia, 6(2), 133-151.

Hardy, M. H., Smythe, P. C., Stennet, R. G., \& Wilson, H. R. (1972). Developmental patterns in elemental reading skills: phoneme-grapheme and grapheme-phoneme correspondences. Journal of Educational Psychology, 63, 433-436. 
Hintikka, S., Aro, M., \& Lyytinen, H. (2005). Computerized training of the correspondences between phonological and orthographic units. Written Language \& Literacy, 8(2), 79102.

Hulme, C., Caravolas, M., Málková, G., \& Brigstocke, S. (2005). Phoneme isolation ability is not simply a consequence of letter-sound knowledge. Cognition, 97(1), B1-B11.

Liberman, I. Y. (1973). 1. Segmentation of the spoken word and reading acquisition. Annals of Dyslexia, 23(1), 64-77.

Liberman, I. Y., Shankweiler, D. P., Fischer, F. W., \& Carter, B. (1974). Explicit syllable and phoneme segmentation in the young child. Journal of Experimental Child Psychology, 18, 201-212. doi: 10.1016/0022-0965(74)90101-5.

Lyytinen, H., Erskine, J., Tolvanen, A., Torppa, M., Poikkeus, A., \& Lyytinen, P. (2006). Trajectories of reading development: A follow-up from birth to school age of children with and without risk for dyslexia. Merrill-Palmer Quarterly, 52(3), 514-546. doi: 10.1353/mpq.2006.0031.

Mann, V. A., \& Wimmer, H. (2002). Phoneme awareness and pathways into literacy: A comparison of German and American children. Reading and Writing, 15(7-8), 653-682. doi: 10.1023/a:1020984704781.

Mattingly, I. G. (1972). Reading, the linguistic process, and linguistic awareness: ERIC.

Morais, J., Bertelson, P., Cary, L., \& Alegria, J. (1986). Literacy training and speech segmentation. Cognition, 24, 45-64. doi: 10.1016/0010-0277(86)90004-1.

Morais, J., Cary, L., Alegria, J., \& Bertelson, P. (1979). Does awareness of speech as a sequence of phones arise spontaneously? Cognition, 7, 323-331. doi: 10.1016/0010-0277(79)90020-9

Perfetti, C. A., Beck, I., Bell, L. C., \& Hughes, C. (1987). Phonemic knowledge and learning to read are reciprocal: a longitudinal study of first grade children. Merill-Palmer Quarterly, 33(3), 283-319.

Raven, J. C., \& Court, J. H. (1998). Raven's progressive matrices and vocabulary scales: Oxford Psychologists Press Oxford, UK.

Scarborough, H. S. (1990). Very early language deficits in dyslexic children. Child Development, 61, 1728-1743. doi: 10.2307/1130834.

Share, D. L. (2008). On the Anglocentricities of current reading research and practice: The perils of overreliance on an 'outlier' orthography. Psychological Bulletin, 134, 584-615. doi: 10.1037/0033-2909.134.4.584. 
Snowling, M. J. (1980). The development of grapheme-phoneme correspondence in normal and dyslexic readers. Journal of Experimental Child Psychology, 29(2), 294-305. doi: 10.1016/0022-0965(80)90021-1.

Snowling, M. J. (2000). Dyslexia. Oxford: Blackwell Publishers.

Snowling, M. J., Gallagher, A., \& Frith, U. (2003). Family risk of dyslexia is continuous: individual differences in the precursors of reading skill. Child Development, 74(2), 358-373. doi: 10.1111/1467-8624.7402003.

Torgesen, J. K., Wagner, R. K., \& Rashotte, C. A. (1994). Longitudinal studies of phonological processing and reading. Journal of Learning Disabilities, 27, 276-291. doi: 10.1177/002221949402700503.

Torgesen, J. K., Wagner, R. K., Rashotte, C. A., Rose, E., Lindamood, P., Conway, T., \& Garvan, C. (1999). Preventing reading failure in young children with phonological processing disabilities: Group and individual responses to instruction. Journal of Educational Psychology, 91(4), 579.

Vaessen, A., Bertrand, D., Tóth, D., Csépe, V., Faísca, L., Reis, A., \& Blomert, L. (2010). Cognitive development of fluent word reading does not qualitatively differ between transparent and opaque orthographies. Journal of Educational Psychology, 102, 827-842. doi: 10.1037/a0019465.

Vaessen, A., \& Blomert, L. (2010). Long term cognitive dynamics of fluent reading development. Journal of Experimental Child Psychology, 105, 213-231. doi: 10.1016/j.jecp.2009.11.005.

Vaessen, A., Gerretsen, P., \& Blomert, L. (2009). Naming problems do not reflect a second, independent core deficit in dyslexia: 'Double deficits' explored. Journal of Experimental Child Psychology, 103, 202-221. doi: 10.1016/j.jecp.2008.12.004.

Van Bon, W. H. J., \& Hoekstra, J. G. (1982). TVK: Taaltest voor Kinderen, handleiding (Language test for Children, manual). Lisse: Swets \& Zeitlinger.

van Otterloo, S. G., \& van der Leij, A. (2009). Dutch home-based pre-reading intervention with children at familial risk of dyslexia. Annals of Dyslexia, 59(2), 169-195. doi: 10.1007/s11881-009-0030-0.

Vellutino, F. R., Fletcher, J. M., Snowling, M. J., \& Scanlon, D. M. (2004). Specific reading disability (dyslexia): what have we learned in the past four decades? Journal of Child Psychology and Psychiatry, 45(1), 2-40. doi: 10.1046/j.0021-9630.2003.00305.x. 
Vellutino, F. R., Scanlon, D. M., Sipay, E. R., Small, S. G., Pratt, A., Chen, R., \& Denckla, M. B. (1996). Cognitive profiles of difficult-to-remediate and readily remediated poor readers: Early intervention as a vehicle for distinguishing between cognitive and experiential deficits as basic causes of specific reading disability. Journal of Educational Psychology, $88(4), 601$.

Wagner, R. K., \& Torgesen, J. K. (1987). The nature of phonological processing and its causal role in the acquisition of reading skills. Psychological Bulletin, 101, 192-212. doi: 10.1037/0033-2909.101.2.192.

Whiteley, H. E., Smith, C. D., \& Connors, L. (2007). Young children at risk of literacy difficulties: Factors predicting recovery from risk following phonologically based intervention. Journal of Research in Reading, 30(3), 249-269.

Wimmer, H., Landerl, K., Linortner, R., \& Hummer, P. (1991). The relationship of phonemic awareness to reading acquisition: more consequence than precondition but still important. Cognition, 4O(3), 219-249. doi: 10.1016/0010-0277(91)90026-Z.

Wolf, M., Bowers, P. G., \& Biddle, K. (2000). Naming-speed processes, timing, and reading: A conceptual review. Journal of Learning Disabilities, 33(4), 387-407. doi: 10.1177/002221940003300409.

Ziegler, J. C., Bertrand, D., Tóth, D., Csépe, V., Reis, A., Faísca, L., \& ...Blomert, L. (2010). Orthographic Depth and its impact on universal predictors of reading: a cross-language investigation. Psychological Science, 21, 551-559. doi: 2010-09433-018.

Ziegler, J. C., \& Goswami, U. (2005). Reading acquisition, developmental dyslexia, and skilled reading across languages: a psycholinguistic grain size theory. Psychological Bulletin, 131(1), 3-29. doi: 10.1037/0033-2909.131.1.3. 


\section{CHAPTER 3}

PHONOLOGICAL-ORTHOGRAPHIC ASSOCIATION DEFICITS IN KINDERGARTEN AND GRADE 1 BEST PREDICT READING OUTCOME IN CHILDREN AT FAMILIAL RISK FOR DYSLEXIA

\section{This chapter is based on:}

Willems, G., Jansma, B., Asteriadis, S., \& Vaessen, A. (Submitted). Phonological-orthographic association deficits in preschool and grade 1 best predict reading failure in children at familial risk for dyslexia. Research in Developmental Disabilities. 


\section{ABSTRACT}

To identify relevant reading-related predictors of reading problems early on, even before the start of reading acquisition, is vital to be able to promote more accurate and effective early diagnostic and intervention efforts, especially for children with a strong familial risk to develop severe reading failure later on. Currently, evidence on which pre-reading cognitive markers are relevant to predict future reading outcome of at-risk children is still scarce. Previous predictor studies mainly focused on typically developing children and found three important cognitive markers as relevant kindergarten predictors that are uniquely associated to typically developing reading outcome: phonological awareness (PA), or a child's understanding of the sound structure of spoken language, letter-speech sound knowledge (LS), or knowing which letter of an alphabet is associated to a certain speech sound, and rapid naming (RAN), or the ability to rapidly name highly familiar visual objects. The present Dutch longitudinal predictor study directly compared the predictive role of these three early cognitive markers to subsequent atrisk and normally developing reading fluency, before and after the start of reading instruction (i.e., Dutch children start primary school with two years of kindergarten before entering grade 1 and starting explicit reading instruction at 7 years of age). Results showed that kindergarten LS was the sole predictor of grade 1 reading outcome in both at-risk and control children. Subsequent reading outcome in grade 2 was also predicted by kindergarten RAN, but only in atrisk children. After the start of reading acquisition in grade 1, LS remained predictive of grade 2 at-risk reading ability, while PA emerged as the sole grade 1 predictor in typically developing children. This finding suggests that measures of phonological awareness only become useful in the prediction of future reading skills once reading achievement is successfully developing. The predictive role of kindergarten and grade 1 LS knowledge in at-risk children, in combination with the fact that kindergarten RAN was related to future at-risk reading in grade 2, was interpreted as evidence for a cross-modal orthographic-phonological association deficit already present in pre-reading children at familial risk for dyslexia. Finally, the predictive role of early cognitive markers commonly identified for typically developing children also seems relevant for children at-risk for dyslexia, although at different developmental stages of the reading acquisition process. More specific, a different predictor pattern emerges between at-risk and control children after the start of reading instruction, most likely due to a different developmental pattern of reading acquisition. 


\subsection{INTRODUCTION}

While most children become fluent readers without much effort within a few years of reading instruction, approximately $4-5 \%$ of school children develop dyslexia and struggle with learning to read and write adequately, despite normal intelligence and adequate educational instruction (Hulme \& Snowling, 2016; Lyon, Shaywitz, \& Shaywitz, 2003; Peterson \& Pennington, 2012; Shaywitz, Shaywitz, Fletcher, \& Escobar, 1990). It is of the utmost importance to recognize these dyslexic children early on to be able to alleviate or even prevent their reading difficulties and any secondary social or emotional consequences by means of early intervention. Accordingly, it is important to identify reading-related cognitive abilities in children at-risk for reading failure as potential predictive markers of subsequent reading problems. Pre-literate children, who have a dyslexic parent or sibling and increased familial risk of becoming dyslexic, form an important risk group. An estimated $40 \%$ of this group will actually become reading disabled (e.g., Borstrøm \& Elbro, 1997; Byrne, Shankweiler, \& Hine, 2008; Hulme \& Snowling, 2016). The current evidence for candidate cognitive kindergarten markers mainly results from longitudinal predictor studies focusing on typically developing children without a familial liability for dyslexia. These studies indicate three reading-related cognitive markers as important predictors of successful reading acquisition: phonological awareness (PA), or a certain understanding of the sound structure of language (e.g., Catts et al., 2014; Landerl et al., 2013; Landerl \& Wimmer, 2008; Parrila, Kirby, \& McQuarrie, 2004; Schatschneider, Fletcher, Francis, Carlson, \& Foorman, 2004; Wagner, Torgesen, \& Rashotte, 1994), letter knowledge (LK), or knowing which letter of an alphabet maps onto which corresponding speech sound (de Jong \& van der Leij, 1999; Hulme \& Snowling, 2016; Landerl et al., 2013; Lyytinen et al., 2004a; Lyytinen et al., 2004b; Schatschneider et al., 2004) and rapid naming (RAN) of highly familiar visual symbols such as letters, digits and objects (e.g., Catts, Fey, Zhang, \& Tomblin, 2001; de Jong \& van der Leij, 1999; Kirby, Georgiou, Martinussen, \& Parrila, 2010; Landerl et al., 2013; Moll et al., 2014; Wolff, 2014). The present Dutch-language study will investigate early cognitive markers that predict successful reading outcome in children with and without a family risk. More specific, we compared the predictive contribution of PA, LK and RAN to reading outcome, before and after the start of reading acquisition, in a group of at-risk and a group of control children.

Given the significance of PA, LK and RAN as identified as important cognitive markers in typically developing children, it doesn't come as a surprise that these measures are all viewed as 
prima candidate kindergarten cognitive precursors of at-risk reading outcome. These three reading-related markers for example all show a unique association to reading outcome in normally developing children and they can be measured early on, prior to the acquisition of reading skills (Caravolas, Lervåg, Defior, Málková, \& Hulme, 2013; Carroll, Solity, \& Shapiro, 2015; Catts et al., 2001; Kirby, Parrila, \& Pfeiffer, 2003; Lyytinen et al., 2004a; Lyytinen et al., 2001; Lyytinen et al., 2004b; Moll et al., 2016; Scarborough, 1990; Thompson et al., 2015). Is it than likely that early predictors of dyslexia would differ from those precursors found in typically developing children? Previous behavioral studies have indicated that family risk has a continuous rather than a discrete nature (Boets et al., 2010; Snowling, Gallagher, \& Frith, 2003; Van Bergen et al., 2011), which consequently results in a higher genetic liability in affected atrisk children than in their unaffected peers or children without a family risk. This causes a variable manifestation of behavioral symptoms. For example, at-risk children who turn out to be reading disabled and other at-risk children without subsequent reading problems show phonological deficits (Puolakanaho, Ahonen, Aro, Eklund, Leppänen, Poikkeus, \& al., 2008; Snowling, 2008). But the observed PA weakness is usually most severe in dyslexics, moderate in at-risk children without reading problems and absent, in typically developing readers (Boets et al., 2010; Boets, Wouters, Van Wieringen, \& Ghesquiere, 2007; Elbro, Borstrøm, \& Petersen, 1998; Pennington \& Lefly, 2001; Snowling, 2008). For kindergarten letter knowledge and RAN skills similar step-wise performance patterns have been reported (e.g., Van Bergen, de Jong, Plakas, Maassen, \& van der Leij, 2012; but see the replication study by Van Bergen et al., 2011 where the same RAN performance was observed in at-risk unaffected and control children). These studies also showed that unaffected at-risk readers still lagged behind on word reading fluency from grade 1 onward up to the fifth grade, even though they performed in the normal range. Thus, a family history of dyslexia seems to influence nearly all the relevant readingrelated determinants of reading and spelling in a continuous fashion from impaired, mildly impaired to non-impaired. This effect is likely also reflected in group differences in the cognitive predictors of subsequent at-risk and typically developing reading skills. Resonating well with these results are the findings of behavioral-genetic studies that compared monozygotic (100\% similar) or dizygotic (sharing $50 \%$ of genes) twins. These studies indicated that individual differences in the development of reading and reading-related skills are on average highly influenced by genetic differences between these two types of twin pairs that differ in their additive genetic similarity but share the same home and school environment (e.g., Christopher 
et al., 2015; Olson, Keenan, Byrne, \& Samuelsson, 2013). While letter knowledge for example was mainly influenced by shared family environmental factors in kindergarten, stronger genetic influences emerged at the end of kindergarten when children were able to read some simple (pseudo)words on age appropriate reading tasks (e.g., Samuelsson et al., 2008). Especially after one year of formal literacy instruction, reading-related and reading skills are increasingly influenced by genetic influences and less by environmental variance, a pattern that continues over the early school grades (Byrne et al., 2009; Olson et al., 2011; Samuelsson et al., 2005; van Bergen, de Jong, Maassen, \& van der Leij, 2014).

Surprisingly, only a handful of longitudinal studies focused on the prediction of reading failure in children at increased familial risk for dyslexia. Several of these studies did not include a control comparison group or only included a small number of control children, making it impossible to directly compare possible differences in the relative contribution of early predictors between these two groups. In her pioneering study, Scarborough $(1989,1990)$ for example confirms the predictive role of early kindergarten PA, LK and RAN, in addition to familial risk status, in a sample of English-speaking at-risk children. The predictive role of PA however disappeared once IQ and general language ability were controlled for (for similar results in children with poor reading-related kindergarten skills but without a family history of dyslexia see Felton \& Brown, 1990). Elbro et al. $(1998,1999)$ showed that kindergarten PA, next to LK and RAN, contributed to the variance in grade 1 and 2 reading of a Danish-speaking at-risk sample, although they also pointed out that these predictive results should be interpreted with caution since one third of children received an intensive PA kindergarten training. Snowling et al. (2003) reported that kindergarten PA and a compound letter-sound score (letter knowledge, non-word reading and phonetic spelling) were significant predictors of subsequent reading in a combined group of English-speaking at-risk and no-risk children. Recently, Thompson et al. (2015) also indicated that in kindergarten at the age of 4,5 and 5,5 years old, PA, LK, familial risk as well as RAN (i.e., although only at the younger age) were significant predictors of subsequent dyslexia outcome in an English-speaking high-risk sample.

A few other longitudinal predictor studies did investigate to what extend the same cognitive precursors apply to at-risk and control children. For example, Gallagher, Frith, and Snowling (2000) showed that in kindergarten, LK was the primary predictor of literacy skill one year later in both at-risk and control English-speaking children, while PA was only predictive in the control group (RAN was not included in their study). Similarly, Pennington and Lefly (2001) 
revealed that kindergarten PA was only predictive for grade 2 reading outcome in controls learning to read in English. LK was the primary kindergarten predictor in at-risk children, while RAN was not predictive in either group. While these two studies showed that kindergarten PA was only predictive of reading outcome in control children, Cardoso-Martins and Pennington (2004) found that kindergarten PA was predictive of grade 1 reading in both English at-risk and control children. Kindergarten RAN was not a significant predictor. Note that this later study did not include letter knowledge, which as a known relevant early predictor, most likely would have explained some of the variance in reading outcome now explained by PA. Interestingly, these two later at-risk studies not only investigated the importance of these potential predictors separately for at-risk and control children, but also at two time points, in kindergarten and after the start of reading instruction in grade 1 . Pennington and Lefly (2001) revealed that grade 1 PA remained the only predictor of grade 2 reading outcome in controls. In at-risk, kindergarten PA was not yet predictive of future reading (LK was the only kindergarten predictor), but became the primary predictor in grade 1. Cardoso-Martins and Pennington (2004) however showed that grade 1 PA, like kindergarten PA, was predictive of reading a year later of not only control children but also at-risk children. Their results also showed that RAN became predictive of grade 2 reading in at-risk children. Taken together, this comparison between children with and without familial risk seems to indicate that predicting normal reading outcome might not necessarily be the same as predicting at-risk reading outcome. Another interesting finding was that the relative contribution of predictors might also differ as a result of the developmental phase of reading acquisition, specifically before and after the start of reading.

A third important factor that might influence the predictive role of early cognitive markers of reading outcome is the orthographic depth of the language in which children learn to read. Opaque or inconsistent orthographies are those who have numerous mappings between letters and speech sounds (e.g., English, Danish), while more transparent orthographies show mainly direct or one-to-one mappings (e.g., Dutch, Italian, and Finnish). As a consequence, learning to read in highly phonologically inconsistent orthographies is thus more effortful and slow than in more consistent and transparent ones (Caravolas et al., 2013; Seymour, Aro, \& Erskine, 2003; Share, 2008). Previous studies have indicated that the roles of early cognitive reading markers underlying reading might differ as a result of orthographic transparency (for an overview see Share, 2008; Ziegler et al., 2010). Given that the large part of dyslexia research is centred on reading development in English, it is moreover suggested that this might have led to 
an overreliance on an outlier orthography and as a result the overestimation of the importance of certain cognitive markers, and specifically PA (Share, 2008). Several cross-language studies for example indicated that while PA is considered a reliable predictor in opaque orthographies for an extended time (Mann \& Wimmer, 2002; Vaessen et al., 2010; Ziegler et al., 2010), it shows only a weak predictive contribution (Bigozzi, Tarchi, Pinto, \& Accorti Gamannossi, 2015; Georgiou, Parrila, \& Papadopoulos, 2008; Wimmer \& Schurz, 2010) or a transient contribution (de Jong \& van der Leij, 1999) to reading outcome in more transparent orthographies (but also see Zakopoulou et al., 2011). In contrast, RAN has been argued to be a specifically important long-term predictor in consistent orthographies (Georgiou et al., 2008; Kirby et al., 2010; Mann \& Wimmer, 2002). However, some other studies have suggested that PA and RAN are equally important across orthographies (Caravolas et al., 2013; Caravolas, Vólin, \& Hulme, 2005; Furnes \& Samuelsson, 2011; Landerl et al., 2013; Patel, Snowling, \& de Jong, 2004; Vaessen \& Blomert, 2010). The predictive value of letter knowledge in transparent language studies, in comparison to opaque language studies, is often also reported limited beyond the initial stages of successful reading (e.g., Braams \& Bosman, 2000; de Jong \& van der Leij, 1999; Wesseling \& Reitsma, 2000). This is most likely due to the fact that letter knowledge mastery is reached within a few months of reading instructing in transparent orthographies (Seymour et al., 2003; Wentink \& Verhoeven, 2003). These results, although inconclusive, indicate that (a) predictor patterns might differ as a function of orthographic depth and (b) show that the ease with which children acquire reading skills is influenced by the spelling inconsistency of the language they learn to read in. This influence of orthography may even be exacerbated in children at-risk for dyslexia. It is thus important to also investigate early predictors of dyslexia in orthographies other than the opaque English language, and we therefore focus on the more transparent Dutch orthography.

To our knowledge, there are merely two previous longitudinal predictor studies focused on kindergarten children with an increased familial risk of dyslexia, learning to read in a transparent orthography. First, the Finnish Jyväskylä longitudinal study of dyslexia showed that LK and a composite of early PA and language skills (including RAN) assessed before and in kindergarten were both predictive of grade 2 reading accuracy (Puolakanaho et al., 2007; Torppa, Lyytinen, Erskine, Eklund, \& Lyytinen, 2010). The authors however reported limitations that affected the predictive role of PA on dyslexia (i.e., a ceiling effect on the reading accuracy outcome measure reduced statistical power of this measure and left little variance to be explained by the investigated predictors). Consequently, the authors also included a reading 
fluency measure, and interestingly, early PA and language skills were no longer predictive for grade 2 reading fluency, while LK did continue to make a significant contribution (Puolakanaho, Ahonen, Aro, Eklund, Leppänen, Poikkeus, \& al., 2008; Torppa et al., 2010). Other transparent language studies that did not include a familial risk factor also reported similar findings on PA being predictive of reading accuracy outcome and not reading fluency outcome (Aro, 2004; Hogan, Catts, \& Little, 2005; Seymour, 2005). In a Dutch-language study, Boets et al. (2010) demonstrated that kindergarten PA predicted individual differences in reading speed and accuracy in grade 1 but not in grade 3, while on the other hand, kindergarten RAN only marginally predicted reading (speed) in grade 1, but became a powerful predictor of grade 3 reading. The present longitudinal predictor study in the relatively transparent Dutch orthography, will build on these transparent language studies, being the first to directly compare relevance of early predictors in children with and without a family risk for dyslexia, before and after the start of reading instruction.

\section{THE PRESENT STUDY}

The goal of the present 3-year longitudinal study was to determine whether early lettersound knowledge and processing (LK/LS), phonological awareness (PA) and rapid naming (RAN) predict later grade 1 and 2 reading fluency for Dutch children with and without familial risk for dyslexia. Moreover, we were interested to know whether the relative predictor pattern of atrisk and controls found in kindergarten might change with the acquisition of literacy skills. In the Netherlands, children attend primary school for eight years between the ages of four and twelve years old, starting with two years of kindergarten. The third year is comparable to what is known as grade 1 in the reading research literature and corresponds to the year of primary school in which formal reading education starts. The longitudinal design of the current study, assessing children in second year of kindergarten, grade 1 and grade 2, made it possible to explore predictor patterns before and after the start of reading instruction: i.e., kindergarten prediction of grade 1 and 2 reading fluency in addition to grade 1 prediction of grade 2 reading fluency. Finally, since the present at-risk predictor study is conducted in the relatively transparent Dutch orthography, we can add to the ongoing debate whether predictor findings of at-risk reading outcome found in reading English can be generalized to more transparent orthographies. We controlled for non-verbal intelligence, vocabulary and baseline reaction time, since it is important to exclude that possible predictor effects are a consequence of individual 
differences in general cognitive abilities (e.g., Scarborough, 1989, 1990). Also note that a measure of reading fluency (i.e., words and pseudo-words) was used as the primary dependent outcome variable, since reading accuracy is known to quickly reach ceiling levels in the Dutch language (Blomert, 2005).

\subsection{METHODS}

\section{PARTICIPANTS}

At the start of the present longitudinal study, the kindergarten sample consisted of 100 children: 53 at-risk children ( 26 girls, 27 boys) with at least one first-degree family member (i.e., sibling or parent) suffering from dyslexia and 47 control children ( 26 girls, 21 boys) without a familial risk for dyslexia. Of this initial sample, eight children ( 5 at-risk and 3 without risk) dropped out of the study during grade 1 and an additional 10 children (5 at-risk and 5 without risk) dropped out during grade 2. Accordingly, the total sample of children that was recruited at the beginning of the last year of kindergarten and that was evaluated at all three time points (January of the last year of kindergarten, April of grade 1 and June of grade 2) included 82 children: 43 with familial risk ( 22 girls) and 39 ( 23 girls) without familial risk for dyslexia. All children were native Dutch speakers without hearing problems, neurological or sensory abnormalities. Informed consent from all parents or caregivers and permission from the local Ethical Committee was obtained. The at-risk and control group did not differ in age (respective age in years, $5.89( \pm 0.35)$ and $5.93( \pm 0.42), t(1)=0.27, p>0.5)$ and gender (respective proportions of girls: 51\%, 22 out of 43 at-risk children and 59\%, 23 out of 39 control children, $\left.\chi^{2}(1)=1.29, p>0.5\right)$. In addition, there was no difference between at-risk and control children in social-economic status (SES) based on the parental education grouping assessed on a 5-point scale ranging from primary school to university level (i.e., low, low average, average, high average or high SES). In fact, the at-risk and control samples were highly homogeneous since the large majority of children belonged to the highest two categories of SES grouping: respective proportions were $81 \%, 35$ out of 43 and $82 \%$, i.e., 32 out of $39, \chi^{2}(1)=.03, p>0.5$ ). The number of parents indicating that their child suffered from ADHD or number processing difficulties was very low and also did not differ between the kindergarten at-risk and control group (ADHD: $2.36 \%$, i.e., 1 at-risk child versus $0 \%, \chi^{2}(1)=.34, p>0.5$; number processing difficulties: $2.36 \%$ 
versus $2.56 \%$, i.e., 1 child in each group, $\chi^{2}(1)=.33, p>0.5$ ). Note that Dutch children start their reading curriculum when they enter grade 1 in September and they are at least 6 years of age. Children are rarely taught to read at home before grade 1 . Thus, the present study followed atrisk and control children from approximately one year before the onset of formal reading instruction till two years into reading instruction.

\section{SPECIFICATION OF THE AT-RISK SELECTION CRITERION}

Of the total sample of children at familial risk for dyslexia, 37 out of 43 (i.e., $86 \%$ ) were recruited at independent, specialized dyslexia institutes across 5 regions in the Netherlands (i.e., either at the Dutch Regional Institutes of Dyslexia (RID) or at the Dutch Institute for Word blindness and Other Learning problems (IWAL) at which their older sibling was diagnosed as dyslexic. At that time, parents or caregivers filled out an elaborate familial reading-status questionnaire at the start of the second year of kindergarten, evaluating severe childhood reading and spelling difficulties in first and second degree family members (FADD; Blomert, unpublished) to further corroborate this family history of dyslexia. This familial reading-status questionnaire was also distributed in 3 kindergartens in the south of the Netherlands. This revealed 6 additional at-risk children included in the present at-risk sample (i.e., 14\%) for which at-risk status was based on severe childhood reading and spelling difficulties experienced by a parent (for similar at-risk selection in case of an affected parent see Gallagher et al., 2000; Pennington \& Lefly, 2001; Scarborough, 1989, 1990). Please note that formal diagnoses of dyslexia are extremely rare in the Netherlands within the parental age group. The comparison group comprised of 39 control children without familial risk of dyslexia and reading and spelling difficulties as verified by the FADD reading-status questionnaire.

To further establish whether our at-risk selection criterion was accurate, we evaluated the proportion of poor readers separately for grade 1 and 2. Given that the chance to develop disabled reading skills is greatly increased in children of dyslexic families (i.e., approximately $40 \%$, Borstrøm \& Elbro, 1997; Byrne et al., 2008), it is expected that the proportions of poor readers in the selected at-risk group is significantly larger than in the comparison group. Performance on the 3DM standardized reading fluency test indicated a child's ability to accurately read aloud as many words as possible within half a minute per subtask (i.e., highfrequency, low-frequency and pseudo-words). A child was categorized as reading disabled if their overall reading fluency performance corresponded with, or was lower than, one standard 
deviation below the standard norm score. In other words, the poor reader group showed a reading fluency performance that corresponded to the lowest $16^{\text {th }}$ percentile norm rank score. Results showed that the number of poor readers in the at-risk group was significantly larger than in the control group in grade 1: 20 out of 43 at-risk children (47\%) versus 4 out of 39 control children (10\%), $\chi^{2}(1)=33.59, p<0.01$, and in 2 grade 2 : 22 out of 43 at-risk (51\%) versus 4 out of 39 control children (10\%), $\chi^{2}(1)=39.65, p<0.01$. The proportion of poor readers did not differ between the at-risk sample in which at-risk status was defined by parental report only (without a formal diagnosis) and the at-risk sample in which at-risk status was defined by a sibling diagnosis and further corroborated by parental report: respective proportions were $51 \%$ (19 out of 37 ) and $50 \%$ ( 3 out of 6$), \chi^{2}(1)=.18, p>0.05$.

\section{PROCEDURE}

A range of cognitive reading, reading-related and general cognitive tasks was administered (3DM, Blomert \& Vaessen, 2009, unless indicated otherwise). All tasks were administered individually, in a fixed order and in a quiet room (see Table 1 for a complete timeline of task assessment and the result section for a group comparison). The 3DM tasks were computerized tasks using a specially designed response-box to precisely measure accuracy and/or response time in milliseconds and test items were slightly adapted to the present age group. The other tasks were paper-and-pencil tasks. The familial reading-status (FADD) questionnaire used to corroborate presence or absence of familial risk for dyslexia also provided information on environmental factors such as social-economic status, number processing difficulties and ADHD characteristics of each kindergartner.

\section{TASKS}

Reading. Reading Accuracy: the number of correctly read words from a list of 20 simple CVC words. This kindergarten test was discontinued if a child made 5 errors in the first 5 items (non-standard task). Please note that this task was only used in kindergarten to identify possible early readers prior to the start of formal reading instruction. Reading fluency (3DM): Children read aloud as many singly presented words as quickly as possible on 3 levels (high-frequent, low-frequent, pseudo-words, 75 items in 30 seconds per level increasing in difficulty, presented on 15 items per screen, 5 screens). Fluency was an overall composite score over 3 levels expressed in number of correct words (items/second) and used to define the poor reader 
criterion (i.e., the lowest $16^{\text {th }}$ percentile) and assess reading ability in grade 1 and 2 . Test-retest reliability coefficient was .95 (reported in the test manual of 3DM).

\section{Table 1. Timeline of task assessment}

\begin{tabular}{|c|c|c|c|}
\hline Tasks (number of items) & $\mathrm{t} 1$ & t2 & $\mathrm{t}^{3}{ }^{3}$ \\
\hline 1 Reading accuracy (20) & $*$ & & \\
\hline 2 Reading fluency (75 per list) $^{1}$ & & * & $*$ \\
\hline 3 Letter knowledge (22) & $*$ & $*$ & \\
\hline 4 Letter-sound identification (45) & $*$ & $*$ & $*$ \\
\hline 5 Letter-sound discrimination (90) & * & $*$ & $*$ \\
\hline 6 Phonemic Auditory Closure (29) & $*$ & $*$ & \\
\hline 7 Phoneme deletion (23) & & $*$ & $*$ \\
\hline 8 RAN objects (2 sheets of 15 objects) & $*$ & & \\
\hline 9 RAN alphanumerical ${ }^{2}$ & & $*$ & $*$ \\
\hline 10 Receptive vocabulary (60) & $*$ & & \\
\hline 11 Non-verbal IQ (36) & $*$ & & \\
\hline 12 Baseline RT (20) & $*$ & $*$ & $*$ \\
\hline
\end{tabular}

Note: ${ }^{1}$ two word lists (high \& low-frequent) and one pseudo-word list; ${ }^{2} 2$ sheets of 15 for letters \& digits; $\mathrm{t} 1, \mathrm{t} 2, \mathrm{t} 3$ : Second year of kindergarten, grade 1 , grade 2 , score reflected number of correct items per $1 / 2$ minute. ${ }^{3}$ Fixed task order: $(\mathrm{t} 1)=12,11,10,8,4,5,6,1,3$ (divided over 2 sessions in the same week of approximately 40-50 minutes); (t2) $=12,2,9,4,5,6,7,3$ (divided over 2 sessions in the same week of approximately 30 minutes); ( $\mathrm{t} 3$ ) $=12,2,9,4,5,7$ (one session of approximately 30 minutes).

Letter knowledge (LK). Twenty-two single letters were presented on the screen. The child had to correctly name or sound out the corresponding name or sound. Dutch children are normally taught both letter names and letter sounds (phonics), consequently both types of response were allowed (non-standard task).

Letter-speech sound processing (LS 3DM). Two tasks were used to measure accuracy (\% correct) of letter-sound processing, letter-sound identification and letter sound discrimination. 
LS Identification (LSSI 3DM). Single auditory speech sounds (i.e., 45 in total) were presented to the child via headphones simultaneous with four letters (or letter combinations) appearing on the screen (e.g., /b/ and ' $b$ ' ' $d$ ' ' $t$ ' ' $p$ '). Accuracy was the number of correctly matched letterspeech sound pairs. The child identified the letter corresponding to the speech sound by pressing the matching button. LS Discrimination (LSSD 3DM). Single auditory speech sounds (i.e., 90 in total) were presented via headphones simultaneously with a visual letter (or letter combination) asking for a same/different decision (e.g., /o/ and ' $a$ '). Accuracy was expressed as the number of correct same/different decisions. Respective internal consistencies of these tasks were .72 and .82 (reported in the test manual of 3DM).

Phonological awareness (PA). Phonological Auditory Closure. A Dutch standardized version of the Illinois Test of Psycholinguistic Abilities (ITPA) subtest 'Auditory Closure' was used to test phonological awareness in kindergarten (TvK; Language Test for Children: Van Bon \& Hoekstra, 1982). The task consisted of 29 single words in which one or more phonemes were deleted and replaced by short silences. Children were asked to pronounce the correct, whole word (e.g., pronounced: /o/ - /i/ - /fant/, the child provides the whole word /olifant/, i.e., 'elephant'). Accuracy was expressed in \% correct. Internal consistency was between .78 and .84 . Phoneme deletion (PD 3DM). Children were asked to delete a phoneme at different positions from pseudo-words presented via headphones (i.e., 23 in total) and pronounce the resulting pseudo-word (e.g., "/dauk/ - /d/, what is left?"). Accuracy was expressed in \% correct and internal consistency of the task was .85 (reported in the test manual of 3DM).

Rapid naming (RAN 3DM). The task consisted of three sets of items presented on a screen: letters, digits and objects. In kindergarten, children were presented with common objects (i.e., black and white line drawings of for example a candle, fish, car or egg). In grade 1 and 2, children were presented with letters (i.e., consonants) and digits (i.e., monosyllabic names of digits below 10). In each subtask, 5 items were repeated 6 times (i.e., 15 items per screen, 2 screens per task). The child had to name the presented items as quickly as possible. Performance was defined as items/sec. The naming task has a split-half reliability of .80 (reported in the test manual of 3DM).

Receptive vocabulary (RAKIT). A Dutch standardized version of the Peabody Picture Vocabulary Test (PPVT) was used to assess receptive vocabulary in kindergarten (RAKIT; Bleichrodt, Drenth, Zaal, \& Resing, 1988). The child had to match one of four pictures to an 
orally presented word. Accuracy was expressed in \% correct (maximum items 60) and subsequently transformed into a vocabulary estimate with a mean of 100 and a standard deviation of 15). The test has an internal consistency of .81 (reported in the test manual of the RAKIT).

Non-verbal intelligence (Raven Coloured Progressive Matrices). The child had to identify the missing segments required to complete a larger pattern (Raven, Court, \& Raven, 1995). The raw scores were transformed into an IQ estimate (mean $=100, S D=15)$. For the Dutch version of this task, reliabilities of .80 and higher were reported (Van Bon, 1986).

Baseline reaction time (RT 3DM). A row of four empty squares was presented on the screen. The child had to identify the correct square out of the four in which an animated figure appeared (i.e., a fish) by pressing the corresponding response button as fast as possible (task design similar to the above described LS knowledge tasks). Mean reaction time was measured over 20 items. The task has an internal consistency of .93 (reported in the test manual of 3DM).

\section{DATA PREPERATION AND ANALYSIS}

To investigate the relevance of early cognitive markers predicting future reading outcome, we first transformed several of our tasks that did not reveal a normal distribution. We calculated log-transformed scores for kindergarten and grade 1 LS discrimination and square root-transformed scores for phonemic auditory closure and grade 1 reading fluency of words and pseudo-words. After this transformation, all scores that were used in subsequent analyses were normally distributed, thus reducing the effects of outliers. Next, we explored possible correlation patterns between our variables by conducting (a) a cross-sectional investigation of the concurrent relationships between the assessed reading and reading-related variables per time point (i.e., kindergarten, grade 1 and grade 2 ) and (b) a longitudinal investigation of the correlations between reading-related variables and reading outcome at a later time point (i.e., relationships between kindergarten markers and grade 1 and 2 reading fluency and relationships between grade 1 markers and grade 2 reading outcome). Thirdly, we further explored whether these relationships found between these cognitive markers and subsequent reading outcome were actually predictive in nature by means of Commonality analyses (RayMukherjee et al., 2014; Seibold \& McPhee, 1979; Zientek \& Thompson, 2006). Most previous longitudinal predictor studies used hierarchical regression analyses, which only report on unique variance explained. However, when several possible predictor variables are correlated, like in 
the present study, it is likely that the variance explained in the outcome measure does not only reflect unique contributions of individual variables, but also shared contributions of groups of predictors. This explains why the unique effects of all predictors in such predictive regression models rarely add up to the total explained variance (Ray-Mukherjee et al., 2014; Seibold \& McPhee, 1979; Zientek \& Thompson, 2006). The method we choose, commonality analysis, is able to partition such unique and common or shared effects (Seibold \& McPhee, 1979; Zientek \& Thompson, 2006). We conducted a series of commonality analyses separately for at-risk and control children, before and after the start of reading instruction, including the main readingrelated cognitive markers LK, PA and RAN. Lastly, we repeated the commonality analyses for grade 1 , including not only the main reading-related cognitive markers but also grade 1 reading levels as a precursor. This way we were able to investigate a possible autoregressive effect of prior or initial reading levels on subsequent grade 2 reading, beyond the influence of the reading-related markers.

\subsection{RESULTS}

\section{DESCRIPTIVES}

Kindergarten reading and reading-related tasks. At-risk and control children did not differ in general cognitive and reading-related performance in kindergarten, except for RAN performance (based on t-testing, two-tailed). Moreover, the majority of these kindergarten children were pre-readers (i.e., $90 \%$ read less than 5 simple consonant-vowel-consonant words correct on a single word reading task), consistent with the fact that children received no reading instruction up until grade 1 . The additional 5 at-risk and 4 control children were able to read between 5-7 simple CVC words only and there was no significant difference in scores between at-risk ( $M=5.6, S D=.89)$ and controls $(M=5.75, S D=.95) ; t(7)=-.24, p>.05$. The near floor reading performance of this small group of 9 children was still considered limited and at preliterary level and these participants where therefore included in the present analyses. See Table 2 for the general cognitive, reading and reading-related performance per group in kindergarten.

Grade 1 and grade 2 reading and reading-related tasks. Though at-risk children did not differ from control children on general cognitive abilities and in baseline response time, they performed significantly worse than control children on all reading and reading-related tasks in 
grade 1 and 2, except for LK on which children showed a ceiling performance (based on twotailed t-tests; for similar results in transparent orthographies see Seymour et al., 2003). Therefore, the LK and word reading accuracy tasks were only used as kindergarten measures (i.e., LK as a kindergarten reading-related predictor of future reading and the word reading task to identify possible early readers in kindergarten). Consequently, the LS tasks were used as extended letter-sound processing measures in grade 1 and 2 and reading fluency was used as the reading outcome measure in subsequent analyses. Note that in kindergarten, a simple phonemic auditory closure task was used as the PA measure. This was done because the phoneme deletion task we used to assess PA skills in grade 1 and 2 still showed floor performance in kindergarten (i.e., a pilot conducted with 10 at-risk and 10 control children showed an average accuracy percentage $4 \%$ and $3 \%$, respectively). However, we also included the phonemic auditory closure task in grade 1 in a separate analysis to be able to evaluate if results were similar with both PA measures. This also allowed us to indirectly validate the usefulness of the phonemic auditory closure task in kindergarten. Since this task showed a near ceiling performance for both at-risk (i.e., $M \geq 85 \%$ correct) and control children (i.e., $M \geq 88 \%$ correct) after grade 1, it was no longer included in the grade 2 analyses. See Table 2 for the general cognitive, reading and reading-related performance per group in kindergarten, grade 1 and grade 2 ). 
Table 2. General cognitive and reading (related) performance of at-risk and control children

\begin{tabular}{|c|c|c|c|c|}
\hline & At-risk $(n=43)$ & Control $(n=39)$ & $t$-test & \\
\hline General Cognitive performance & $\mathrm{M}(\mathrm{SD})$ & $\mathrm{M}(\mathrm{SD})$ & & \\
\hline Non-verbal IQ t1 ${ }^{1}$ & $101.02(14.56)$ & $98.91(15.57)$ & -.63 & $(p=.53)$ \\
\hline Vocabulary t $1^{1}$ & $100.97(14.37)$ & $98.93(15.78)$ & -.62 & $(p=.54)$ \\
\hline \multicolumn{5}{|l|}{ Baseline RT (items/sec) } \\
\hline t1 & $0.76(0.15)$ & $0.80(0.17)$ & 1.17 & $(p=.28)$ \\
\hline t2 & $0.98(0.16)$ & $1.03(0.18)$ & 1.72 & $(p=.19)$ \\
\hline t3 & $1.16(0.24)$ & $1.20(0.20)$ & 0.79 & $(p=.38)$ \\
\hline \multicolumn{5}{|l|}{ Reading tasks } \\
\hline t1 $w$ accuracy ${ }^{2}$ & $3.37(5.19)$ & $2.00(4.67)$ & 1.57 & $(p=.21)$ \\
\hline t2 w accuracy & $17.91(2.88)$ & $19.38(.78)$ & 9.63 & $(p<.01)$ \\
\hline t2 w fluency (correct/sec) & $0.46(0.26)$ & $0.74(0.31)$ & 19.54 & $(p<.01)$ \\
\hline t2 pw fluency (correct/sec) & $0.31(0.17)$ & $0.47(0.23)$ & 13.24 & $(p<.01)$ \\
\hline t3 w fluency (correct/sec) & $1.00(0.27)$ & $1.45(0.28)$ & 54.21 & $(p<.01)$ \\
\hline t3 pw fluency (correct/ sec) & $0.54(0.17)$ & $0.81(0.23)$ & 34.68 & $(p<.01)$ \\
\hline \multicolumn{5}{|l|}{ Reading-related tasks } \\
\hline \multicolumn{5}{|l|}{ Letter Knowledge (\% corr) } \\
\hline $\mathrm{t} 1$ & $51.06(27.77)$ & $41.61(25.41)$ & 2.57 & $(p=.11)$ \\
\hline t2 & $97.84(3.65)$ & $96.97(5.14)$ & 0.77 & $(p=.38)$ \\
\hline \multicolumn{5}{|l|}{ LS Identification ${ }^{3}$ (\% corr) } \\
\hline $\mathrm{t} 1$ & $54.87(19.47)$ & $47.76(17.92)$ & 2.94 & $(p=.09)$ \\
\hline t2 & $88.94(11.46)$ & $95.04(3.87)$ & 10.01 & $(p<.01)$ \\
\hline t3 & $91.94(6.54)$ & $94.53(4.26)$ & 4.42 & $(p<.05)$ \\
\hline \multicolumn{5}{|l|}{ LS Discrimination ${ }^{3}$ (\% corr) } \\
\hline $\mathrm{t} 1$ & $67.23(14.30)$ & $61.26(14.58)$ & 3.50 & $(p=.07)$ \\
\hline t2 & $81.63(13.55)$ & $87.83(9.18)$ & 5.78 & $(p<.05)$ \\
\hline t3 & $85.50(12.01)$ & $89.37(5.20)$ & 5.65 & $(p<.05)$ \\
\hline \multicolumn{5}{|l|}{ Phonological Awareness (\% corr) } \\
\hline t1 (phonemic auditory closure) & $62.64(14.04)$ & $60.92(16.26)$ & 0.26 & $(p=.61)$ \\
\hline t2 (phonemic auditory closure) & $76.74(7.64)$ & $83.02(7.81)$ & 13.53 & $(p<.01)$ \\
\hline t2 (phoneme deletion) & $39.86(26.94)$ & $51.19(22.85)$ & 4.18 & $(p<.05)$ \\
\hline t3 (phoneme deletion) & $51.04(23.44)$ & $68.90(19.76)$ & 13.64 & $(p<.01)$ \\
\hline \multicolumn{5}{|l|}{ Rapid Naming (items/sec) } \\
\hline t1 (objects) & $0.66(0.15)$ & $0.80(0.18)$ & 14.29 & $(p<.01)$ \\
\hline t2 (letters) & $1.23(0.33)$ & $1.39(0.53)$ & 2.74 & $(p=.10)$ \\
\hline t2 (digits) & $1.04(0.26)$ & $1.27(0.21)$ & 19.37 & $(p<.01)$ \\
\hline t3 (letters) & $1.50(0.23)$ & $1.69(0.25)$ & 12.71 & $(p<.01)$ \\
\hline t3 (digits) & $1.73(0.25)$ & $1.97(0.28)$ & 16.53 & $(p<.01)$ \\
\hline
\end{tabular}

Note: $\mathrm{w}=$ words, $\mathrm{pw}=$ pseudo-words; $\mathrm{t} 1$ (second year of kindergarten), t2 (grade 1) and t3 (grade 2); LS $=$ letter-speech sound processing. ${ }^{1}$ Standardized scores: IQ and vocabulary expressed in estimate scores (mean $=100, S D=15),{ }^{2} 90 \%$ of all children were non-readers (floor performance), ${ }^{3}$ chance level on LS identification $25 \%$ correct, LS discrimination $50 \%$ correct. 


\section{CONCURRENT CORRELATIONS BETWEEN VARIABLES PER GRADE}

First, we conducted a cross-sectional investigation of the concurrent relationships between the assessed reading and reading-related variables for each of the three time points (i.e., $\mathrm{t} 1=$ kindergarten, $\mathrm{t} 2=$ grade 1 and $\mathrm{t} 3=$ grade 2 ). The most important correlations (Pearson's $r$, two-tailed) are mentioned below (all significant, unless stated otherwise, for a full overview of the concurrent correlations between reading and reading-related variables per grade see Table 3).

Concurrent correlations in kindergarten. LK and LS tasks and word reading accuracy were strongly correlated (Pearson's $r$ between .66 and .82). LK/LS showed a moderate to high correlation with RAN ( $r$ between .31 and .48). PA showed no correlation to other kindergarten measures.

Concurrent correlations in grade 1. Both LS tasks were substantially related $(r=.54)$ and showed a moderate to high correlation with phoneme deletion ( $r$ between .39 and .59 ) and RAN ( $r$ between .33 and .47). Phoneme deletion and RAN showed a moderate correlation (between .32 and .18, the latter ns). Reading fluency of words and pseudo-words were strongly related ( $r$ $=.88$ ) and showed a moderate to high correlation with LS ( $r$ between .50 and .61), phoneme deletion ( $r$ between .57 and .58 ) and RAN ( $r$ between .40 and .56 ). Phoneme deletion and phonemic auditory closure were substantially related $(r=.47)$.

Concurrent correlations in grade 2 . The LS tasks still showed a substantial inter-correlation $(r=.54)$ and showed a moderate correlation with phoneme deletion ( $r$ between .30 and .31 ). RAN showed a moderate to high correlation with phoneme deletion ( $r$ between .36 and .44 ). Reading fluency of words and pseudo-words were strongly correlated $(r=.89)$ and showed moderate to high correlations with LS tasks ( $r$ between .36 and .50 ), phoneme deletion ( $r$ between .62 and .68) and RAN ( $r$ between .45 and .62). 
Table 3. Concurrent correlations between reading and reading-related variables per grade

\begin{tabular}{|c|c|c|c|c|c|c|c|c|c|}
\hline Kindergarten (t1) & 1 & 2 & 3 & 4 & 5 & 6 & 7 & 8 & \\
\hline \multicolumn{10}{|l|}{1 Letter knowledge } \\
\hline 2 LS identification & $.82 * *$ & & & & & & & & \\
\hline 3 LS discrimination & $.68 * *$ & $.66 * *$ & & & & & & & \\
\hline 4 PA phon aud closure & -.16 & -.20 & -.03 & & & & & & \\
\hline 5 RAN objects & $.34 * *$ & $.48^{* *}$ & $.31^{*}$ & -.21 & & & & & \\
\hline 6 Word Reading (acc) & $.72 * *$ & $.69 * *$ & $.73^{* *}$ & -.05 & .26 & & & & \\
\hline 7 Baseline RT & .12 & .08 & -.10 & -.13 & -.05 & -.07 & & & \\
\hline 8 Non-verbal IQ & .12 & .14 & .12 & -.09 & .07 & .17 & -.21 & & \\
\hline 9 Vocabulary & .20 & $.24^{*}$ & .11 & -.07 & .17 & $.29 *$ & .02 & .04 & \\
\hline Grade 1 (t2) & 1 & 2 & 3 & 4 & 5 & 6 & 7 & 8 & 9 \\
\hline \multicolumn{10}{|l|}{1 Letter knowledge } \\
\hline 2 LS identification & -.11 & & & & & & & & \\
\hline 3 LS discrimination & .02 & $.54 * *$ & & & & & & & \\
\hline 4 PA phon aud closure & -.05 & .06 & -.14 & & & & & & \\
\hline 5 PA phoneme deletion & -.07 & $.39 * *$ & $.59 * *$ & $.47^{* *}$ & & & & & \\
\hline 6 RAN letter & .17 & $.47^{* *}$ & $.33 *$ & .14 & .18 & & & & \\
\hline 7 RAN digits & -.03 & $.36 * *$ & $.34 * *$ & $.24 *$ & $.32 * *$ & $.32 * *$ & & & \\
\hline 8 Reading fluency $(w)$ & -.06 & $.61 * *$ & $.50 * *$ & $.33^{* *}$ & $.57^{* *}$ & $.40 * *$ & $.56 * *$ & & \\
\hline 9 Reading fluency (pw) & .03 & $.53 * *$ & $.56 * *$ & $.31 * *$ & $.58 * *$ & $.41 * *$ & $.52 * *$ & $.88 * *$ & \\
\hline 10 Baseline RT & -.02 & -.01 & -.18 & -.08 & -.16 & .03 & -.03 & -.11 & -.14 \\
\hline Grade 2 (t3) & 1 & 2 & 3 & 4 & 5 & 6 & 7 & & \\
\hline \multicolumn{10}{|l|}{1 LS identification } \\
\hline 2 LS discrimination & $.54 * *$ & & & & & & & & \\
\hline 3 PA phoneme deletion & $.31 * *$ & $.30 * *$ & & & & & & & \\
\hline 4 RAN letters & .14 & .17 & $.44 * *$ & & & & & & \\
\hline 5 RAN digits & .20 & .15 & $.36 * *$ & $.49 * *$ & & & & & \\
\hline 6 Reading fluency (w) & $.36 * *$ & $.50 * *$ & $.62 * *$ & $.45^{* *}$ & $.59 * *$ & & & & \\
\hline 7 Reading fluency (pw) & $.38 * *$ & $.44 * *$ & $.68^{* *}$ & $.50 * *$ & $.62 * *$ & $.89 * *$ & & & \\
\hline 8 Baseline RT & -.04 & -.03 & $-.24 *$ & $-.28^{*}$ & -.13 & -.15 & -.16 & & \\
\hline
\end{tabular}

Note: $\mathrm{LS}=$ letter-sound processing, $\mathrm{PA}=$ phonological awareness; phon aud closure = phonemic auditory closure, RAN = rapid naming, $\mathrm{w}=$ words, $\mathrm{pw}=$ pseudo-words, correlations $>.30$ in bold; * $\mathrm{p}<.05 ; * * \mathrm{p}<$ .01. 
LONGITUDINAL CORRELATIONS BETWEEN KINDERGARTEN AND GRADE 1 VARIABLES AND SUBSEQUENT READING OUTCOME OF RISK AND CONTROL CHILDREN

Next, we conducted a longitudinal investigation of the relationships between the relevant kindergarten and grade 1 variables and subsequent reading fluency of words and pseudo-words in grade 1 and grade 2 . These correlations were computed for the at-risk and control group separately. See Table 4 for the longitudinal correlations (Pearson's $r$, two-tailed) between kindergarten variables and grade 1 and 2 reading outcome and Table 5 for the longitudinal correlations between grade 1 variables and grade 2 reading outcome. Correlations are mentioned below (all significant, unless stated otherwise, please note that we found no difference in pattern between word and pseudo-word reading).

Correlation between kindergarten variables and grade 1 and 2 reading fluency. For grade 1 reading, we found moderate to high correlations between kindergarten LK and LS and fluency outcome in both at-risk children ( $r$ between .37 and.48) and control children ( $r$ between .41 and .67). PA and RAN showed no significant correlation with grade 1 reading outcome. For grade 2 reading, we found significant correlations between kindergarten RAN objects and reading ability of at-risk children ( $r$ between .39 and .42 ) and between kindergarten LS identification and reading outcome of control children ( $r$ between .33 and .46).

Correlation between grade 1 variables and grade 2 reading fluency. Grade 1 LS tasks were substantially related with grade 2 reading in at-risk ( $r$ between .31 and .51 ) and showed a low to moderate correlation with reading fluency outcome in controls ( $r$ between .08 and .33, the former ns). Phoneme deletion showed a moderate to high correlation with grade 2 reading in controls ( $r$ between .67 and .73) and was less related in at-risk children ( $r$ between .30 and .36 , the former ns). Grade 1 and grade 2 reading fluency were substantially related in both groups ( $r$ between .46 and .81). 
Table 4. Longitudinal correlations between kindergarten variables and grade 1 and 2 reading

\begin{tabular}{|c|c|c|c|c|c|c|c|c|}
\hline \multirow[b]{3}{*}{ Kindergarten predictors (t1) } & \multicolumn{4}{|c|}{ Reading fluency Grade 1 (t2) } & \multicolumn{4}{|c|}{ Read fluency Grade 2 (t3) } \\
\hline & \multicolumn{2}{|c|}{ At-Risk } & \multicolumn{2}{|c|}{ Control } & \multicolumn{2}{|c|}{ At-Risk } & \multicolumn{2}{|c|}{ Control } \\
\hline & W & PW & W & PW & W & PW & W & PW \\
\hline Letter knowledge & $.48 * *$ & $.39 *$ & $.43^{* *}$ & $.46 * *$ & .18 & .34 & .29 & .26 \\
\hline LS identification & $.48 * *$ & $.39 * *$ & $.51 * *$ & $.46 * *$ & .25 & .31 & $.46 * *$ & $.33^{*}$ \\
\hline LS discrimination & $.44^{* *}$ & $.37 *$ & $.41 * *$ & $.67^{* *}$ & .24 & .31 & .30 & .21 \\
\hline PA phon aud closure & -.06 & .07 & -.12 & -.20 & .09 & .01 & .29 & .25 \\
\hline RAN objects & .30 & .28 & .31 & .15 & $.39 * *$ & $.42 * *$ & .29 & .30 \\
\hline
\end{tabular}

Note: $\mathrm{t} 1$ (second year of kindergarten), t2 (grade 1) and t3 (grade 2); LS = letter-sound processing, PA = phonological awareness, phon aud closure $=$ phonemic auditory closure, $\mathrm{RAN}=$ rapid naming, $\mathrm{w}=$ words, $\mathrm{pw}=$ pseudo-words, At-Risk: $\mathrm{n}=43$, Control: $\mathrm{n}=39$, correlations $>.30$ in bold, $* p<.05$. $^{* *} \mathrm{p}<$ 01 .

Table 5. Longitudinal correlations between grade 1 variables and grade 2 reading outcome

\begin{tabular}{lllll}
\hline & \multicolumn{3}{l}{ Reading fluency Grade 2 (t3) } \\
& At-Risk & \multicolumn{3}{l}{ Control } \\
\hline Grade 1 predictors (t2) & W & PW & W & PW \\
\hline LS identification & $.51^{* *}$ & $.42^{* *}$ & .08 & .12 \\
LS discrimination & $.37^{*}$ & $.31^{*}$ & $.33^{*}$ & $.31^{*}$ \\
PA phon aud closure & .10 & .02 & $.37^{*}$ & $.32^{*}$ \\
PA phoneme deletion & .30 & $.36^{*}$ & $.67^{* *}$ & $.73^{*}$ \\
RAN letters & .11 & .15 & .26 & .23 \\
RAN digits & .26 & .22 & .29 & .30 \\
Reading fluency grade 1 (w) & $.62^{* *}$ & $.54^{* *}$ & $.80^{* *}$ & $.81^{* *}$ \\
Reading fluency grade 1 (pw) & $.53^{* *}$ & $.46^{* *}$ & $.74^{* *}$ & $.81^{* *}$ \\
\hline
\end{tabular}

Note: $\mathrm{t} 2$ (grade 1) and t3 (grade 2); LS = letter-sound processing, PA = phonological awareness, phon aud closure $=$ phonemic auditory closure, RAN = rapid naming, $w=$ words, $p w=$ pseudo-words, At-Risk: $\mathrm{n}=43$; Control: $\mathrm{n}=39$, correlations $>.30$ in bold, $* \mathrm{p}<.05$. $^{* *} \mathrm{p}<.01$. 
KINDERGARTEN PREDICTORS OF AT-RISK AND CONTROL READING OUTCOME: UNIQUE AND SHARED VARIANCE EXPLAINED

To explore the relevance of potential predictor variables to reading outcome further, we employed a commonality analysis separately for at-risk and control children. Commonality analyses are able to address the close correlations between a number of our independent, potential predictor variables (i.e., multicollinearity). Traditionally employed hierarchical regression models of prediction are less able to deal with such multicollinearity and the variance in such multi-regression models accounted for by unique predictor variables rarely adds up to the total variance explained in the outcome variable, in this case reading outcome. This is due to the fact that explained variance in the outcome variable is likely accounted for not only by unique effects but also common or shared variance of amongst a group of variables. Commonality analysis is a method able to partition these effects (Seibold \& McPhee, 1979; Zientek \& Thompson, 2006). Since the inclusion of multiple predictor variables in a model will exponentially increase the number of calculations, it is important to look for underlying latent variables that are theoretically meaningful sum variables to the aim of reducing the number of input variables. We thus conducted an exploratory factor analysis (principal components with oblimin rotation, Jolliffe's criterion was used allowing eigenvalues of 1 and higher; Jolliffe, 1972, 1986) on the following kindergarten cognitive variables: LK, LS discrimination, LS identification, phonological auditory closure (PA) and RAN objects. We extracted three factors in kindergarten that where further used in the commonality analysis: an LS factor, a PA factor and a RAN factor (eigenvalues: resp. 2.51, 1.23, .76; cumulative explained variance 89.8\%). In the first step of the commonality analysis, we entered non-verbal IQ and receptive vocabulary to correct the predictor model for general cognitive influences (contributions of IQ and vocabulary were always small and non-significant in all prediction models). In the second step, the three predictor factors were entered. Reading outcome was a combined score of the word and pseudo-word subtask that showed strong inter-correlations and similar correlation patterns with potential predictors (see Table 3 ) validating the merge of these subtasks to increase power of the outcome measure employed. The unique and common contribution of kindergarten predictors to subsequent reading fluency in grade 1 and 2 are displayed in Table 6. 
Table 6. Unique and common contribution of kindergarten predictors to grade 1 and 2 reading

\begin{tabular}{llllc}
\hline & \multicolumn{3}{l}{ Reading fluency grade 1 (t2) } & \multicolumn{2}{c}{ Reading fluency grade 2 (t3) } \\
Kindergarten predictors (t1) & At-Risk & Control & At-Risk & Control \\
\hline Correction $^{1}$ & .04 & .05 & .03 & .05 \\
\hline Unique LS & $.21^{*}$ & $.25^{*}$ & .09 & .13 \\
Unique PA & .01 & .00 & .03 & .02 \\
Unique RAN & .04 & .04 & $.14^{*}$ & .04 \\
\hline Common LS \& PA & .00 & .01 & .00 & .03 \\
Common LS \& RAN & .05 & .03 & .00 & .02 \\
Common PA and RAN & -.01 & .00 & -.02 & .02 \\
Common LS, PA \& RAN & .00 & .01 & -.01 & .01 \\
\hline Sum (total $R^{2}$ ) & .34 & .39 & .26 & .32 \\
\hline
\end{tabular}

Note: ${ }^{1}$ to correct for general cognitive influences, non-verbal IQ and Vocabulary were entered to the model first. $\mathrm{LS}=$ letter-speech sound processing, PA = phonological awareness, RAN = rapid naming, AtRisk: $\mathrm{n}=43$; Control: $\mathrm{n}=39,{ }^{*} \mathrm{p}<.05 . * * \mathrm{p}<.01$.

Predicting grade 1 reading. The results showed that kindergarten predictors explained $34 \%$ of the variance in individual reading differences in grade of at-risk children and $39 \%$ of that in control children. Furthermore, the results showed that a large part of this proportion of shared variance can be explained by individual differences in kindergarten LS accounting for $21 \%$ and $25 \%$ of the explained variance respectively. PA and RAN were not predictive of later reading outcome in either group. For instance, the unique contribution of kindergarten PA and RAN to grade 1 reading level of at-risk children was only $1 \%$ and $4 \%$, respectively (both non-significant). Also, common effects of a combination of the predictor variables did not significantly explained variance in at-risk reading outcome (i.e., values were close to zero, either negative or positive), totalling up to only $5 \%$.

Prediction grade 2 reading. Kindergarten predictors explained $26 \%$ of the variance of atrisk and $32 \%$ of the control reading level two years later in grade 2 . Only kindergarten RAN emerged as a significant kindergarten predictor, and only in the at-risk group, accounting for $14 \%$ of the explained variance. None of the kindergarten predictors made a significant 
contribution to grade 2 reading outcome in the control group. Common elements again were small in both groups.

GRADE 1 PREDICTORS OF AT-RISK AND CONTROL READING OUTCOME: UNIQUE AND SHARED VARIANCE EXPLAINED

Next, we explored the relevance of grade 1 predictors to reading outcome of at-risk and control children in grade 2 by means of another commonality analysis, separately for at-risk and control children. We first conducted a second exploratory factor analysis to reduce the number of grade 1 input variables for our prediction model (principal components with oblimin rotation, Jolliffe's criterion was used allowing eigenvalues of 1 and higher; Jolliffe, 1972, 1986). We included LS discrimination accuracy, LS identification accuracy, phoneme deletion accuracy, RAN letters and RAN digits and subsequently subtracted three factors: a LS, PA and RAN factor (eigenvalues: resp. $2.40, .97, .74$; cumulative explained variance $82.2 \%$ ). In the first step of the commonality analysis, we again entered non-verbal IQ and receptive vocabulary. In the second step the LS, PA and RAN factors were included. The unique and common contributions of grade 1 predictors to reading fluency of risk and control children in grade 2 resulting from the commonality analysis are displayed in Table 7.

Prediction grade 2 reading. The results showed that kindergarten predictors explained $33 \%$ of the variance in individual reading differences in grade of at-risk children and $41 \%$ of that in control children. In the at-risk group, LS remained the only significant unique predictor after the start of reading education, accounting for $12 \%$ of the total variance explained. In the control group, LS was no longer a significant predictor. Now, PA (phoneme deletion) emerged as the only relevant unique contributor of subsequent reading, accounting for $13 \%$ of the total variance explained. RAN did not make a significant contribution to reading outcome in both groups. Furthermore, reading outcome variance explained by common elements in grade 1 increased as compared to common elements measured in kindergarten. For example, common elements in grade 1 accounted for a total of 13\% of at-risk reading outcome in grade 2 and for $21 \%$ of control reading. In both the at-risk and control group, common elements were largest for shared LS and PA prediction (i.e., $8 \%$ and 9\%, respectively), indicating some overlap between these variables after the first few months of reading instruction. We also repeated the above 
described commonality analysis which employed phoneme deletion as predictor variable, the phonemic auditory closure predictor, which was the main PA task in kindergarten (all other input variables remained the same). Results showed a comparable predictor pattern when including this PA task in the model as was found with phoneme deletion: LS (21\%) was the only significant, unique predictor of at-risk grade 2 reading outcome and PA (phonemic auditory closure, $12 \%$ ) was the only significant, unique predictor of control grade 2 reading level. RAN made no contribution in both groups.

Table 7. Unique and common contribution of grade 1 predictors to grade 2 reading

\begin{tabular}{lll}
\hline & \multicolumn{2}{l}{ Reading fluency grade $\mathbf{2}$ (t3) } \\
Grade 1 predictors (t2) & At-Risk & Control \\
\hline Correction $^{1}$ & .03 & .05 \\
\hline Unique LS & $.12^{*}$ & .00 \\
Unique PA & .04 & $.13^{*}$ \\
Unique RAN & .01 & .02 \\
\hline Common LS \& PA & .08 & .09 \\
Common LS \& RAN & .02 & .00 \\
Common PA and RAN & .00 & .07 \\
Common LS, PA \& RAN & .03 & .41 \\
\hline Sum (total ${ }^{2}$ ) & .33 & \\
\hline
\end{tabular}

Note: ${ }^{1}$ to correct for general cognitive influences, non-verbal IQ and Vocabulary were entered to the model first. $L S=$ letter-sound processing, $P A=$ phoneme deletion, RAN = rapid naming, At-Risk: $n=43$; Control: $\mathrm{n}=39, * \mathrm{p}<.05 . * * \mathrm{p}<.01$.

\section{THE AUTOREGRESSIVE EFFECT OF READING}

Finally, we investigated whether the relevant predictors found for at-risk and control children predict grade 2 reading over and above the autoregressive effect of reading ability itself (i.e., the causal influence of reading level at an earlier time point, namely grade 1 reading 
ability). We employed another commonality analysis in which grade 1 reading fluency was entered in the model first, followed by grade 1 PA (phoneme deletion), LS and RAN predictor variables. The unique and common contributions of grade 1 reading (i.e., autoregressor) and the predictors to subsequent reading fluency in grade 2 are displayed in Table 8.

Table 8. Unique and common contribution grade 1 predictors and the autoregressive effect of prior reading to grade 2 reading

\begin{tabular}{lll}
\hline & \multicolumn{2}{l}{ Reading fluency grade $\mathbf{2}$ (t3) } \\
Grade 1 predictors (t2) & At-Risk & Control \\
\hline Reading (autoregressor) & $.14^{* *}$ & $.33^{* * *}$ \\
Unique LS & .04 & .00 \\
Unique PA & .01 & .00 \\
Unique RAN & .05 & .00 \\
\hline Common Reading \& LS & .10 & .01 \\
Common Reading \& PA & .04 & .20 \\
Common Reading \& RAN & -.04 & .05 \\
Common LS \& PA & .02 & .00 \\
Common LS \& RAN & .01 & .00 \\
Common PA \& RAN & .01 & .00 \\
Common Reading, LS \& PA & .07 & .02 \\
Common Reading, LS \& RAN & .01 & .00 \\
Common Reading, PA \& RAN & .01 & .00 \\
Common LS, PA \& RAN & .01 & .00 \\
Common Reading, LS, PA \& RAN & .03 & .08 \\
\hline Sum (total R ${ }^{2}$ ) & & .00 \\
\hline
\end{tabular}

Note: the largest unique and common grade 1 contribution to grade 2 reading in bold. LS = lettersound processing, PA = phonological awareness, Risk: $\mathrm{n}=43$; Control: $\mathrm{n}=39,{ }^{*} \mathrm{p}<.05 .{ }^{* *} \mathrm{p}<.01 .{ }^{* * *}$ $\mathrm{p}<.001$. 
Result showed that the grade 1 predictors including the autoregressive effect of prior grade 1 reading explained $49 \%$ of the variance in individual reading differences in at-risk reading outcome in grade 2 and $69 \%$ of that in control reading. Prior grade 1 reading level emerged as the only significant grade 1 predictor of grade 2 reading (i.e., explained variance: $14 \%$ at-risk; $33 \%$ controls). None of the other unique predictors significantly contributed to explaining the variance of grade 2 reading. This is most likely due to the high level of stability in reading skill (see Table 5 for predictive correlations between grade 1 and grade 2 reading tasks), leaving little variance for other unique predictors (Parrila et al., 2004; Stoolmiller \& Bank, 1995). In a longitudinal design, absence of a unique predictive relationship between the reading-related predictors and reading outcome (over and above the autoregressive effect) however does not necessarily mean that predictors are no longer relevant (de Jong \& van der Leij, 2002; Lervåg, Bråten, \& Hulme, 2009). Next to the unique contribution of prior reading level, common elements involving this autoregressor and LS knowledge were largest in the at-risk group and common elements involving the autoregressor and PA were largest in the control group. This indicates that while the autoregressive effect overruled an independent influence of the unique predictor variables after the start of reading, the same pattern remained: LS was most strongly related to reading development in at-risk children, while PA was in control children. 


\subsection{DISCUSSION}

The present 3-year longitudinal study investigated the role of phonological awareness (PA), letter-sound association knowledge (LK/LS) and rapid naming (RAN) as potential predictors of subsequent grade 1 and 2 reading fluency outcome, separately for a group of children with and without a familial risk for dyslexia. These potential predictors where measured in kindergarten and grade 1, before and after the start of reading instruction, respectively. By doing so, we were able to examine differential developmental patterns as a function of family risk and as a function of acquiring literacy skills. Finally, this predictor study was conducted in the relatively transparent Dutch language, whereas most previous longitudinal predictor studies were conducted in opaque orthographies. Our results can therefore give insight in relevant, early predictors in more transparent orthographies. Familial risk status in the present study was genuine: approximately half of our at-risk group had developed a reading deficit in grade 1, whereas only $10 \%$ of the control children turned into poor readers. These proportions only marginally changed in grade 2, indicating the importance of grade 1 reading prediction. Results indicated that several of the independent, predictor variables and reading measures showed significant concurrent correlations in each grade (i.e., kindergarten, grade 1 and grade 2 as presented in Table 3). There were moreover significant longitudinal, predictive correlations between early predictors and reading fluency outcome (i.e., kindergarten - grade 1, kindergarten - grade 2 and grade 1 - grade 2, see Table 4). To explore these predictive correlations further, we choose a model that is able to address such multi-collinearity, or in other words, the close correlations found between a number of predictor variables. When trying to predict or understand a dependent variable, in this case reading fluency outcome of at-risk and control children, such multicollinearity may lead to skewed or misleading results when employing more traditionally stepwise or hierarchical regression prediction models (RayMukherjee et al., 2014). This is due to the fact that explained variance in the outcome variable is likely accounted for by not only unique variance but also common or shared variance amongst groups of variables. Commonality analysis is a method able to partition unique and shared effects. Results showed that kindergarten LK was the only significant and unique kindergarten predictor of grade 1 reading in both pre-reading at-risk and control children, while kindergarten PA and RAN were not predictive in either group (see Table 6). Grade 1 LS remained the unique predictor of grade 2 reading fluency in at-risk children, while grade 1 PA emerged as the only 
significant predictor in control children (see Table 7). Even after controlling for autoregressive effects of prior grade 1 reading level on grade 2 reading in a second commonality analysis, the differential effect between at-risk and control children remained visible in the common explained variance between grade 1 reading fluency and the reading-related predictors (i.e., LS in at-risk children and PA in control children, as presented in Table 8). In addition, RAN was the only unique kindergarten measure explaining any variance in grade 2 at-risk reading. None of the kindergarten measures were predictive of grade 2 reading of control children.

These main results are well in line with earlier findings. First, letter-sound knowledge (LK) of pre-reading children was also identified as the most salient predictor of initial reading in numerous earlier longitudinal studies focused on children with and without a familial risk for dyslexia (e.g., Adams, 1990; de Jong \& van der Leij, 1999; Elbro et al., 1998; Gallagher et al., 2000; Lyytinen et al., 2004a; Lyytinen et al., 2004b; Puolakanaho, Ahonen, Aro, Eklund, Leppänen, Poikkeus, Tolvanen, et al., 2008; Puolakanaho et al., 2007; Scarborough, 1989, 1990; Thompson et al., 2015; Torppa et al., 2010). However, since all children (dyslexic and typically developing) learning to read in a transparent orthography reach full letter knowledge mastery within a few months of reading instruction (Blomert \& Willems, 2010; Seymour et al., 2003; Wentink \& Verhoeven, 2003), LK as such may only contribute to the prediction of very early stages of reading (e.g., Braams \& Bosman, 2000; de Jong \& van der Leij, 1999; Wesseling \& Reitsma, 2000). In line with this, the simple LK task we employed in kindergarten was no longer a valuable measure after the initial stages of literacy acquisition due to ceiling effects in both atrisk and control children in grade 1 . Nevertheless, performance on the two included letterspeech sound processing (LS) tasks showed an extended contribution of knowledge on letterspeech sound pairs in grade 1 to reading outcome a year later in at-risk children. Second, the absence of a predictive role of kindergarten phonological awareness (PA) for subsequent reading fluency corroborates the predictor results of at-risk studies conducted in more opaque orthographies (Gallagher et al., 2000; Pennington \& Lefly, 2001; Scarborough, 1989, 1990). It also resonates well with the findings of one of the two other at-risk longitudinal predictor studies conducted in a transparent orthography investigating a combined at-risk and control group (Puolakanaho, Ahonen, Aro, Eklund, Leppänen, Poikkeus, \& al., 2008). In our control sample, PA was also not predictive of reading outcome (for similar results in other Dutch samples see Aarnoutse, Van Leeuwe, \& Verhoeven, 2005; de Jong \& van der Leij, 1999), whereas early PA is often identified as a useful predictor of future reading in non-risk children learning to 
read in the English language (Parrila et al., 2004; Schatschneider et al., 2004; Wagner et al., 1994). Third, the significance of kindergarten rapid naming skills (RAN) in predicting reading in at-risk children after the initial reading stage in grade 2 is consistent with results from earlier predictor studies showing that kindergarten RAN was a valid predictor of the later reading stages in at-risk children (Cardoso-Martins \& Pennington, 2004; Elbro et al., 1998; Scarborough, $1989,1990)$ and is in line with the observation that RAN is a more important predictor of reading among relatively poor readers than among better readers (Johnston \& Kirby, 2006; McBride-Chang \& Manis, 1996). And fourth, the differential predictor pattern between at-risk and control children that emerged only after the start of reading acquisition is consistent with findings of two earlier predictor studies focusing on English-speaking children (Cardoso-Martins \& Pennington, 2004; Pennington \& Lefly, 2001).

\section{THEORETICAL IMPLICATIONS}

The fact that the present results corroborate the findings of earlier at-risk predictor studies conducted in opaque orthographies, showing the importance of kindergarten LK and RAN in addition to the weak role of kindergarten PA for the prediction of at-risk reading, suggests that these early predictor findings can be generalized to more transparent orthographies. The absent predictive role of PA in both at-risk and control children in kindergarten does seem puzzling however in light of the dominant phonological deficit theory of dyslexia. It is therefore insightful that PA only emerged as a predictor for grade 2 reading fluency after the start of reading instruction in grade 1 and only for control readers. Kindergarten PA was not predictive of reading outcome in grade 1 or 2 in both groups, and at-risk and control children showed a comparable PA performance prior to reading as can be seen in Table 2 (for similar results see Blomert \& Willems, 2010; de Jong \& van der Leij, 2003; van Bergen et al., 2014; Van Bergen et al., 2011). Furthermore, LK prior to reading did contribute to initial grade 1 reading in both at-risk and control kindergartners and remained predictive of grade 2 reading, but only in the at-risk group. These findings together strongly indicate that (a) learning lettersound associations is a prerequisite for learning to read and that problems learning these associations may hamper reading development over an extended period of time beyond initial reading and that (b) PA measures only start to differentiate between at-risk and control children in grade 1, becoming predictive of future reading skills only once reading acquisition is developing successfully in control children. In other words, PA levels only added relevant 
predictive information to reading outcome once reading instruction started and only in those children that showed little difficulty in mastering adequate reading skills, corroborating the before mentioned finding that PA is mainly important in predicting future normal reading and not at-risk reading. This supports the idea that some phonological skills, especially at the phoneme level, arise as a consequence of adequately mastering the alphabetic principle of a language (Ziegler \& Goswami, 2005), or that there is at least a reciprocal relation between PA development and literacy achievement (Morais, 1991; Morais, Cary, Alegria, \& Bertelson, 1979; Perfetti, Beck, Bell, \& Hughes, 1987). Our finding that PA performance only differentiated at-risk from control children once they started to acquire reading skills in grade 1 further supports this notion. This reciprocal relationship between PA and successful reading might also explain why kindergarten PA was previously identified as a useful predictor in typically developing children learning to read in opaque orthographies, but not in the present Dutch no-risk sample. More specifically, the onset of reading instruction in English-speaking countries often starts in kindergarten, while in Dutch, like in other more transparent languages, the educational system postpones reading instruction to the beginning of grade 1 (de Jong \& van der Leij, 2003; Mann \& Wimmer, 2002; Wimmer, Landerl, Linortner, \& Hummer, 1991). Consequently, variance in PA might already be related to reading outcome in English-language learners, due to the earlier start in reading instruction. Since Dutch children do not get formal reading instruction in kindergarten, it is likely that the reading abilities of our kindergarten samples with or without a family history of dyslexia were not sufficiently developed to start to show such a relationship with variance in the level of PA. Indeed, the large majority of our children were considered nonreaders when tested in kindergarten. In line with this, Mann and Wimmer (2002) found that English-speaking kindergartners already acquired some level of reading ability and also excelled on PA tasks, while the majority of German children could not read yet and also showed rather low PA skills, an advantage that disappeared after German children started their formal reading instruction in grade 1 as well. Interestingly, kindergarten PA was only predictive of grade 1 and 2 reading accuracy and speed in English-speaking children but not in pre-reading German children, which is in line with the hypothesis that a certain amount of PA should have developed due to successful literacy learning before it becomes predictive of future reading ability.

The extended importance of LS knowledge as a predictor of at-risk reading in grade 1 is corroborated by recent brain imaging studies that demonstrated that dyslexic children (Blau et al., 2010; Froyen, Willems, \& Blomert, 2011) and even adults (Blau, Van Atteveldt, Ekkebus, 
Goebel, \& Blomert, 2009) exhibit deficits in adequately processing letter-sound associations. More recently, Žarić et al. (2014) showed that these deficits in letter-speech sound integration in dyslexic children also depends on the severity of the reading fluency problems of the child. Moreover, recent behavioural evidence confirmed that poor primary school readers performed less accurate on LS tasks in grade 1 and 2 and remained slower on these tasks up to grade 5 (Blomert \& Vaessen, 2009; summarized in Blomert, 2011). Furthermore, a kindergarten training study showed that a core group of at-risk children was unable to profit from a LS association training (Blomert \& Willems, 2010). Taken together, these results indicate that the relevance of certain early cognitive markers to predict reading outcome in at-risk and typically developing children seems to differ, or alternatively, may be relevant at different developmental phases. In the latter case, it is expected that once at-risk children have acquired sufficient reading skills, PA would also emerge as the main literacy predictor and letter-sound knowledge by itself would no longer be relevant as a predictor (Pennington \& Lefly, 2001). Predictors related to fluent/automated integration of LS associations are however expected to remain relevant, as indicated by the extended role found in dyslexic children and even in adults (see above). It seems that at least a certain level of reading skills should be acquired before reading starts to correlate with PA, which is in line with previous research findings with illiterates (Morais, 1991; Morais, Bertelson, Cary, \& Alegria, 1986; Morais et al., 1979) and beginning readers (Mann \& Wimmer, 2002; Wimmer et al., 1991). Taken together, the absence of a predictive PA role prior to reading in both at-risk and control children sheds doubts on the assumed causality claim of the phonological deficit hypothesis which places a PA deficit at the origin of reading deficits (Blomert \& Willems, 2010; Ziegler \& Goswami, 2005). Instead, these results seem to provide further support for the concept of a letter-sound association deficit as a proximate predictor of reading failure in dyslexia (Blomert, 2011).

RAN was the main kindergarten predictor of grade 2 reading, but only for at-risk children. How can this finding be related to this multisensory integration deficit interpretation of the results? First, the fact that risk status and subsequent at-risk reading outcome was related to early RAN confirmed a multitude of studies that indicated that RAN deficits are especially related to reading disability (Bigozzi et al., 2015; Boets et al., 2010; de Jong \& van der Leij, 1999; Thompson et al., 2015; Vaessen \& Blomert, 2010; Van Bergen et al., 2012; Van Bergen et al., 2011; Wimmer, 1993; Wimmer, Mayringer, \& Landerl, 1998; Wolf \& Bowers, 1999). Second, the predictive role of RAN is found to be more prominent in later stages of reading development. 
Boets et al. (2010) for example reported that kindergarten RAN was an especially prominent predictor of later, grade 3 reading outcome in a mixed group of Dutch-speaking children with and without a familial risk for dyslexia, while it only marginally contributed to grade 1 reading prediction. Interestingly, our data showed that Kindergarten RAN differentiated between at-risk and controls (also see Van Bergen et al., 2012; Van Bergen et al., 2011), supporting the notion that it is RAN (rather than PA) that differentiates between reading groups in transparent orthographies (de Jong \& van der Leij, 2003; Georgiou et al., 2008; Landerl \& Wimmer, 2008). This often reported relation between RAN and reading (dys)fluency in at-risk and dyslexic readers has been attributed to a lack of fast and automatic matching of speech codes and orthographic symbols (e.g., Bowers \& Ishaik, 2003; Vaessen, Gerretsen, \& Blomert, 2009). This seems to imply that speeded naming tasks are sensitive to fast and efficient phonologicalorthographic integration, an ability that is central to reading, and more particular to the crossmodal binding of letters and speech sounds (Blomert, 2011). The RAN task may thus pick up direct or indirect effects of effortful letter-sound association/integration processes on the development of reading skills in children at familial risk for dyslexia. In support, the RAN and LS measures used in the present study showed a substantial correlation in kindergarten and grade 1. The finding that kindergarten RAN was only predictive of grade 2 when reading was well under way, but not grade 1 reading, might be explained by the fact that during the initial phases of reading, when the decoding process is still slow and effortful in all children, adequate and fast cross-modal matching abilities are not influential yet (Vaessen et al., 2010). However, once reading starts to exhibit the first signs of fluency, a cross-modal binding deficit might become more influential in those children struggling to achieve adequate levels of reading ability. Although the role of RAN in reading disability is well established, the specific underlying cognitive mechanisms accounting for the predictive and discriminative value of RAN in dyslexia, are largely unknown, and thus seem an interesting candidate deserving further behavioural, neural and genetic investigation.

A word of caution relates to two limitations of the present study. First, the generalization of the findings to a broader population might be limited by the smaller sample size, an issue that is often inherent in longitudinal designs including at-risk samples (for comparable sample sizes see for instance, Elbro et al., 1998; Gallagher et al., 2000; Scarborough, 1989, 1990; Snowling et al., 2003). Second, we used a less conventional phonemic auditory closure task as a kindergarten measure of PA that was adequately suited to the ability level of 
our kindergartner samples (motivated by a floor effect on phoneme deletion). One could argue that this task might not have been a sensitive or valid measure for the detection of children's differences in kindergarten PA in relation to their reading outcome. However, in grade 1 we administered both phonemic auditory closure and phoneme deletion, providing the opportunity to compare the predictive pattern of both phonological tests. The results showed that these two tasks were substantially correlated and showed highly similar predictive results of at-risk and normal reading outcome in grade 2 . Thus, the predictive validity of the phonemic auditory closure task seems comparable to the commonly used phoneme deletion measure, lending support for the fact that the absence if a predictive kindergarten effect of PA found in the present study is a genuine effect.

In conclusion, the present longitudinal study revealed that familial risk is highly predictive of later reading problems. Letter-sound knowledge and letter-sound processing skills were the only unique cognitive kindergarten predictors of grade 1 reading skills of at-risk and control children, not phonological awareness. Letter-sound processing remained a significant predictor of grade 2 reading after the initial grade 1 reading stages, but only in at-risk children. Kindergarten rapid naming predicted reading in at-risk children only after the development of some reading fluency in grade 2 . In line with findings of recent brain studies these results were interpreted as evidence for a cross-modal letter-sound association/integration deficit (Blomert, 2011; Wimmer \& Schurz, 2010) already present in pre-reading kindergarten children at familial risk for dyslexia. In addition to this main finding, the present study revealed that the relative predictor pattern for at-risk and control children may differ as a result of the start of reading acquisition. More specific, measures of phonological awareness were not useful in the prediction of future reading skills before the reading achievement was developing successfully. 


\section{REFERENCES}

Aarnoutse, C., Van Leeuwe, J., \& Verhoeven, L. (2005). Early literacy from a longitudinal perspective. Educational Research and Evaluation, 11(3), 253-275.

Adams, M. J. (1990). Beginning to Read: Thinking and Learning about Print. Cambridge, Massachusetts: The MIT Press.

Aro, M. (2004). Learning to read: The effect of orthography: Jyväskylän yliopisto.

Bigozzi, L., Tarchi, C., Pinto, G., \& Accorti Gamannossi, B. (2015). Predicting Dyslexia in a Transparent Orthography From Grade 1 Literacy Skills: A Prospective Cohort Study. Reading \& Writing Quarterly, 1-20.

Blau, V., Reitler, J., Van Atteveldt, N., Gerretsen, P., Seitz, J., Goebel, R., \& Blomert, L. (2010). Deviant processing of letters and speech sounds as proximate cause of reading failure: an fMRI study of dyslexic children. Brain, 133(3), 868-879. doi:10.1093/brain/awp308.

Blau, V., Van Atteveldt, N., Ekkebus, M., Goebel, R., \& Blomert, L. (2009). Reduced neural integration of letters and speech sounds links phonological and reading deficits in adult dyslexia. Current Biology, 19(6), 503-508. doi:10.1016/j.cub.2009.01.065.

Bleichrodt, N., Drenth, P. D., Zaal, J. N., \& Resing, W. C. M. (1988). RAKIT: Revisie Amsterdamse Kinder Intelligentie Test [revision Amsterdam Children Intelligence test Children's Intelligence Test Amsterdam]. Lisse: Swets \& Zeitlinger.

Blomert, L. (2005). Dyslexie in Nederland - theorie, praktijk en beleid [Dyslexia in The Netherlands - theory, practice and policy]. Amsterdam: Nieuwezijds Publishers.

Blomert, L. (2011). The neural signature of orthographic-phonological binding in successful and failing reading development. Neuroimage, 57(3), 695-703. doi:10.1016/j.neuroimage.2010.11.003.

Blomert, L., \& Vaessen, A. (2009). 3DM: Cognitieve analyse van lezen en spellen [3DM: Cognitive analysis of reading and spelling]. Amsterdam: Boom test publishers BV.

Blomert, L., \& Willems, G. (2010). Is there a causal link from a phonological awareness deficit to reading failure in children at familial risk for dyslexia? Dyslexia: An International Journal of Research and Practice, 16, 300-317. doi:10.1002/dys.405.

Boets, B., Smedt, B., Cleuren, L., Vandewalle, E., Wouters, J., \& Ghesquiere, P. (2010). Towards a further characterization of phonological and literacy problems in Dutch-speaking 
children with dyslexia. British Journal of Developmental Psychology, 28(1), 5-31. doi:10.1348/026151010X485223.

Boets, B., Wouters, J., Van Wieringen, A., \& Ghesquiere, P. (2007). Auditory processing, speech perception and phonological ability in pre-school children at high-risk for dyslexia: A longitudinal study of the auditory temporal processing theory. Neuropsychologia, 45(8), 1608-1620. doi:10.1016/j.neuropsychologia.2007.01.009.

Borstrøm, I., \& Elbro, C. (1997). Prevention of dyslexia in kindergarten: effects of phoneme awareness training with children of dyslexic parents. In C. Hulme, \& M. Snowling (Ed.), Dyslexia: Biology, cognition, and intervention (pp. 235-253). London: Whurr Publishers.

Bowers, P. G., \& Ishaik, G. (2003). RAN's contribution to understanding reading disabilities. In S. Graham, H. Swanson, \& K. R. Lee Harris (Eds.), Handbook of learning disabilities (pp. 140-157). New York, US: Guilford Press.

Braams, T., \& Bosman, A. M. T. (2000). Fonologische vaardigheden, geletterdheid en lees- en spellinginstructie. [Phonological skills, literacy, and reading and spelling instruction]. Tijdschrift voor orthopedagogiek, 39, 199-211. doi: 10.1007/s11881-009-0030-0.

Byrne, B., Coventry, W. L., Olson, R. K., Samuelsson, S., Corley, R., Willcutt, E. G., . . DeFries, J. C. (2009). Genetic and environmental influences on aspects of literacy and language in early childhood: Continuity and change from preschool to Grade 2. Journal of Neurolinguistics, 22(3), 219-236.

Byrne, B., Shankweiler, D., \& Hine, D. W. (2008). Reading development in children at risk for dyslexia. In M. Mody \& K. Silliman (Eds.), Brain, Behavior and Learning in Language and Reading disorders (pp. 240-270). New York, US: Guilford Press.

Caravolas, M., Lervåg, A., Defior, S., Málková, G. S., \& Hulme, C. (2013). Different patterns, but equivalent predictors, of growth in reading in consistent and inconsistent orthographies. Psychological Science, 0956797612473122. doi:10.1177/0956797612473122.

Caravolas, M., Vólin, J., \& Hulme, C. (2005). Phoneme awareness is a key component of alphabetic literacy skills in consistent and inconsistent orthographies: evidence from Czech and English children. Journal of Experimental Child Psychology, 92, 107-139. doi: 10.1016/j.jecp.2005.04.003.

Cardoso-Martins, C., \& Pennington, B. F. (2004). The relationship between phoneme awareness and rapid serial naming skills and literacy acquisition: The role of developmental period and reading ability. Scientific Studies of Reading, 8, 27-52. doi:10.1207/s1532799xssr08. 
Carroll, J. M., Solity, J., \& Shapiro, L. R. (2015). Predicting dyslexia using prereading skills: the role of sensorimotor and cognitive abilities. Journal of Child Psychology and Psychiatry.

Catts, H. W., Fey, M., Weismer, S., Bridges, M., Tomblin, J., \& Nippold, M. (2014). The relationship between language and reading abilities. Understanding individual differences in language development across the school years, 144-165.

Catts, H. W., Fey, M. E., Zhang, X., \& Tomblin, J. B. (2001). Estimating risk for future reading difficulties in kindergarten children: A research-based model and its clinical implications. Language, Speech, and Hearing Services in Schools, 32, 38-50. doi:10.1044/01611461(2001/004).

Christopher, M. E., Hulslander, J., Byrne, B., Samuelsson, S., Keenan, J. M., Pennington, B. F., . . . Olson, R. K. (2015). Genetic and environmental etiologies of the longitudinal relations between prereading skills and reading. Child development, 86(2), 342-361.

de Jong, P. F., \& van der Leij, A. (1999). Specific contributions of phonological abilities to early reading acquisition: results from a Dutch latent variable longitudinal study. Journal of Educational Psychology, 91(3), 450-476. doi:10.1037/0022-0663.91.3.450.

de Jong, P. F., \& van der Leij, A. (2002). Effects of phonological abilities and linguistic comprehension on the development of reading. Scientific Studies of Reading, 6(1), 5177. doi:10.1207/S1532799XSSR0601_03.

de Jong, P. F., \& van der Leij, A. (2003). Developmental changes in the manifestation of a phonological deficit in dyslexic children learning to read a regular orthography. Journal of Educational Psychology, 95(1), 22-40. doi:10.1037/0022-0663.95.1.22.

Elbro, C., Borstrøm, I., \& Petersen, D. K. (1998). Predicting dyslexia from kindergarten. The importance of distinctness of phonological representations of lexical items. Reading Research Quarterly, 33(1), 36-60. doi:10.1598/RRQ.33.1.3.

Felton, R. H., \& Brown, I. S. (1990). Phonological processes as predictors of specific reading skills in children at risk for reading failure. Reading and Writing: An Interdisciplinary Journal, 2(1), 39-59. doi:10.1007/BF00383373.

Froyen, D., Willems, G., \& Blomert, L. (2011). Evidence for a specific cross-modal association deficit in dyslexia: an electrophysiological study of letter-speech sound processing. Developmental Science, 14(4), 635-648. doi:10.1111/j.1467-7687.2010.01007.x. 
Furnes, B., \& Samuelsson, S. (2011). Phonological awareness and rapid automatized naming predicting early development in reading and spelling: results from a cross-linguistic longitudinal study. Learning and Individual Differences, 21, 85-95. doi:10.1016/j.lindif.

Gallagher, A., Frith, U., \& Snowling, M. J. (2000). Precursors of literacy-delay among children at genetic risk of dyslexia. Journal of Child Psychology \& Psychiatry, 41(2), 203-213. doi:10.1111/1469-7610.00601.

Georgiou, G. K., Parrila, R., \& Papadopoulos, T. C. (2008). Predictors of word decoding and reading fluency across languages varying in orthographic consistency. Journal of Educational Psychology, 100, 566-580. doi:10.1037/0022-0663.100.3.566.

Hogan, T. P., Catts, H. W., \& Little, T. D. (2005). The Relationship Between Phonological Awareness and ReadingImplications for the Assessment of Phonological Awareness. Language, Speech, and Hearing Services in Schools, 36(4), 285-293. doi:10.1044/01611461(2005/029).

Hulme, C., \& Snowling, M. J. (2016). Reading disorders and dyslexia. Current Opinion in Pediatrics, 28(6), 731-735.

Johnston, T. C., \& Kirby, J. R. (2006). The contribution of naming speed to the simple view of reading. Reading and Writing, 19(4), 339-361. doi:10.1007/s11145-005-4644-2.

Jolliffe, I. T. (1972). Discarding variables in a principle component analysis, I: artificial data. Applied Psycholinguistics, 21, 160-173.

Jolliffe, I. T. (1986). Principle component analysis. New York: Springer-Verlag.

Kirby, J. R., Georgiou, G. K., Martinussen, R., \& Parrila, R. (2010). Naming speed and reading: From prediction to instruction. Reading Research Quarterly, 45(3), 341-362.

Kirby, J. R., Parrila, R. K., \& Pfeiffer, S. L. (2003). Naming speed and phonological awareness as predictors of reading development. Journal of Educational Psychology, 95(3), 453-464. doi:10.1037/0022-0663.95.3.453.

Landerl, K., Ramus, F., Moll, K., Lyytinen, H., Leppänen, P., Lohvansuu, K., . . Bruder, J. (2013). Predictors of developmental dyslexia in European orthographies with varying complexity. Journal of Child Psychology and Psychiatry, 54(6), 686-694.

Landerl, K., \& Wimmer, H. (2008). Development of word reading fluency and spelling in a consistent orthography: an 8-year follow-up. Journal of Educational Psychology, 100, 150-161. doi:10.1037/0022-0663.100.1.150. 
Lervåg, A., Bråten, I., \& Hulme, C. (2009). The cognitive and linguistic foundations of early reading development: A Norwegian latent variable longitudinal study. Developmental Psychology, 45(3), 764. doi:10.1037/a0014132.

Lyon, G. R., Shaywitz, S. E., \& Shaywitz, B. A. (2003). A definition of dyslexia. Annals of Dyslexia, 53, 1-14. doi:10.1007/s11881-003-0001-9.

Lyytinen, H., Ahonen, T., Eklund, K., Guttorm, T., Kulju, P., Laakso, M. L., . . . Viholainen, H. (2004a). Early Development of Children at Familial Risk for Dyslexia: Follow-up from Birth to School Age. Dyslexia, 10(3), 146-178. doi:10.1002/dys.274.

Lyytinen, H., Ahonen, T., Eklund, K., Guttorm, T. K., Laakso, M. L., Leinonen, S., . . Viholainen, H. (2001). Developmental pathways of children with and without familial risk for dyslexia during the first years of life. Developmental Neuropsychology, 20(2), 535-554. doi:10.1207/S15326942DN2002_5.

Lyytinen, H., Aro, M., Eklund, K., Erskine, J., Guttorm, T., Laakso, M. L., . . Richardson, U. (2004b). The development of children at familial risk for dyslexia: birth to early school age. Annals of Dyslexia, 54(2), 184-220. doi:10.1007/s11881-004-0010-3.

Mann, V. A., \& Wimmer, H. (2002). Phoneme awareness and pathways into literacy: A comparison of German and American children. Reading and Writing: An Interdisciplinary Journal, 15, 653-682. doi:10.1023/A:1020984704781.

McBride-Chang, C., \& Manis, F. R. (1996). Structural invariance in the associations of naming speed, phonological awareness, and verbal reasoning in good and poor readers: A test of the double deficit hypothesis. Reading and Writing: An Interdisciplinary Journal, 8(4), 323-339. doi:10.1007/BF00395112.

Moll, K., Ramus, F., Bartling, J., Bruder, J., Kunze, S., Neuhoff, N., . . Lohvansuu, K. (2014). Cognitive mechanisms underlying reading and spelling development in five European orthographies. Learning and Instruction, 29, 65-77.

Moll, K., Thompson, P. A., Mikulajova, M., Jagercikova, Z., Kucharska, A., Franke, H., . . . Snowling, M. J. (2016). Precursors of Reading Difficulties in Czech and Slovak Children At-Risk of Dyslexia. Dyslexia, 22(2), 120-136.

Morais, J. (1991). Constraints on the development of phonemic awareness. In S. Brady \& D. Shankweiler (Eds.), Phonological Processes in Literacy. A Tribute to Isabelle Liberman. New Jersey: LEA Publishers. 
Morais, J., Bertelson, P., Cary, L., \& Alegria, J. (1986). Literacy training and speech segmentation. Cognition, 24, 45-64. doi:10.1016/0010-0277(86)90004-1.

Morais, J., Cary, L., Alegria, J., \& Bertelson, P. (1979). Does awareness of speech as a sequence of phones arise spontaneously? Cognition, 7, 323-331. doi:10.1016/0010-0277(79)90020-9.

Olson, R. K., Keenan, J. M., Byrne, B., \& Samuelsson, S. (2013). Why Do Children Differ in Their Development of Reading and Related Skills? Scientific Studies of Reading, 18(1), 38-54. doi:10.1080/10888438.2013.800521.

Olson, R. K., Keenan, J. M., Byrne, B., Samuelsson, S., Coventry, W. L., Corley, R., . . Hulslander, J. (2011). Genetic and Environmental Influences on Vocabulary and Reading Development. Scientific Studies of Reading, 15(1), 26-46. doi:10.1080/10888438.2011.5.

Parrila, R., Kirby, J. R., \& McQuarrie, L. (2004). Articulation rate, naming speed, verbal short-term memory, and phonological awareness: longitudinal predictors of early reading development? Scientific Studies of Reading, 8(1), 3-26. doi:10.1207/s1532799xssr0801.

Patel, T. K., Snowling, M. J., \& de Jong, P. F. (2004). A cross-linguistic comparison of children learning to read in English and Dutch. Journal of Educational Psychology, 96, 785-797. doi:10.1037/0022-0663.96.4.785.

Pennington, B. F., \& Lefly, D. L. (2001). Early reading development in children at family risk for dyslexia. Child development, 72(3), 816-833. doi:10.1111/1467-8624.00317.

Perfetti, C. A., Beck, I., Bell, L. C., \& Hughes, C. (1987). Phonemic knowledge and learning to read are reciprocal: a longitudinal study of first grade children. Merill-Palmer Quarterly, 33(3), 283-319.

Peterson, R. L., \& Pennington, B. F. (2012). Developmental dyslexia. Lancet, 379(9830), 19972007. doi:S0140-6736(12)60198-6.

Puolakanaho, A., Ahonen, T., Aro, M., Eklund, K., Leppänen, P., Poikkeus, A., . . Lyytinen, H. (2008). Developmental Links of Very Early Phonological and Language Skills to Second Grade Reading Outcomes: Strong to Accuracy but Only Minor to Fluency. Journal of Learning Disabilities, 41(4), 353-370. doi:10.1177/0022219407311747.

Puolakanaho, A., Ahonen, T., Aro, M., Eklund, K., Leppänen, P. H. T., Poikkeus, A. M., \& al., e. (2008). Developmental links of very early phonological and language skills to secondgrade reading outcomes: Strong to accuracy but only minor to fluency. Journal of Learning Disabilities, 41(4), 353-370. doi: 10.1177/0022219407311747. 
Puolakanaho, A., Ahonen, T., Aro, M., Leppanen, P. H. T., Tolvanen, A., Lyytinen, H., . . Eklund, K. (2007). Very early phonological and language skills: Estimating individual risk of reading disability. Journal of Child Psychology and Psychiatry, 48, 923-931. doi:10.1111/j.1469-7610.2007.01763.x.

Raven, J., Court, J. H., \& Raven, J. C. (1995). Coloured Progressive Matrices. Oxford: Psychologists Press Ltd.

Ray-Mukherjee, J., Nimon, K., Mukherjee, S., Morris, D. W., Slotow, R., \& Hamer, M. (2014). Using commonality analysis in multiple regressions: a tool to decompose regression effects in the face of multicollinearity. Methods in Ecology and Evolution, 5(4), 320-328.

Samuelsson, S., Byrne, B., Olson, R. K., Hulslander, J., Wadsworth, S. J., Corley, R., . . DeFries, J. C. (2008). Response to early literacy instruction in the United States, Australia, and Scandinavia: A behavioral-genetic analysis. Learning and Individual Differences, 18(3), 289-295. doi:10.1016/j.lindif.2008.03.004.

Samuelsson, S., Byrne, B., Quain, P., Wadsworth, S., Corley, R., DeFries, J. C., . . . Olson, R. K. (2005). Environmental and genetic influences on prereading skills in Australia, Scandinavia, and the United States. Journal of Educational Psychology, 97(4), 705-722. doi:10.1037/0022-0663.97.4.705.

Scarborough, H. S. (1989). Prediction of reading disability from familial and individual differences. Journal of Educational Psychology, 81(1), 101-108. doi:10.1037/00220663.81.1.101.

Scarborough, H. S. (1990). Very early language deficits in dyslexic children. Child development, 61, 1728-1743. doi:10.2307/1130834.

Schatschneider, C., Fletcher, J. M., Francis, D. J., Carlson, C. D., \& Foorman, B. R. (2004). Kindergarten Prediction of Reading skills: a longitudinal comparative analysis. Journal of Educational Psychology, 96, 265-282. doi:10.1037/0022-0663.96.2.265.

Seibold, D. R., \& McPhee, R. D. (1979). Commonality Analysis: a method for decomposing explained variance in multiple regression analyses. Human Communication Research, 5(4), 355-365. doi:10.1111/j.1468-2958.1979.tb00649.x.

Seymour, P. (2005). Early reading development in European Orthographies. doi:10.1002/9780470757642.ch16.

Seymour, P., Aro, M., \& Erskine, J. (2003). Foundation literacy acquisition in European orthographies. British Journal of Psychology, 94(2), 143-174. doi:10.1348/00071260332. 
Share, D. L. (2008). On the Anglocentricities of current reading research and practice: The perils of overreliance on an 'outlier' orthography. Psychological bulletin, 134, 584-615. doi:10.1037/0033-2909.134.4.584.

Shaywitz, S. E., Shaywitz, B. A., Fletcher, J. M., \& Escobar, M. D. (1990). Prevalence of reading disability in boys and girls. Results of the Connecticut Longitudinal Study. The journal of the American Medical Association, 264(8), 998-1002. doi:10585988.

Snowling, M. J. (2008). Specific disorders and broader phenotypes: the case of dyslexia. The Quarterly Journal of Experimental Psychology, 61(1), 142-156. doi:10.1080/1747021070.

Snowling, M. J., Gallagher, A., \& Frith, U. (2003). Family risk of dyslexia is continuous: individual differences in the precursors of reading skill. Child development, 74(2), 358-373. doi:10.1111/1467-8624.7402003.

Stoolmiller, M., \& Bank, L. (1995). Autoregressive effects in structural equation models: we see some problems. In J. Gottman (Ed.), The analysis of change. Mahwah, NJ: Lawrence Erlbaum Associates.

Thompson, P. A., Hulme, C., Nash, H. M., Gooch, D., E., H. T., \& Snowling, M. J. (2015). Developmental dyslexia: predicting individual risk. Journal of Child Psychology and Psychiatry, 56(9), 976-987.

Torppa, M., Lyytinen, P., Erskine, J., Eklund, K., \& Lyytinen, H. (2010). Language development, literacy skills, and predictive connections to reading in Finnish children with and without familial risk for dyslexia. Journal of Learning Disabilities.

Vaessen, A., Bertrand, D., Tóth, D., Csépe, V., Faísca, L., Reis, A., \& Blomert, L. (2010). Cognitive development of fluent word reading does not qualitatively differ between transparent and opaque orthographies. Journal of Educational Psychology, 102, 827-842. doi:10.1037/a0019465.

Vaessen, A., \& Blomert, L. (2010). Long term cognitive dynamics of fluent reading development. Journal of Experimental Child Psychology, 105, 213-231. doi:10.1016/j.jecp.2009.11.005.

Vaessen, A., Gerretsen, P., \& Blomert, L. (2009). Naming problems do not reflect a second, independent core deficit in dyslexia: 'Double deficits' explored. Journal of Experimental Child Psychology, 103, 202-221. doi:10.1016/j.jecp.2008.12.004.

van Bergen, E., de Jong, P. F., Maassen, B., \& van der Leij, A. (2014). The Effect of Parents' Literacy Skills and Children's Preliteracy Skills on the Risk of Dyslexia. Journal of Abnormal Child Psychology, 42(7), 1187-1200. doi:10.1007/s10802-014-9858-9. 
Van Bergen, E., de Jong, P. F., Plakas, A., Maassen, B., \& van der Leij, A. (2012). Child and parental literacy levels within families with a history of dyslexia. Journal of Child Psychology and Psychiatry, 53(1), 28-36. doi:10.1111/j.1469-7610.2011.02418.x.

Van Bergen, E., de Jong, P. F., Regtvoort, A., Oort, F., van Otterloo, S., \& van der Leij, A. (2011). Dutch children at familial risk for dyslexia: precursors, reading development, and parental effects. Dyslexia, 17(1), 2-18. doi:10.1002/dys.423.

Van Bon, W. H. J. (1986). Raven's coloured progressive matrices. Nederlandse normen en enige andere uitkomsten van onderzoek. Lisse, NL: Swets \& Zeitlinger.

Van Bon, W. H. J., \& Hoekstra, J. G. (1982). TvK: Taaltest voor Kinderen, handleiding (Language test for Children, manual). Lisse: Swets \& Zeitlinger.

Wagner, R. K., Torgesen, J. K., \& Rashotte, C. A. (1994). Development of reading-related phonological processing abilities: New evidence of bidirectional causality from a latent variable longitudinal study. Developmental Psychology, 30, 73-87. doi:10.1037/00121649.30.1.73.

Wentink, H., \& Verhoeven, L. (2003). Protocol leesproblemen en dyslexie [protocol reading problems and dyslexia]. Nijmegen: Expertisecentrum Nederlands.

Wesseling, R., \& Reitsma, P. (2000). The transient role of explicit phonological recoding for reading acquisition. Reading and Writing, 13, 313-336. doi:10.1023/A:1026432502088.

Wimmer, H. (1993). Characteristics of developmental dyslexia in a regular writing system. Applied Psycholinguistics, 14, 1-33. doi:10.1017/S0142716400010122.

Wimmer, H., Landerl, K., Linortner, R., \& Hummer, P. (1991). The relationship of phonemic awareness to reading acquisition: more consequence than precondition but still important. Cognition, 4O(3), 219-249. doi:10.1016/0010-0277(91)90026-Z.

Wimmer, H., Mayringer, H., \& Landerl, K. (1998). Poor reading: a deficit in skill-automatization or a phonological deficit? Scientific Studies of Reading, 2, 321-340. doi:10.1207/s1532799.

Wimmer, H., \& Schurz, M. (2010). Dyslexia in regular orthographies: manifestation and causation. Dyslexia, 16(4), 283-299.

Wolf, M., \& Bowers, P. G. (1999). The double-deficit hypothesis for the developmental dyslexias. Journal of Educational Psychology, 91(3), 415-438. doi:10.1037/0022-0663.91.3.415.

Wolff, U. (2014). RAN as a predictor of reading skills, and vice versa: results from a randomised reading intervention. Annals of Dyslexia, 64(2), 151-165. 
Zakopoulou, V., Anagnostopoulou, A., Christodoulides, P., Stavrou, L., Sarri, I., Mavreas, V., \& Tzoufi, M. (2011). An interpretative model of early indicators of specific developmental dyslexia in preschool age: A comparative presentation of three studies in Greece. Research in developmental disabilities, 32(6), 3003-3016.

Žarić, G., González, G. F., Tijms, J., van der Molen, M. W., Blomert, L., \& Bonte, M. (2014). Reduced neural integration of letters and speech sounds in dyslexic children scales with individual differences in reading fluency. PLoS ONE, 9(10), e110337.

Ziegler, J. C., Bertrand, D., Tóth, D., Csépe, V., Reis, A., Faísca, L., \& ...Blomert, L. (2010). Orthographic Depth and its impact on universal predictors of reading: a cross-language investigation. Psychological Science, 21, 551-559. doi:2010-09433-018.

Ziegler, J. C., \& Goswami, U. (2005). Reading acquisition, developmental dyslexia, and skilled reading across languages: a psycholinguistic grain size theory. Psychological bulletin, 131(1), 3-29. doi:10.1037/0033-2909.131.1.3.

Zientek, L. R., \& Thompson, B. (2006). Commonality analysis: Partitioning variance to facilitate better understanding of data. Journal of Early Intervention, 28(4), 299-307. 


\section{CHAPTER 4}

COGNITIVE AND FAMILIAL RISK EVIDENCE CONVERGED: A DATA-DRIVEN IDENTIFICATION OF DISTINCT AND HOMOGENEOUS SUBTYPES WITHIN THE HETEROGENEOUS SAMPLE OF READING DISABLED CHILDREN

This chapter is based on:

Willems, G., Jansma, B., Blomert, L., \& Vaessen, A. (2016). Cognitive and familial risk evidence converged: A data-driven identification of distinct and homogeneous subtypes within the heterogeneous sample of reading disabled children. Research in Developmental Disabilities, 53, 213-231, doi:10.1016/j.ridd.2015.12.018. 


\section{ABSTRACT}

The evident degree of heterogeneity observed in reading disabled children has puzzled reading researchers for decades. Recent advances in the genetic underpinnings of reading disability have indicated that the heritable, familial risk for dyslexia is a major risk factor. The present datadriven, classification attempt aims to revisit the possibility of identifying distinct cognitive deficit profiles in a large sample of 334 second to fourth grade reading disabled children. In this sample we investigated whether genetic and environmental risk factors are able to distinguish between poor reader subtypes. In this profile, we included reading-related measures of phonemic awareness, letter-speech sound processing and rapid naming, known as candidate vulnerability markers associated with dyslexia and familial risk for dyslexia, as well as general cognitive abilities (non-verbal IQ and vocabulary). Clustering was based on a 200 multi-start K-means approach. Results revealed four emerging subtypes of which the first subtype showed no cognitive deficits underlying their poor reading skills (Reading-only impaired poor readers). The other three subtypes shared a core phonological deficit (PA) with a variable and discriminative expression across the other underlying vulnerability markers. More specific, type 2 showed low to poor performance across all reading-related and general cognitive abilities (general poor readers), type 3 showed a specific letter-speech sound mapping deficit next to a PA deficit (PALS specific poor readers) and type 4 showed a specific rapid naming deficit complementing their phonological weakness (PA-RAN specific poor readers). The first three poor reader profiles were more characterized by variable environmental risk factor, while the fourth, PA-RAN poor reader subtype showed a significantly strong familial risk for dyslexia. Overall, when we zoom in on the heterogeneous phenomenon of reading disability, unique and distinct cognitive subtypes can be identified, distinguishing between those poor readers more influenced by the role of genes and those more influenced by environmental risk factors. Taking into account this diversity of distinct cognitive subtypes, instead of looking at the reading disabled sample as a whole, will help tailor future diagnostic and intervention efforts more specifically to the needs of children with such a specific deficit and risk pattern, as well as providing a more promising way forward for genetic studies of dyslexia. 


\subsection{INTRODUCTION}

While most children become fluent readers without much effort within a few years of reading instruction, a considerable number of children experience great difficulties in acquiring adequate literacy skills. Developmental dyslexia, a specific learning disability resulting in reading and spelling impairments despite normal intelligence and proper educational instruction (Lyon, Shaywitz, \& Shaywitz, 2003; Peterson \& Pennington, 2012), is only one possible cause of the reading failure experienced by the heterogeneous group of poor readers (Heim \& Grande, 2012; Menghini et al., 2010; Pennington et al., 2012; van Bergen, van der Leij, \& de Jong, 2014). Consequently, there have been numerous attempts to classify distinct and coherent cognitive profiles of reading failure. Traditionally, classification studies have divided poor readers into predefined categories, based on existing theoretical insights regarding the etiology of the different reading profiles, such as the 'IQ-reading performance discrepancy' hypothesis (Rutter \& Yule, 1975), the 'phonological-core variable-difference' model (Stanovich, 1988) or according to a specific word decoding deficit or a broader decoding-comprehension deficit, i.e., the 'simple view of reading' (Gough \& Tunmer, 1986). These earlier studies have significantly influenced the ongoing debate on what constitutes dyslexia and have at least supported the possibility to distinguish between a specific reading disabled, or dyslexic profile, and a more general poor, or garden-variety profile (Gough \& Tunmer, 1986; Rutter \& Yule, 1975; Stanovich, 1988). In more recent years however, new developments in the genetic underpinnings of reading disability added greatly to the current definition of dyslexia as a specific learning disability with a neurobiological origin and strong genetic disposition to develop reading difficulties (Byrne et al., 2006; Castles, Datta, Gayan, \& Olson, 1999; Grigorenko, 2001; Pennington \& Olson, 2008; Williams \& O'Donovan, 2006). Reading problems experienced by dyslexic children are highly heritable and run in families (Pennington \& Olson, 2008). Approximately $40 \%$ to $65 \%$ of children at familial risk are expected to develop dyslexia (Blomert \& Willems, 2010; Pennington \& Lefly, 2001; Pennington \& Olson, 2008; Scarborough, 1990), indicating that the chances to develop dyslexia, given a dyslexic parent or sibling, amount to at least 10 times the population prevalence (i.e., 4-5\%, Blomert, 2005). Although having a familial history of dyslexia is one of the strongest risk factors of the disorder (Thompson et al., 2015), it should not be considered as a pure genetic component (Plomin, Reiss, Hetherington, \& Howe, 1994; Rutter \& Silberg, 2002). Since at-risk children share both genes and home literacy environment with their close relatives, 
gene-environment interaction has been studied to understand reading deficits better. It has been shown that children with general impairments across various cognitive abilities are often more specially influenced by environmental risk factors and less by familial risk (Castles et al., 1999; Gayan \& Olson, 2001; Grigorenko, 2001; Rack \& Olson, 1993; Wadsworth, Olson, Pennington, \& DeFries, 2000). A neuroimaging study supported two subtypes demonstrating the existence of two distinct brain activation profiles characterizing a primarily genetic poor reader type and an environmentally influenced more generally impaired type (Shaywitz \& Shaywitz, 2005). One relevant question now is whether this environmental poor reader subtype can be differentiated from the poor reader subtype with a familial risk of dyslexia based on distinct, underlying cognitive deficit patterns. The present clustering study, for the first time, aims to investigate emerging cognitive subtypes of reading disability related to at-risk status based on history of dyslexia as well as environmental factors. We hypothesize that if the development of reading difficulties of a certain cognitive subtype of reading disability is influenced more strongly by a familial predisposition or alternatively more strongly by environmental risk factors, that this influence will also be reflected in their underlying cognitive deficit pattern. The possibility of identifying unique poor reading profiles will help tailor future diagnostic and intervention efforts more effectively than is currently possible.

Several important cognitive risk factors, or 'vulnerability markers', have been identified as important behavioural markers useful for the identification of reading disability. Traditional single deficit accounts of dyslexia point to weakness in phonological awareness (PA) as the core deficit in dyslexia (Adams, 1990; Goswami \& Bryant, 1990; Ramus, 2003; Snowling, 2000; Vellutino, Fletcher, Snowling, \& Scanlon, 2004). However, more recently a growing tendency emerged to view neurodevelopmental disorders like literacy impairment as the product of various interacting vulnerability markers with distinct, behavioural profiles as a result (Bishop, 2006, 2008; Pennington \& Olson, 2008; Snowling, 2008, 2012). Family studies of dyslexia confirm that there is indeed a spectrum of reading disorders (Snowling \& Hulme, 2012). Although a single PA deficit explanation of dyslexia is under discussion, it is undisputed that PA is a main characteristic of reading disability (e.g., Ramus et al., 2003; Sunseth \& Bowers, 2002). Reading disabled children at increased familial risk for dyslexia show significantly weaker PA skills than non-risk controls (e.g., Carroll, Mundy, \& Cunningham, 2014). In turn, both impaired and unimpaired at-risk children show PA problems (Puolakanaho et al., 2008; Snowling, Gallagher, \& Frith, 2003), resulting in a parametric increase of reading problems (i.e., healthy < 
unimpaired at-risk < impaired at-risk: Boets, Wouters, Van Wieringen, \& Ghesquiere, 2007; Elbro, Borstrøm, \& Petersen, 1998; Moll, Loff, \& Snowling, 2013; Pennington \& Lefly, 2001; Snowling et al., 2003). Although it was always assumed that PA plays a causal role in reading acquisition (Snowling, 2000; Vellutino et al., 2004; Wagner \& Torgesen, 1987), this has been opposed by researchers who indicated that a PA deficit develops in close relation with the developing reading deficit (Blomert \& Willems, 2010; Castles \& Coltheart, 2004; Castles, Wilson, \& Coltheart, 2011; Morais, Cary, Alegria, \& Bertelson, 1979; Perfetti, Beck, Bell, \& Hughes, 1987). Genetic studies also indicated that a PA deficit is associated with a genetic predisposition of dyslexia which, although often differing in severity, can be present in both affected and unaffected family members (Berninger et al., 2006; Snowling, 2008).

Another candidate vulnerability marker of dyslexia is the ability to rapidly name familiar visual symbols such as objects, letters or colours, known as Rapid automatized naming (RAN) (Berninger, Abbott, Billingsley, \& Nagy, 2001; Berninger et al., 2006; Bowers \& Wolf, 1993). RAN is thought to reflect efficient and fast matching of visual and phonological codes and is often found to be impaired in poor readers (Berninger et al., 2001; Bowers \& Ishaik, 2003; Bowers \& Wolf, 1993; Caravolas, Lervåg, Defior, Málková, \& Hulme, 2013; Caravolas et al., 2012; Vaessen, Gerretsen, \& Blomert, 2009). While some investigators suggested that RAN and PA might be different manifestations of the same underlying PA deficit (e.g., Clarke, Hulme, \& Snowling, 2005; Torgesen, Wagner, \& Rashotte, 1994; Vaessen et al., 2009), the double-deficit theory proposed that RAN constitutes a separate factor in dyslexia, independent of PA problems (Wolf, 1997; Wolf \& Bowers, 1999). Regardless of this ongoing discussion, there is a unique and strong (predictive) association between RAN and reading failure (de Jong \& van der Leij, 1999; McBride-Chang \& Manis, 1996; Puolakanaho et al., 2008; Vaessen et al., 2009). Also, twin studies indicated that RAN deficits in dyslexics are significantly heritable (Byrne et al., 2006; Davis et al., 2001; Gayan \& Olson, 2001; van Bergen, de Jong, Maassen, \& van der Leij, 2014) and RAN performance shows a similar parametric variation from healthy to at-risk non-dyslexic readers to at-risk dyslexic readers, as does PA (Pennington \& Lefly, 2001; Puolakanaho et al., 2008).

A third candidate vulnerability marker of reading disability is letter-speech sound processing (LS). This process can be defined into two sub-processes: letter-to-sound mapping and automatic letter-speech integration. Letter-to-sound mapping is relatively fast. Most children learn this within months of reading education (Seymour, Aro, \& Erskine, 2003). In 
contrast, automatic integration of letter-speech sound pairs takes much longer during development, even in normal readers (Froyen, Bonte, Van Atteveldt, \& Blomert, 2009; Froyen, Van Atteveldt, Bonte, \& Blomert, 2008). Poor readers are significantly slower in processing LS pairs than normal readers over six primary school grades, indicating persistent problems to efficiently and automatically integrate letters to speech sounds (summarized in Blau et al., 2010; Blau, Van Atteveldt, Ekkebus, Goebel, \& Blomert, 2009; Blomert, 2011; Blomert \& Vaessen, 2009; Froyen, Willems, \& Blomert, 2011). This LS learning deficit is already present in a core group of children at familial risk for dyslexia before they start to read (Blomert \& Willems, 2010). Recent neuroimaging results showed that the reduced neural LS integration activity can be moderately improved by an intensive letter-speech sound coupling training next to regular reading instruction (Zaric et al., 2015). Similar to PA and RAN, at-risk non-dyslexic as well as atrisk dyslexic children were both found to demonstrate slow acquisition of letter-speech sound knowledge (Puolakanaho et al., 2008; Snowling et al., 2003).

A fourth potential reading-related risk factor might be verbal working memory (VWM). Although reduced performance on tasks of verbal working memory involving phonologically represented material are often reported in struggling readers (Beneventi, Tønnessen, Ersland, \& Hugdahl, 2010; Berninger et al., 2006; Georgiou, Das, \& Hayward, 2008), the exact role of a VWM deficit in dyslexia has been disputed. For example, it has been shown that memory span deficits in dyslexic readers are mainly restricted to tasks with a phonological component (Blomert \& Vaessen, 2009; Carroll \& Snowling, 2004; Felton \& Brown, 1990; Tijms, 2004) whereas their performance on tasks without this verbal component (e.g., spatial working memory) is comparable to that of non-dyslexic readers (Jeffries \& Everatt, 2004; Kibby, Marks, Morgan, \& Long, 2004). This has led to the debate whether VWM impairments are uniquely related to poor reading outcome, independent of phonological problems (Georgiou et al., 2008; McCallum et al., 2006) or not (Tijms, 2004). Nevertheless, a VWM deficit seems a candidate vulnerability marker since it predicts reading development (Georgiou et al., 2008; McCallum et al., 2006) and is subject to genetic effects already prior to schooling (e.g., Byrne et al., 2006). VWM deficits are shared by at-risk reading impaired and at-risk non-impaired children (Pennington \& Lefly, 2001).

Finally, we return to the validity of an IQ-reading performance discrepancy criterion traditionally used to identify reading disability assuming that the cause of reading failure might vary between low and high IQ readers. Current working definitions have not fully eliminated its 
use as an exclusionary criterion, defining dyslexia to be unexpected and a 'specific' learning deficit (e.g., Lyon et al., 2003). The use of discrepancy criterion in the diagnosis of dyslexia has been challenged from its inception though. Behavioural findings reveal that discrepant and nondiscrepant poor readers did not differ in terms of long-term prognosis, severity of their PA deficits or response to intervention (for a review; Jiménez, Siegel, O’Shanahan, \& Ford, 2009; Stanovich \& Siegel, 1994; Stuebing, Barth, Molfese, Weiss, \& Fletcher, 2009; Stuebing et al., 2002). Practical and psychometric problems also caused identification of dyslexia solely based on an IQ-reading discrepancy or strict cut-off scores to become (Lyon, 1989, 1995). Moreover, recent neuroimaging studies confirm the lack of validity of the IQ-reading discrepancy definition of dyslexia by showing that regardless of $I Q$, dyslexic readers show similar functional organization of the brain network involved in phonological processing of print (Simos, Rezaie, Papanicolaou, \& Fletcher, 2013; Tanaka et al., 2011). Although the behavioural and neuroimaging profiles of poor readers do not seem to differ as a function of $\mathrm{IQ}$, recent genetic twin studies found that the degree of genetic influences does vary as a linear function of IQ. More specific, reading failure in high-IQ dyslexics are due to substantially genetic causes whereas the aetiology of reading failure in low-IQ dyslexics seem to be due to more environmental causes (Knopik et al., 2002; Wadsworth, Olson, \& DeFries, 2010; Wadsworth et al., 2000). The existence of two potential aetiologies for childhood reading disability was confirmed by a neuroimaging study by Shaywitz and Shaywitz (2005) indicating a predominantly genetic, specifically impaired reading impaired type with IQ scores over 100 and a more environmentally influenced type with IQ scores below 100. Thus, although the same genetic factors could be operating across varying levels of $I Q$, genetic influence is stronger in high-IQ dyslexics which may require different or more thorough remediation.

Previous poor reader classification attempts, focused on the above described cognitive vulnerability markers, are rather limited and can be divided into two major categories. The first category employs a top-down, theory-driven approach, classifying subjects into one of the hypothesized subtypes by means of a predefined division (Compton, DeFries, \& Olson, 2001; Wolf \& Bowers, 1999; Zoubrinetzky, Bielle, \& Valdois, 2014). The second type of classification studies employs bottom-up, data-driven, analysis in large representative samples of children which provides the opportunity to explore distinct profiles without making a priori assumptions on the nature and number of the expected subtypes. An advantage of such data-driven classification over theory-driven studies is that they circumvent possible limitations of the 
boundaries of the theoretical model and look beyond this adopted framework to find different, emerging subtypes (Heim et al., 2008; King, Giess, \& Lombardino, 2007; Morris et al., 1998; Pacheco et al., 2014). Several data-driven studies focused on reading abilities in unselected samples of children, but not on the underlying cognitive deficits (e.g., Buly \& Valencia, 2002; Pierce, Katzir, Wolf, \& Noam, 2007). Others have investigated reading problems as one manifestation of learning disabilities amongst a widespread range of deficits in general language, reading, perceptual, motoric and other cognitive processes (e.g., Morris et al., 1998; Rourke, 1985; Satz \& Morris, 1981). The data-driven classification study by King et al. (2007) did focus on reading impaired children, using PA and RAN as main clustering variables. Results revealed evidence for three impaired subtypes of distinct underlying cognitive deficits, namely one phonological deficit profile, a rapid naming deficit profile and a profile reflecting a double deficit in both domains. Another more recent clustering study by Pacheco et al. (2014) focused on a wider range of cognitive abilities when profiling dyslexic children with normal-range IQ scores, including measures of PA, RAN, VWM and vocabulary. Results suggested a cluster with phoneme deletion and RAN deficiencies and a cluster with phonological processing difficulties (phoneme deletion and digit span) without a RAN deficit. A limitation was the small sample size of 37 children. The present clustering attempt will further explore this broader cognitive spectrum of poor reading across these reading-related vulnerability markers in a much larger and representative sample of grade 2 to 4 poor readers. We will moreover also take into account recent major advances in the genetic underpinnings of reading disability by adding information on the familial occurrence of reading problems in addition to possible environmental influences. Since genetic influence varies with the level of $I Q$, we moreover included non-verbal IQ as a general cognitive clustering variable not as an inclusion criteria like in the study of Pacheco and colleagues (2014).

\section{THE PRESENT STUDY}

The present, data-driven clustering study was executed within a large sample of 334 second to fourth grade poor readers between 7 and 10 years old. We aimed to explore the possibility of identifying distinct types of reading disability and investigated whether these cognitive profiles can differentiate between poor readers with a family history of dyslexia and those influenced mainly by environmental factors. We hypothesize that a strong familial risk should be reflected in disabled reading skills and also in underlying cognitive deficits. Cognitive 
clustering was based on a 200 multi-start K-means approach (Steinley, 2006) with the following vulnerability markers of reading failure: phonological awareness (PA), rapid naming (RAN), letter-speech sound processing accuracy and response time (LS) and verbal working memory (VWM) as clustering variables, next to general cognitive abilities of non-verbal IQ and vocabulary. Subsequently, the obtained subtypes were compared on characteristics of familial risk (i.e., first-degree family member with severe childhood reading and spelling difficulties), environmental risk factors (i.e., socio-economic status and reading performance level at schools) and co-morbidity characteristics (i.e., arithmetic deficits and ADHD characteristics).

\subsection{METHODS}

\section{PARTICIPANTS}

The current sample of poor readers investigated in the present study consisted of 334 children (i.e., 155 girls; $n=134$ in grade $2 ; n=111$ in grade $3, n=89$ in grade 4 ) obtained from two larger samples:

- The first sample is an unselected school sample of 1717 children (i.e., all children in one classroom were evaluated) enrolled in 13 primary schools spread across 5 different regions in the Netherlands. This sample was originally used for the standardization of the 3DM test battery (i.e., psycho-metric Differential Diagnosis Dyslexia Maastricht (3DM), Blomert \& Vaessen, 2009);

- The second sample consisted of 108 children attending regular primary school that were also referred to a specialized dyslexia institute in their region to further investigate their reading or reading-related development. These children were also part of the norming and validation study by Blomert and Vaessen (2009) and tested at the dyslexia institute.

Children were labelled as poor readers if they met the often used reading deficit cut-off criteria of one standard deviation (i.e., percentile score $<16$ ) below the age-specific mean norm score (Snowling \& Stackhouse, 2013) on a Dutch standardized word reading fluency test of the 3DM test battery (Blomert \& Vaessen, 2009). Based on this selection criterion the following poor reading samples emerged:

- In the first sample, 257 children of 1717 met the present's study poor reader criterion;

- In the second sample, 77 of 108 children were labelled as poor readers. 
All children were native Dutch speakers. Note that the Dutch school system approves the use of a handful of reading instruction protocols of which the basic principles of instructions focus on developing awareness of the basic phonological structure of written language in addition to learning the important letter-speech sound relations in isolation and in the context of structured words. As a consequence, the reading instruction and interventions provided at Dutch schools are highly comparable. This is further guaranteed by the national protocol for reading intervention, or the pupil evaluation system, dictating schools how to monitor and remediate children struggling with their literacy development. An informed consent from all parents/caregivers and permission from the Ethical Faculty Committee was obtained. Age and mean performance (raw and standardized z-scores) of the poor reader sample on literacy tasks and on the general cognitive and the reading-related tasks subsequently used for clustering are presented in Table 1. We used SPSS (version 21). The overall poor reader sample was on average $8.9( \pm 0.99)$ years old and showed general cognitive abilities that fell within the average range. They moreover showed a disabled performance on all reading and spelling tasks (confirming the employed poor reader selection criterion). Finally, the poor readers demonstrated poor to lowaverage PA, LS, RAN and VWM skills.

\section{PROCEDURE}

Children were tested at their school or dyslexia institute in a quiet room. Tasks were administered individually, in a fixed order by trained project workers (except for the classically administered non-verbal IQ). Independent Dutch national norms for the 3DM test battery range from grade 1 to the end of grade 6 of primary school and all subtest were computerized, using a specially designed response-box to precisely measure accuracy and/or response time in milliseconds. Independent Dutch national norms were also available for all other included tasks (norm range included in the task description below) and were all paper-to-pencil tasks. Please note that the performance from all children from the original norming and validation study of the 3DM study by Blomert and Vaessen (2009) were used for the present study. Thus, the 3DM tests (or other included measures) were not administered previously, excluding a possible influence of multiple testing with the same test battery. 
Table 1 - Age and mean performance of overall poor reader group on cognitive tasks

\begin{tabular}{|c|c|c|c|c|}
\hline \multirow[b]{2}{*}{ Age \& general cognitive performance } & \multicolumn{2}{|c|}{ Raw scores } & \multicolumn{2}{|c|}{ Standardized scores ${ }^{1}$} \\
\hline & $\mathrm{M}$ & SD & $\mathrm{M}$ & SD \\
\hline Age (years) & 8.90 & 0.99 & n.a. & n.a. \\
\hline Non-verbal IQ (mean 100, SD 15) & n.a. & n.a. & 99.15 & 13.95 \\
\hline Vocabulary (\% correct) & 72.93 & 8.80 & 0.10 & 0.97 \\
\hline Baseline RT (sec/item) & 0.97 & 0.22 & -0.15 & 0.89 \\
\hline \multicolumn{5}{|l|}{ Reading \& spelling performance } \\
\hline Reading fluency 3DM (correct/sec) & 0.66 & 0.26 & -1.62 & 0.55 \\
\hline Reading fluency OMT (correct/sec) & 0.49 & 0.22 & -1.49 & 0.76 \\
\hline Reading fluency Klepel (correct/sec) & 0.18 & 0.08 & -1.38 & 0.51 \\
\hline Spelling acc 3DM (\% correct) & 61.01 & 16.10 & -0.98 & 0.91 \\
\hline Spelling-to-Dictation (\% correct) & 34.03 & 17.29 & -0.71 & 1.01 \\
\hline \multicolumn{5}{|l|}{ Reading-related risk markers } \\
\hline PA (\% correct) & 44.21 & 24.34 & -0.90 & 0.87 \\
\hline RAN letters (sec/15 items) & 10.97 & 2.67 & -0.64 & 0.92 \\
\hline RAN digits (sec/15 items) & 11.81 & 2.99 & -0.93 & 0.96 \\
\hline LSSI acc (\% correct) ${ }^{2}$ & 90.73 & 7.64 & -0.52 & 1.10 \\
\hline LSSI RT (sec/item) & 2.55 & 0.63 & -0.63 & 1.04 \\
\hline LSSD acc (\% correct) ${ }^{2}$ & 82.91 & 10.46 & -0.59 & 1.02 \\
\hline LSSD RT (sec/item) & 1.84 & 0.55 & -0.31 & 1.09 \\
\hline VWM (acc) & 10.38 & 2.22 & -0.31 & 0.96 \\
\hline
\end{tabular}

Note. Reading fluency is items correct/second, $P A$ = phonological awareness - phoneme deletion, RAN = rapid naming, $L S S I=$ letter-speech sound identification, $L S S D=$ letter - speech sound discrimination, $V W M=$ verbal working memory, acc = accuracy, $R T=$ response time, n.a. $=$ not available. ${ }^{1}$ Standardized scores: IQ expressed in IQ scores (mean $\left.=100, S D=15\right)$. Performance on reading, spelling and reading-related vulnerability markers expressed in z-scores. ${ }^{2}$ Chance level on LSI 25\% correct, LSD 50\% correct. 
Poor reader criterion - Reading Fluency (3DM).

Children read aloud as many singly presented words as quickly as possible on 3 levels (high-frequent, low-frequent, pseudo-words, 75 items in 30 seconds per level on 5 screens, 15 items). Fluency was an overall composite score over 3 levels expressed in number of correct words (items/second) and used to define the poor reader criterion (i.e., the lowest $16^{\text {th }}$ percentile). Test-retest reliability coefficient was .95 (reported in the test manual of 3DM).

\section{Initial clustering variables}

Phonemic awareness - Phoneme Deletion (PA 3DM). The task presented 23 pseudowords via headphones. The child deleted a speech sound at different positions and pronounced the resulting pseudo-word (e.g., "/dauk/ - /d/, what is left?"). Accuracy (\% correct) and response time (seconds/item) was measured but response time (RT) was excluded from further analyses due to floor accuracy performance in $1 / 3$ of children (i.e., $\leq 5$ items correct). The task had an internal consistency of .85 for accuracy and .93 for speed (reported in the test manual of 3DM).

Rapid naming (RAN 3DM). The child named items on a sheet (letter and digit task) as quickly as possible (i.e., 2 sheets per task, 15 items per sheet in different order). Response time was mean RT over two sheets. The naming task had a split-half reliability of .80 (reported in the test manual of 3DM).

Letter-speech sound processing (LS 3DM). Two tasks were used to measure accuracy and response time of letter-speech sound knowledge, a letter-speech sound identification task and a letter-speech sound discrimination task. In the letter-speech sound identification (LSSI) task, a phoneme was presented over headphones (in total 45 unique trials) simultaneously with four letters (or letter combinations) appearing on a screen (e.g. /b/ and ' $b$ ' ' $d$ ' ' $t$ ' ' $p$ '). The child identified the corresponding letter-speech sound pair by pressing the button matching to the correct letter. In the letter-speech sound discrimination (LSSD) task, a speech sound was presented via headphones (90 in total) simultaneously with one visual letter (or letter combination). By pressing a button, the child indicated whether the letter and the sound were the same or different (e.g. /o/ and ' $a$ '). Accuracy (\% correct) as well as response time (sec/item) was measured for both tasks. The accuracy scores of the LSSI and LSSD tasks had an internal 
consistency of respectively .72 and .82 and the speed scores of the LSSI and LSSD tasks had an internal consistency of respectively .90 and .96 (reported in the test manual of 3DM).

Verbal working memory (VWM). Digit span (WISC-R) required children to repeat a digit sequence in forward or backward order (de Bruyn, van der Steenen, \& van Haasen, 1986). The sequence length increased from 2 to 9 digits and 2 trials per sequence length were offered. The task was stopped if both trials of a given length were incorrect. Accuracy score was the sum of the largest correctly repeated forward and backward sequence. The digit span test had a splithalf reliability of 0.78 (reported in the test manual WISC-R). The Dutch version of WISC-R has norms for children between 6 and 16 years of age.

Non-verbal IQ. RAVEN-Coloured Progressive Matrices required children to identify missing segments required to complete a larger pattern to measure non-verbal IQ at schools (Van Bon, 1986) For the Dutch version of this task, reliabilities of .80 and higher were reported. WISC-R-NL Block design measured IQ at the dyslexia institutes (WISC-R: de Bruyn et al., 1986). Children copied geometric designs with four or nine plastic cubes. The reliability coefficient for the Block Design subtest in a Dutch population is between .88 and .89. To compare RAVEN and WISC performance, both scores were transformed into an IQ estimate ( mean $=100, S D=15$ ). The transformed IQ scores did not differ significantly for RAVEN and WISC, respective values were 98.26 (14.64) and 101.42 (14.35), $t(1)=2.77, p>.05$. Normative data for RAVEN-CPM ranged from 5 to 11 years of age (for norm range of WISC-R see VWM section above).

Receptive vocabulary. Children matched one of four pictures to an orally presented word (RAKIT; Bleichrodt, Drenth, Zaal, \& Resing, 1988). Accuracy was expressed in \% correct (maximum items 60). The test has an internal consistency of .81 (reported in the test manual Rakit). Dutch norms were available for children from 4 to 11 years of age.

Baseline response time (3DM). An animated figure (20 in total) appeared in one of four squares on the screen. The child identified the location of the figure by pressing the corresponding button as fast as possible. The task has an internal consistency of .93 (reported in the test manual of 3DM). 


\section{Comparing clusters: Reading and spelling tasks}

Reading Fluency. Children read aloud single words as quickly as possible in the presented time: One-Minute test (OMT: high and low frequent words, 1 minute, Brus \& Voeten, 1973), Klepel (pseudo-words, 2 minutes, van den Bos, Lutje Spelberg, Scheepstra, \& de Vries, 1994) and 3DM reading fluency used for the initial poor reader selection (for a description see above). Fluency was expressed in correctly read words (items/second). Test-retest reliabilities are reported to be over .80 for the OMT, .89 for the Klepel and .95 for 3DM reading fluency. Dutch norms ranged from grade 1 to the first class of secondary school for both the OMT and the Klepel (for norm range of 3DM see Procedure section above).

Spelling. Two spelling tasks were administered. Spelling-to-dictation (PI-dictee, Geelhoed \& Reitsma, 1999): 135 words were dictated to the child in a sentence (i.e., from simple words to multi-syllable words with complex spelling rules) until 8 or more incorrect spellings in one block of 15 sentences were made. The internal consistency of this standardized test is between .90 and .96 (reported in the PI-dictee test manual). Dutch norms are available for children from grade 1 to 6. Computerized spelling task (3DM): an auditory word (e.g., /boom/) was presented via headphone simultaneously with a visual, incomplete word (e.g., /b_ $m /$ ). Below the incomplete word, four options of the missing part were presented (e.g., 'oo', 'a', 'o', 'aa'). The child selected the option to complete the word correctly by pressing a corresponding button. Accuracy was expressed in \% correct. The task accuracy measure has an internal consistency of .80 (reported in the manual of 3DM).

\section{Comparing clusters: Reports on familial risk, co-morbidity and environmental factors}

The emerging subtypes were compared on familial risk for dyslexia, environmental risk factors (school performance level, socio-economic status (SES) based on parental education and on neighborhood status) and co-morbidity characteristics were obtained through parent-ratings on a reading-status questionnaire (FADD, Blomert, unpublished).

Familial risk for dyslexia. A child was defined as at-risk for dyslexia if at least one firstdegree family member (i.e., a parent or sibling) indicated to have suffered from severe childhood reading and spelling difficulties.

Environmental factors. Parental Education Level SES. Parental education was assessed on a 5-point scale ranging from 'primary school' to 'vocational bachelor or university level' (i.e., 5 levels ranging from low, low average, average, high average or high parental education). For 
the current analyses we defined two socio-economic status categories: poor parental education for low to low average and normal parental education for the remaining level. Neighborhood SES. This neighborhood social status score was adopted from extensive research by the Netherlands Institute for Social Research (Knol, 2012). A factor analysis defined the status score of each Dutch postal code area based on four characteristics of neighbourhood residents within each area: mean income, percentage low incomes, percentage of low educated residents and percentage of unemployed residents (i.e., scores ranged from -7.25 to 3.19 , a low score indicates low neighbourhood status, average score in 2010 was of 0.17). For the current analysis, we defined two neighbourhood social status categories: poor neighbourhood status with a status score of 1 standard deviation below the mean norm and a normal neighbourhood status.

School reading performance level. Within the original, unselected grade 1-6 school sample $(n=1717)$ from which the present grade 2-4 poor reader sample $(n=334)$ was selected, we evaluated the overall proportion of poor reading children based on the 3DM reading fluency performance of 1 SD below the norm (i.e., the 16th percentile). Overall proportions of poor readers were set for all 13 participating schools. Next, we ranked the 13 schools based on a median cut-off (i.e., $\leq 13.33 \%$ ) we divided the schools in two categories: lower reading level schools and higher reading level schools. More specific, 7 schools were labelled as low proportion of poor reader schools and 6 schools as high proportion of poor reader schools.

Co-morbidity characteristics. Parent-ratings on the FADD questionnaire indicated presence/absence of severe arithmetic difficulties for a minimum period of 6 months. Parentratings on the AVL questionnaire (Scholte \& van der Ploeg, 2005) consisting of 18 questions on attention, concentration and (hyper)activity indicated whether the child exhibited behavioural symptoms of ADHD for the last 6 months or more. The overall score resulted in three categories; ADHD symptoms were low, moderate or considerably present, of which the latter category was considered ADHD behaviour. 


\subsection{RESULTS}

\section{DATA PREPERATION}

The present data-driven, clustering approach investigated the possibility to identify distinct types of underlying cognitive deficit patterns in a large sample of poor readers and subsequently explored the relation between these subtypes and familial risk and environmental factors contributing to reading failure. This statistical classification was previously employed to successfully identify distinct cognitive subtypes within an independent heterogeneous sample of children with arithmetic difficulties (Bartelet, Ansari, Vaessen, \& Blomert, 2014). We now apply it in the context of reading disability. Note that all variables scores were nationally normed measures (i.e., normally distributed and corrected for age ensuring that a child's performance is compared to children that received a similar amount of reading instruction). For all analyses, the scores on each measure were transformed into standardized z-scores to ensure that differences in measurement scale did not influence the results.

In order to distinguish theoretically meaningful latent variables, we first conducted an exploratory factor analysis (principal components with oblimin rotation) on the eight readingrelated vulnerability markers: phonological awareness accuracy (PA), rapid naming speed (RAN) letters and digits, letter-speech sound (LS) identification and discrimination accuracy and response time, and verbal working memory accuracy (VWM). Response time on reading-related measures may be influenced by individual variations in motor response, or in other words a tendency to work fast/slow resulting in a possible speed/accuracy trade-off. Corroborating this was the strong correlation between the baseline response time task and the LS tasks ( $r$ between .39 - .49). We therefore corrected the LS response time tasks for individual differences in motor response prior to the factor analysis. Specifically, we regressed the performance on the baseline response time task (which was similar in design to the LS tasks) on the response time performance on the LS identification and discrimination tasks. Subsequently, we computed the corrected response time residuals for the LS tasks. We did not perform such a correction for the RAN processing tasks since we found no substantial correlation between these tasks and baseline response time performance $(r<.21)$. Please note that the baseline reaction time was not separately included in the factor or subsequent analyses. Note that post-hoc comparisons revealed that baseline response time was comparable across emerging clusters (type 1: $M=-$ $.07, S D=1.08$, type $2: M=-.16, S D=1.03$, type $3: M=-.15, S D=1.04$ and type $4: M=-.21, S D=$ 
1.19, $\mathrm{F}(3,330)=.22, p=.88)$. The factor solution for the current reading disabled sample resulted in the following five theoretically relevant factors with eigenvalues of at least .70 (Jolliffe, 1986) and a communality estimate of at least .70 (MacCallum, Widaman, Zhang, \& Hong, 1999): phonological awareness (PA; accuracy), rapid naming (RAN; reaction time on letters and digits), letter-speech sound accuracy (LS accuracy; on identification and discrimination), letter-speech sound fluency (LS rt; reaction time on identification and discrimination) and verbal working memory (VWM; accuracy). Factor loadings and eigenvalues of the five extracted factors, which had a cumulative explained variance of $77 \%$, are presented in Table 2.

\section{Identifying clusters of reading disability}

Nonverbal IQ, vocabulary performance and the five identified factors were entered as variables in the subsequent clustering analyses conducted with SPSS (version 21). We firstly conducted an Agglomerative hierarchical clustering approach Ward's method) as a preprocessing step in our data analyses. Specifically, this bottom-up clustering approach provides us with the mechanism for monitoring data merging, on the one hand and, on the other, a strategy to determine the optimal number of clusters representing the data. 
Table 2 - Results of exploratory factor analysis

\begin{tabular}{lccllll}
\hline & \multicolumn{7}{c}{ Factors } \\
& PA & RAN & LSacc & LSrt & VWM & Communalities \\
\hline PA acc & .89 & .01 & .10 & -.05 & -.20 & .91 \\
RAN digits & -.19 & .81 & .08 & -.01 & .27 & .79 \\
RAN letters & .18 & .86 & -0.7 & .04 & .22 & .81 \\
LSSI acc & .11 & .02 & .90 & .17 & .13 & .82 \\
LSSD acc & -.04 & -.03 & .80 & -.22 & -.12 & .76 \\
LSSI RT & -.10 & .03 & .09 & .76 & -.15 & .76 \\
LSSD RT & .03 & .00 & -.06 & .90 & .03 & .81 \\
VWM acc & .18 & .01 & -.02 & .08 & -.91 & .90 \\
Eigen values & 2.39 & 1.88 & 1.13 & 0.93 & 0.80 & \\
\hline
\end{tabular}

Note. Principal component analysis with oblimin rotation. $P A=$ phonological awareness phoneme deletion, RAN = rapid naming, LSSI = letter-speech sound identification, $L S S D=$ letterspeech sound discrimination, $V W M=$ verbal working memory, acc $=$ accuracy, $R T=$ response time.

The analysis initially starts with every single case within a separate cluster, considering each individual case separate from all the others. Subsequently, cases are merged (i.e., agglomerated) together into new clusters based on highest similarity in each following iteration. Similarity is based on the lowest increase in error of sum-of-squares or in other words the smallest distance to the cluster centre (i.e., SUMD). This merging process is continued until all of the data is merged into one cluster (Field, 2005; Sarstedt \& Mooi, 2014). Thus, clusters generated in early stages are nested in those generated in later stage which is reflected in the hierarchy of the clustering tree plot. The results can be described in a dendrogram (Figure 1 bottom) and a plot of the mean sum-of-squares (mean SUMD) as a function of $\mathrm{K}$ number of clusters (Figure 1 - top). The dendrogram visualizes the hierarchy within the final cluster in which each iteration merge is represented by a binary tree. Interpreting the height between the different nodes and its leaf indicated that the largest threshold distances can be seen at four clusters. The optimal four cluster solution best representing the data was further confirmed by the observed 'elbow' at $K=4$ (i.e., while the average sum-of-squares monotonically decreased for increasing $K(1$ to 4$)$, it decreases remarkably for $K>4$ ) in the mean SUMD plot. 

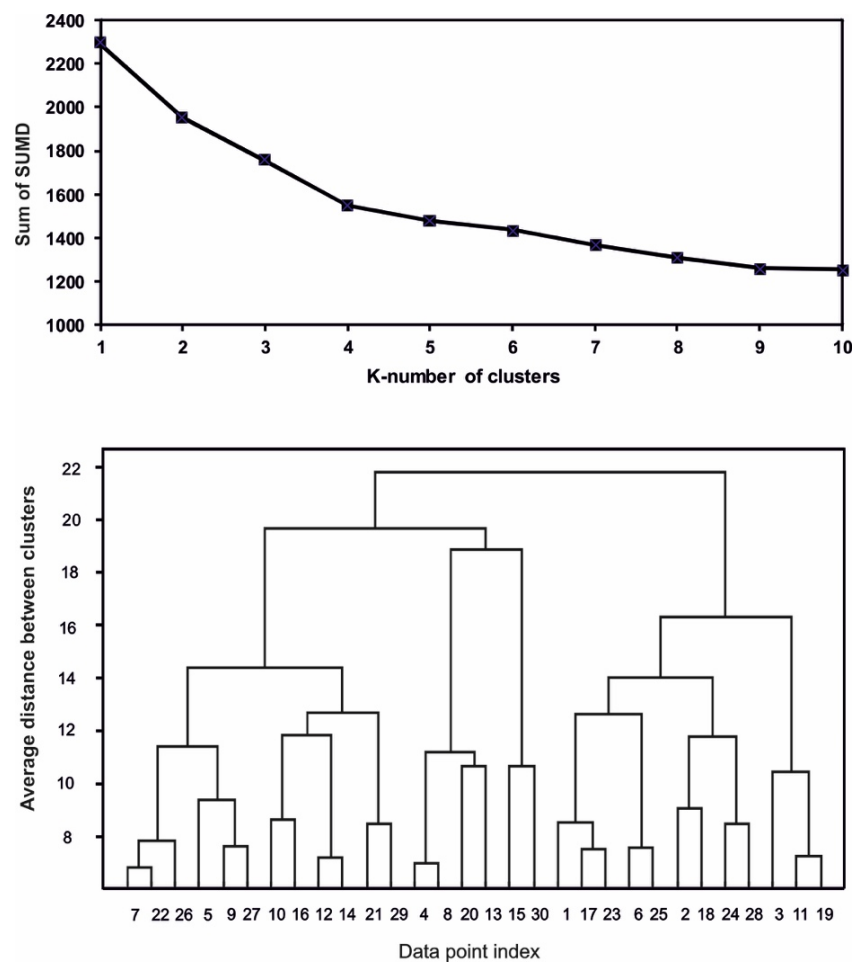

Figure 1. Identifying the optimal number of clusters. (Top) -Total sum-of-squared within cluster distances (SUMD) as a function of k-number of clusters. Note that the total SUMD shows an 'elbow' at $K=4$ and that after that the decrease of total SUMD is markedly reduced, indicating four as the optimal number of clusters representing the data. (Bottom)-Dendrogram plot of the agglomerative hierarchical binary cluster tree (Wards linkage, Euclidean distance). The Dendrogram is collapsed over lower branches to increase visibility of the plot (some nodes in the plot thus correspond to more than one data point). The largest threshold distances (i.e., height between the node and the leaf) can be seen at four clusters.

Hierarchical agglomerative clustering thus provided us with the optimal indication of the number of clusters represented in our data. However, using this approach for clustering alone, although leading to a cluster grouping of our data, only leads to one possible (and possibly suboptimal) solution. Hence, we applied a second step, employing K-means clustering (Steinley, 2006). 
Iterative partitioning K-means multi-start (200 runs) clustering approach (Euclidean distance) provided us with a mechanism for assessing different configurations (cluster solutions) based on multiple initializations to subsequently identify the cognitive profiles of these four clusters estimated to be the best fit of the current data. K-means clustering performs an iterative fitting process to form the specified optimal number of clusters $(K=4)$ a solution that derived from Agglomerative hierarchical clustering specified above. This is done by selecting a set of cluster seeds as a first guess of the starting point as the initial cluster centers. Subsequently, each case is assigned to one of the four clusters it most closely resembles, after which the cluster mean is re-calculated. This process continues until the clusters stabilize. The choice of this initial starting point for clustering can greatly affect the resulting classification which may be a sub-optimal representation of the data (King et al., 2007). However, by resampling the data 200 times using MATLAB (2001), using randomly chosen, cluster centers to start clustering from, we circumvent the well-known problem of local optima. We moreover can guarantee that the final four cluster solution obtained (i.e., the most optimal fit out of 200 runs) represented the clustering result with the minimal sum of average squared distances within clusters. In other words, we would ensure maximal cluster stability and obtain the result that reduces the Euclidean distance most effectively and represents the global optima or best fit of the data (Steinley, 2006). The best fitting four-cluster solutions resulting from this multi-start Kmeans revealed the following cognitive profiles of reading disability (standardized z-scores of the mean performance on the classification variables per cluster are presented in Table 3, for a visual representation of this data see Figure 2 ):

Type $1(n=86)$ holds poor readers with average general cognitive IQ, vocabulary and average performance on PA, RAN, LS and VWM (z-scores ranging between 0.46 to -0.50 ). This type thus showed difficulties with reading without showing underlying general or readingrelated cognitive deficits and was therefore labelled reading-only impaired readers.

Type $2(n=76)$ showed low IQ and vocabulary ( $z$-scores of -0.84 and -0.81 , respectively) which were in correspondence to their low-to-poor performance across all reading-related skills, indicated by impaired PA (z-score of -1.35), low-average RAN (z-score between -0.75 and -0.84), low-average-to-poor LS accuracy and RT (z-score between -0.52 and -1.07) and poor VWM (zscore of -0.99). Thus, this type consisted of general poor readers. 
Type $3(n=79)$ poor readers exhibited low-average IQ scores (z-score of -0.46$)$ and normal vocabulary (z-score of 0.06) next to a specific impairment in LS processing (Accuracy zscore between -1.09 and -1.54) and PA (z-score of -1.16). Their performance on RAN and VWM performance where in the average norm range ( $z$-score between -0.55 and -0.10 ). Note that these children performed average on LS processing speed. This type was labeled PA-LS specific poor readers.

Type $4(n=93)$ poor readers showed average IQ and vocabulary (i.e., a z-score of 0.55 on both measures) discrepant to their impaired RAN and PA performance (respective z-scores were -1.38 to -1.47 and -0.94$)$. The performance on LS accuracy, LS RT and VWM was in the low average range ( $z$-scores ranging between -0.49 and -0.72 ). This type was labeled as PA-RAN specific poor readers. Note. A cross-validation confirmatory analysis (i.e., randomly split the present poor reader sample in half to repeat the clustering approach for each sub-sample using the 200 multi-start procedure) yielded the same four cognitive types of poor reading as described above. To further confirm that a four-cluster solution was the best fit for the present data, we also explored a five and six-cluster solution. Both analyses revealed the same important clusters as four-cluster solution, and although additional cluster(s) emerged, none corroborated any poor reader types predicted by theoretically relevant models of poor reading (e.g., no additional speed/RAN-only disabled type of poor reading, predicted by the doubledeficit hypothesis), confirming the validity of the emerging optimal four cluster solution. 

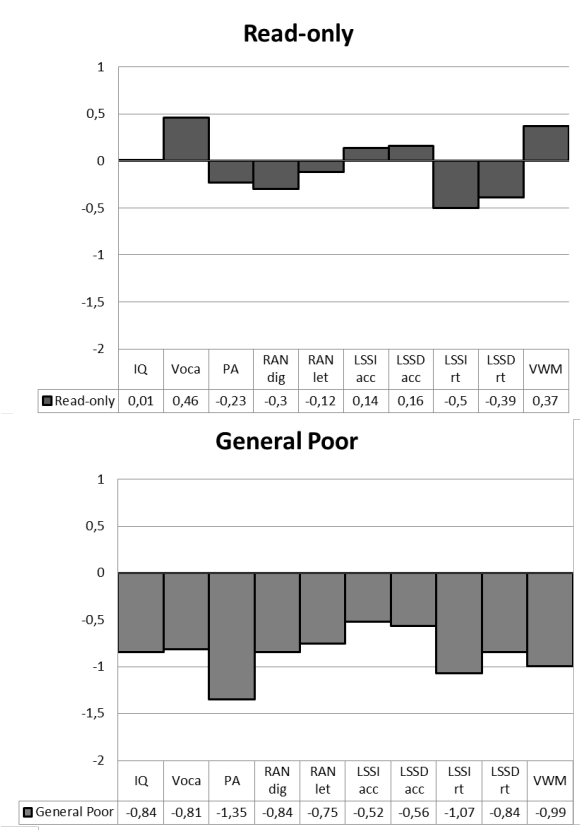

PA-LS

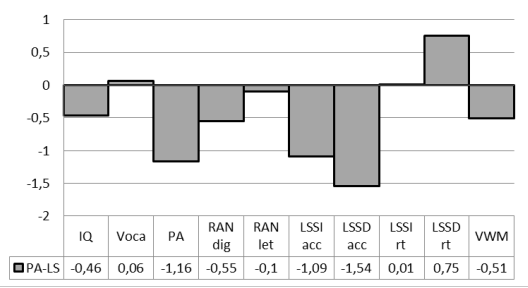

PA-RAN

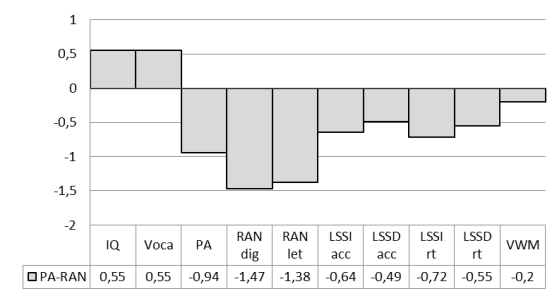

Figure 2. Visual representation of the cognitive profiles of the poor reader subtypes.

Average performance expressed in standardized $z$-scores ( $x$-axis) with standard error bars on the general cognitive variables and reading-related vulnerability markers ( $y$-axis) per poor reader type. Voca $=$ vocabulary, $V W M=$ verbal working memory, $P A=$ phonological awareness phoneme deletion, $R A N=$ rapid naming, dig = digits, let = letters, LSSI = letter-speech sound identification, $L S S D=$ letter -speech sound discrimination, acc $=$ accuracy, $R T=$ response time. For a summary of z-scores, standard deviations and post-hoc analyses (Bonferroni-corrected) see Table 3. 
Table 3 - Mean performance and standard deviations on general cognitive variables and reading-related vulnerability markers per poor reader type

\begin{tabular}{|c|c|c|c|c|c|c|c|c|c|c|}
\hline & \multirow{2}{*}{\multicolumn{2}{|c|}{$\begin{array}{l}\text { Type } 1 \\
\text { Read-only }\end{array}$}} & \multirow{2}{*}{\multicolumn{2}{|c|}{$\begin{array}{l}\text { Type } 2 \\
\text { Gen Poor }\end{array}$}} & \multirow{2}{*}{\multicolumn{2}{|c|}{$\begin{array}{l}\text { Type } 3 \\
\text { PA-LS }\end{array}$}} & \multirow{2}{*}{\multicolumn{2}{|c|}{$\begin{array}{l}\text { Type } 4 \\
\text { PA-RAN }\end{array}$}} & \multirow[b]{4}{*}{ F-value } & \multirow[b]{4}{*}{ Post-hoc } \\
\hline & & & & & & & & & & \\
\hline & \multicolumn{2}{|c|}{$\mathrm{n}=86$} & \multicolumn{2}{|l|}{$n=76$} & \multicolumn{2}{|c|}{$n=79$} & \multicolumn{2}{|c|}{$n=93$} & & \\
\hline & $M$ & SD & $M$ & SD & M & SD & $M$ & SD & & \\
\hline \multicolumn{11}{|l|}{ General cogn } \\
\hline IQ & 0.01 & 0.90 & -0.84 & 0.72 & -0.46 & 0.88 & 0.55 & 0.72 & $46.07 * *$ & $4>1>2=3$ \\
\hline Vocabulary & 0.46 & 0.84 & -0.81 & 0.80 & 0.06 & 0.77 & 0.55 & 0.80 & $46.49 * *$ & $4=1>3>2$ \\
\hline \multicolumn{11}{|l|}{ Read-related } \\
\hline $\mathrm{PA}$ & -0.23 & 0.72 & -1.35 & 0.65 & -1.16 & 0.87 & -0.94 & 0.80 & $33.55 *$ & $1>4=3>2$ \\
\hline RAN digits & -0.30 & 0.73 & -0.84 & 0.93 & -0.55 & 0.75 & -1.47 & 0.70 & $37.93 *$ & $1=3>2>4$ \\
\hline RAN letters & -0.12 & 0.70 & -0.75 & 0.90 & -0.10 & 0.72 & -1.38 & 0.73 & $56.66 *$ & $1=3>2>4$ \\
\hline LSSI acc & 0.14 & 0.86 & -0.52 & 1.02 & -1.09 & 1.06 & -0.64 & 1.07 & $21.52 *$ & $1>4=2>3$ \\
\hline LSSD acc & 0.16 & 0.74 & -0.56 & 0.92 & -1.54 & 0.73 & -0.49 & 0.91 & $58.06 *$ & $1>4=2>3$ \\
\hline LSSI RT & -0.50 & 0.86 & -1.07 & 0.88 & 0.01 & 0.97 & -0.72 & 1.01 & $18.51 *$ & $3>1>4=2$ \\
\hline LSSD RT & -0.39 & 0.87 & -0.84 & 0.82 & 0.75 & 0.89 & -0.55 & 0.88 & $51.06 *$ & $3>1>4=2$ \\
\hline VWM & 0.37 & 0.89 & -0.99 & 0.83 & -0.51 & 0.80 & -0.20 & 0.78 & $38.86 *$ & $1>4=3>2$ \\
\hline
\end{tabular}

Note. Read-only $=$ reading-only impaired readers, Gen Poor $=$ general-poor readers, PA = phonological awareness - phoneme deletion, RAN = rapid naming, LSSI = letter-speech sound identification, $L S S D=$ letter-speech sound discrimination, $V W M=$ verbal working memory, acc = accuracy, $R T=$ response time, performance of all tasks expressed in standardized z-scores. Significance level: ${ }^{*} p<0.01$. For a visual representation of the data see Figure 2. 
Comparison of types of poor readers on clustering variables

Validation and interpretation are the two last steps of a clustering process. We firstly compared the obtained four types of poor reading on the initial cluster variables to be able to investigate on which specific clustering variables significant differences occurred between the poor reading subtypes. The subtypes of poor reading were compared on the clustering variables by means of analyses of variance (ANOVA). Type 1 (reading-only impaired reader) performed within the average range on all general cognitive and markers. Due to the already extensive nature of the results section, we list the most interesting significant differences between the other three subtypes of poor readers (Table 3 summarizes the comparisons and post-hoc analyses, Bonferroni-corrected).

The three poor reader types in which we identified variable underlying patterns of cognitive deficits all showed a PA deficit, with type 2 (general poor readers) showing the most impaired PA skills. Significantly poorer LS accuracy was characteristic of type 3 (PA-LS specific poor readers), while type 4 (RAN-PA specific poor readers) and type 2 (general poor readers) did not differ. A significant RAN deficit was specific for type 4 (PA-RAN poor readers) revealing an inferior performance as compared to type 3 (PA-LS specific poor readers) and type 2 (general poor readers). Less impaired LS RT was found for type 3 (PA-LS specific poor readers) compared to type 2 (general poor readers) and type 4 (PA-RAN specific poor readers). Low VWM was characteristic of type 2 (general poor readers), while type 3 (PA-LS specific poor readers) and type 4 (PA-RAN specific poor readers) showed no difference. As for the general cognitive performance, type 3 (PA-LS specific poor readers) and type 4 (PA-RAN specific poor readers) IQ performance was within average range with the later showing superior IQ skills. The general poor readers showed below average IQ. Finally, Vocabulary was significantly better in type 4 (PA-RAN specific poor readers) than the general poor readers but not as compared to type 3 (PALS specific poor readers).

\section{External validity of the obtained poor reading types}

Next, the obtained poor reading subtypes were compared on external validation variables, independent of the initial classification variables. First, age and reading and spelling fluency of the four subtypes were compared by means of an ANOVA (Table 4 lists mean z-scores and standard deviations per subtype and the comparisons and post-hoc analyses, Bonferronicorrected). 
Second, familial risk for dyslexia and environmental risk factors (i.e., SES based on parental education, SES based on social neighbourhood status and poor school performance level) expressed in proportions were compared (Table 5 lists the proportions per subtype in addition to the chi-square comparison). The PA-RAN specific deficit poor readers (type 4) showed a significantly larger familial risk $(63 \%)$ as compared to the other three types that did not differ from each other (19\% in type 1, 24\% in type 2 and $20 \%$ in type 3 ). Please note that information for 7 children in the PA-RAN type was missing. Familial risk was based on at least one first-degree family member (sibling or parent) suffering from severe childhood literacy difficulties since official dyslexia diagnoses in parental generations are rare in the Netherlands. We did however have information on proportions of impaired first-degree family members who also had an official dyslexia diagnosis and results showed that official diagnosis of either a sibling or parent was more common in PA-RAN poor readers $(50 \%)$ compared to the other poor reader types (19\% in type $1,22 \%$ in type 2 and $31 \%$ in type 3 ). The general poor and PA-LS specific poor readers showed a significantly higher proportion of children with a poor SES based on parental education than the PA-RAN specific and reading-only impaired poor readers, respective proportions were $67 \%$ (type 2), 68\% (type 3), 24\% (type 4) and 33\% (type 1). Similarly, the general poor and PA-LS specific poor readers showed a significantly higher proportion of children with poor social SES based on neighborhood social status score than the PA-RAN specific and reading-only impaired poor readers, respective proportions were 50\% (type 2), 51\% (type 3), 31\% (type 4) and 32\% (type 1). The information of SES was missing for in total 35 children (i.e., between 9\%-13\% per type). The reading-only impaired reader subtype (type 1) showed a significantly higher proportion of children (69\%) attending school with a lower school reading performance level (i.e., a high proportion of poor readers) than the other three subtypes that did not differ ( $44 \%$ in type $2,43 \%$ in type 3 and $46 \%$ in type 4 ). Please note, proportion could only be calculated based on participants recruited via schools since school information of children from the dyslexia institutes was missing (i.e., 13 from reading-only impaired, 41 from PA-RAN, 18 from PA-LS and 5 from general poor). 
Table 4 - Mean reading and spelling performance per poor reader type

\begin{tabular}{|c|c|c|c|c|c|c|c|c|c|c|}
\hline & $\begin{array}{l}\text { Type } 1 \\
\text { Read-or } \\
n=86\end{array}$ & & $\begin{array}{l}\text { Type } 2 \\
\text { Gen Poc } \\
n=76\end{array}$ & & $\begin{array}{l}\text { Type } 3 \\
\text { PA-LS } \\
n=79\end{array}$ & & $\begin{array}{l}\text { Type } 4 \\
\text { PA-RAN } \\
n=93\end{array}$ & & & \\
\hline & $\mathrm{M}$ & SD & $\mathrm{M}$ & SD & $\mathrm{M}$ & SD & $\mathrm{M}$ & SD & F-value & Post-hoc \\
\hline Age & 103.15 & 12.31 & 109.01 & 12.91 & 108.11 & 11.34 & 107.43 & 10.83 & $4.02 *$ & $1<2=3=4$ \\
\hline \multicolumn{11}{|l|}{ Reading } \\
\hline 3DM & -1.40 & 0.60 & -1.62 & 0.56 & -1.65 & 0.60 & -1.81 & 0.60 & $8.95^{* *}$ & $1<2=3=4$ \\
\hline OMT & -1.32 & 0.82 & -1.51 & 0.74 & -1.46 & 0.82 & -1.51 & 0.79 & $9.56^{* *}$ & $1<2=3=4$ \\
\hline Klepel & -1.27 & 0.50 & -1.42 & 0.55 & -1.42 & 0.46 & -1.41 & 0.53 & $12.57^{* *}$ & $1<2=3=4$ \\
\hline \multicolumn{11}{|l|}{ Spelling } \\
\hline $3 \mathrm{DM}$ & -0.47 & 0.82 & -1.40 & 0.81 & -1.13 & 0.82 & -0.98 & 0.93 & $17.47^{* *}$ & $1<2=3=4$ \\
\hline Spel-to-dic & -0.46 & 1.02 & -0.87 & 0.96 & -0.73 & 1.04 & -0.79 & 0.98 & $7.62 * *$ & $1<2=3=4$ \\
\hline
\end{tabular}

Note. Read-only = reading-only impaired readers, Gen Poor = general poor readers, $P A-L S=P A$ LS specific poor readers, PA-RAN $=$ PA-RAN specific poor readers, Spel-to-dic $=$ spelling-todictation. Reading fluency in correct items/second, Spelling in number of correct items. Performance on all tasks expressed in standardized z-scores. Significance level: ${ }^{*} p<0.05,{ }^{* *} p<$ 0.01 .

Table 5 - Proportions on familial and environmental risk factors per poor reader type

\begin{tabular}{|c|c|c|c|c|c|c|c|c|c|c|}
\hline & \multicolumn{2}{|c|}{$\begin{array}{l}\text { Type } 1 \\
\text { Read-only }\end{array}$} & \multicolumn{2}{|c|}{$\begin{array}{l}\text { Type } 2 \\
\text { Gen Poor }\end{array}$} & \multicolumn{2}{|c|}{$\begin{array}{l}\text { Type } 3 \\
\text { PA-LS }\end{array}$} & \multicolumn{2}{|c|}{$\begin{array}{l}\text { Type } 4 \\
\text { PA-RAN }\end{array}$} & \multirow[b]{2}{*}{$\overline{\chi^{2}}$} & \multirow[b]{2}{*}{ Comparison } \\
\hline & $\%$ & $n$ & $\%$ & $n$ & $\%$ & $n$ & $\%$ & $n$ & & \\
\hline Fam Risk & 19 & 16 of 86 & 24 & 18 of 76 & 20 & 16 of 79 & 63 & 54 of 86 & $52.15^{*}$ & $4>2=3=1$ \\
\hline Par SES & 33 & 28 of 86 & 67 & 51 of 76 & 68 & 54 of 79 & 24 & 21 of 86 & $51.59 *$ & $2=3>1=4$ \\
\hline Soc SES & 32 & 25 of 78 & 50 & 33 of 66 & 51 & 36 of 70 & 31 & 26 of 85 & $11.74^{*}$ & $2=3>1=4$ \\
\hline School read & 69 & 50 of 73 & 44 & 31 of 71 & 43 & 26 of 61 & 46 & 24 of 52 & $12.67^{*}$ & $1>2=3=4$ \\
\hline
\end{tabular}

Note. Read-only = reading-only impaired readers, Gen Poor = general poor readers, $P A-L S=P A-$ LS specific poor readers, $P A-R A N=P A-R A N$ specific poor readers, Fam Risk = familial risk for dyslexia, Par SES = parental education SES, Soc SES = social neighbourhood status, School read = lower school reading performance level. $\chi^{2}=$ chi-square test. Significance level: ${ }^{*} p<0.01$. 
Finally, gender (proportions of girls) and co-morbidity characteristics (i.e., arithmetic difficulties and ADHD) were compared. There was no difference in gender between the poor reader types, showing similar proportions of girls: reading-only impaired reader type (44\%, 38 of 86$)$, general poor $(51 \%, 39$ of 76), PA-LS specific ( $43 \%, 34$ of 79$)$ and PA-RAN specific $(47 \%, 44$ of 93$), \chi^{2}(3)=1.30 p=.73$. Proportions of parental concern on arithmetic difficulties was very small and similar across poor reader types: reading-only impaired reader type $(6 \%, 5$ of 86$)$, general poor (7\%, 5 of 76), PA-LS ( $8 \%, 6$ of 79) and PARAN $(7 \%, 6$ of 86$), \chi^{2}(3)=.23, p=.97$. The number of children with a formal ADHD diagnosis was very small and did not differ between types: reading-only impaired reader type $(0 \%)$, general poor $(1 \%, 1$ of 76), PA-LS specific (0\%) and PA-RAN specific (4\%, 3 of 86$), \chi^{2}(3)=5.70, p=.13$. 


\subsection{DISCUSSION}

The present data-driven classification approach identified profiles of cognitive deficits in a large sample of grade 2-4 poor readers and subsequently explored the relation between these cognitive profiles and familial history risk and environmental risk factors contributing to reading failure. Four stable subtypes of reading disability emerged from cluster analyses: the reading-only impaired readers (type 1), the general poor readers (type 2), the PA-LS specific poor readers (type 3) and the PA-RAN specific poor readers (type 4). They are based on the following four cognitive, candidate risk factors known to mark vulnerability for reading failure: phonological awareness (PA), rapid naming (RAN), letter-speech sound processing (LS), and verbal working memory (VWM), next to general cognitive abilities (i.e., IQ and vocabulary). The reading-only impaired readers (type 1 ) show no impairments on any clustering variables despite their reading failure. The other three identified types of poor reading (general poor readers, PALS specific, PA-RAN specific) share a PA deficit and reveal a specific and unique deficit pattern across the other cognitive clustering variables. The general poor readers (type 2 ) demonstrate a general impaired performance on all vulnerability markers in accordance with their inferior general cognitive skills. The PA-LS specific poor readers (type 3) exhibit a specific deficit in LS in addition to the shared PA deficit, with average RAN, low average IQ and average vocabulary. The PA-RAN poor readers (type 4) reveal impaired PA and RAN, low average LS in combination with average IQ and vocabulary. The reading-only impaired type 1 poor readers are significantly younger ( 5 months) than the other three poor reader types and attend schools classified as lower reading performance schools (i.e., $69 \%$ of children attend one of the schools out of the 13 participating schools ranked as lower reading performance schools compared to approximately $45 \%$ in the other three subtypes of poor reading). The general poor readers (type 2) and the PA-LS specific poor readers (type 3) are characterized by overall poorer SES based on poorer parental education (i.e., two-third of poor readers are characterized by a socio-economic status level within the low to low-average categories, which was around one-third in the PA-RAN specific and reading-only impaired poor readers) and poorer neighborhood social SES (i.e., half of the general poor and PA-LS specific poor readers show a poor social status score of 1 SD below the norm as compared to one-third in the PA-RAN specific and reading-only impaired poor readers). On the other hand, the poor readers in the PA-RAN specific profile (type 4) are at a significant higher familial risk for dyslexia (i.e., two-third of the PA-RAN specific poor readers have one or more first-degree family member(s) with severe reading difficulties, which was only around one-fifth of poor readers in the other three profiles). 
Finally, the four subtypes show no clinically significant co-morbidity (i.e., occurrence of ADHD and arithmetic problems was very low and non-discriminative).

The present results confirmed the existence of heterogeneity at the level of cognitive deficits in reading disability (Menghini et al., 2010; Pennington et al., 2012; van Bergen, van der Leij, et al., 2014) and support the view that it is possible to identify distinct poor reading subtypes within the heterogeneous group that constitutes reading disabled children (e.g., Heim \& Grande, 2012; Heim et al., 2008; King et al., 2007; Morris et al., 1998; Pacheco et al., 2014). The reading-only impaired type 1 poor readers without underlying general cognitive deficits seems puzzling. These poor readers score within the normal standardized range on all reading-related and general cognitive abilities despite their reading difficulties. A closer look reveals that this subtype has significantly less impaired reading fluency skills than the other three subtypes with cognitive deficits underlying their reading difficulties, and also is the only poor reader type scoring within average range on spelling. Results show that these poor readers are significantly younger than in the other three subtypes, making it possible that specific underlying cognitive deficits are not yet revealed. Although younger, type 1 poor readers however did not attend a significantly lower school grade, indicating that their non-specific reading deficit is not due to not yet being exposed to higher grade reading instruction. These poor readers did however attend schools with a lower reading performance level based on high proportions of poor readers at that school (i.e., twothirds of this subtype compared to $44 \%$ in type $2,43 \%$ in type 3 and $46 \%$ in type 4 , although the proportion of the latter group should be interpreted with care since PA-RAN poor readers were tested at their dyslexia institute and school information was missing in $40 \%$ of this subtype). As for the comparison between the other three subtypes, although we acknowledge that factors beyond the scope of the current study may explain why type 1 children showed poor reading skill in the absence of other deficits and adequate intellectual ability, the school reading performance level may indicate that a possible explanation might lie in inadequate reading instruction at school, which seems more easily counterattacked by more adequate or intensive instruction.

The other three identified poor reader profiles did show a unique and distinct cognitive deficit pattern underlying their reading problems. Firstly, all three subtypes of poor reading share a PA deficit which is in line with findings from other classification attempts (e.g., Fletcher et al., 1994; Morris et al., 1998) and corroborates the phonological-core variable difference model (Stanovich \& Siegel, 1994). This model suggests that poor readers with lower intellectual capacities and educational opportunities (i.e., IQ-reading congruent type) are more likely to show a more generally impaired profile across general and reading-related abilities (i.e., type 2 in the current study) compared to those disabled readers with 
relatively higher IQs (i.e., IQ-reading discrepant type) with a more specific reading-related deficit (i.e., type 3 and 4). Although this model predicts that the phonological deficit of the IQ-reading discrepant poor readers would be more severe, the current findings indicated that the PA deficit in the general poor readers was worse consistent with their overall cognitive deficit profile, Nevertheless, results are in compliance with various reports that show that all poor reading types are well predicted by PA deficits, irrespective of IQ level (e.g., Fletcher et al., 1994; Stanovich, 1991; Stanovich \& Siegel, 1994). In line with this are the results of recent neuroimaging studies confirming that brain activation patterns during phonological processing of print are similar for low-IQ and high-IQ poor readers (Simos et al., 2013; Tanaka et al., 2011). The present result moreover supports the generally accepted reciprocal correlation between phonological awareness and reading (Blomert \& Willems, 2010; Castles \& Coltheart, 2004; Wagner \& Torgesen, 1987). While IQ scores seem to differ between our emerging cognitive subtypes of poor reading, our results also indicate that it is important in for the identification and remediation of reading disability to look at the overall general and reading-related cognitive profile of children. This finding corroborates previous accounts made against solely basing classification of reading failure on the more traditionally used IQ-discrepancy definition (Stanovich \& Siegel, 1994; Stuebing et al., 2002).

Next to a shared PA deficit, a differential expression of underlying cognitive deficits across other domains was found in these three poor reader subtypes. The generally impaired poor readers (type 2) reveal a rather poor and non-differentiated cognitive profile across all reading-related risk markers and general cognitive skills (being the only profile with impaired verbal working memory, for similar VWM results in general poor readers see for instance Daal \& Leij, 1999; De Jong, 1998). In contrast, the two specifically impaired poor reader profiles each show a unique reading-related deficit, in addition to the common PA deficit. More specifically, the PA-LS specific poor readers show poor letter-speech sound accuracy processing skills, next to a PA deficit. The PA-RAN specific type demonstrates additional impaired rapid naming skills, suggesting a relation between PA and RAN. Overall, we can conclude that these results do not directly fit into a double-deficit framework proposed by Wolf and Bowers (1999). One would expect a PA-only deficit type, a RAN- only deficit type and a type showing deficits in both domains (for classification results pointing in this direction see King et al., 2007; Morris et al., 1998). The double-deficit hypothesis expects the two deficits to be independent and additive, resulting in a more severe form of dyslexia in the double-deficit subtype as compared to the single deficit subtypes. However, the present results reveal no 'pure' RAN-only core deficit type, independent of PA problems (corroborating the findings of other behavioral studies directly investigating the main assumptions of the double-deficit hypothesis; Badian, 1997; Bowers \& Ishaik, 2003; Pennington, Cardoso-Martins, Green, \& 
Lefly, 2001; Vaessen et al., 2009; Vukovic \& Siegel, 2006; Wagner \& Torgesen, 1987). Pennington et al. (2001) for example only found 1 child within their sample of 71 dyslexic readers with a RAN specific impairment. Similarly, Vaessen et al. (2009) indicated that only 5\% of their sample showed RAN difficulties without affected PA skills, leaving them to conclude that RAN is merely a different (speeded) manifestation of the same underlying deficit in the phonological domain, with the unique addition that RAN problems might reflect the inefficient and slower cross-modal matching of visual-orthographic codes (also see Araújo et al., 2011). The present data cannot contribute directly to the discussion on whether RAN reflects cross-modal ability uniquely and independent of phonological processing. Nevertheless our results demonstrate that RAN is a useful cognitive clustering variable, able to differentiate between distinct cognitive profiles within the heterogeneous sample of poor readers, where traditional PA tasks alone cannot.

The finding of an LS specific deficit, next to a shared PA deficit, in our PA-LS specific poor readers (type 3 ) is in line with the few previous studies focusing on this vulnerability marker. Learning lettersound pairs is found to be an immediate problem for a substantial part of kindergarten children at-risk for reading failure, already before reading instruction (Blomert \& Willems, 2010). Moreover, older poor readers are slower in LS mapping skills than normally developing peers up to the end of primary school (Blomert \& Vaessen, 2009). In fact, while normal readers improve this skill up to grade 6, poor readers show a premature halting after grade 3 . This extended weakness or even inability to efficiently map letters-sound pairs in dyslexic children is further confirmed by recent brain imaging studies (Blau et al., 2010; Froyen et al., 2011) and even indicated far beyond primary school in dyslexic adults (Blau et al., 2009; for a summery see Blomert, 2011). Although LS processing is a seemingly important vulnerability marker of poor reading it has, to our knowledge, never been included in previous poor reading classification studies (Fletcher et al., 1994; King et al., 2007; Morris et al., 1998; Pacheco et al., 2014). At least, the present result of a distinct poor reader type with LS problems indicates the importance of including such a differentiating measure in future classification research, especially given the information it can provide for subsequent diagnostic and intervention efforts.

Finding distinct cognitive patterns of deficits in three of the four emerging poor reader profiles suggests a possible difference in underlying etiology through which these three subtypes arrive at their similar poor reading and spelling levels. Our results are in line with previous findings of a primarily genetic poor reader type and an environmentally influenced impaired type (Shaywitz \& Shaywitz, 2005). The general poor readers (type 2) and the PA-LS specific poor readers (type 3) are characterized by environmental risk factors. Both subtypes of poor reading show significantly poorer socio-economic 
status (SES) on two measures generally agreed to cover the three most influential components of SES (i.e., the cultural component of parental education, the social component of labor market position and the economical component of family income; Israel, Beaulieu, \& Hartless, 2001). More specific, around two-thirds of the children in type 2 and 3 come from families with a low to low-average parental education (compared to one-third in the PA-RAN and reading-only impaired poor readers). In accordance, they also reveal a poorer neighbourhood social status composite score based on average family education, income and occupation status of the child's area of residence (i.e., half of the children scored $1 \mathrm{SD}$ below the norm as compared to one-third of the children in the reading-only impaired type and PA-RAN specific profiles). The PA-RAN specific poor readers (type 4), on the other hand, exhibit a stronger familial predisposition to the reading failure they experienced: more than two-thirds of children have one or more first-degree family members with dyslexia, whereas only one-fifth show a familial risk in the other three types. Although only genetic testing (e.g., twin study designs) can detangle how much variation in a trait is related to genes or environmental factors and family history of dyslexia is not a pure genetic trait (Pennington \& Olson, 2008; Plomin et al., 1994; Rutter \& Silberg, 2002), being at familial risk is one of the strongest predictive factors of the disorder (Thompson et al., 2015). It is possible that parents with higher SES (based on parental education or higher neighbourhood scores) are more aware of possible reading difficulties in their children, over-reporting family history of dyslexia on our parental reports. Results however showed that parents with average to above average education level showed similar proportions of at-risk indications (30\%) to parents of a lower educational level $(36 \%), \chi^{2}=1.17, p$ $=.28$. Families with an average to high social neighbourhood status score also showed comparable proportions of at-risk indications (33\%) compared to families with a lower score $(30 \%), \chi^{2}=.51, p=.47$. Similarly, parent reports on family history for dyslexia may also be higher in parents from children already referred to a specialized dyslexia institute (sample 2) compared to parents from school children with poor reading skills (sample 1). Results nonetheless showed no difference in at-risk indications between the samples with $30 \%$ at-risk in sample 1 and $39 \%$ at-risk in sample $2, \chi^{2}=1.88, p=.17$. Taken together, these results seem to support the validity of parental report of family risk of reading failure.

The PA-RAN subtype with increased familial risk for dyslexia also shows significantly higher IQ than the other subtypes influenced more by environmental risk factors. Specifically, the IQ scores of type 4 are approximately 1 SD higher than for the PA-LS type 3 poor readers and up to 1.4 SD higher than for the general type 2 poor readers. Finding two types of aetiologies, one predominantly influenced by familial risk and characterized by high IQs discrepant to their poor reading profile (i.e., type 4) and one primarily environmentally influenced with lower to poor intellectual capabilities (type 2 and 3 ), is well in 
line with previous recent genetic behavioural results (Castles et al., 1999; Friend, DeFries, \& Olson, 2008; Knopik et al., 2002; Rack \& Olson, 1993; Wadsworth et al., 2010; Wadsworth et al., 2000) and neuroimaging results (Shaywitz \& Shaywitz, 2005). Finding support for the existence of these two possible aetiologies for childhood reading could still mean that the same familial risk factors are operative in both aetiologies, but that the PA-RAN specific type with high IQs is a more homogeneous environmental subtype and this in turn results in this profile showing a higher impact of familial risk for dyslexia (also see Wadsworth et al., 2010; Wadsworth et al., 2000 for similar results). Thus, these findings do not suggest that different familial risk factors are influencing different types of reading disability as a function of $I Q$, but the proportion of variance accounted for by a familial predisposition may vary since a differential environmental impact might be at play. It is not only known that there is a significantly higher heritability of reading deficits in children with higher IQs (Wadsworth et al., 2000), it is also shown that heritability of dyslexia increases linearly with high levels of parental education (Friend et al., 2008). Consistently, our PA-RAN children at increased familial risk for dyslexia, characterized by higher IQs, also showed a more favourable socio-economic background (based on parental education and income). Although it is still unknown which proximal environmental factors mediate such a geneenvironment interaction (Peterson \& Pennington, 2012), possible candidates include language and (pre)literacy environments provided to children by their parents at home. The PA-RAN children at increased risk for dyslexia who come from families with higher parental education might thus enjoy a more supportive home literacy environment. A recent genetic study even suggested that children with increased genetic predispositions evoke more cognitively stimulating experiences from their environments (Tucker-Drob \& Harden, 2012). Interestingly, previous studies also reveal that, in addition to PA, difficulties with RAN (the deficit specific to type 4) are found to be more related to genetic risk (e.g., Gayan \& Olson, 2001; Petrill, Deater-Deckard, Thompson, DeThorne, \& Schatschneider, 2006; Samuelsson et al., 2005), while letter name and sound knowledge problems (the deficit specific to type 3 ) is mostly influenced by shared home/preschool environmental factors and only to a small degree by genetic influences (e.g., Byrne et al., 2006; Byrne et al., 2013; Samuelsson et al., 2005). It is thus conceivable that a more enriching home environment support might have ameliorated presence of LS weakness in our PA-RAN subtype, but not in our PA-LS poor readers from less favourable SES backgrounds. Reading and reading-related deficits due to a substantial larger genetic influence may in turn require more intensive remediation efforts though (Wadsworth et al., 2010).

Taken together, the present clustering approach was able to confirm the existence of distinct and homogeneous subtypes of poor reading substantially characterized by either familial risk factors or 
environmental risk factors, purely based on cognitive vulnerability markers commonly used for the diagnostics of dyslexia. And although IQ has fallen out of favour for sole diagnosis of dyslexia based on discrepancy or cut-off criteria (Stanovich \& Siegel, 1994; Stuebing et al., 2002), the way IQ forms distinct patterns with these cognitive vulnerability markers as well as family history of dyslexia, seems informative and supports the idea that IQ can provide more information on the cause of the reading deficit experienced by the child (Friend et al., 2008; Wadsworth et al., 2010; Wadsworth et al., 2000) as well as have a valuable attribution for exclusion purposes in diagnostic processes (Coltheart \& Jackson, 1998; Rack \& Olson, 1993). It may be noted that these clustering results are supported by the use of a data-driven, bottom-up approach, making no a priori assumptions on either the number or theoretical nature of subtypes, beyond the included clustering variables. A possible limitation might be that these included cognitive markers are based on one cognitive task only. A recommended improvement would be to include more than on measure per marker to increase stability of each cognitive, clustering construct. Moreover, we do not exclude the existence of additional, emerging types if more than the currently employed classification measures were included. Finally, given that the relative severity and impact of cognitive deficits are commonly found to vary as a function of reading expertise and age (Landerl \& Wimmer, 2008; Vaessen \& Blomert, 2010), we recommend utilizing periodic re-evaluation to determine whether the obtained latent deficit profiles continue to be appropriate.

The present classification study provides evidence for distinct and coherent cognitive deficit patterns of poor reading. Despite a shared deficit in phonological awareness, a variable expression of other underlying cognitive deficits was found across several reading-related vulnerability markers and general cognitive domains, which differentiated between a poor reader type with a predominantly familial predisposition and two other poor readers, characterized mostly by poor environmental factors. While letter-speech sound difficulties where characteristic in one of the environmentally influenced profiles (the other being the general poor reader type), a rapid automatized naming deficit was specific for the poor reader type at elevated familial risk for dyslexia. The present results indicate that it is useful to include information on familial and environmental risk when identifying subtypes of poor reading and subsequently define tailored intervention efforts. Moreover, it might also be a promising way forward for genetic testing studies to not just look at the reading impaired group as a whole as is usually done, but look at the heterogeneous group of poor readers with finer clustering resolution, focusing in on underlying cognitive subtypes. From a methodological point of view, we could demonstrate that using large sample size and the external validation of the different subtypes in combination with a multi-start re-sampling method ensured the optimal number and stability of clusters representing the present data. 


\section{ACKNOWLEDGMENTS}

We thank the schools, children, parents and assistants for their enthusiastic participation and contribution. We are grateful to the Regional Institute of Dyslexia (RID) for their assistance in participant recruitment. The authors also wish to thank dr. Arie van der Lugt and dr. Stylianos Asteriadis and the four reviewers for their useful comments on the manuscript. This research was partly supported by a grant (608/001/2005) of the Dutch National Board of Health Care Insurance to our co-author Prof. dr. Leo Blomert, who passed away on November 25, 2012. 


\section{REFERENCES}

Adams, M. J. (1990). Beginning to Read: Thinking and Learning about Print. Cambridge, Massachusetts: The MIT Press.

Araújo, S., Faísca, L., Bramão, I., Inácio, F., Petersson, K. M., \& Reis, A. (2011). Object naming in dyslexic children: More than a phonological deficit. The Journal of general psychology, 138(3), 215-228. doi:10.1002/dys.433.

Badian, N. A. (1997). Dyslexia and the double deficit hypothesis. Annals of Dyslexia, 47, 69-87. doi:10.1007/s11881-997-0021-y.

Bartelet, D., Ansari, D., Vaessen, A., \& Blomert, L. (2014). Cognitive subtypes of mathematics learning difficulties in primary education. Research in developmental disabilities, 35(3), 657-670. doi:10.1016/j.ridd.2013.12.010

Beneventi, H., Tønnessen, F. E., Ersland, L., \& Hugdahl, K. (2010). Working Memory Deficit in Dyslexia: Behavioral and fMRI Evidence. International Journal of Neuroscience, 120(1), 51-59. doi:10.3109/00207450903275129.

Berninger, V. W., Abbott, R. D., Billingsley, F., \& Nagy, W. (2001). Processes underlying timing and fluency: efficiency, automaticity, coordination and morphological awareness. In M. Wolf (Ed.), Dyslexia, fluency and the brain (pp. 383-414). Timonium, MD: York Press.

Berninger, V. W., Abbott, R. D., Thomson, J., Wagner, R., Swanson, H. L., Wijsman, E. M., \& Raskind, W. (2006). Modeling Phonological Core Deficits Within a Working Memory Architecture in Children and Adults With Developmental Dyslexia. Scientific Studies of Reading, 10(2), 165-198. doi:10.1207/s1532799xssr1002_3.

Bishop, D. V. M. (2006). Developmental cognitive genetics: How psychology can inform genetics and vice versa. The Quarterly Journal of Experimental Psychology, 59(7), 1153-1168. doi:10.1080/17470210500489372.

Bishop, D. V. M. (2008). Specific language impairment, dyslexia, and autism: Using genetics to unravel their relationship. Understanding developmental language disorders: From theory to practice, 67-78.

Blau, V., Reitler, J., Van Atteveldt, N., Gerretsen, P., Seitz, J., Goebel, R., \& Blomert, L. (2010). Deviant processing of letters and speech sounds as proximate cause of reading failure: an fMRI study of dyslexic children. Brain, 133(3), 868-879. doi:10.1093/brain/awp308. 
Blau, V., Van Atteveldt, N., Ekkebus, M., Goebel, R., \& Blomert, L. (2009). Reduced neural integration of letters and speech sounds links phonological and reading deficits in adult dyslexia. Current Biology, 19(6), 503-508. doi:10.1016/j.cub.2009.01.065.

Bleichrodt, N., Drenth, P. D., Zaal, J. N., \& Resing, W. C. M. (1988). RAKIT: Revisie Amsterdamse Kinder Intelligentie Test [revision Amsterdam Children Intelligence Test]. Lisse: Swets \& Zeitlinger.

Blomert, L. (2005). Dyslexie in Nederland - theorie, praktijk en beleid [Dyslexia in The Netherlands theory, practice and policy]. Amsterdam: Nieuwezijds Publishers.

Blomert, L. (2011). The neural signature of orthographic-phonological binding in successful and failing reading development. Neuroimage, 57(3), 695-703. doi:10.1016/j.neuroimage.2010.11.003.

Blomert, L., \& Vaessen, A. (2009). 3DM: Cognitieve analyse van lezen en spellen [3DM: Cognitive analysis of reading and spelling]. Amsterdam: Boom test publishers BV.

Blomert, L., \& Willems, G. (2010). Is there a causal link from a phonological awareness deficit to reading failure in children at familial risk for dyslexia? Dyslexia: An International Journal of Research and Practice, 16, 300-317. doi:10.1002/dys.405.

Boets, B., Wouters, J., Van Wieringen, A., \& Ghesquiere, P. (2007). Auditory processing, speech perception and phonological ability in pre-school children at high-risk for dyslexia: A longitudinal study of the auditory temporal processing theory. Neuropsychologia, 45(8), 1608-1620. doi:10.1016/j.neuropsychologia.2007.01.009.

Bowers, P. G., \& Ishaik, G. (2003). RAN's contribution to understanding reading disabilities. In S. Graham, H. Swanson, \& K. R. Lee Harris (Eds.), Handbook of learning disabilities (pp. 140-157). New York, US: Guilford Press.

Bowers, P. G., \& Wolf, M. (1993). Theoretical links among naming speed, precise timing mechanisms and orthographic skill in dyslexia. Reading and Writing, 5(1), 69-85. doi:10.1007/BF01026919.

Brus, B. T., \& Voeten, M. J. M. (1973). Een-minuuttest, vorm A en B. Nijmegen: Berkhout.

Buly, M. R., \& Valencia, S. W. (2002). Below the Bar: Profiles of Students Who Fail State Reading Assessments. Educational Evaluation and Policy Analysis, 24(3), 219-239. doi:10.2307/3594166.

Byrne, B., Olson, R. K., Samuelsson, S., Wadsworth, S. J., Corley, R., DeFries, J. C., \& Willcutt, E. (2006). Genetic and environmental influences on early literacy. Journal of Research in Reading, 29(1), 3349. doi:10.1111/j.1467-9817.2006.00291.x.

Byrne, B., Wadsworth, S. J., Boehme, K., Talk, A. C., Coventry, W. L., Olson, R. K., . . . Corley, R. (2013). Multivariate genetic analysis of learning and early reading development. Scientific Studies of Reading, 17(3), 224-242. doi:10.1080/10888438.2011.654298. 
Caravolas, M., Lervåg, A., Defior, S., Málková, G. S., \& Hulme, C. (2013). Different patterns, but equivalent predictors, of growth in reading in consistent and inconsistent orthographies. Psychological Science, 0956797612473122. doi:10.1177/0956797612473122.

Caravolas, M., Lervag, A., Mousikou, P., Efrim, C., Litavsky, M., Onochie-Quintanilla, E., . . Hulme, C. (2012). Common patterns of prediction of literacy development in different alphabetic orthographies. Psychol Sci, 23(6), 678-686. doi:0956797611434536.

Carroll, J. M., Mundy, I. R., \& Cunningham, A. J. (2014). The roles of family history of dyslexia, language, speech production and phonological processing in predicting literacy progress. Developmental Science, 17(5), 727-742. doi:10.1111/desc.12153.

Carroll, J. M., \& Snowling, M. J. (2004). Language and phonological skills in children at high risk of reading difficulties. Journal of Child Psychology and Psychiatry, 45(3), 631-640. doi:10.1111/j.14697610.2004.00252.x.

Castles, A., \& Coltheart, M. (2004). Is there a causal link from phonological awareness to success in learning to read? Cognition, 91(1), 77-111. doi:10.1016/S0010-0277(03)00164-1.

Castles, A., Datta, H., Gayan, J., \& Olson, R. K. (1999). Varieties of Developmental Reading Disorder: Genetic and Environmental Influences. Journal of Experimental Child Psychology, 72(2), 73-94. doi:10.1006/jecp.1998.2482.

Castles, A., Wilson, K., \& Coltheart, M. (2011). Early orthographic influences on phonemic awareness tasks: Evidence from a preschool training study. Journal of Experimental Child Psychology, 108(1), 203-210. doi:10.1016/j.jecp.2010.07.006.

Clarke, P., Hulme, C., \& Snowling, M. J. (2005). Individual differences in RAN and reading: A response timing analysis. Journal of Research in Reading, 28(2), 73-86. doi:10.1111/j.14679817.2005.00255.x.

Coltheart, M., \& Jackson, N. E. (1998). Defining Dyslexia. Child and Adolescent Mental Health, 3(1), 12-16. doi:10.1111/1475-3588.00202.

Compton, D. L., Defries, J. C., \& Olson, R. K. (2001). Are RAN- and phonological awareness-deficits additive in children with reading disabilities? Dyslexia, 7(3), 125-149. doi:10.1002/dys.198.

Daal, V., \& Leij, A. (1999). Developmental dyslexia: Related to specific or general deficits? Annals of Dyslexia, 49(1), 71-104. doi:10.1007/s11881-999-0020-2.

Davis, C. J., Gayán, J., Knopik, V. S., Smith, S. D., Cardon, L. R., Pennington, B. F., . . DeFries, J. C. (2001). Etiology of Reading Difficulties and Rapid Naming: The Colorado Twin Study of Reading Disability. Behavior Genetics, 31(6), 625-635. doi:10.1023/a:1013305730430. 
de Bruyn, E., van der Steenen, G., \& van Haasen, P. (1986). Wechsler Intelligence Scale for ChildrenRevided (WISC-R), Nederlandstalige uitgave en verantwoording. Lisse: Swets \& Zeitlinger.

De Jong, P. F. (1998). Working Memory Deficits of Reading Disabled Children. Journal of Experimental Child Psychology, 70(2), 75-96. doi:10.1006/jecp.1998.2451.

de Jong, P. F., \& van der Leij, A. (1999). Specific contributions of phonological abilities to early reading acquisition: results from a Dutch latent variable longitudinal study. Journal of Educational Psychology, 91(3), 450-476. doi:10.1037/0022-0663.91.3.450.

Elbro, C., Borstrøm, I., \& Petersen, D. K. (1998). Predicting dyslexia from kindergarten. The importance of distinctness of phonological representations of lexical items. Reading Research Quarterly, 33(1), 36-60. doi:10.1598/RRQ.33.1.3.

Felton, R. H., \& Brown, I. S. (1990). Phonological processes as predictors of specific reading skills in children at risk for reading failure. Reading and Writing: An Interdisciplinary Journal, 2(1), 39-59. doi:10.1007/BF00383373.

Field, A. (2005). Discovering statistics using SPSS. Sussex: Sage Publications.

Fletcher, J. M., Shaywitz, S. E., Shankweiler, D. P., Katz, L., Liberman, I. Y., Stuebing, K. K., . . Shaywitz, B. A. (1994). Cognitive Profiles of Reading Disability: Comparisons of Discrepancy and Low Achievement Definitions. Journal of Educational Psychology, 86(1), 6-23. doi:10.1037/00220663.86.1.6.

Friend, A., DeFries, J. C., \& Olson, R. K. (2008). Parental education moderates genetic influences on reading disability. Psychological Science, 19(11), 1124-1130. doi:10.1111/j.1467-9280.2008.022.

Froyen, D., Bonte, M., Van Atteveldt, N., \& Blomert, L. (2009). The long road to automation: neurocognitive development of letter-speech sound processing. Journal of Cognitive Neuroscience, 21, 567-580. doi:10.1162/jocn.2009.21061.

Froyen, D., Van Atteveldt, N., Bonte, M., \& Blomert, L. (2008). Cross-modal enhancement of the MMN to speech-sounds indicates early and automatic integration of letters and speech-sounds. Neuroscience Letters, 430(1), 23-28. doi:10.1016/j.neulet.2007.10.014.

Froyen, D., Willems, G., \& Blomert, L. (2011). Evidence for a specific cross-modal association deficit in dyslexia: an electrophysiological study of letter-speech sound processing. Developmental Science, 14(4), 635-648. doi:10.1111/j.1467-7687.2010.01007.x.

Gayan, J., \& Olson, R. K. (2001). Genetic and Environmental Influences on Orthographic and Phonological Skills in Children With Reading Disabilities. Developmental Neuropsychology, 20(2), 483-507. doi:10.1207/s15326942dn2002_3. 
Geelhoed, J., \& Reitsma, P. (1999). Pi-dictee. Lisse: Swets \& Zeitlinger.

Georgiou, G. K., Das, J. P., \& Hayward, D. V. (2008). Comparing the contribution of two tests of working memory to reading in relation to phonological awareness and rapid naming speed. Journal of Research in Reading, 31(3), 302-318. doi:10.1111/j.1467-9817.2008.00373.x.

Goswami, U., \& Bryant, P. (1990). Phonological skills and learning to read. Hove, UK: Lawrence Erlbaum.

Gough, P. B., \& Tunmer, W. E. (1986). Decoding, reading, and reading disability. Remedial and Special Education, 7, 6-10. doi:10.1177/074193258600700104.

Grigorenko, E. L. (2001). Developmental Dyslexia: An Update on Genes, Brains, and Environments. Journal of Child Psychology and Psychiatry, 42(1), 91-125. doi:10.1111/1469-7610.00704.

Heim, S., \& Grande, M. (2012). Fingerprints of developmental dyslexia. Trends in Neuroscience and Education, 1(1), 10-14. doi: http://dx.doi.org/10.1016/j.tine.2012.09.001.

Heim, S., Tschierse, J., Amunts, K., Wilms, M., Vossel, S., Willmes, K., . . Huber, W. (2008). Cognitive subtypes of dyslexia. Acta Neurobiologiae Experimentalis, 68(1), 73-82.

Israel, G. D., Beaulieu, L. J., \& Hartless, G. (2001). The Influence of Family and Community Social Capital on Educational Achievement. Rural Sociology, 66(1), 43-68. doi:10.1111/j.15490831.2001.tb00054.x.

Jeffries, S., \& Everatt, J. (2004). Working memory: its role in dyslexia and other specific learning difficulties. Dyslexia, 10(3), 196-214. doi:10.1002/dys.278.

Jiménez, J. E., Siegel, L., O’Shanahan, I., \& Ford, L. (2009). The relative roles of IQ and cognitive processes in reading disability. Educational Psychology, 29(1), 27-43. doi:10.1080/01443410802459226.

Jolliffe, I. T. (1986). Principle component analysis. New York: Springer-Verlag.

Kibby, M. Y., Marks, W., Morgan, S., \& Long, C. J. (2004). Specific Impairment in Developmental Reading Disabilities: A Working Memory Approach. Journal of Learning Disabilities, 37(4), 349-363. doi:10.1177/00222194040370040601.

King, W. M., Giess, S. A., \& Lombardino, L. J. (2007). Subtyping of children with developmental dyslexia via bootstrap aggregated clustering and the gap statistic: comparison with the double-deficit hypothesis. International Journal of Language \& Communication Disorders, 42(1), 77-95. doi:10.1080/13682820600806680.

Knol, F. (2012). Statusontwikkeling van wijken in Nederland 1998-2010. Publication by Sociaal Cultureel Planbureau. 
Knopik, V., Smith, S., Cardon, L., Pennington, B. F., Gayan, J., Olson, R. K., \& DeFries, J. C. (2002). Differential Genetic Etiology of Reading Component Processes as a Function of IQ. Behavior Genetics, 32(3), 181-198. doi:10.1023/A:1016069012111.

Landerl, K., \& Wimmer, H. (2008). Development of word reading fluency and spelling in a consistent orthography: an 8-year follow-up. Journal of Educational Psychology, 100, 150-161. doi:10.1037/0022-0663.100.1.150.

Lyon, G. R. (1989). IQ is irrelevant to the definition of learning disabilities: a position in search of logic and data. Journal of Learning Disabilities, 22(8), 504.

Lyon, G. R. (1995). Toward a definition of dyslexia. Annals of Dyslexia, 45(1), 1-27. doi:10.1007/BF02648210.

Lyon, G. R., Shaywitz, S. E., \& Shaywitz, B. A. (2003). A definition of dyslexia. Annals of Dyslexia, 53, 1-14. doi:10.1007/s11881-003-0001-9.

MacCallum, R. C., Widaman, K. F., Zhang, S., \& Hong, S. (1999). Sample size in factor analysis. Psychological methods, 4(1), 84.

MATLAB. (2001). Version 6. The Mathworks. Inc., Natick, MA, USA.

McBride-Chang, C., \& Manis, F. R. (1996). Structural invariance in the associations of naming speed, phonological awareness, and verbal reasoning in good and poor readers: A test of the double deficit hypothesis. Reading and Writing: An Interdisciplinary Journal, 8(4), 323-339. doi:10.1007/BF00395112.

McCallum, R. S., Bell, S. M., Wood, M. S., Below, J. L., Choate, S. M., \& McCane, S. J. (2006). What Is the Role of Working Memory in Reading Relative to the Big Three Processing Variables (Orthography, Phonology, and Rapid Naming)? Journal of Psychoeducational Assessment, 24(3), 243-259. doi:10.1177/0734282906287938.

Menghini, D., Finzi, A., Benassi, M., Bolzani, R., Facoetti, A., Giovagnoli, S., . . Vicari, S. (2010). Different underlying neurocognitive deficits in developmental dyslexia: a comparative study. Neuropsychologia, 48(4), 863-872.

Moll, K., Loff, A., \& Snowling, M. J. (2013). Cognitive endophenotypes of dyslexia. Scientific Studies of Reading, 17(6), 385-397. doi:10.1080/10888438.2012.736439.

Morais, J., Cary, L., Alegria, J., \& Bertelson, P. (1979). Does awareness of speech as a sequence of phones arise spontaneously? Cognition, 7, 323-331. doi:10.1016/0010-0277(79)90020-9. 
Morris, R. D., Stuebing, K. K., Fletcher, J. M., Shaywitz, S. E., Lyon, G. R., Shankweiler, D. P., . . Shaywitz, B. A. (1998). Subtypes of reading disability: Variability around a phonological core. Journal of Educational Psychology, 90(3), 347-373. doi:10.1037/0022-0663.90.3.347.

Pacheco, A., Reis, A., Araújo, S., Inácio, F., Petersson, K. M., \& Faísca, L. (2014). Dyslexia heterogeneity: cognitive profiling of Portuguese children with dyslexia. Reading and Writing, 27(9), 1529-1545. doi:10.1007/s11145-014-9504-5.

Pennington, B. F., Cardoso-Martins, C., Green, P. A., \& Lefly, D. L. (2001). Comparing the phonological and double deficit hypotheses for developmental dyslexia. Reading and Writing: An Interdisciplinary Journal, 14, 707-755. doi:10.1023/A:1012239018038.

Pennington, B. F., \& Lefly, D. L. (2001). Early reading development in children at family risk for dyslexia. Child development, 72(3), 816-833. doi:10.1111/1467-8624.00317.

Pennington, B. F., \& Olson, R. K. (2008). Genetics of Dyslexia. The Science of Reading: A Handbook, 453472. doi:10.1002/9780470757642.ch24.

Pennington, B. F., Santerre-Lemmon, L., Rosenberg, J., MacDonald, B., Boada, R., Friend, A., . . Willcutt, E. G. (2012). Individual prediction of dyslexia by single versus multiple deficit models. Journal of Abnormal Psychology, 121(1), 212.

Perfetti, C. A., Beck, I., Bell, L. C., \& Hughes, C. (1987). Phonemic knowledge and learning to read are reciprocal: a longitudinal study of first grade children. Merill-Palmer Quarterly, 33(3), 283-319.

Peterson, R. L., \& Pennington, B. F. (2012). Developmental dyslexia. Lancet, 379(9830), $1997-2007$. doi:S0140-6736(12)60198-6.

Petrill, S. A., Deater-Deckard, K., Thompson, L. A., DeThorne, L. S., \& Schatschneider, C. (2006). Genetic and Environmental Effects of Serial Naming and Phonological Awareness on Early Reading Outcomes. Journal of Educational Psychology, 98(1), 112-121. doi:10.1037/0022-0663.98.1.112.

Pierce, M. E., Katzir, T., Wolf, M., \& Noam, G. G. (2007). Clusters of second and third grade dysfluent urban readers. Reading and Writing, 20(9), 885-907. doi:10.1007/s11145-007-9058-x.

Plomin, R., Reiss, D., Hetherington, E. M., \& Howe, G. W. (1994). Nature and nurture: genetic contributions to measures of the family environment. Developmental Psychology, 30(1), 32. doi:10.1037/0012-1649.30.1.32.

Puolakanaho, A., Ahonen, T., Aro, M., Eklund, K., Leppänen, P., Poikkeus, A., . . . Lyytinen, H. (2008). Developmental Links of Very Early Phonological and Language Skills to Second Grade Reading Outcomes: Strong to Accuracy but Only Minor to Fluency. Journal of Learning Disabilities, 41(4), 353-370. doi:10.1177/0022219407311747. 
Rack, J. P., \& Olson, R. K. (1993). Phonological Deficits, IQ, and Individual Differences in Reading Disability: Genetic and Environmental Influences. Developmental Review, 13(3), 269-278. doi:10.1006/drev.1993.1013.

Ramus, F. (2003). Developmental dyslexia: specific phonolical deficit or general sensorimotor dysfunction? Current Opinion in Neurobiology, 13, 212-218. doi:10.1016/S0959-4388(03)00035.

Ramus, F., Rosen, S., Dakin, S. C., Day, B. L., Castellote, J. M., White, S., \& Frith, U. (2003). Theories of developmental dyslexia: Insights from a multiple case study of dyslexic adults. Brain: A Journal of Neurology, 126(4), 841-865. doi:10.1093/brain/awg076.

Rourke, B. P. (1985). Neuropsychology of learning disabilities: Essentials of subtype analysis.

Rutter, M., \& Silberg, J. (2002). Gene-environment interplay in relation to emotional and behavioral disturbance. Annual review of psychology, 53(1), 463-490. doi:10.1146/annurev.psych.53.10090.

Rutter, M., \& Yule, W. (1975). The concept of specific reading retardation. Journal of Child Psychology and Psychiatry, 16, 181-197. doi:10.1111/j.1469-7610.1975.tb01269.x.

Samuelsson, S., Byrne, B., Quain, P., Wadsworth, S., Corley, R., DeFries, J. C., . . . Olson, R. (2005). Environmental and genetic influences on prereading skills in Australia, Scandinavia, and the United States. Journal of Educational Psychology, 97(4), 705-722. doi:10.1037/00220663.97.4.705.

Sarstedt, M., \& Mooi, E. (2014). A concise guide to market research: the process, data, and methods using IBM SPSS statistics: Springer.

Satz, P., \& Morris, R. (1981). Learning disability subtypes: A review. In F. J. Pirozzolo \& M. C. Wittrock (Eds.), Neuropsychological and cogntivie processes in reading (pp. 109-141). New York: Academic Press.

Scarborough, H. S. (1990). Very early language deficits in dyslexic children. Child development, 61, 17281743. doi:10.2307/1130834.

Scholte, E. M., \& van der Ploeg, J. D. (2005). Handleiding ADHD-vragenlijst (AVL). Houten: Bohn Stafleu Van Loghum.

Seymour, P., Aro, M., \& Erskine, J. (2003). Foundation literacy acquisition in European orthographies. British Journal of Psychology, 94(2), 143-174. doi:10.1348/000712603321661859.

Shaywitz, S. E., \& Shaywitz, B. A. (2005). Dyslexia (Specific Reading Disability). Biological Psychiatry, 57(11), 1301-1309. doi:10.1016/j.biopsych.2005.01.043. 
Simos, P. G., Rezaie, R., Papanicolaou, A. C., \& Fletcher, J. M. (2013). Does IQ affect the functional brain network involved in pseudoword reading in students with reading disability? $A$ magnetoencephalography study. Frontiers in Human Neuroscience, 7, 932. doi:10.3389/fnhum.

Snowling, M. J. (2000). Dyslexia. Oxford: Blackwell Publishers.

Snowling, M. J. (2008). Specific disorders and broader phenotypes: the case of dyslexia. The Quarterly Journal of Experimental Psychology, 61(1), 142-156. doi:10.1080/17470210701508830.

Snowling, M. J. (2012). Changing concepts of dyslexia: nature, treatment and comorbidity. Journal of Child Psychology and Psychiatry, 53(9), e1-e3. doi:10.1111/j.1469-7610.2009.02197.x.

Snowling, M. J., Gallagher, A., \& Frith, U. (2003). Family risk of dyslexia is continuous: individual differences in the precursors of reading skill. Child development, 74(2), 358-373. doi:10.1111/1467-8624.7402003.

Snowling, M. J., \& Hulme, C. (2012). Annual Research Review: The nature and classification of reading disorders-a commentary on proposals for DSM-5. Journal of Child Psychology and Psychiatry, 53(5), 593-607. doi:10.1111/j.1469-7610.2011.02495.x.

Snowling, M. J., \& Stackhouse, J. (2013). Dyslexia, speech and language: a practitioner's handbook: John Wiley \& Sons.

Stanovich, K. E. (1988). Explaining the differences between dyslexic and the garden-variety poor reader. The phonological-core varibale-difference model. Journal of Learning Disabilities, 21, 590-612. doi:10.1177/002221948802101003.

Stanovich, K. E. (1991). Discrepancy definitions of reading disability: has intelligence led us astray? Reading Research Quarterly, 26, 7-29.

Stanovich, K. E., \& Siegel, L. S. (1994). Phenotypic performance profile of children with reading disabilities: A regression-based test of the phonological-core-variable-difference model. Journal of Educational Psychology, 86, 24-53. doi:10.1037//0022-0663.86.1.24.

Steinley, D. (2006). K-means clustering: A half-century synthesis. British Journal of Mathematical and Statistical Psychology, 59(1), 1-34. doi:10.1348/000711005×48266.

Stuebing, K. K., Barth, A. E., Molfese, P. J., Weiss, B., \& Fletcher, J. M. (2009). IQ Is Not Strongly Related to Response to Reading Instruction: A Meta-Analytic Interpretation. Except Child, 76(1), 31-51.

Stuebing, K. K., Fletcher, J. M., LeDoux, J. M., Lyon, G. R., Shaywitz, S. E., \& Shaywitz, B. A. (2002). Validity of IQ-Discrepancy Classifications of Reading Disabilities: A Meta-Analysis. American Educational Research Journal, 39(2), 469-518. doi:10.3102/00028312039002469. 
Sunseth, K., \& Bowers, P. G. (2002). Rapid naming and phonemic awareness: Contributions to reading, spelling, and orthographic knowledge. Scientific Studies of Reading, 6, 401-429. doi:10.1207/S1532799XSSR0604_05.

Tanaka, H., Black, J. M., Hulme, C., Stanley, L. M., Kesler, S. R., Whitfield-Gabrieli, S., . . Hoeft, F. (2011). The brain basis of the phonological deficit in dyslexia is independent of IQ. Psychol Sci, 22(11), 1442-1451. doi:0956797611419521.

Thompson, P. A., Hulme, C., Nash, H. M., Gooch, D., Hayiou-Thomas, E., \& Snowling, M. J. (2015). Developmental dyslexia: predicting individual risk. J Child Psychol Psychiatry, 56(9), 976-987. doi:10.1111/jcpp.12412.

Tijms, J. (2004). Verbal memory and phonological processing in dyslexia. Journal of Research in Reading, 27, 300-310. doi:10.1111/j.1467-9817.2004.00233.x.

Torgesen, J. K., Wagner, R. K., \& Rashotte, C. A. (1994). Longitudinal studies of phonological processing and reading. Journal of Learning Disabilities, 27, 276-291. doi:10.1177/002221949402700503

Tucker-Drob, E. M., \& Harden, K. P. (2012). Early childhood cognitive development and parental cognitive stimulation: evidence for reciprocal gene-environment transactions. Dev Sci, 15(2), 250-259. doi:10.1111/j.1467-7687.2011.01121.x.

Vaessen, A., \& Blomert, L. (2010). Long term cognitive dynamics of fluent reading development. Journal of Experimental Child Psychology, 105, 213-231. doi:10.1016/j.jecp.2009.11.005.

Vaessen, A., Gerretsen, P., \& Blomert, L. (2009). Naming problems do not reflect a second, independent core deficit in dyslexia: 'Double deficits' explored. Journal of Experimental Child Psychology, 103, 202-221. doi:10.1016/j.jecp.2008.12.004.

van Bergen, E., de Jong, P. F., Maassen, B., \& van der Leij, A. (2014). The Effect of Parents' Literacy Skills and Children's Preliteracy Skills on the Risk of Dyslexia. Journal of Abnormal Child Psychology, 42(7), 1187-1200. doi:10.1007/s10802-014-9858-9.

van Bergen, E., van der Leij, A., \& de Jong, P. F. (2014). The intergenerational multiple deficit model and the case of dyslexia. Frontiers in Human Neuroscience, 8, 346. doi:10.3389/fnhum.2014.00346.

Van Bon, W. H. J. (1986). Raven's coloured progressive matrices. Nederlandse normen en enige andere uitkomsten van onderzoek. Lisse, NL: Swets \& Zeitlinger.

van den Bos, K. P., Lutje Spelberg, H. C., Scheepstra, A. J. M., \& de Vries, J. R. (1994). Handleiding van de Klepel. Nijmegen: Berkhout. 
Vellutino, F. R., Fletcher, J. M., Snowling, M. J., \& Scanlon, D. M. (2004). Specific reading disability (dyslexia): what have we learned in the past four decades? Journal of Child Psychology and Psychiatry, 45(1), 2-40. doi:10.1046/j.0021-9630.2003.00305.x.

Vukovic, R. K., \& Siegel, L. S. (2006). The double-deficit hypothesis: A comprehensive analysis of the evidence. Journal of Learning Disabilities, 39(1), 25-47. doi:10.1177/00222194060390010401.

Wadsworth, S. J., Olson, R. K., \& DeFries, J. C. (2010). Differential genetic etiology of reading difficulties as a function of IQ: an update. Behavior Genetics, 40(6), 751-758. doi:10.1007/s10519-010-9349.

Wadsworth, S. J., Olson, R. K., Pennington, B. F., \& DeFries, J. C. (2000). Differential Genetic Etiology of Reading Disability as a Function of IQ. Journal of Learning Disabilities, 33(2), 192-199. doi:10.1177/002221940003300207.

Wagner, R. K., \& Torgesen, J. K. (1987). The nature of phonological processing and its causal role in the acquisition of reading skills. Psychological bulletin, 101, 192-212. doi:10.1037/00332909.101.2.192.

Williams, J., \& O'Donovan, M. C. (2006). The genetics of developmental dyslexia. European Journal of Human Genetics, 14(6), 681-689. doi:10.1038/sj.ejhg.5201575.

Wolf, M. (1997). A provisional, integrative account of phonological and naming-speed deficits in dyslexia: Implications for diagnosis and intervention. In B. A. Blachman \& A. Benita (Eds.), Foundations of reading acquisition and dyslexia: Implications for early intervention (pp. 67-92). Mahwah, NY: Lawrence Erlbaum Associates.

Wolf, M., \& Bowers, P. G. (1999). The double-deficit hypothesis for the developmental dyslexias. Journal of Educational Psychology, 91(3), 415-438. doi:10.1037/0022-0663.91.3.415.

Zaric, G., Fraga Gonzalez, G., Tijms, J., van der Molen, M. W., Blomert, L., \& Bonte, M. (2015). Crossmodal deficit in dyslexic children: practice affects the neural timing of letter-speech sound integration. Front Hum Neurosci, 9, 369. doi:10.3389/fnhum.2015.00369.

Zoubrinetzky, R., Bielle, F., \& Valdois, S. (2014). New Insights on Developmental Dyslexia Subtypes: Heterogeneity of Mixed Reading Profiles. PLOS ONE, 9(6), e99337. doi:10.1371/journal.pone.009. 
CHAPTER 5

SUMMARY 
In this fifth chapter we will summarize the findings of the research presented in chapter 2, 3, and 4 in order to evaluate if and how well we could answer the research questions presented in the general introduction of the present thesis (chapter 1). Following this summary, chapter 6 will provide a general discussion and relevant conclusions of the research presented, debating the relevance of the introduced cognitive vulnerability markers of future reading failure in children with a family history of dyslexia.

The research in chapter 2 aimed to test the causality claim of the phonological deficit hypothesis of dyslexia by exploring the directionality of the relationship between kindergarten phonological awareness (PA) and grade 1 reading fluency in children with and without familial risk of dyslexia. The phonological deficit hypothesis proposes that difficulty with the representation, storage and/or retrieval of speech sounds, in other words a PA deficit, is the main deficit causing and preceding reading failure (Ramus, 2003; Snowling, 2000; Adams, 1990; Goswami \& Bryant, 1990; Vellutino et al., 2004). There is ample support for this hypothesis across reading researchers and sufficient empirical evidence indicating a reciprocal influence between reading and PA (Morais, Cary, Alegria, \& Bertelson, 1979; Perfetti et al., 1987). Nevertheless, clear evidence for the generally assumed PA-to-reading causality claim is surprisingly ever so elusive. Children at familial risk of dyslexia pose the best possible candidate for such an investigation before and after acquiring reading skills (i.e., kindergarten and grade 1 when formal reading instruction starts, respectively) since it is known that approximately $40 \%$ up to $65 \%$ of children with a least one first-degree dyslexic family member will develop a serious future reading deficit (Badian, McAnulty, Duffy, \& Als, 1990; Blomert, 2005; Byrne, Shankweiler, \& Hine, 2008; Pennington \& Lefly, 2001; Shaywitz, Shaywitz, Fletcher, \& Escobar, 1990; present thesis chapter 2). We addressed the following basic claims of the phonological awareness deficit:

\section{Is a phonological awareness (PA) deficit characteristic for a familial dyslexia risk?}

Difficulties with PA did not characterize our sample of kindergarten children at familial risk of dyslexia. More specific, only a small proportion (i.e., 14\%, 7 of 48) of these at-risk children showed a kindergarten PA deficit. Moreover, a kindergarten PA deficit was also not characteristic for at-risk children who turned out dyslexic (i.e., $19 \%, 4$ of 21 ). 


\section{Is a PA deficit causally linked to a reading deficit?}

Our results showed no support for the strong claim of the phonological deficit hypothesis that all children with a PA deficit prior to reading instruction turn out dyslexic. The large majority of the current at-risk sample who developed a reading deficit in grade 1 performed within the normal range on kindergarten phonological awareness (i.e., 81\%, 17 of 21). Of all at-risk children, only 8\% showed a PA deficit in kindergarten and subsequently developed a reading deficit in grade 1 (i.e., 4 out of 48). In our control group, only 4 children showed reading problems in grade 1 (i.e., 9\%, 4 of 44) and none of them showed a preceding kindergarten $P A$ deficit.

3. Is 'phonological insensitivity' linked to a reading deficit?

Difficulty with phonological processing skills other than phonological awareness (i.e., working memory and lexical processing) did not precede the development of subsequent reading deficits in the present atrisk and control cohort. More specific, only a small proportion of kindergarten at-risk children showed poor phonological lexical processing (i.e., 6\%, 3 of 48) or poor phonological working memory (i.e., 2\%, 1 of 48). In fact, the majority of at-risk children who developed a reading deficit revealed normal kindergarten lexical processing skills (i.e., 86\%, 18 of 21) and normal kindergarten working memory (i.e., 95\%, 20 of 21). Similar to at-risk, the proportion of control children with 'phonological insensitivity' in kindergarten also showing subsequent reading problems in grade 1 was low (lexical processing (i.e., 14\%, 1 of 7 for lexical processing and 20\%, 2 of 10 for working memory).

Taken together, these investigations of the direct claims of the phonological deficit hypothesis do not support that a PA deficit is a causal deficit preceding reading failure in dyslexia. Surprisingly, the phonological deficit hypothesis never proposed an explicit explanation how a PA deficit would in fact cause subsequent reading failure, although the hypothesis does suggest that a child need to acquire some level of PA before being able to link letters to speech sounds (Castles \& Coltheart, 2004). One often assumed, indirect claim is that poor phonological representations lead to 'unstable' or poor letterspeech sound associations (LS) and as such in turn cause reading deficits (Snowling, 2000; Vellutino, Fletcher, Snowling, \& Scanlon, 2004). The research in chapter 2 further investigated this claim: 
4. Is a PA deficit causing later reading deficits by causing unstable or otherwise poor letter-speech sound associations?

We found little to no evidence that a PA deficit underlies reading failure as a result of some interference in the relations between letters and their corresponding speech sounds since a PA deficit and a LS deficit rarely accompanied each other in the same kindergarten at-risk children (i.e., 4\%, 2 of 48) and never in control children. This was confirmed by a weak concurrent correlation in kindergarten between de PA and LS measures. Instead, PA deficits emerged only after the beginning of reading instruction in grade 1 and only in those at-risk and control children who developed a reading deficit by then (67\%, 14 of 21 at-risk children and both reading-disabled control children). The development of letter-speech sound associations was by then well on its way. This finding indicated that a PA deficit seems to develop as a consequence or at least in parallel with the reading deficit.

These results indicated that a PA deficit in the present kindergarten cohort is not causally linked to a LS deficit. In fact, a PA deficit only emerged in grade 1 , when children with a reading deficit already developed some level of letter-speech sound knowledge. Since successfully acquiring alphabetical skills is considered the essence of adequately learning to read (Ehri, 2005), the research in chapter 2 lastly explored whether it is a LS deficit, or difficulties with learning the associations between letters and their corresponding speech sounds, that is characteristic of children at increased familial risk of dyslexia. To investigate a potential LS learning deficit, we used a child-friendly, computerized training game aimed at teaching the links between letters and speech sounds to Dutch kindergartners (for an elaborate description of the original Finnish Graphogame method see Richardson \& Lyytinen, 2014, pp.; for an elaborate description of the present, Dutch adaptation of the training see Appendix 1, present thesis). If LS learning poses a problem in children at increased risk, we would expect a difference in training effects between these children and control children.

5. Can children at-risk for dyslexia at pre-reading age be differentiated from control subjects on the basis of their letter-speech sound learning ability on a training specifically designed to accurately teaching these associations?

While all of our control children improved their LS skills due to training, more than one third of at-risk children did not profit from training, showing LS learning problems in kindergarten. Interestingly, 
although this LS learning resistant at-risk group did not improve their ability to actively couple letters to their corresponding speech sounds, they did improve their letter knowledge, outperforming their untrained counterparts, similar to the trained control children. Also, both at-risk and control children reached ceiling on letter knowledge at a similar pace within half a year of reading instruction in grade 1. Our results finally demonstrated that this kindergarten LS learning deficit revealed in a core at-risk group was not related to a later reading deficit in grade 1. More specific, (a) only a quarter to a third of at-risk LS training resisters actually developed a reading deficit in grade 1 and (b) the proportion of at-risk LS training resistant children and at-risk LS training respondent children with a grade 1 reading deficit did not differ.

Chapter 3 further investigated if PA and LS in addition to the ability to rapidly name highly familial visual objects (RAN) were predictively correlated to subsequent reading in children at familial risk of dyslexia. These three important reading-related markers are known to be uniquely correlated to reading outcome in normally developing children (e.g., de Jong \& van der Leij, 1999; Kirby, Georgiou, Martinussen, \& Parrila, 2010; Landerl et al., 2013; Lyytinen et al., 2004a; Lyytinen et al., 2004b; Schatschneider, Fletcher, Francis, Carlson, \& Foorman, 2004; Schatschneider \& Torgesen, 2004). It is unclear however whether predicting reading success is the same as predicting high risk reading outcome. Identifying early risk markers predicatively correlated to at-risk reading outcome is vital given to possibility to promote more accurate and effective early diagnostic and intervention efforts. Moreover, since we explored the correlation between these cognitive markers and reading outcome both in kindergarten and grade 1 , we could explore possible changes in these predictive relationships as a consequence of acquired reading context. Finding a differential predictive pattern in the current sample would confirm the findings of chapter 2 that PA deficits emerged only after the start of reading acquisition.

6. Are kindergarten $P A, R A N$ and $L S$ knowledge important predictors of subsequent grade 1 and 2 reading ability in at-risk children learning to read in a relatively transparent orthography?

$L S$ knowledge was the only kindergarten reading-related marker correlated to grade 1 reading fluency in our at-risk sample. Kindergarten RAN was correlated to at-risk reading outcome in grade 2. PA in kindergarten was not correlated to subsequent at-risk reading outcome in first or second grade. 
7. Does the emerging correlation pattern in kindergarten change as a result of acquiring basic literacy skills in grade 1 (i.e., grade 1 prediction of grade 2 reading fluency)?

Grade 1 results indicated that LS knowledge remained the only marker correlated to reading fluency of children at increased familial risk for dyslexia a year later. The correlation between kindergarten and grade 1 LS knowledge and reading outcome of at-risk children in our sample, combined with the finding that kindergarten RAN was predicatively related to grade 2 at-risk reading, was interpreted as a possible early cross-modal orthographic-phonological association deficit that was already noticeable in at-risk children prior to the start of reading instruction.

8. Is the correlation pattern found over kindergarten and grade 1 in children at-risk for a deficient reading development comparable to the pattern found in their normally developing peers without such a family history of dyslexia?

Before the start of reading instruction, the at-risk and control children both shared LS knowledge as the sole kindergarten marker correlated to subsequent reading outcome in grade 1. After the start of reading instruction in grade 1, we saw that LS knowledge remained predictive of grade 2 reading in our at-risk sample. At that point, PA emerged as the sole predictor in our control sample. RAN showed no predictive relationship after reading instruction started in both groups. Together, these results revealed that the relevance of kindergarten predictive markers changed as a result of acquiring reading skills, specifically in those children without risk.

Our findings of chapter 3 indicated that once reading instruction started a differential correlation pattern between potential predictive risk markers and reading outcome emerged for children with and children without a familial risk for dyslexia. This is possibly due to a different developmental pace of reading acquisition in the former at-risk group, in which early identification of subsequent reading failure is most evident and necessary. Our collective results of chapter 2 and 3 indicate that PA, LS and RAN are all relevant markers of at-risk and normal reading outcome. However, the contribution of these markers seems to differ on the developmental stage of the reading acquisition process that is reached, which in turn seems to vary with the presence or absence of familial risk for dyslexia (for similar results see, Cardoso-Martins \& Pennington, 2004; Pennington \& Lefly, 2001). Chapter 4 therefore further investigated to which extend these reading-related vulnerability markers differentiate within a large, heterogeneous sample of already established reading disabled children with or without such a familial 
predisposition to the experienced reading failure. To this aim, chapter 4 explored whether we could identify distinct patterns of cognitive deficits underlying reading problems based on these three important reading-related markers, next to working memory and general cognitive abilities (non-verbal IQ and receptive vocabulary). A data-driven clustering attempt was conducted in a large heterogeneous sample that includes slightly older poor reading children attending second to fourth grade. We investigated whether emerging cognitive subtypes of poor reading are specifically characterized by an increased familial risk of dyslexia or instead by more environmental risk factors (i.e., socio-economic status, reading performance level of attended schools, or co-morbidity factors like arithmetic deficits and ADHD). In doing so, the present study was an application of the first bottom-up classification taking into account recent major genetic advances in the reading field that indicate that familial risk undermines the development of reading in dyslexic families (e.g., Grigorenko, 2001; Castles, Datta, Gayan, \& Olson, 1999). The questions addressed in chapter 4 were:

9. Can a data-driven classification based on the cognitive reading-related vulnerability markers PA, RAN, LS processing and VWM differentiate distinct and coherent cognitive deficit profiles within a large sample of grade 2 to 4 poor readers?

Our results revealed four distinguishable clusters of reading disability, specifically three of which showed a distinct underlying cognitive deficits pattern in addition to below average spelling scores, while a fourth subtype showed no cognitive deficits despite their reading failure. This latter reading-only impaired reader type, although performing below average on reading fluency, showed significantly less impaired reading ability than the other three poor reader types and was the only type with average range spelling skills. The other three subtypes shared a PA deficit but showed a variable and discriminative expression across the other included cognitive vulnerability markers: (a) general poor readers with deficits across all reading-related and general cognitive markers, (b) PA-LS specific poor readers with an additional LS deficit next to the common PA deficit and (c) PA-RAN specific poor readers with an additional RAN deficit besides PA problems. 
10. Are possible emerging cognitive profiles of deficits underlying different types of poor reading distinguishable based on genetic influences, environmental influences or a combination?

Although only genetic testing (e.g., twin study designs) can detangle how much variation in a trait is related to genes or environmental factors, and familial risk of dyslexia is not a pure genetic trait since both genes and environments are shared by families (Pennington \& Olson, 2008; Plomin, Reiss, Hetherington, \& Howe, 1994; Rutter \& Silberg, 2002), it is one of the strongest predictors of the development of reading disorders (Scarborough, 1989, 1990; Snowling, Gallagher, \& Frith, 2003; Thompson et al., 2015). The results in the current poor reader sample revealed that the general poor readers and the PA-LS specific poor readers were characterized most by poor socio-economic status, while the PA-RAN poor readers showed a very strong familial risk of dyslexia. Interestingly, this familial risk PA-RAN subtype showed high IQ scores discrepant to their reading skills, while the other two more environmentally characterized types showed relatively poorer intellectual skills (i.e., approximately 1 standard deviation below the PA-RAN subtype). The fourth reading-only impaired showing a less severe reading deficit compared to the other three subtypes and being the only poor reader type without spelling difficulties were significantly younger although they did not attend a significantly lower school grade. This indicates that their exposure to certain levels of grade specific reading instruction was comparable to that in the other subtypes and therefore could not have been a factor explaining their reading difficulties. The children in this subtype did however attend schools with a significantly poorer overall reading level. Taken this into account, together with their less severe and non-specific (i.e., no underlying cognitive deficit pattern) reading problems and average spellings skills, indicate that these children are influenced by external factors instead of a specific altered cognitive development. Reading difficulties as a result of less adequate reading instruction at school seems more easily counterattacked by more adequate or intensive instruction.

Together, the research described in chapter 4 identified four homogeneous and distinguishable clusters within the current poor reading sample, which strengthened the notion that different cognitive subtypes of reading disability exist (for previous clustering attempts see for example Morris et al., 1998; King et al., 2006). Our results moreover show that data-driven classification solely based on cognitive vulnerability markers commonly used for the diagnostics of dyslexia can differentiate between poor reading as a result of increased familial risk for dyslexia and reading failure as a result of poor environmental factors. This confirms previous neuroimaging results indicating a primarily genetic poor 
readers type and an environmentally influenced impaired type (Shaywitz \& Shaywitz, 2005). Moreover, although diagnostics of dyslexia solely based on an IQ-reading discrepancy cut-off criteria has been discarded over de past two decades (Stanovich \& Siegel, 1994; Stuebing et al., 2002), our results did indicate that the way IQ forms distinct patterns with cognitive and familial risk markers seems informative. More specific, our findings supported the idea that IQ can provide more information on the cause of the reading deficit experienced by the child (Friend, DeFries, \& Olson, 2008; Wadsworth, Olson, \& DeFries, 2010; Wadsworth, Olson, Pennington, \& DeFries, 2000) as well as have a valuable attribution for exclusion purposes in diagnostic processes (Coltheart \& Jackson, 1998; Rack \& Olson, 1993). Being able to identifying homogeneous subtypes within the heterogeneous reading disabled group is a promising way forward for future neuroimaging and genetic studies as well as future diagnostic and remediation attempts. Focusing on meaningful subtypes creates the possibility to design research and intervention efforts more specifically and avoids potential downfalls of generalizing based on a cognitively mixed group. 


\section{References}

Badian, N. A., McAnulty, G. B., Duffy, F. H., \& Als, H. (1990). Prediction of dyslexia in kindergarten boys. Annals of Dyslexia, 40(1), 152-169. doi:10.1007/BF02648146.

Blomert, L. (2005). Dyslexie in Nederland - theorie, praktijk en beleid [Dyslexia in The Netherlands theory, practice and policy]. Amsterdam: Nieuwezijds Publishers.

Byrne, B., Shankweiler, D., \& Hine, D. W. (2008). Reading development in children at risk for dyslexia. In M. Mody \& K. Silliman (Eds.), Brain, Behavior and Learning in Language and Reading disorders (pp. 240-270). New York, US: Guilford Press.

Cardoso-Martins, C., \& Pennington, B. F. (2004). The relationship between phoneme awareness and rapid serial naming skills and literacy acquisition: The role of developmental period and reading ability. Scientific Studies of Reading, 8, 27-52. doi:10.1207/s1532799xssr0801_3.

Castles, A., \& Coltheart, M. (2004). Is there a causal link from phonological awareness to success in learning to read? Cognition, 91(1), 77-111. doi:10.1016/S0010-0277(03)00164-1.

Coltheart, M., \& Jackson, N. E. (1998). Defining Dyslexia. Child and Adolescent Mental Health, 3(1), 12-16. doi:10.1111/1475-3588.00202.

de Jong, P. F., \& van der Leij, A. (1999). Specific contributions of phonological abilities to early reading acquisition: results from a Dutch latent variable longitudinal study. Journal of Educational Psychology, 91(3), 450-476. doi:10.1037/0022-0663.91.3.450.

Ehri, L. C. (2005). Development of sight word reading: Phases and findings. In M. J. Snowling \& C. Hulme (Eds.), The Science of Reading: A Handbook (pp. 135-154). Oxford: Blackwell publishing.

Friend, A., Defries, J. C., \& Olson, R. K. (2008). Parental education moderates genetic influences on reading disability. Psychological Science, 19(11), 1124-1130. doi:10.1111/j.14679280.2008.02213.x.

Kirby, J. R., Georgiou, G. K., Martinussen, R., \& Parrila, R. (2010). Naming speed and reading: From prediction to instruction. Reading Research Quarterly, 45(3), 341-362.

Landerl, K., Ramus, F., Moll, K., Lyytinen, H., Leppänen, P., Lohvansuu, K., . . Bruder, J. (2013). Predictors of developmental dyslexia in European orthographies with varying complexity. Journal of Child Psychology and Psychiatry, 54(6), 686-694.

Lyytinen, H., Ahonen, T., Eklund, K., Guttorm, T., Kulju, P., Laakso, M. L., . . Viholainen, H. (2004a). Early Development of Children at Familial Risk for Dyslexia: Follow-up from Birth to School Age. Dyslexia, 10(3), 146-178. doi:10.1002/dys.274. 
Lyytinen, H., Aro, M., Eklund, K., Erskine, J., Guttorm, T., Laakso, M. L., . . Richardson, U. (2004b). The development of children at familial risk for dyslexia: birth to early school age. Annals of Dyslexia, 54(2), 184-220. doi:10.1007/s11881-004-0010-3.

Pennington, B. F., \& Lefly, D. L. (2001). Early reading development in children at family risk for dyslexia. Child development, 72(3), 816-833. doi:10.1111/1467-8624.00317.

Pennington, B. F., \& Olson, R. K. (2008). Genetics of Dyslexia. The Science of Reading: A Handbook, 453472. doi:10.1002/9780470757642.ch24.

Plomin, R., Reiss, D., Hetherington, E. M., \& Howe, G. W. (1994). Nature and nurture: genetic contributions to measures of the family environment. Developmental Psychology, 30(1), 32. doi:10.1037/0012-1649.30.1.32.

Rack, J. P., \& Olson, R. K. (1993). Phonological Deficits, IQ, and Individual Differences in Reading Disability: Genetic and Environmental Influences. Developmental Review, 13(3), 269-278. doi:10.1006/drev.1993.1013.

Richardson, U., \& Lyytinen, H. (2014). The GraphoGame method: The theoretical and methodological background of the technology-enhanced learning environment for learning to read. Human Technology: An Interdisciplinary Journal on Humans in ICT Environments, 10(1), 39-60.

Rutter, M., \& Silberg, J. (2002). Gene-environment interplay in relation to emotional and behavioral disturbance. Annual review of psychology, 53(1), 463-490. doi:10.1146/annurev.psych.53.100901.135223

Scarborough, H. S. (1989). Prediction of reading disability from familial and individual differences. Journal of Educational Psychology, 81(1), 101-108. doi:10.1037/0022-0663.81.1.101.

Scarborough, H. S. (1990). Very early language deficits in dyslexic children. Child development, 61, 17281743. doi:10.2307/1130834.

Schatschneider, C., Fletcher, J. M., Francis, D. J., Carlson, C. D., \& Foorman, B. R. (2004). Kindergarten Prediction of Reading skills: a longitudinal comparative analysis. Journal of Educational Psychology, 96, 265-282. doi:10.1037/0022-0663.96.2.265.

Schatschneider, C., \& Torgesen, J. K. (2004). Using our Current Understanding of Dyslexia to Support Early Identification and Intervention. Journal of Child Neurology, 19(10), 759-765. doi: 10.1177/08830738040190100501.

Shaywitz, S. E., \& Shaywitz, B. A. (2005). Dyslexia (Specific Reading Disability). Biological Psychiatry, 57(11), 1301-1309. doi:10.1016/j.biopsych.2005.01.043. 
Shaywitz, S. E., Shaywitz, B. A., Fletcher, J. M., \& Escobar, M. D. (1990). Prevalence of reading disability in boys and girls. Results of the Connecticut Longitudinal Study. The journal of the American Medical Association, 264(8), 998-1002. doi:10585988.

Snowling, M. J. (2000). Dyslexia. Oxford: Blackwell Publishers.

Snowling, M. J., Gallagher, A., \& Frith, U. (2003). Family risk of dyslexia is continuous: individual differences in the precursors of reading skill. Child development, 74(2), 358-373. doi:10.1111/1467-8624.7402003.

Stanovich, K. E., \& Siegel, L. S. (1994). Phenotypic performance profile of children with reading disabilities: A regression-based test of the phonological-core-variable-difference model. Journal of Educational Psychology, 86, 24-53. doi:10.1037//0022-0663.86.1.24.

Stuebing, K. K., Fletcher, J. M., LeDoux, J. M., Lyon, G. R., Shaywitz, S. E., \& Shaywitz, B. A. (2002). Validity of IQ-Discrepancy Classifications of Reading Disabilities: A Meta-Analysis. American Educational Research Journal, 39(2), 469-518. doi:10.3102/00028312039002469.

Thompson, P. A., Hulme, C., Nash, H. M., Gooch, D., E., H. T., \& Snowling, M. J. (2015). Developmental dyslexia: predicting individual risk. Journal of Child Psychology and Psychiatry, 56(9), 976-987.

Vellutino, F. R., Fletcher, J. M., Snowling, M. J., \& Scanlon, D. M. (2004). Specific reading disability (dyslexia): what have we learned in the past four decades? Journal of Child Psychology and Psychiatry, 45(1), 2-40. doi:10.1046/j.0021-9630.2003.00305.x.

Wadsworth, S. J., Olson, R. K., \& DeFries, J. C. (2010). Differential genetic etiology of reading difficulties as a function of IQ: an update. Behavior Genetics, 4O(6), 751-758. doi:10.1007/s10519-010-9349.

Wadsworth, S. J., Olson, R. K., Pennington, B. F., \& DeFries, J. C. (2000). Differential Genetic Etiology of Reading Disability as a Function of IQ. Journal of Learning Disabilities, 33(2), 192-199. doi:10.1177/002221940003300207. 
CHAPTER 6

GENERAL DISCUSSION AND CONCLUSIONS 
The present thesis set out to investigate the cognitive deficit pattern that is characteristic of children at familial risk for dyslexia during their first steps of learning to read. We focused on cognitive markers that have been suggested to reveal vulnerability for reading failure: phonological awareness, which relates to a child's understanding of the sound structure of spoken language (PA), letter-speech sound knowledge, which reflects knowing which letter of an alphabet maps on to which speech sound (LS) and rapid naming, indicating the ability to rapidly name highly familiar visual objects such as letters, digits or objects (RAN). In this concluding sixth chapter, the implications of the findings resulting from the experimental studies presented in chapter 2, 3 and 4, as summarized in chapter 5, will be discussed in the light of several important issues in reading research and specifically our current understanding of cross-modal integration deficits of dyslexia. Future directions for research probing possible dyslexia deficits in children with a family history will be given, in addition to possible ways forward for identification and intervention efforts aimed to alleviate or even prevent reading failure in this group.

\subsection{PHONOLOGICAL AWARENESS AND READING DEFICITS - CAUSE, CONSEQUENCE OR COVARIATE OF READING FAILURE}

Learning to read successfully involves a wide variety of processes in which inaccuracy or lack of fluency at various levels may result in reading problems. Given this multi-componential nature of reading, it follows that the premise of reading disability is clearly not simple. The poor reader population as a whole represents a highly heterogeneous group from which, as we show in chapter 4 , distinct cognitive deficit profiles can be derived with data-driven classification approaches. This suggests that the underlying aetiologies of deficient reading and spelling differ across readers. As a result of this observed heterogeneity, numerous definitions of dyslexia have been proposed and the quest to find consensus on a core deficit explanation of dyslexia is very much alive today (Snowling, 2000). Nevertheless, a working definition has been formulated, indicating the reading disorder to have a neurobiological origin and strong genetic predisposition (Byrne et al., 2006; Castles, Datta, Gayan, \& Olson, 1999; Grigorenko, 2001; Pennington \& Olson, 2008; Williams \& O'Donovan, 2006) in addition to a specific nature manifesting itself in childhood despite adequate educational opportunity, intellectual capacity and socio-cultural advantages. Moreover, the most dominant and well-supported core deficit hypothesis of dyslexia is the 'phonological deficit' hypothesis, which indicates that difficulty in the representation, storage and/or retrieval of speech sounds, or in other words a deficit in phonological awareness (PA), lies at the core of 
reading failure (Adams, 1990; Boets et al., 2010; Goswami \& Bryant, 1990; Ramus, 2003; Snowling, 2000; Vellutino, Fletcher, Snowling, \& Scanlon, 2004). A body of behavioral and neuroimaging evidence supports the strong PA-reading ability relationship across orthographies (e.g., Cardoso-Martins \& Pennington, 2004; Mann \& Wimmer, 2002b; Pugh et al., 2001; Schatschneider, Fletcher, Francis, Carlson, \& Foorman, 2004; Share, Jorm, Maclean, \& Matthews, 1984; Turkeltaub, Gareau, Flowers, Zeffiro, \& Eden, 2003; Vaessen \& Blomert, 2010; Wagner, Torgesen, \& Rashotte, 1994; Ziegler et al., 2010). Moreover, phonological deficiencies undisputedly characterize dyslexic readers (e.g., Ramus, 2003; Ramus et al., 2003; Sunseth \& Bowers, 2002; Vellutino, 1979; Vellutino et al., 2004; Vellutino et al., 1996; Wagner et al., 1994; present thesis). Given this body of evidence stressing the role of PA in learning to read, it does not come as a surprise that the present chapter 4 data-driven classification study reveals a PA deficit amongst established grade 2 to 4 Dutch impaired readers. More specific, while a unique cognitive deficit pattern was found for three (of four) emerging reading disabled subtypes, they share a deficiency in phoneme deletion skills. The general poor reader type shows deficits across all general and reading-related cognitive skills. The PA-LS specific poor reader type demonstrates a letter-speech sound deficit (LS) next to the shared PA deficit and the PA-RAN specific poor reader type shows an additional deficit in rapidly matching familiar visual symbols (RAN) to their phonological counterparts. The later subtype was characterized by a high familial risk for dyslexia and the first two subtypes by environmental risk factors, which shows that a PA deficit was not just specific to children predisposed to dyslexia. The fourth type, a reading-only impaired subtype, show less severe reading difficulties, normal range spelling skills, and no underlying reading-related deficits. These children came from schools with lower reading performance levels (i.e., a higher proportion of poor readers), which indicates that their less severe reading problems may be adequately reduced by well targeted intervention. A shared PA deficit across various cognitive types of poor reading has been reported before in a previous classification study (e.g., Morris et al., 1998) and corroborates the acknowledged reciprocal relationship PA and reading achievement (Perfetti, Beck, Bell, \& Hughes, 1987; Wagner \& Torgesen, 1987; Ziegler \& Goswami, 2005). Finding a PA deficit across the three subtypes moreover indicates that a core PA deficit alone could not explain the discriminative cognitive deficit patterns, challenging the view that the cognitive aetiology of dyslexia is purely at the level of poor speech sounds representations of spoken language. Instead, a multi-deficit model of reading disability seems in place (Bishop \& Snowling, 2004; Pennington, 2006; van Bergen, van der Leij, \& de Jong, 2014) in which other factors than PA should be taken into consideration, such as audio-visual integration of speech sounds with their corresponding orthographic counterparts 
and fast audio-visual matching of phonological codes to known visual information (Blomert, 2011; Ehri, 2005; Kronschnabel, Brem, Maurer, \& Brandeis, 2014).

Chapter 2 investigated a claim of the phonological deficit hypothesis which indicates that a causal influence of instable or degraded phonological representations causes and/or precedes the development of reading deficits (see Snowling, 2000; Vellutino et al., 2004; Wagner \& Torgesen, 1987 for reviews). Although the PA deficit hypothesis received a wide range of empirical support and a reciprocal PA-reading relationship in established readers is undisputed (Perfetti et al., 1987; Wagner \& Torgesen, 1987; Wimmer, Landerl, Linortner, \& Hummer, 1991; Ziegler \& Goswami, 2005), evidence for its causal claim of impairments in PA and the aetiology of reading deficits is weak (for an overview see Castles \& Coltheart, 2004; Ziegler \& Goswami, 2005). Within our sample of children at familial risk for dyslexia, we only disclosed a very small proportion of at-risk children with a kindergarten PA deficit prior to reading and of these children even less actually develop a reading deficit in grade 1 . Finding no predictive correlation of kindergarten PA to reading outcome corroborates previous findings ( Gallagher, Frith, \& Snowling, 2000; Pennington \& Lefly, 2001; Puolakanaho et al., 2008; Puolakanaho et al., 2007; Scarborough, 1989, 1990; Torppa, Lyytinen, Erskine, Eklund, \& Lyytinen, 2010) but also see other results (Boets et al., 2010; Elbro, Borstrøm, \& Petersen, 1998). Instead, the large majority of our at-risk sample as well as our control sample without a familial predisposition for dyslexia, that developed a reading deficit in grade 1, performed within the normal range on kindergarten PA. Most at-risk children showed a normal performance on PA in kindergarten and a large part nevertheless develops a reading deficit later on. A reading deficit was thus not necessarily preceded or caused by a PA deficit in our sample. Our chapter 3 correlation results corroborate this as they indicate no predictive relationship between PA before the start of reading acquisition and subsequent grade 1 and 2 reading failure in the at-risk sample. These findings thus at least shed further doubts on the assumptions that a PA deficit (a) precedes and (b) directly facilitates the development of a reading deficit. Our results only reveal a predictive PA influence to reading outcome after the start of reading instruction (i.e., grade 1 PA was measured with a phoneme deletion or elision task) and only in typically developing children, not in atrisk poor readers. Thus, the usefulness of PA as prediction of future reading skills is limited, and depends on the interaction of PA with other factors. Here we could show that one such interaction is PA and emerging literacy skills and only when reading acquisition is successfully on its way. Why than did several studies indicate that PA before the start of reading instruction was predicatively correlated to normal reading outcome in typically developing children (e.g., Landerl \& Wimmer, 2008; Parrila, Kirby, \& McQuarrie, 2004; Schatschneider et al., 2004; Wagner et al., 1997)? One potential reason for differences 
in test outcomes might be the diversity in orthographic structures across target languages in the studies. The previous studies were mainly conducted in opaque orthographies in which reading instruction is known to start already in kindergarten (e.g., Parrila et al., 2004; Schatschneider et al., 2004). It is possible that variance in PA level was already related to emerging, successful reading at an earlier stage. In contrast, in more transparent orthographies reading instruction only starts in grade 1 (e.g., Mann \& Wimmer, 2002a; Wimmer et al., 1991; Ziegler \& Goswami, 2005; present thesis chapter 2 and 3). Our results resonate well with other transparent language studies which also indicate a weaker, unreliable or absent role of early PA in predicting reading outcome (e.g., Turkish: Babayiğit \& Stainthorp, 2010; Greek: Harris \& Giannouli, 1999; Finnish: Holopainen, Ahonen, \& Lyytinen, 2001; German: Wimmer \& Mayringer, 2002).

An important weakness of the causal claim of the phonological deficit hypothesis is that it does not in and by itself explain how this deficit leads to reading problems. It was proposed that PA deficits assumedly cause 'unstable' letter-speech sounds (LS) associations resulting in poor subsequent reading skills (e.g., Snowling, 2000; Vellutino et al., 2004). Our chapter 2 findings did not support this claim since PA deficits and difficulties with adequately matching LS correspondences rarely coincided in the same children in kindergarten. In fact, we demonstrate that many children could learn LS associations in kindergarten due to a training specifically aimed to teach these correspondences (for a detailed description of the Dutch Graphogame training, see appendix 1), even though they have limited phonological knowledge at the level of the phoneme at that time (i.e., based on a pilot study with a sample of at-risk and control children that reveal a floor performance on a phoneme deletion). Being able to acquire LS knowledge without awareness of phonemes is in line with previous research (Castles, Coltheart, Wilson, Valpied, \& Wedgwood, 2009). Chapter 2 further reveals that within our cohort PA deficits only emerge after the start of reading instruction and in close relation with developing reading problems in grade 1. More specific, both at-risk and control children with a reading deficit develop a PA deficit in grade 1. These results are in line with earlier research findings in beginning readers (e.g., Mann \& Wimmer, 2002a; Wimmer et al., 1991) in illiterates (Morais, Bertelson, Cary, \& Alegria, 1986; Morais, Cary, Alegria, \& Bertelson, 1979). These studies show that adults that never learned how to read do not adequately develop phonological awareness. They moreover corroborate our chapter 3 results that indicate that a PA-reading correlation only emerges once reading is successfully on its way.

Taken together, the present thesis suggests that prior to reading there is no relationship between kindergarten PA and reading ability measured subsequently in grade 1 and 2 . Instead, we found that it is the process of learning to read that attracts children to the phonemic segments in spoken 
language. Although we do not dispute that PA is intrinsically linked to reading development over many years in all alphabetical languages (Vaessen \& Blomert, 2010; Ziegler \& Goswami, 2005), these findings do seem to suggest that PA did not precede or causally influence the aetiology of reading impairment in the present cohort of Dutch at-risk and control children. We recognize that the absence of evidence does not equal evidence of absence and that generalizing the observation of an absent causal effect of a PA deficit on reading has its limits. Like other well-controlled longitudinal study designs, we cannot demonstrate non-spuriousness (Bradley \& Bryant., 1983; Bryant \& Goswami, 1987; Castles \& Coltheart, 2004; Macmillan, 2002). It is possible that variation in possible third variables (e.g., school or home literacy environment) may be at play. Also, the chosen cognitive measurements might limit the generalization of this result. For example, our reading fluency measure, combining speed and accuracy, reflects the number of correct words read within a set time limit. It is to be expected that beginning readers show a higher error percentage than more established readers and therefore our fluency score may have been biased expressing both factors. This in turn might influence the relationship between kindergarten PA and subsequent reading. We however do not expect this bias to be strong since chapter 3 results also indicates that grade 1 accuracy levels of both at-risk and no-risk children are near or at ceiling levels (i.e., $90 \%$ in the at-risk and $97 \%$ in no-risk sample), which is common in more transparent orthographies (Seymour, 2005; Seymour, Aro, \& Erskine, 2003; Vaessen et al., 2010; Vaessen \& Blomert, 2010). Finally, our chapter 3 prediction results indicate that predicting successful reading is thus not necessarily the same as predicting reading failure since results varied between at-risk and control children. Generalizing results from normally developing children to at-risk children should thus be done with caution and certain cognitive risk markers might be relevant at different stages of reading development within each group. With the idea that PA is not the only and causal factor for reading problems, we investigate what other factors corrupt reading development?

\subsection{ANOMALOUS LETTER-SPEECH SOUND PROCESSING, A PROXIMAL PRECURSOR OF DYSLEXIA}

Reading is intrinsically a cross-modal task and ability. It rests on the involvement of the visual and auditory system that meet in association areas such as left posterior superior temporal sulcus and the superior temporal gyrus (McCandliss \& Noble, 2003; Schlaggar \& McCandliss, 2007; Van Atteveldt, Formisano, Goebel, \& Blomert, 2004). Via the visual system written information enters the brain via the eye, the lateral geniculate nucleus, early visual systems, and visual word form area (Dehaene et al., 
2010). Via the auditory system acoustic signals enter the ear, are transformed via midbrain nuclei in the auditory cortex in which acoustic and phonological properties are processed and interpreted (Dehaene et al., 2010). A child's ability to make meaningful, automated connections between these phonological interpretations and the visual form of associated symbols in letters and words is key in literacy. In fact, it led reading researcher to declare the systematic translation of graphemes into phonological code as the primary building block (Adams, 1990), sine qua none (Share, 1995) or central bottleneck (Stanovich, 1986) of reading acquisition. Reduced ability to integrate auditory and visual stimuli was already indicated as a possible cause of subnormal reading development more than fifty years ago (Birch \& Belmont, 1964, p. 853). Given its primacy in learning to read (Ehri, 2005), it is surprising that research probing possible cross-modal processing deficit explanations of dyslexia is still relatively limited and only started to grow over the last decade. A robust finding seems that letter-speech sound knowledge (LK) is an important early marker predicatively correlated to subsequent reading in both opaque and transparent orthographies (Adams, 1990; de Jong \& van der Leij, 1999; Elbro et al., 1998; Lyytinen et al., 2004a; Lyytinen et al., 2004b; Scarborough, 1989, 1990), a result confirmed by the longitudinal research in chapter 3. We found that LK in pre-reading kindergartners with and without a familial risk for dyslexia is predictive of their subsequent grade 1 reading performance. After the start of reading instruction in grade 1, LS accuracy remains the sole predictor correlated to reading outcome a year later, but only in children at familial risk for dyslexia. The test results in grade 1 demonstrated that LK performance on the task employed in kindergarten is at ceiling in both our samples. Such ceiling effects are problematic as they reduce possible variance across samples. They may well explain why previous transparent language studies reported LK as no relevant predictor for future reading outcome beyond kindergarten (e.g., Braams \& Bosman, 2000; de Jong \& van der Leij, 1999; Wesseling \& Reitsma, 2000). Relevance of LS is confirmed by our study reported in Chapter 4 . We observed extended weakness in LS mapping in one of the four emerging reading disabled subtypes (i.e., the PA-LS specific type) which resonates well with previous behavioral findings in reading disabled children (Vaessen \& Blomert, 2010). Electrophysiological and neuroimaging studies also demonstrate a relation between LS mapping and fluency. They showed that disrupted letter-speech sound automaticity and influent integration is a core deficit in dyslexic children (Blau et al., 2010; Froyen, Willems, \& Blomert, 2011; Zaric et al., 2015) that persist into adulthood (Blau, Van Atteveldt, Ekkebus, Goebel, \& Blomert, 2009; Kronschnabel et al., 2014; Mittag, Thesleff, Laasonen, \& Kujala, 2013). The ERP study by Froyen et al. (2011) for example shows absence of typical neural activation related to automatic LS integration in 11-year-old dyslexics. This was the case even after 4 years of reading instruction, despite performing fully accurate on a behavioral LK task and 
scoring similar to normal reading peers on isolated speech sound discrimination (for similar results see Žarić et al., 2014). Subsequent research showed that this reduced neural integration of letters and speech sounds in dyslexic readers moderately improved as a result of 6 month LS coupling training next to general reading instruction (Zaric et al., 2015). The fMRI studies by Blau et al. (2009; 2010) likewise found that both 9 year old dyslexic children and adult dyslexic readers show reduced audiovisual activity during LS integration. Even more importantly, they do not differentiate between congruent and incongruent LS pairs (i.e., meaningful versus non-existing and valueless associations), while normal reading subjects do, quantified by a difference in BOLD signal change across conditions. A different response to congruent and incongruent pairs is only possible if the unimodal information is successfully integrated into a new multimodal construct and lack of congruency effects were therefore interpreted as a specific cross-modal integration deficit (Blau et al., 2010; Blau et al., 2009; Kronschnabel et al., 2014).

Our finding of a predictive LK-reading relationship in both at-risk and control kindergarten children and an extended LS-reading relationship after the start of reading acquisition in at-risk children only, seems to suggest that difficulty in LS learning is a good candidate in the search for a causal factor of reading failure. Indeed, we found that a substantial portion of at-risk children struggled with learning LS associations on our kindergarten LS training specifically designed to teach these links (Chapter 2, see Appendix 1 for the Dutch version of Graphogame). In contrast, all control children without a familial risk of dyslexia profited from this LS training. Brem et al. (2010), who used an identical training to the one we used, revealed a change in cortical mapping due to LS training in pre-reading children without a risk for dyslexia. Successful learning LS correspondences resulted in sensitization to written word stimuli previously found activated by symbol-strings and object processing. This indicates that relevant visual word form cortical areas start to become fine-tuned to print-specific functions once LS coupling abilities start to develop. Since in a core group of at-risk kindergarten children we observed a strong training resistance for LS abilities, we speculate that LS based neural sensitization is disrupted in children at-risk for dyslexia. The brain imaging studies of Mauer and colleagues corroborate this by showing that sensitivity for words compared to symbol strings within the first two years of reading instruction differ between typically developing readers and young dyslexic children (Mauer, Brem, Bucher, \& Brandeis, 2005; Maurer et al., 2007) and adult dyslexics (Helenius, Tarkiainen, Cornelissen, Hansen, \& Salmelin, 1999; Shaywitz \& Shaywitz, 2005).

Together, the aforementioned results point to a LS cross-modal deficit account in a core group of children with a familial predisposition for dyslexia. This cross-modal LS deficit was independent of phonological weakness, since these children showed no phonological awareness difficulties in 
kindergarten. The possibility to further explain the consistent lack of fluent reading ability, the most persistent symptom of dyslexia, according to an overall cross-modal integration framework of dyslexia, thus seems a fruitful area for future research.

\subsection{PHONEMIC AWARENESS DEFICITS IN THE LIGHT OF THE CROSS-MODAL DEFICIT EXPLANATION OF DYSLEXIA}

In light of a possible cross-modal integration deficit of dyslexia it is interesting to consider if the assumed PA hypothesis of dyslexia might also be explained in terms of an audiovisual integration framework. In this paragraph we therefore explore what phoneme awareness actually reflects. The commonly employed phoneme deletion task (i.e., elision, give an example here) developed by Bruce (1964) is often viewed as a pure spoken language marker. In cognitive terms, the task requires the auditory processing of the entire sound segment, the detections of the target phoneme, and actively omitting the phonological segment from an auditory-presented word to subsequently produce the resulting novel word, all without providing explicit visual-orthographic information. This makes it an attractive nonreading measure related to reading (dis)ability (Gelder \& Vroomen, 1991; Goswami, 2000; Ramus, 2003; Vaessen \& Blomert, 2010; Vellutino et al., 2004; Ziegler \& Goswami, 2005; chapter 4 present thesis). Although in theory, phoneme deletion should not depend on a child's reading ability, our results of a limited phonemic knowledge in kindergarten suggest otherwise. Also, the absent predictive and causal relationship between PA and subsequent reading prior to structured exposure to orthographic knowledge confirm this (chapter 2 and 3). Similarly, limited ability on individual phoneme segmentations tasks have been found in illiterates (De Santos Loureiro, Willadino Braga, Souza, Queiroz, \& Dellatolas, 2004; Landgraf et al., 2012; Morais et al., 1979), non-alphabetic readers (De Gelder, Vroomen, \& Bertelson, 1993; Read, Yun-Fei, Hong-Yin, \& Bao-Qing, 1986) and pre-reading children (Ehri, Nunes, Stahl, \& Willows, 2001; Wimmer et al., 1991). This indirectly indicates that there might be a possible interactive influence of orthographic knowledge and phonemic awareness we should consider. We discuss direct evidence supporting this idea below.

Several behavioral studies show direct evidence of an intrusion effect of orthographic representations influencing phonemic task performance (Ben-Dror, Bentin, \& Frost, 1995; Ehri \& Wilce, 1980; Ventura, Kolinsky, Brito-Mendes, \& Morais, 2001). When processing auditory presented words containing the same amount of phonemes but a variable amount of graphemes (e.g., pitch and rich), 
subjects view them as phonologically different, containing more sounds (Ehri \& Wilce, 1980). Also, children and adults find it more difficult to delete a phoneme from words with less consistent spelling (e.g., ghost in which the $h$ is silent) than from consistent words with a one-to-one grapheme-phoneme match (Castles, Davis, \& Forster, 2003). Similar 'orthographic intrusion' effects are found during phoneme deletion and phoneme counting tasks (Ehri \& Wilce, 1980; Landerl, Frith, \& Wimmer, 1996; Seidenberg \& Tanenhaus, 1979). In the study by Landerl et al. (1996) this intrusion occurs significantly less in dyslexic readers than in aged-matched and even reading-matched controls (for similar results see Bruck, 1992). The authors propose that these impaired readers, when processing spoken words, do not always evoke the internal orthographic image it is connected to and vice versa. Neuroimaging studies already indicate disruption of the cross-modal mechanisms at small grain size in dyslexic children and adults, namely at the level of LS pairs (Blau et al., 2010; Froyen et al., 2011) and syllables (Mittag et al., 2013), to which Kronschnabel et al. (2014) recently added that these audio-visual deficits in dyslexics are even more pronounced in more natural linguistic stimuli (i.e., CVC letter strings). A recent fMRI study by McNorgan, Randazzo-Wagner, and Booth (2013) explored cross-modal integration during whole word processing, which is specifically important during early reading in opaque orthographies (Ziegler \& Goswami, 2005). Children completed a rhyme judgment task of word pairs presented either auditoryonly or cross-modally (auditory followed by visual presentation). Behavioral phoneme deletion ability was correlated to the neural activity in the cross-modal conditions in the fusiform gyrus and the posterior superior temporal sulcus, but only in the typically developing children. There was no such correlation in the unimodal condition, which collectively reinforces the idea that PA may not represent a pure spoken language measure but instead reflects sensitivity to the access of orthographic knowledge during cross-modal processes. In dyslexic children no correlation was found between phoneme deletion and the unimodal or crossmodal conditions.

Taken together, it seems that orthographic experience or fluency is a facilitator that attracts children to the phonemic segments in spoken language (Landerl et al., 1996; McNorgan et al., 2013; Morais et al., 1979; Ziegler \& Goswami, 2005), although this does not exclude that isolated phonemes can be trained without knowing the corresponding orthographic form (Castles et al., 2009; Hulme, Caravolas, Málková, \& Brigstocke, 2005). This moreover reinforces our suggestion that a relationship between PA-reading ability seems to develop as a by-product once reading acquisition is successfully on its way (chapter 2 and 3). Deficient phonemic awareness in dyslexic children may thus be seen as a sign of a weakly developed cross-modal bond between phonological and orthographic information that seems to act as a proximal cause for reading deficits in dyslexics (Blomert, 2011). Since phoneme 
deletion ability is unlikely a pure spoken language ability, but instead a composite skills sensitive to both phoneme awareness and cross-modal integration, we conclude that the shared PA deficit found across specific subtypes of established poor readers in chapter 4 is unlikely a pure phonological problem but may also be viewed within a cross-modal framework of dyslexia.

\subsection{RAPID NAMING AND ITS RELATION TO READING DISABILITY}

Additional support for a cross-modal deficit explanation of dyslexia comes from the observation that disabled readers struggle with rapid visual naming (RAN), which by nature is a cross-modal task requiring recognition of well-known visual symbols and fast matching of these symbols to their corresponding phonological counterparts (e.g., Wolf, Bowers, \& Biddle, 2000b). RAN and reading both seem to build upon similar cognitive abilities and neural systems (e.g., attention, working memory, motor movements and efficient multimodal processing) as well as rely heavily on automaticity. This comparable nature has recently lead reading researchers to suggested that RAN can be conceptualized as a mini-circuit of the more intricate reading circuitry, and failure in one circuit is likely to be reflected in the other (Norton \& Wolf, 2012). Studies indeed demonstrate that the RAN-reading relationship is especially strong in dyslexic readers (e.g., Berninger, Abbott, Billingsley, \& Nagy, 2001; Berninger et al., 2006; Bowers \& Wolf, 1993; Catts, Fey, Zhang, \& Tomblin, 2001; de Jong \& van der Leij, 1999; Frijters et al., 2011; Lyytinen et al., 2004a; Lyytinen et al., 2004b; Meyer, Wood, Hart, \& Felton, 1998; Scarborough, 1998). In our at-risk sample we also found a significant relationship between kindergarten RAN and reading ability 2 grades later (chapter 3 ). The control children moreover outperform at-risk children on RAN as early as kindergarten as well as in grade 1 and 2 (for similar results see Torppa et al., 2010; Van Bergen, de Jong, Plakas, Maassen, \& van der Leij, 2012; Van Bergen et al., 2011). RAN deficits are known to persist over primary school years into adulthood (for an overview see Felton \& Brown, 1990; Jones, Branigan, \& Kelly, 2009; Thomson, Fryer, Maltby, \& Goswami, 2006; Vukovic, Wilson, \& Nash, 2004; Wolf et al., 2000b) and across alphabetic and non-alphabetic orthographies (Georgiou, Parrila, \& Liao, 2008; Tan, Laird, Li, \& Fox, 2005; Vaessen et al., 2010; Ziegler et al., 2010). Within our chapter 4 poor reader sample, we also identified a subtype with a specific RAN deficit next to the shared PA deficit (i.e., PA-RAN specific). This subtype showed an especially high familial predisposition of dyslexia.

Although the RAN-reading relationship is broadly acknowledged and RAN clearly resembles a similar, albeit simpler cross-modal mini-circuit of reading, earlier explanations of the RAN-reading 
relationship have been sought in understanding the relationship between RAN and PA and not in explanations of cross-modal efficiency. This originates in the reasoning that RAN involves fast and efficient retrieval of phonological code from memory and it was therefore thought to reflect a component of phonological processing (Torgesen, Wagner, Rashotte, Burgess, \& Hecht, 1997). Nevertheless, accumulating research indicates that RAN and PA are independent reading-related measures (for extensive reviews see Norton \& Wolf, 2012; Wolf, Bowers, \& Biddle, 2000a). We for example found that RAN explains unique predictive and discriminative variance in reading ability when PA is controlled for, indicating an independence of RAN and PA (also see e.g., Araújo, Faísca, Bramão, et al., 2011; Katzir et al., 2006; Kirby, Georgiou, Martinussen, \& Parrila, 2010; Vaessen \& Blomert, 2010). In our sample, RAN is also only modestly correlated with PA (also see the meta-analysis by Swanson, Trainin, Necoechea, \& Hammil, 2003 indicating an overall correlation of $r=.38$ ). Another indication of independence between RAN and PA are findings that relate PA to reading performance during the early steps of reading development, when reading relies heavily on decoding ability. RAN, on the other hand, has been associated to later stages of reading acquisition, associated with increased reading fluency (e.g., Vaessen \& Blomert, 2010).

Since PA and RAN seem to contribute to reading differently and in an attempt to move away from the dominant single PA deficit account of dyslexia, Wolf and Bowers (1999) proposed the doubledeficit (DD) hypothesis. This DD hypothesis proposes that reading problems can either be caused by a single PA deficit, a single RAN deficit or by a double deficit. Previous findings however indicate that a RAN-only deficit without PA problems is unlikely (Badian, 1997; Bowers \& Ishaik, 2003; Vaessen, Gerretsen, \& Blomert, 2009; Vukovic \& Siegel, 2006; Wagner \& Torgesen, 1987). For example, Vaessen et al. (2009) demonstrate that only $5 \%$ of their sample showed RAN difficulties without affected PA skills of any kind. Approximately $32 \%$ of their sample showed a single phoneme deletion deficit, $41 \%$ showed a double deficit and the rest showed no RAN or PA deficit. They moreover indicated that phonological processing and naming speed were not significantly correlated ( $r$ between .10 and .17 ) further indicating independence between PA and RAN in their sample. In our data driven clustering approach (chapter 4) we did not identify a poor reading subtype characterized by a sole, 'pure' speeded naming impairment either. Instead, the PA-RAN specific poor readers, the subtype at particular high familial risk of dyslexia, show a RAN deficit accompanying the shared common PA deficit.

More recently, reading researchers suggested that RAN deficits may reflect reduced efficiency in cross-modal integration of orthographic symbols and phonological codes (Araújo, Faísca, Bramão, et al., 2011; Araújo, Faísca, Petersson, \& Reis, 2011; Bowers \& Ishaik, 2003; Bowers \& Newby-Clark, 2002; 
Georgiou, Parrila, Kirby, \& Stephenson, 2008; Vaessen et al., 2009), which is an ability central to reading and more particular to efficient letter-speech sound binding (Blomert, 2011). RAN for example shows a stronger relation to reading ability of dyslexics during high-frequent word reading which involves a high degree of orthographic knowledge, compared to pseudo-word reading that is proposed to lean more on phonological decoding ability (Araújo, Faísca, Petersson, et al., 2011). The RAN tasks may in fact be a quantification of effortful LS integration processes during the early steps of reading development. But at this point, this is only speculation.

Together our findings show that a deficit in cross-modal association is already noticeable in atrisk children prior to reading in our samples (chapter 2 and 3). Our observed correlation between RAN and LS measures in at-risk kindergarten and grade 1 as well as a predictive relation of kindergarten RAN and LS knowledge to later reading show that both, RAN and LS, are relevant factors to quantify and predict reading outcome. The relation of RAN and LS needs further investigation within this cross modal integration context.

\subsection{GENES, ENVIRONMENT AND SUBTYPES OF READING DISABILITY}

Familial risk of dyslexia is known to be one of the strongest predictive factors of the disorder (Snowling, Gallagher, \& Frith, 2003; Thompson et al., 2015). Dyslexia is known to run in families (Pennington \& Olson, 2008). The elevated risk to develop the disorder in case of a first degree family member suffering for dyslexia is as high as of 40-50\% (Borstrøm \& Elbro, 1997; Byrne, Shankweiler, \& Hine, 2008; Lyytinen et al., 2006; Puolakanaho et al., 2007), which is a risk ten times larger than the population prevalence. Since children share both genes and home literacy environment with their close relatives, a geneenvironment interaction is always at play. Family history of dyslexia can thus not be considered a pure genetic trait (Pennington \& Olson, 2008; Plomin, Reiss, Hetherington, \& Howe, 1994; Rutter \& Silberg, 2002). Only genetic testing by means of twin study design can detangle how much variation in a trait is related to genes or to environmental factors. Such twin studies indicate that while dyslexic readers are strongly affected by genetic components, children with a more generally impaired profile showing deficits across various reading-related and general cognitive abilities are often more specially influenced by environmental risk factors and less by familial risk (Castles et al., 1999; Gayan \& Olson, 2001; Grigorenko, 2001; Rack \& Olson, 1993; Wadsworth, Olson, Pennington, \& DeFries, 2000). In other words, twin studies have identified two main types of reading failure, a primarily genetic, specific impaired type 
with adequate general cognitive capacities and a more generally impaired, environmentally influenced type (Castles et al., 1999; Friend, DeFries, \& Olson, 2008; Knopik et al., 2002; Olson, Wise, Conners, Rack, \& Fulker, 1989; Rack \& Olson, 1993; Wadsworth, Olson, \& DeFries, 2010; Wadsworth et al., 2000). Interestingly, neuroimaging results corroborated the existence of these two types of childhood reading failure amongst young adults followed prospectively and longitudinally from the age of five onward: one primarily genetic poor reader type with higher IQ scores and a more generally impaired type influenced most by environmental risk factors and poorer IO scores (Shaywitz \& Shaywitz, 2005). Real word reading resulted in a relative under activation in posterior neural systems in the superior temporal and occipitotemporal regions in the first subtype, while the later showed activated posterior systems. The results of our chapter 4 data-driven clustering attempt, which was based on behavioral cognitive vulnerability measures, were also in line with the existence of these two types of reading impairment. More specific, the unique and distinct subtypes we extracted were either influenced mainly by environmental risk factors like socio-economic status and poorer reading status of schools (i.e., type 1, 2 and 3) or characterized most by a high familial risk of dyslexia (i.e., type 4). Type 1 (i.e., Reading-only impaired readers) showed no cognitive deficits underlying their reading problems. The other three subtypes shared an underlying core phonological deficit (PA) with a variable and discriminative expression across the other underlying vulnerability markers: type 2 (i.e., General poor readers) performed poor across all reading-related and general cognitive markers included in clustering, type 3 (i.e., PA-LS specific poor readers) struggled with LS mapping next to PA problems, and type 4 (i.e., PA-RAN specific poor readers) showed a RAN deficit next to the common PA deficit.

The PA-RAN specific poor readers at high familial risk of dyslexia moreover showed significantly higher IQ scores compared to the other, more environmentally influenced, subtypes (i.e., approximately 1 standard deviations higher). This finding resonates well with the above mentioned results from Shaywitz and Shaywitz (2003), who also found that their suggested predominantly genetic influenced poor reading subtype showed higher IQ scores compared to the predominantly environmentally influenced subtype that demonstrated lower IQ scores. Although a gene-environmental interplay should always be considered, twin studies have indeed shown that readers with a higher IQ scores are more prone to the influence of higher genetic risk of reading deficits (Castles et al., 1999; Friend et al., 2008; Knopik et al., 2002; Rack \& Olson, 1993; Wadsworth et al., 2010; Wadsworth et al., 2000).

It is interesting to speculate that the PA-RAN specific type 4 poor readers at high familial risk for dyslexia and higher IQ scores represent mainly a predominantly genetic type of dyslexia. In line with this, it is shown that the PA and RAN specific cognitive deficits characteristic of this subtype are found to be 
more influenced by genetic risk than environmental factors (Gayan \& Olson, 2001; Petrill, DeaterDeckard, Thompson, DeThorne, \& Schatschneider, 2006; Samuelsson et al., 2005). LS deficits on the other hand are found to be more influenced by shared home or kindergarten environment with a limited degree of genetic influences (Byrne et al., 2006; Byrne et al., 2013; Samuelsson et al., 2005). Another possibility is that none of our identified subtypes specifically reflects a predominantly genetic type over the others, but that the genetic influence in the PA-RAN specific subtype is somewhat modified by their positive home or school environment and higher IQ scores. Compared to the other subtypes of poor reading, our PA-RAN specific type showed more favourable environmental influences like higher SES skills, higher levels of parental education and a good reading level at their primary school. In line with this suggestion, a more supportive, homogeneous home environment is found to be related with a higher genetic impact on cognitive deficits developed (Friend et al., 2008; Wadsworth et al., 2010; Wadsworth et al., 2000 for similar results). It is conceivable that a deficit like LS weakness, which as mentioned above is more influenced by weaker shared home or kindergarten environment, was ameliorated by the rich and presumably more supportive home environment found in our PA-RAN specific poor readers.

Finally, genes and environmental risk factors are not only found to variably influence the development of reading impairments and related cognitive deficits, these factors are also related to the ease with which such deficits are overcome. Environmentally caused deficits are likely to be more easily remediated by more adequate or intensive instruction, while the remediation of reading and readingrelated deficits due to a substantial larger genetic influence may be more challenging (Olson, 1999; Wadsworth et al., 2010). If an LS deficit is more influenced by shared home or school environment and a RAN deficit is mostly related to genetic influences, is follows that our PA-RAN specific type at high familial risk for dyslexia will experience greater difficulty to overcome or compensate for their underlying cognitive deficits. Subsequent research on the remediation effects for the subtypes identified in chapter 4 will be a promising way forward to confirm this suggestion.

Taken together, these results showed that it is possible to subtract distinct deficit patterns from the heterogeneous group of reading deficient readers, and more importantly also distinguish between those poor reader types characterized by a familial history of dyslexia and those influenced by environmental risk, solely based on behavioral cognitive measures. And although an IQ-reading discrepancy criterion alone has fallen out of favour for sole diagnostic purposes of dyslexia (Stanovich \& Siegel, 1994; Stuebing, Barth, Molfese, Weiss, \& Fletcher, 2009; Stuebing et al., 2002), it seems informative on the possible cause of the reading deficit experienced by the child (Friend et al., 2008; 
Wadsworth et al., 2010; Wadsworth et al., 2000) as well as serve as a valuable exclusion attribute during diagnostics (Coltheart \& Jackson, 1998; Rack \& Olson, 1993).

\subsection{CONCLUSION}

The research presented in this thesis supports a cognitive multi-componential view of dyslexia and argue that the various reading-related deficits found in our at-risk reading disabled samples seem to have an underlying cross-modal deficit in which efficient mapping of orthographic and phonological information plays a large role. With this, we add to the still relatively small but promising body of evidence indicating a cross-modal deficit account of dyslexia (Blau et al., 2010; Blau et al., 2009; Blomert, 2011; Blomert \& Froyen, 2010; Froyen, Bonte, Van Atteveldt, \& Blomert, 2009; Froyen, Van Atteveldt, Bonte, \& Blomert, 2007; Froyen et al., 2011; Hahn, Foxe, \& Molholm, 2014; Jones, Branigan, Parra, \& Logie, 2013; Kronschnabel et al., 2014; Mittag et al., 2013; Widmann, Schröger, Tervaniemi, Pakarinen, \& Kujala, 2012). Letter-speech sound and rapid naming ability, skills that both rely heavily on orthographicphonological links (e.g., Araújo, Faísca, Bramão, et al., 2011; Araújo, Faísca, Petersson, et al., 2011; Blau et al., 2010; Blomert, 2011; Georgiou, Parrila, \& Liao, 2008; Vaessen et al., 2009), predicted future reading abilities already prior to the start of reading instruction in our at-risk sample. A link between phoneme processing and reading emerged once reading ability was successfully on its way in typically developing children (Morais et al., 1979; Perfetti et al., 1987). We however found no evidence of a causative influence of PA deficits in the development of subsequent reading deficits, which reinforces the idea that exact PA develops as a consequence of orthographic influence - at least in the current tasks used to measure phonological awareness (Ziegler \& Goswami, 2005). This also indicates that this skill is not a pure spoken language marker of reading, but instead depends on the co-activation of orthographic knowledge, reflecting (in)efficiency of cross-modal matching (e.g., Landerl et al., 1996; McNorgan et al., 2013). The lack of a predictive PA-reading relationship we found in our at-risk sample, even after the start of reading instruction, may also be explained by such a weaker co-activation of orthographic information during phoneme processing. We point to the importance of fully understanding cross-modal abilities involved throughout the typically developing reading network. We also emphasis to separately explore the role of a phonological-orthographic connectivity deficit as a causative explanation of future reading deficits in pre-reading at-risk children (for a review see Blomert, 2011; Wimmer \& Schurz, 2010), 
since we found that different cognitive processes are at play during different developmental phases in at-risk and no-risk children.

If dyslexia deficits are more pronounced in cross-modal than in uni-modal conditions, this should also be reflected in future remediation efforts. These efforts traditionally focused on overcoming the assumed core PA deficit in dyslexia. Although PA training is found to advance PA skills (Bus \& van IJzendoorn, 1999), it is likely that a lack of focus on the orthographic influence linked to phonological codes is at the expense of overcoming the actual underlying deficit, namely a cross-modal binding deficit (McNorgan et al., 2013). We moreover have shown that it is possible to distinguish distinct subtypes of reading disability from a heterogeneous sample of poor readers based on behavioural measures. This provides a promising way forward for any diagnostic efforts to take into consideration the specific nature of the reading disability and consequently provide more adequate, tailored interventions, aiding the specific needs of each subtype. Some evidence already points to more successful outcomes of PA training when paired with alphabetical training (Bus \& van IJzendoorn, 1999; Ecalle, Magnan, Bouchafa, \& Gombert, 2009; Kast, Bezzola, Jancke, \& Meyer, 2011; Zaric et al., 2015). Clearly, if the goal of training is to ensure that dyslexics can become fluent and comprehensive readers, emphasis on orthographicphonological integration is eminent. Including risk and biomarkers research is also important since it is likely that reading deficits due to genetic risk are more difficult to remediate than others in which poor reading is related to unfavourable home or school environments. We started with listing the detected subtypes in the context of such a treatment sensitivity, but this is not more than a suggestion at this point and needs further evidence.

Another fruitful research area would be to test whether cross-modal deficits in dyslexia are specific to reading-related abilities such as PA, LS and RAN or more fundamental in nature. Although the research on more general audio-visual deficits in dyslexia is limited, some studies recently demonstrate more general, widespread non-linguistic audio-visual deficits in dyslexic readers (Jones et al., 2013; Kujala \& Näätänen, 2001; Veuillet, Magnan, Ecalle, Thai-Van, \& Collet, 2007; Widmann et al., 2012). Others propose that cross-modal deficits in dyslexia are restricted to orthographic-phonological elements, while basic audio-visual integration is intact (Kronschnabel et al., 2014). Nevertheless, further investigations on more basic audio-visual processing during the early steps of at-risk literacy acquisition is needed to resolve this debate. 


\section{REFERENCES}

Adams, M. J. (1990). Beginning to Read: Thinking and Learning about Print. Cambridge, Massachusetts: The MIT Press.

Araújo, S., Faísca, L., Bramão, I., Inácio, F., Petersson, K. M., \& Reis, A. (2011). Object naming in dyslexic children: More than a phonological deficit. The Journal of general psychology, 138(3), 215-228. doi:10.1002/dys.433.

Araújo, S., Faísca, L., Petersson, M. K., \& Reis, A. (2011). What does rapid naming tell us about dyslexia? Avances en Psicología Latinoamericana, 29, 199-213.

Babayiğit, S., \& Stainthorp, R. (2010). Component processes of early reading, spelling, and narrative writing skills in Turkish: a longitudinal study. Reading and Writing, 23, 539-568. doi: 10.1007/s11145-009-9173-y.

Badian, N. A. (1997). Dyslexia and the double deficit hypothesis. Annals of Dyslexia, 47, 69-87. doi:10.1007/s11881-997-0021-y.

Ben-Dror, I., Bentin, S., \& Frost, R. (1995). Semantic, phonologic, and morphologic skills in reading disabled and normal children: Evidence from perception and production of spoken Hebrew. Reading Research Quarterly, 876-893.

Berninger, V. W., Abbott, R. D., Billingsley, F., \& Nagy, W. (2001). Processes underlying timing and fluency: efficiency, automaticity, coordination and morphological awareness. In M. Wolf (Ed.), Dyslexia, fluency and the brain (pp. 383-414). Timonium, MD: York Press.

Berninger, V. W., Abbott, R. D., Thomson, J., Wagner, R., Swanson, H. L., Wijsman, E. M., \& Raskind, W. (2006). Modeling Phonological Core Deficits Within a Working Memory Architecture in Children and Adults With Developmental Dyslexia. Scientific Studies of Reading, 10(2), 165-198. doi:10.1207/s1532799xssr1002_3.

Birch, H. G., \& Belmont, L. (1964). Auditory-visual integration in normal and retarded readers. American Journal of Orthopsychiatry, 34(5), 852.

Bishop, D. V., \& Snowling, M. J. (2004). Developmental dyslexia and specific language impairment: Same or different? Psychological bulletin, 130(6), 858.

Blau, V., Reitler, J., Van Atteveldt, N., Gerretsen, P., Seitz, J., Goebel, R., \& Blomert, L. (2010). Deviant processing of letters and speech sounds as proximate cause of reading failure: an fMRI study of dyslexic children. Brain, 133(3), 868-879. doi:10.1093/brain/awp308. 
Blau, V., Van Atteveldt, N., Ekkebus, M., Goebel, R., \& Blomert, L. (2009). Reduced neural integration of letters and speech sounds links phonological and reading deficits in adult dyslexia. Current Biology, 19(6), 503-508. doi:10.1016/j.cub.2009.01.065.

Blomert, L. (2011). The neural signature of orthographic-phonological binding in successful and failing reading development. Neuroimage, 57(3), 695-703. doi:10.1016/j.neuroimage.2010.11.003.

Blomert, L., \& Froyen, D. (2010). Multi-sensory learning and learning to read. International journal of psychophysiology, 77(3), 195-204.

Boets, B., Smedt, B., Cleuren, L., Vandewalle, E., Wouters, J., \& Ghesquiere, P. (2010). Towards a further characterization of phonological and literacy problems in Dutch-speaking children with dyslexia. British Journal of Developmental Psychology, 28(1), 5-31. doi:10.1348/026151010X485223.

Borstrøm, I., \& Elbro, C. (1997). Prevention of dyslexia in kindergarten: effects of phoneme awareness training with children of dyslexic parents. In C. Hulme, \& M. Snowling (Ed.), Dyslexia: Biology, cognition, and intervention (pp. 235-253). London: Whurr Publishers.

Bowers, P. G., \& Ishaik, G. (2003). RAN's contribution to understanding reading disabilities. In S. Graham, H. Swanson, \& K. R. Lee Harris (Eds.), Handbook of learning disabilities (pp. 140-157). New York, US: Guilford Press.

Bowers, P. G., \& Newby-Clark, E. (2002). The role of naming speed within a model of reading acquisition. Reading and Writing: An Interdisciplinary Journal, 15(1-2), 109-126.

Bowers, P. G., \& Wolf, M. (1993). Theoretical links among naming speed, precise timing mechanisms and orthographic skill in dyslexia. Reading and Writing, 5(1), 69-85. doi:10.1007/BF01026919.

Braams, T., \& Bosman, A. M. T. (2000). Fonologische vaardigheden, geletterdheid en lees- en spellinginstructie. [Phonological skills, literacy, and reading and spelling instruction]. Tijdschrift voor orthopedagogiek, 39, 199-211. doi: 10.1007/s11881-009-0030-0.

Bradley, L., \& Bryant., P. E. (1983). Categorizing sounds and learning to read - a causal connection. Nature, 301, 419-421. doi:10.1038/301419a0.

Brem, S., Bach, S., Guttorm, T. K., Martin, E., Lyytinen, H., Brandeis, D., \& Richardson, U. (2010). Brain sensitivity to print emerges when children learn letter-speech sound correspondences. Proceedings of the national academy of sciences of the united states of america, 107(17), 79397944. doi:10.1073/pnas.0904402107.

Bruce, D. J. (1964). The analysis of word sounds by young children. British Journal of Educational Psychology, 34, 158-170. doi:10.1111/j.2044-8279.1964.tb00620.x. 
Bruck, M. (1992). Persistence of dyslexics' phonological awareness deficits. Developmental Psychology, 28(5), 874-886. doi:10.1037/0012-1649.28.5.874.

Bryant, P., \& Goswami, U. (1987). Beyond grapheme-phoneme correspondence.

Bus, A. G., \& van IJzendoorn, M. H. (1999). Phonological awareness and early reading: A meta-analysis of experimental training studies. Journal of Educational Psychology, 91(3), 403-414.

Byrne, B., Olson, R. K., Samuelsson, S., Wadsworth, S. J., Corley, R., DeFries, J. C., \& Willcutt, E. (2006). Genetic and environmental influences on early literacy. Journal of Research in Reading, 29(1), 3349. doi:10.1111/j.1467-9817.2006.00291.x.

Byrne, B., Shankweiler, D., \& Hine, D. W. (2008). Reading development in children at risk for dyslexia. In M. Mody \& K. Silliman (Eds.), Brain, Behavior and Learning in Language and Reading disorders (pp. 240-270). New York, US: Guilford Press.

Byrne, B., Wadsworth, S. J., Boehme, K., Talk, A. C., Coventry, W. L., Olson, R. K., . . Corley, R. (2013). Multivariate genetic analysis of learning and early reading development. Scientific Studies of Reading, 17(3), 224-242. doi:10.1080/10888438.2011.654298.

Cardoso-Martins, C., \& Pennington, B. F. (2004). The relationship between phoneme awareness and rapid serial naming skills and literacy acquisition: The role of developmental period and reading ability. Scientific Studies of Reading, 8, 27-52. doi:10.1207/s1532799xssr0801_3.

Castles, A., \& Coltheart, M. (2004). Is there a causal link from phonological awareness to success in learning to read? Cognition, 91(1), 77-111. doi:10.1016/S0010-0277(03)00164-1.

Castles, A., Coltheart, M., Wilson, K., Valpied, J., \& Wedgwood, J. (2009). The genesis of reading ability: What helps children learn letter-sound correspondences? Journal of Experimental Child Psychology, 104(1), 68-88.

Castles, A., Datta, H., Gayan, J., \& Olson, R. K. (1999). Varieties of Developmental Reading Disorder: Genetic and Environmental Influences. Journal of Experimental Child Psychology, 72(2), 73-94. doi:10.1006/jecp.1998.2482.

Castles, A., Davis, C., \& Forster, K. I. (2003). Word recognition development in children. Masked priming: The state of the art, 345-360.

Catts, H. W., Fey, M. E., Zhang, X., \& Tomblin, J. B. (2001). Estimating risk for future reading difficulties in kindergarten children: A research-based model and its clinical implications. Language, Speech, and Hearing Services in Schools, 32, 38-50. doi:10.1044/0161-1461(2001/004).

Coltheart, M., \& Jackson, N. E. (1998). Defining Dyslexia. Child and Adolescent Mental Health, 3(1), 12-16. doi:10.1111/1475-3588.00202. 
De Gelder, B., Vroomen, J., \& Bertelson, P. (1993). The effects of alphabetic-reading competence on language representation in bilingual Chinese subjects. Psychological research, 55(4), 315-321.

de Jong, P. F., \& van der Leij, A. (1999). Specific contributions of phonological abilities to early reading acquisition: results from a Dutch latent variable longitudinal study. Journal of Educational Psychology, 91(3), 450-476. doi:10.1037/0022-0663.91.3.450.

De Santos Loureiro, C., Willadino Braga, L., Souza, L. d. N., Queiroz, E., \& Dellatolas, G. (2004). Degree of illiteracy and phonological and metaphonological skills in unschooled adults. Brain and Language, 89(3), 499-502. doi:10.1016/j.bandl.2003.12.008.

Dehaene, S., Pegado, F., Braga, L. W., Ventura, P., G., N. F., Jobert, A., . . Cohen, L. (2010). How learning to read changes the cortical networks for vision and language. Science, 330(6009), 1359-1364.

Ecalle, J., Magnan, A., Bouchafa, H., \& Gombert, J. E. (2009). Computer-based training with orthophonological units in dyslexic children: new investigations. Dyslexia, 15(3), 218-238.

Ehri, L. C. (2005). Development of sight word reading: Phases and findings. In M. J. Snowling \& C. Hulme (Eds.), The Science of Reading: A Handbook (pp. 135-154). Oxford: Blackwell publishing.

Ehri, L. C., Nunes, S. R., Stahl, S. A., \& Willows, D. M. (2001). Systematic phonics instruction helps students learn to read: Evidence from the National Reading Panel's meta-analysis. Review of educational research, 71(3), 393-447. doi:10.3102/00346543071003393.

Ehri, L. C., \& Wilce, L. S. (1980). The influence of orthography on readers' conceptualization of the phonemic structure of words. Applied Psycholinguistics, 1(04), 371-385.

Elbro, C., Borstrøm, I., \& Petersen, D. K. (1998). Predicting dyslexia from kindergarten. The importance of distinctness of phonological representations of lexical items. Reading Research Quarterly, 33(1), 36-60. doi:10.1598/RRQ.33.1.3.

Felton, R. H., \& Brown, I. S. (1990). Phonological processes as predictors of specific reading skills in children at risk for reading failure. Reading and Writing: An Interdisciplinary Journal, 2(1), 39-59. doi:10.1007/BF00383373

Friend, A., DeFries, J. C., \& Olson, R. K. (2008). Parental education moderates genetic influences on reading disability. Psychological Science, 19(11), 1124-1130. doi:10.1111/j.14679280.2008.02213.x.

Frijters, J. C., Lovett, M. W., Steinbach, K. A., Wolf, M., Sevcik, R. A., \& Morris, R. D. (2011). Neurocognitive predictors of reading outcomes for children with reading disabilities. Journal of Learning Disabilities, 44(2), 150-166. 
Froyen, D., Bonte, M., Van Atteveldt, N., \& Blomert, L. (2009). The long road to automation: neurocognitive development of letter-speech sound processing. Journal of Cognitive Neuroscience, 21, 567-580. doi:10.1162/jocn.2009.21061.

Froyen, D., Van Atteveldt, N., Bonte, M., \& Blomert, L. (2007). The long road to automaticity: Development of letter - speech sound integration in normal and dyslexic readers. Paper presented at the Annual Meeting SSSR, Prague.

Froyen, D., Willems, G., \& Blomert, L. (2011). Evidence for a specific cross-modal association deficit in dyslexia: an electrophysiological study of letter-speech sound processing. Developmental Science, 14(4), 635-648. doi:10.1111/j.1467-7687.2010.01007.x.

Gallagher, A., Frith, U., \& Snowling, M. J. (2000). Precursors of literacy-delay among children at genetic risk of dyslexia. Journal of Child Psychology \& Psychiatry, 41(2), 203-213. doi:10.1111/1469 7610.00601.

Gayan, J., \& Olson, R. K. (2001). Genetic and Environmental Influences on Orthographic and Phonological Skills in Children With Reading Disabilities. Developmental Neuropsychology, 20(2), 483-507. doi:10.1207/s15326942dn2002_3.

Gelder, B., \& Vroomen, J. (1991). 5. Phonological Deficits: A Source of Asymmetries Between Developmental and Acquired Dyslexia. Mind \& Language, 6(2), 123-129.

Georgiou, G. K., Parrila, R., Kirby, J. R., \& Stephenson, K. (2008). Rapid naming components and their relationship with phonological awareness, orthographic knowledge, speed of processing, and different reading outcomes. Scientific Studies of Reading, 12(4), 325-350. doi:10.1080/10888430.

Georgiou, G. K., Parrila, R., \& Liao, C. H. (2008). Rapid naming speed and reading across languages that vary in orthographic consistency. Reading and Writing, 21(9), 885-903.

Goswami, U. (2000). Phonological representations, reading development and dyslexia: towards a crosslinguistic theoretical framework. Dyslexia, 6(2), 133-151.

Goswami, U., \& Bryant, P. (1990). Phonological skills and learning to read. Hove, UK: Lawrence Erlbaum.

Grigorenko, E. L. (2001). Developmental Dyslexia: An Update on Genes, Brains, and Environments. Journal of Child Psychology and Psychiatry, 42(1), 91-125. doi:10.1111/1469-7610.00704.

Hahn, N., Foxe, J. J., \& Molholm, S. (2014). Impairments of multisensory integration and cross-sensory learning as pathways to dyslexia. Neuroscience \& Biobehavioral Reviews, 47, 384-392.

Harris, M., \& Giannouli, V. (1999). Learning to read and spell in Greek: The importance of letter knowledge and morphological awareness. Learning to read and write: $A$ cross-linguistic perspective, 4, 51-70. 
Helenius, P., Tarkiainen, A., Cornelissen, P., Hansen, P., \& Salmelin, R. (1999). Dissociation of normal feature analysis and deficient processing of letter-strings in dyslexic adults. Cerebral Cortex, 9(5), 476-483.

Holopainen, L., Ahonen, T., \& Lyytinen, H. (2001). Predicting delay in reading achievement in a highly transparent language. Journal of Learning Disabilities, 34(5), 401-413. doi:10.1177/002221940103400502.

Hulme, C., Caravolas, M., Málková, G., \& Brigstocke, S. (2005). Phoneme isolation ability is not simply a consequence of letter-sound knowledge. Cognition, 97(1), B1-B11.

Jones, M. W., Branigan, H. P., \& Kelly, M. L. (2009). Dyslexic and nondyslexic reading fluency: Rapid automatized naming and the importance of continuous lists. Psychonomic bulletin \& review, $16(3), 567-572$.

Jones, M. W., Branigan, H. P., Parra, M. A., \& Logie, R. H. (2013). Cross-modal binding in developmental dyslexia. Journal of Experimental Psychology: Learning, Memory, and Cognition, 39(6), 1807.

Kast, M., Bezzola, L., Jancke, L., \& Meyer, M. (2011). Multi- and unisensory decoding of words and nonwords result in differential brain responses in dyslexic and nondyslexic adults. Brain Lang, 119(3), 136-148. doi:10.1016/j.bandl.2011.04.002.

Katzir, T., Youngsuk, K., Wolf, M., O'Brien, B., Kennedy, B., Lovett, M., \& Morris, R. (2006). Reading fluency: the whole is more than the parts. Annals of Dyslexia, 56, 51-82. doi:doi:10.1007/s11881006-0003-5.

Kirby, J. R., Georgiou, G. K., Martinussen, R., \& Parrila, R. (2010). Naming speed and reading: From prediction to instruction. Reading Research Quarterly, 45(3), 341-362.

Knopik, V., Smith, S., Cardon, L., Pennington, B. F., Gayan, J., Olson, R. K., \& DeFries, J. C. (2002). Differential Genetic Etiology of Reading Component Processes as a Function of IQ. Behavior Genetics, 32(3), 181-198. doi:10.1023/A:1016069012111.

Kronschnabel, J., Brem, S., Maurer, U., \& Brandeis, D. (2014). The level of audiovisual print-speech integration deficits in dyslexia. Neuropsychologia, 62, 245-261.

Kujala, T., \& Näätänen, R. (2001). The mismatch negativity in evaluating central auditory dysfunction in dyslexia. Neuroscience \& Biobehavioral Reviews, 25(6), 535-543.

Landerl, K., Frith, U., \& Wimmer, H. (1996). Intrusion of orthographic knowledge on phoneme awareness: Strong in normal readers, weak in dyslexic readers. Applied Psycholinguistics, 17(1), 1-14. 
Landerl, K., \& Wimmer, H. (2008). Development of word reading fluency and spelling in a consistent orthography: an 8-year follow-up. Journal of Educational Psychology, 100, 150-161. doi:10.1037/0022-0663.100.1.150.

Landgraf, S., Beyer, R., Hild, I., Schneider, N., Horn, E., Schaadt, G., . . van der Meer, E. (2012). Impact of phonological processing skills on written language acquisition in illiterate adults. Developmental cognitive neuroscience, 2, S129-S138.

Lyytinen, H., Ahonen, T., Eklund, K., Guttorm, T., Kulju, P., Laakso, M. L., . . Viholainen, H. (2004a). Early Development of Children at Familial Risk for Dyslexia: Follow-up from Birth to School Age. Dyslexia, 10(3), 146-178. doi:10.1002/dys.274.

Lyytinen, H., Aro, M., Eklund, K., Erskine, J., Guttorm, T., Laakso, M. L., . . . Richardson, U. (2004b). The development of children at familial risk for dyslexia: birth to early school age. Annals of Dyslexia, 54(2), 184-220. doi:10.1007/s11881-004-0010-3.

Lyytinen, H., Erskine, J., Tolvanen, A., Torppa, M., Poikkeus, A., \& Lyytinen, P. (2006). Trajectories of reading development: A follow-up from birth to school age of children with and without risk for dyslexia. Merrill-Palmer Quarterly, 52(3), 514-546. doi:10.1353/mpq.2006.0031.

Macmillan, B. M. (2002). Rhyme and reading: a critical review of the research methodology. Journal of Research in Reading, 25(1), 4-42. doi:10.1111/1467-9817.00156.

Mann, V. A., \& Wimmer, H. (2002a). Phoneme awareness and pathways into literacy: A comparison of German and American children. Reading and Writing: An Interdisciplinary Journal, 15, 653-682. doi:10.1023/A:1020984704781.

Mann, V. A., \& Wimmer, H. (2002b). Phoneme awareness and pathways into literacy: A comparison of German and American children. Reading and Writing, 15(7-8), 653-682. doi:10.1023/a:1020984.

Mauer, U., Brem, S., Bucher, K., \& Brandeis, D. (2005). Emerging neurophysiological specialization for letter strings. Journal of Cognitive Neuroscience, 17, 1532-1552.

Maurer, U., Brem, S., Bucher, K., Kranz, F., Benz, R., Steinhausen, H.-C., \& Brandeis, D. (2007). Impaired tuning of a fast occipito-temporal response for print in dyslexic children learning to read. Brain, $130(12), 3200-3210$.

McCandliss, B. D., \& Noble, K. G. (2003). The development of reading impairment: a cognitive neuroscience model. Mental Retardation and Developmental Disabilities Research Review, 9(3), 196-204. 
McNorgan, C., Randazzo-Wagner, M., \& Booth, J. R. (2013). Cross-modal integration in the brain is related to phonological awareness only in typical readers, not in those with reading difficulty. Front Hum Neurosci, 7, 388. doi:10.3389/fnhum.2013.00388.

Meyer, M. S., Wood, F. B., Hart, L. A., \& Felton, R. H. (1998). Selective predictive value of rapid automatized naming in poor readers. Journal of Learning Disabilities, 31(2), 106-117.

Mittag, M., Thesleff, P., Laasonen, M., \& Kujala, T. (2013). The neurophysiological basis of the integration of written and heard syllables in dyslexic adults. Clinical Neurophysiology, 124(2), 315-326.

Morais, J., Bertelson, P., Cary, L., \& Alegria, J. (1986). Literacy training and speech segmentation. Cognition, 24, 45-64. doi:10.1016/0010-0277(86)90004-1.

Morais, J., Cary, L., Alegria, J., \& Bertelson, P. (1979). Does awareness of speech as a sequence of phones arise spontaneously? Cognition, 7, 323-331. doi:10.1016/0010-0277(79)90020-9.

Morris, R. D., Stuebing, K. K., Fletcher, J. M., Shaywitz, S. E., Lyon, G. R., Shankweiler, D. P., ... Shaywitz, B. A. (1998). Subtypes of reading disability: Variability around a phonological core. Journal of Educational Psychology, 90(3), 347-373. doi:10.1037/0022-0663.90.3.347.

Norton, E. S., \& Wolf, M. (2012). Rapid automatized naming (RAN) and reading fluency: Implications for understanding and treatment of reading disabilities. Annual review of psychology, 63, 427-452.

Olson, R. K. (1999). Genes, environment, and reading disabilities. Perspectives on learning disabilities, 322.

Olson, R. K., Wise, B., Conners, F., Rack, J., \& Fulker, D. (1989). Specific deficits in component reading and language skills: Genetic and environmental influences. Journal of Learning Disabilities., 22, 339348. doi:10.1177/002221948902200604.

Parrila, R., Kirby, J. R., \& McQuarrie, L. (2004). Articulation rate, naming speed, verbal short-term memory, and phonological awareness: Longitudinal predictors of early reading development? Scientific Studies of Reading, 8(1), 3-26.

Pennington, B. F. (2006). From single to multiple deficit models of developmental disorders. Cognition, 101(2), 385-413.

Pennington, B. F., \& Lefly, D. L. (2001). Early reading development in children at family risk for dyslexia. Child development, 72(3), 816-833. doi:10.1111/1467-8624.00317.

Pennington, B. F., \& Olson, R. K. (2008). Genetics of Dyslexia. The Science of Reading: A Handbook, 453472. doi:10.1002/9780470757642.ch24.

Perfetti, C. A., Beck, I., Bell, L. C., \& Hughes, C. (1987). Phonemic knowledge and learning to read are reciprocal: a longitudinal study of first grade children. Merill-Palmer Quarterly, 33(3), 283-319. 
Petrill, S. A., Deater-Deckard, K., Thompson, L. A., DeThorne, L. S., \& Schatschneider, C. (2006). Genetic and Environmental Effects of Serial Naming and Phonological Awareness on Early Reading Outcomes. Journal of Educational Psychology, 98(1), 112-121. doi:10.1037/0022-0663.98.1.112.

Plomin, R., Reiss, D., Hetherington, E. M., \& Howe, G. W. (1994). Nature and nurture: genetic contributions to measures of the family environment. Developmental Psychology, 30(1), 32. doi:10.1037/0012-1649.30.1.32.

Pugh, K. R., Mencl, W. E., Jenner, A. R., Katz, L., Frost, S. J., Lee, J. R., . . Shaywitz, B. A. (2001). Neurobiological studies of reading and reading disability. Journal of communication disorders, 34(6), 479-492.

Puolakanaho, A., Ahonen, T., Aro, M., Eklund, K., Leppänen, P., Poikkeus, A., . . Lyytinen, H. (2008). Developmental Links of Very Early Phonological and Language Skills to Second Grade Reading Outcomes: Strong to Accuracy but Only Minor to Fluency. Journal of Learning Disabilities, 41(4), 353-370. doi:10.1177/0022219407311747.

Puolakanaho, A., Ahonen, T., Aro, M., Leppanen, P. H. T., Tolvanen, A., Lyytinen, H., . . Eklund, K. (2007). Very early phonological and language skills: Estimating individual risk of reading disability. Journal of Child Psychology and Psychiatry, 48, 923-931. doi:10.1111/j.1469-7610.2007.01763.x.

Rack, J. P., \& Olson, R. K. (1993). Phonological Deficits, IQ, and Individual Differences in Reading Disability: Genetic and Environmental Influences. Developmental Review, 13(3), 269-278. doi:10.1006/drev.1993.1013.

Ramus, F. (2003). Developmental dyslexia: specific phonolical deficit or general sensorimotor dysfunction? Current Opinion in Neurobiology, 13, 212-218. doi:10.1016/\$0959-4388(03)00035

Ramus, F., Rosen, S., Dakin, S. C., Day, B. L., Castellote, J. M., White, S., \& Frith, U. (2003). Theories of developmental dyslexia: Insights from a multiple case study of dyslexic adults. Brain: A Journal of Neurology, 126(4), 841-865. doi:10.1093/brain/awg076.

Read, C., Yun-Fei, Z., Hong-Yin, N., \& Bao-Qing, D. (1986). The ability to manipulate speech sounds depends on knowing alphabetic writing. Cognition, 24(1), 31-44.

Rutter, M., \& Silberg, J. (2002). Gene-environment interplay in relation to emotional and behavioral disturbance. Annual review of psychology, 53(1), 463-490. doi:10.1146/annurev.psych.53.10090.

Samuelsson, S., Byrne, B., Quain, P., Wadsworth, S., Corley, R., DeFries, J. C., . . Olson, R. K. (2005). Environmental and genetic influences on prereading skills in Australia, Scandinavia, and the United States. Journal of Educational Psychology, 97(4), 705-722. doi:10.1037/00220663.97.4.705. 
Scarborough, H. S. (1989). Prediction of reading disability from familial and individual differences. Journal of Educational Psychology, 81(1), 101-108. doi:10.1037/0022-0663.81.1.101.

Scarborough, H. S. (1990). Very early language deficits in dyslexic children. Child development, 61, 17281743. doi:10.2307/1130834.

Scarborough, H. S. (1998). Predicting the future achievement of second graders with reading disabilities: Contributions of phonemic awareness, verbal memory, rapid naming, and IQ. Annals of Dyslexia, 48(1), 115-136. doi:10.1007/s11881-998-0006-5.

Schatschneider, C., Fletcher, J. M., Francis, D. J., Carlson, C. D., \& Foorman, B. R. (2004). Kindergarten Prediction of Reading skills: a longitudinal comparative analysis. Journal of Educational Psychology, 96, 265-282. doi:10.1037/0022-0663.96.2.265.

Schlaggar, B. L., \& McCandliss, B. D. (2007). Development of neural systems for reading. Annual Review of Neuroscience, 30, 475-503.

Seidenberg, M. S., \& Tanenhaus, M. K. (1979). Orthographic effects on rhyme monitoring. Journal of Experimental Psychology: Human Learning and Memory, 5(6), 546.

Seymour, P. (2005). Early reading development in European Orthographies. doi:10.1002/978047075764.

Seymour, P., Aro, M., \& Erskine, J. (2003). Foundation literacy acquisition in European orthographies. British Journal of Psychology, 94(2), 143-174. doi:10.1348/000712603321661859.

Share, D. L. (1995). Phonological recoding and self-teaching: sine qua non of reading acquisition. Cognition, 55, 151-218. doi:10.1016/0010-0277(94)00645-2.

Share, D. L., Jorm, A. F., Maclean, R., \& Matthews, R. (1984). Sources of individual differences in reading acquisition. Journal of Educational Psychology, 76, 1309-1324. doi:doi:10.1037/00220663.76.6.1309.

Shaywitz, S. E., \& Shaywitz, B. A. (2005). Dyslexia (Specific Reading Disability). Biological Psychiatry, 57(11), 1301-1309. doi:10.1016/j.biopsych.2005.01.043.

Snowling, M. J. (2000). Dyslexia. Oxford: Blackwell Publishers.

Snowling, M. J., Gallagher, A., \& Frith, U. (2003). Family risk of dyslexia is continuous: individual differences in the precursors of reading skill. Child development, 74(2), 358-373. doi:10.1111/1467-8624.7402003.

Stanovich, K. E. (1986). Matthew effects in reading: Some consequences of individual differences in the acquisition of literacy. Reading Research Quarterly, 360-407. 
Stanovich, K. E., \& Siegel, L. S. (1994). Phenotypic performance profile of children with reading disabilities: A regression-based test of the phonological-core-variable-difference model. Journal of Educational Psychology, 86, 24-53. doi:10.1037//0022-0663.86.1.24.

Stuebing, K. K., Barth, A. E., Molfese, P. J., Weiss, B., \& Fletcher, J. M. (2009). IQ Is Not Strongly Related to Response to Reading Instruction: A Meta-Analytic Interpretation. Except Child, 76(1), 31-51.

Stuebing, K. K., Fletcher, J. M., LeDoux, J. M., Lyon, G. R., Shaywitz, S. E., \& Shaywitz, B. A. (2002). Validity of IQ-Discrepancy Classifications of Reading Disabilities: A Meta-Analysis. American Educational Research Journal, 39(2), 469-518. doi:10.3102/00028312039002469.

Sunseth, K., \& Bowers, P. G. (2002). Rapid naming and phonemic awareness: Contributions to reading, spelling, and orthographic knowledge. Scientific Studies of Reading, 6, 401-429. doi:10.1207/S1532799XSSR0604_05.

Swanson, H. L., Trainin, G., Necoechea, D. M., \& Hammil, D. D. (2003). Rapid naming, phonological awareness, and reading: a meta-analysis of the correlational evidence. Review of educational research, 73(4), 407-440.

Tan, L. H., Laird, A. R., Li, K., \& Fox, P. T. (2005). Neuroanatomical correlates of phonological processing of Chinese characters and alphabetic words: A meta-analysis. Human brain mapping, 25(1), 83-91.

Thompson, P. A., Hulme, C., Nash, H. M., Gooch, D., E., H. T., \& Snowling, M. J. (2015). Developmental dyslexia: predicting individual risk. Journal of Child Psychology and Psychiatry, 56(9), 976-987.

Thomson, J. M., Fryer, B., Maltby, J., \& Goswami, U. (2006). Auditory and motor rhythm awareness in adults with dyslexia. Journal of Research in Reading, 29(3), 334-348.

Torgesen, J. K., Wagner, R. K., Rashotte, C. A., Burgess, S. R., \& Hecht, S. A. (1997). Contributions of phonological awareness and rapid automatic naming ability to the growth of word-reading skills in second- to fifth-grade children. Scientific Studies of Reading, 1(2), 161-185. doi:10.1207/s1532799xssr0102_4.

Torppa, M., Lyytinen, P., Erskine, J., Eklund, K., \& Lyytinen, H. (2010). Language development, literacy skills, and predictive connections to reading in Finnish children with and without familial risk for dyslexia. Journal of Learning Disabilities.

Turkeltaub, P. E., Gareau, L., Flowers, D. L., Zeffiro, T. A., \& Eden, G. F. (2003). Development of neural mechanisms for reading. Nature neuroscience, 6(7), 767-773.

Vaessen, A., Bertrand, D., Tóth, D., Csépe, V., Faísca, L., Reis, A., \& Blomert, L. (2010). Cognitive development of fluent word reading does not qualitatively differ between transparent and opaque orthographies. Journal of Educational Psychology, 102, 827-842. doi:10.1037/a0019465. 
Vaessen, A., \& Blomert, L. (2010). Long term cognitive dynamics of fluent reading development. Journal of Experimental Child Psychology, 105, 213-231. doi:10.1016/j.jecp.2009.11.005.

Vaessen, A., Gerretsen, P., \& Blomert, L. (2009). Naming problems do not reflect a second, independent core deficit in dyslexia: 'Double deficits' explored. Journal of Experimental Child Psychology, 103, 202-221. doi:10.1016/j.jecp.2008.12.004.

Van Atteveldt, N., Formisano, E., Goebel, R., \& Blomert, L. (2004). Integration of letters and speech sounds in the human brain. Neuron, 43(2), 271-282.

Van Bergen, E., de Jong, P. F., Plakas, A., Maassen, B., \& van der Leij, A. (2012). Child and parental literacy levels within families with a history of dyslexia. Journal of Child Psychology and Psychiatry, 53(1), 28-36. doi:10.1111/j.1469-7610.2011.02418.x.

Van Bergen, E., de Jong, P. F., Regtvoort, A., Oort, F., van Otterloo, S., \& van der Leij, A. (2011). Dutch children at familial risk for dyslexia: precursors, reading development, and parental effects. Dyslexia, 17(1), 2-18. doi:10.1002/dys.423.

van Bergen, E., van der Leij, A., \& de Jong, P. F. (2014). The intergenerational multiple deficit model and the case of dyslexia. Frontiers in Human Neuroscience, 8, 346. doi:10.3389/fnhum.2014.00346

Vellutino, F. R. (1979). Dyslexia: Theory and research. Cambridge, MA: MIT Press.

Vellutino, F. R., Fletcher, J. M., Snowling, M. J., \& Scanlon, D. M. (2004). Specific reading disability (dyslexia): what have we learned in the past four decades? Journal of Child Psychology and Psychiatry, 45(1), 2-40. doi:10.1046/j.0021-9630.2003.00305.x.

Vellutino, F. R., Scanlon, D. M., Sipay, E. R., Small, S. G., Pratt, A., Chen, R., \& Denckla, M. B. (1996). Cognitive profiles of difficult-to-remediate and readily remediated poor readers: Early intervention as a vehicle for distinguishing between cognitive and experiential deficits as basic causes of specific reading disability. Journal of Educational Psychology, 88(4), 601.

Ventura, P., Kolinsky, R., Brito-Mendes, C., \& Morais, J. (2001). Mental representations of the syllable internal structure are influenced by orthography. Language and cognitive processes, 16(4), 393418.

Veuillet, E., Magnan, A., Ecalle, J., Thai-Van, H., \& Collet, L. (2007). Auditory processing disorder in children with reading disabilities: effect of audiovisual training. Brain, 130(11), 2915-2928.

Vukovic, R. K., \& Siegel, L. S. (2006). The double-deficit hypothesis: A comprehensive analysis of the evidence. Journal of Learning Disabilities, 39(1), 25-47. doi:10.1177/00222194060390010401. 
Vukovic, R. K., Wilson, A. M., \& Nash, K. K. (2004). Naming speed deficits in adults with reading disabilities: a test of the double-deficit hypothesis. Journal of Learning Disabilities, 37(5), 440450 .

Wadsworth, S. J., Olson, R. K., \& DeFries, J. C. (2010). Differential genetic etiology of reading difficulties as a function of IQ: an update. Behavior Genetics, 40(6), 751-758. doi:10.1007/s10519-010-9349.

Wadsworth, S. J., Olson, R. K., Pennington, B. F., \& DeFries, J. C. (2000). Differential Genetic Etiology of Reading Disability as a Function of IQ. Journal of Learning Disabilities, 33(2), 192-199. doi:10.1177/002221940003300207.

Wagner, R. K., \& Torgesen, J. K. (1987). The nature of phonological processing and its causal role in the acquisition of reading skills. Psychological bulletin, 101, 192-212. doi:10.1037/00332909.101.2.192.

Wagner, R. K., Torgesen, J. K., \& Rashotte, C. A. (1994). Development of reading-related phonological processing abilities: New evidence of bidirectional causality from a latent variable longitudinal study. Developmental Psychology, 30, 73-87. doi:10.1037/0012-1649.30.1.73.

Wagner, R. K., Torgesen, J. K., Rashotte, C. A., Hecht, S. A., Barker, T. A., Burgess, S. R., . . Garon, T. (1997). Changing relations between phonological processing abilities and word-level reading as children develop from beginning to skilled readers: a 5-year longitudinal study. Developmental Psychology, 33(3), 468-479. doi:10.1037/0012-1649.33.3.468.

Wesseling, R., \& Reitsma, P. (2000). The transient role of explicit phonological recoding for reading acquisition. Reading and Writing, 13, 313-336. doi:10.1023/A:1026432502088.

Widmann, A., Schröger, E., Tervaniemi, M., Pakarinen, S., \& Kujala, T. (2012). Mapping symbols to sounds: electrophysiological correlates of the impaired reading process in dyslexia. Front Psychol, 3(60), 1-12.

Williams, J., \& O'Donovan, M. C. (2006). The genetics of developmental dyslexia. European Journal of Human Genetics, 14(6), 681-689. doi:10.1038/sj.ejhg.5201575.

Wimmer, H., Landerl, K., Linortner, R., \& Hummer, P. (1991). The relationship of phonemic awareness to reading acquisition: more consequence than precondition but still important. Cognition, 40(3), 219-249. doi:10.1016/0010-0277(91)90026-Z.

Wimmer, H., \& Mayringer, H. (2002). Dysfluent reading in the absence of spelling difficulties: A specific disability in regular orthographies. Journal of Educational Psychology, 94(2), 272-277.

Wimmer, H., \& Schurz, M. (2010). Dyslexia in regular orthographies: manifestation and causation. Dyslexia, 16(4), 283-299. 
Wolf, M., \& Bowers, P. G. (1999). The double-deficit hypothesis for the developmental dyslexias. Journal of Educational Psychology, 91(3), 415-438. doi:10.1037/0022-0663.91.3.415.

Wolf, M., Bowers, P. G., \& Biddle, K. (2000a). Naming-speed processes, timing, and reading A conceptual review. Journal of Learning Disabilities, 33(4), 387-407.

Wolf, M., Bowers, P. G., \& Biddle, K. (2000b). Naming-speed processes, timing, and reading: A conceptual review. Journal of Learning Disabilities, 33(4), 387-407. doi:10.1177/002221940003300409.

Zaric, G., Fraga Gonzalez, G., Tijms, J., van der Molen, M. W., Blomert, L., \& Bonte, M. (2015). Crossmodal deficit in dyslexic children: practice affects the neural timing of letter-speech sound integration. Front Hum Neurosci, 9, 369. doi:10.3389/fnhum.2015.00369.

Žarić, G., González, G. F., Tijms, J., van der Molen, M. W., Blomert, L., \& Bonte, M. (2014). Reduced neural integration of letters and speech sounds in dyslexic children scales with individual differences in reading fluency. PLoS ONE, 9(10), e110337.

Ziegler, J. C., Bertrand, D., Tóth, D., Csépe, V., Reis, A., Faísca, L., \& ...Blomert, L. (2010). Orthographic Depth and its impact on universal predictors of reading: a cross-language investigation. Psychological Science, 21, 551-559. doi:2010-09433-018.

Ziegler, J. C., \& Goswami, U. (2005). Reading acquisition, developmental dyslexia, and skilled reading across languages: a psycholinguistic grain size theory. Psychological bulletin, 131(1), 3-29. doi:10.1037/0033-2909.131.1.3. 
CHAPTER 7

KNOWLEDGE VALORISATION 


\subsection{RELEVANCE}

The ability to read and write effectively serves as an important dimension of human capital in today's modern and knowledge based societies. Reading is a complex cognitive process that involves the mastery of a set of arbitrary printed symbols which enable us to acquire meaning from written linguistic messages. While humans are born to speak, literacy ability is an acquired set of skills that doesn't come natural. Instead, it requires intensive and explicit instruction. It is therefore remarkable that the large majority of children learn to read and write with relative ease. Nevertheless, there is still a substantial part of the population that struggles with the acquisition of reading skills despite adequate reading instruction and sufficient cognitive ability. These people are suffering from developmental dyslexia, a specific learning disability with a neurological basis that is known to run in families (Pennington \& Olson, 2008). Most researchers agree that dyslexia has a genetic component and difficulty with fluent reading is the most characteristic symptom that can persist into adulthood (Katzir et al., 2006). While the present thesis sets out to investigate the primary cognitive symptoms and underlying causes of this disorder to possibly aid future diagnostic and intervention efforts, it is important to also acknowledge the secondary consequences with which dyslexic readers struggle. Not being successful in de acquisition of literacy can result in emotional and behavioral problems, such as frustration, low self-esteem and motivational challenges, which, in turn, may have negative effects on social well-being, economical success and educational opportunities. Most professions in Western cultures require adequate literacy skills, and the need for highly educated people is increasing rapidly in an era of fully autonomous cars, 3D printing and artificial intelligence, causing more and more jobs to become obsolete. If we look at the numbers, the human capital that is affected by dyslexia in the Netherlands alone is approximately 640.000 individuals of the general population. Unsurprisingly, dyslexia is considered the most prevailing developmental disorder acknowledged in the Western world. If I could simply answer the question central in this valorisation paragraph, as to how my research may disseminate into value for society, it would be that it adds to the theoretical understanding of dyslexia deficits, and as such, would benefit dyslexic individuals and those that guide them in the future. 


\subsection{THE VALORISATION CHALLENGE}

Nowadays, academic communities are expected to increase knowledge valorisation of its scientific output. Maastricht University challenges its PhD students to explore the bridge between science and the market or practice, and, to this aim, asks them to elaborate on the possibility to "creating value from knowledge, by making knowledge suitable and/or available for social (and/or economic) use and making knowledge suitable for translation into competitive products, services, processes and new commercial activities" (Maastricht promotion regulations, 2013). To me this seems like a fair challenge and it is logical that the University feels responsible to prepare PhD students for a future in which valorisation is becoming more and more eminent. If we, for example, choose to continue to work in the scientific arena after we obtain our PhD degree, we collectively compete for highly selective research grants that nowadays always ask for a well formulated valorisation strategy. Alternatively, knowing how to valorise one's obtained knowledge and skills outside the ivory tower of academia seems like an enriching exercise, since the reality is that the majority of PhD graduates, like me, will leave the academic sphere and therefore need to think about how to apply and invest their built experience in a new profession. I do feel that this process, of making assumptions about the value of your research, comes with a large responsibility, and has to be done with consideration. If, for example, the claims of the before mentioned valorisation strategies proposed in most grant proposals, which almost always suggest tangible benefits for society, would have come true, consensus on how to define a specific learning disability like dyslexia, or a cure for, for example, Parkinson's disease, would have surely been found by now. Especially in research fields like dyslexia and reading research, which has known great debate since its inception in the second half of the nineteenth century, a feeling of responsibility, when valorising research findings into the practical domain, is ever so important. The dyslexic population is considered very heterogeneous, which resulted in the formulation of numerous theories that try to explain the variable cognitive symptoms observed in dyslexic readers from a variety of research perspectives and backgrounds. Consequently, many myths and misconceptions surround dyslexia research and practice. Generalizing research findings without knowledge of the right context, theoretical framework and background expertise, may result in harmful or inappropriate translation into practice. Factors like, for example, orthographic depth of the language in which children learn to read, age and environmental or genetic influences, need to be taken into account, to avoid that dyslexic children and their caregivers are misguided by wrongly valorised products or methods, promising a cure for the reading challenges haunting them. Think of colour overlays or tinted lenses, special balancing exercise programmes, brain 
stimulating methods, modelling clay letters or a prescription of fish-oil tablets, often expensive methods that unrightfully claim their existence in some kind of theoretical findings. Not surprisingly, most of these remedies have been highly contested due to a lack of actual scientific evidence backing up their effectiveness. I am hopeful that, in the future, the practice of valorisation will become a more integrated competence in the training of $\mathrm{PhD}$ students in which connections to society and conversations with the market place or practice will play an increasing role.

\subsection{FIRST STEPS OF LITERACY ACQUISTION: FINDINGS AND PRACTICAL SUGGESTIONS}

Reading research is a field that is very complex due to the interrelations and reciprocal influences between cognitive reading and reading-related processes, like phonological awareness, rapid naming, letter knowledge and letter-speech sound mapping, also studied in this thesis. The design we choose for our first two studies (chapter 2 and 3), being a 3-year longitudinal follow-up and starting prior to the commencement of formal reading instruction, enabled us to unravel this entanglement and provided an important window on the causal mechanisms involved in the developmental dynamics of reading acquisition. By comparing pre-literate children, with and without an increased familial risk of becoming dyslexic, we could, moreover, shed light on the cognitive dynamics underlying emergent reading failure early on, before children fall behind. This work is relevant for children that struggle with reading acquisition and the educators, parents and other caregivers that guide them, as these findings might, in the future, improve diagnostics processes and the development of early intervention for this group. This is especially true for dyslexia professionals working with children learning to reading in relative transparent orthographies, since most previous work was conducted in English.

We found that prior to reading instruction letter-sound knowledge is a particularly important predictor of early reading in grade 1 , in both at-risk and control children, and that RAN at this time plays a predictive role in at-risk reading fluency outcome in grade 2. Phonological awareness (PA) only became the important grade 1 predictor of reading the subsequent year, but only in children without a familial risk, showing normal reading acquisition. Letter-speech sound mapping (LS) remained the core predictor of at-risk reading outcome. Although longitudinal predictor studies cannot decide on causal influences of predictors to reading outcome, it is surprising that PA did not emerge as the main predictor of reading in light of the largely supported claims of the phonological deficit theory of dyslexia, claiming a causal role of PA in reading development. The assumption that a PA deficit precedes and directly influences a 
reading deficit, although never proven, has been a truism for many reading researchers over the years. From a practical point of view, such an unsettled claim may be misleading educators and dyslexia professionals, expecting difficulties in the ability to manipulate spoken language prior to the start of reading instruction as a preluding symptom of troubled, subsequent reading. We found no support for this claimed PA-reading relationship. In more detail, only a very small proportion of at-risk children exhibited phonological awareness or other phonological processing problems prior to reading, and only a part of these children developed a reading deficit. Furthermore, $80 \%$ of all at-risk children who developed a reading deficit performed in the normal range on all of our kindergarten PA tasks. On the contrary, a PA deficit only emerged after the start of reading instruction in grade 1 and in close relation with a developing reading deficit. More specific, at-risk and control children with reading problems did develop a PA deficit in grade 1. Our results thus render against the causal claim of the phonological deficit theory.

Our findings are clear within a scientific scope and reflect the state of the art for now. The findings have limits, as always in science. First of all, the sample is not fully representative given the diversity within dyslexia and a definition of representative samples is not available yet. Second, the study related to a Dutch sample and cannot be generalized to other languages directly. Having these limits in mind we should advise with caution. Hence with caution, we advise the following in an attempt to aid parents, educators and dyslexia professionals guiding reading disabled children in their first steps of literacy: (1) Firstly, know your family history and be aware of the fact that your child may have an increased chance of struggling with reading acquisition if you or one of your child's siblings is dyslexic. Keep in mind that such an increased risk does not necessarily akin to a definite reading deficit, since approximately $50 \%$ of at-risk children will develop reading skills within the normal range (present thesis, Pennington \& Olson, 2008). Similarly, not having a recognizable family risk does not guarantee your child will not need special guidance with reading, since around $5 \%$ of no-risk children will also struggle with reading acquisition (Blomert, 2005). (2) If a child shows inadequate PA ability once reading started in grade 1 , this is a tell-tale sign of a reading deficit developing in close relation. Prior to reading however, a causal link is less likely. If you, for example, encounter a child with a PA deficit prior to the start of reading instruction, this does not necessarily indicate they will struggle with reading acquisition later on, and vice versa, not finding a PA deficit does not indicate that a child will develop adequate reading skills. Practically speaking, this indicates that there is no need for concern by parents or educators, if a prereading child is not able to accomplish the PA exercises, which are already part of the (preparatory) reading methods offered in Dutch kindergartens. (3) Be aware of a child's ability to correctly match 
letter-speech sound pairs, since difficulties shown as early as kindergarten, can be a sign of later reading failure in children at familial risk. We also found that difficulty in learning these cross-modal orthographic-phonological pairs via a specifically design training can be a characteristic of a core group of kindergarten at-risk children. These training-resistant at-risk children may benefit from early special attention or adapted instruction. (4) Regular follow-up is recommended since cognitive signs of dyslexia become relevant at different developmental stages or reading levels in at-risk and no-risk children. Starting at a young age with a variety of tests will, in the future, increasing the change of identifying these children early and enables dyslexia professionals to develop adapted, intensive guidance for struggling readers, and to minimize any accompanying secondary social or emotional consequences as quickly as possible.

\subsection{CLUSTERING INSIGHTS AND FUTURE DIRECTIONS}

The evident degree of heterogeneity observed in the total reading disabled population has puzzled reading researchers for decades. Traditionally, classification studies that attempted to confirm the existence of more homogeneous subtypes within this diverse group did so based on a predefined division, determined by cut-off criteria and existing theoretical insights regarding aetiology and subtypes. The design we choose for our third study (chapter 4), being a bottom-up, data-driven classification in a large sample of grade 2 to 4 poor readers, enabled us to zoom in on this divers phenomenon and revisit the possibility of identifying distinct cognitive deficit profiles, without making any a priori assumptions on the nature and number of possible subtypes. As such, we looked beyond an adopted theoretical framework and its possible limitations.

Our findings confirmed the possibility to find more homogeneous subtypes of reading disability and identified four cognitive profiles: (1) a Reading-only impaired subtype without underlying cognitive deficits, (2) a General poor subtype with deficit across all general and reading-related vulnerability markers, (3) a PA-LS specific poor reader type characterized by a PA deficit and impaired letter-speech sound mapping skills and (4) a PA-RAN specific poor reader type characterized by a PA deficit and impaired rapid automatized naming ability. The Reading-only impaired profile showed a less severe reading deficit compared to the other profiles and moreover was the only type that showed normal spelling skills. Profiles 1, 2, and 3 were more characterized by environmental risk factors, while the fourth profile (PA-RAN) showed a significantly strong familial risk for dyslexia. These later PA-RAN 
specific poor readers showed significantly higher IQ scores than the other two profiles that showed distinct underlying deficit pattern. Interestingly, these emerging cognitive profiles based on behavioral measures were in line with earlier finding of genetic and neuroimaging studies, showing the existence of two potential aetiologies for childhood reading failure; a predominantly genetic, specifically impaired reading type with IQ scorers over 100 and a more environmental influences type with IQ scores below 100 (Shaywitz \& Shaywitz, 2005; Wadsworth et al., 2010). It is relevant for educators and dyslexia professionals to know that it is possible to identify poor reader profiles characterized either by family risk or by environmental risk factors solely based on behavioral measures. Reading and reading-related deficits that are due to a substantial larger genetic influence for example require more intensive remediation efforts (Wadsworth et al., 2010). It is important to remember however that family risk it is not a purely genetic trait, since children share both genes and home literacy environment with their close relatives. Also of practical value is the insight that, although IQ has fallen out of favour for sole diagnosis of dyslexia based on discrepancy or cut-off criteria (e.g., Stuebing et al., 2002), the way it forms distinct patterns with reading-related vulnerably markers and family risk may render valuable information for exclusion purposed in diagnostic processes (e.g., Wadsworth et al., 2010). A one-size-fits all approach may not be adequate for the overall reading disabled population. Instead, a more finegrained approach focusing on different profiles may be a more promising way forward in tailoring future diagnostic and intervention efforts more precisely to the needs of a specific cognitive profile. It would be interesting to further research whether the identified cognitive profiles of poor reading also respond to training differently and how these cognitive profiles develop over time.

Once the practical implications of these subtypes are further investigated, we could think of valorising these cognitive profiles further by using them alongside a newly to be developed diagnostic tool that can effectively be used in a diagnostic setting or classroom. Such a tool would use a child's test scores on the nine included cognitive behavioural vulnerability factors (PA accuracy, LS identification and discrimination accuracy and fluency, RAN, memory, IQ and vocabulary) to make a diagnostic allocation of an individual being tested for dyslexia into one of these four identified subtypes. For the development of such a tool a number of techniques can be borrowed from the data science and machine intelligence domains, for example a technique called k-NN (k-nearest neighbour, e.g., Aha, 1991). This instancebased learning method classifies individual test scores according to their proximity or belongingness to members of the existing model (in our case the four identified subtypes that resulted from a K-means data driven classification). More in detail, the k-nearest instances (i.e., neighbours (children) with similar cognitive profiles) can be easily retrieved and, through a majority voting schema, the class with the 
highest number of nearest neighbours is chosen. A method like K-NN is powerful, since it does not assume anything about the data being clustered, and it moreover offers confidence (percentage) of belongingness (to a class or subtype). In other words, educators and dyslexia professionals using such a diagnostic tool may gain insight on classification accuracy of that individuals cognitive profile, which for example corresponds to $70 \%$ subtype 1, 15\% subtype 2 and 15\% subtype 3 . We would recommend utilizing periodic revaluation to determine whether the obtained latent clustering and level of belongingness continues to be appropriate. More precise clustering is not only beneficial from a practical diagnostic or remediation perspective, future research in genetics and neuroimaging may use such a preprocessing instrument for sample classification. If, for example, research would zoom in on children with a high belongingness to the PA-RAN subtype, which unveiled a significantly high familial risk of dyslexia, it is possible that genetic techniques may achieve a different result than that when focusing on the reading disabled sample as a whole. Finally, the result of this thesis may also be of interest to policy makers with respect to healthcare and treatment costs offered to children with dyslexia. The Dutch political and societal framework of healthcare and insurance of dyslexia changed in 2009, when the national Healthcare Insurance Board (College voor Zorgverzekeringen, CVZ) adopted the protocol Dyslexia Diagnostics and Treatment (Blomert, 2006). In more detail, this protocol guides dyslexia professionals along five steps that can lead to a positive or negative indication for subsequent dyslexiadiagnostics and treatment. Children with a positive indication are eligible for reimbursement of the costs of dyslexia care, which was implemented step-wise; starting in 2009 with children that obtained their indication before the age of nine, until in 2013 , care was reimbursed for all children in primary school from ages seven to thirteen years old. The cognitive measures our subtyping classification was based upon, is part of the Dyslexia Differential Diagnosis 3DM battery (Blomert \& Vaessen, 2009), the test battery that was developed in service of the five steps introduced in the before mentioned protocol. Adding a more fine-grained approach by employing mathematically strong data driven techniques, may add much needed nuance to policies that decide on who is eligible for care and financial compensation. Moreover, an eloquent tool such as the one described above seems a possible, innovative addition to the 3DM test battery. 


\section{REFERENCES}

Aha, D. W., Kibler, D., \& Albert, M. K. Instance-based learning algorithms (1991). Machine learning, 6 (1), 37-66. doi : 10.1007/BF00153759.

Blomert, L. (2005). Dyslexie in Nederland - theorie, praktijk en beleid [Dyslexia in The Netherlands theory, practice and policy]. Amsterdam: Nieuwezijds Publishers.

Blomert L. Protocol Dyslexie Diagnostiek en behandeling [Protocol dyslexia diagnostics and treatment] Maastricht: University of Maastricht; 2006.

Blomert, L., \& Vaessen, A. (2009). 3DM: Cognitieve analyse van lezen en spellen [3DM: Cognitive analysis of reading and spelling]. Amsterdam: Boom test publishers BV.

Katzir, T., Youngsuk, K., Wolf, M., O'Brien, B., Kennedy, B., Lovett, M., \& Morris, R. (2006). Reading fluency: the whole is more than the parts. Annals of Dyslexia, 56, 51-82. doi:10.1007/s11881006-0003-5.

Pennington, B. F., \& Olson, R. K. (2008). Genetics of Dyslexia. The Science of Reading: A Handbook, 453472. doi:10.1002/9780470757642.ch24.

Shaywitz, S. E., \& Shaywitz, B. A. (2005). Dyslexia (Specific Reading Disability). Biological Psychiatry, 57(11), 1301-1309. doi: 10.1016/j.biopsych.2005.01.043.

Stuebing, K. K., Fletcher, J. M., LeDoux, J. M., Lyon, G. R., Shaywitz, S. E., \& Shaywitz, B. A. (2002). Validity of IQ-Discrepancy Classifications of Reading Disabilities: A Meta-Analysis. American Educational Research Journal, 39(2), 469-518. doi:10.3102/00028312039002469.

Wadsworth, S. J., Olson, R. K., \& DeFries, J. C. (2010). Differential genetic etiology of reading difficulties as a function of IQ: an update. Behavior Genetics, 40(6), 751-758. doi: 10.1007/s10519-0109349-x. 


\section{NEDERLANDSE SAMENVATTING}

Vloeiend lezen en schrijven is een uitermate belangrijke vaardigheid in de huidige kennis gebaseerde maatschappij. Indien het onder de knie krijgen van deze vaardigheid moeizaam gaat, zoals bij mensen met dyslexie, kan dit negatieve gevolgen hebben op iemands sociaal welbevinden, academische kansen en economisch succes. Helaas wordt dyslexie in de praktijk pas vastgesteld als er een leesachterstand van ongeveer twee jaar wordt waargenomen ten opzichte van een kinds chronologische leeftijd. In een relatief transparante taal als het Nederlands is dit vaak pas als een kind in groep 5 zit. Het is uiterst belangrijk om meer inzicht te krijgen in de eerste stappen van de cognitieve ontwikkeling van geletterdheid en wat er mis kan gaan, wat mogelijk is door te focussen op kinderen met een verhoogd familierisico om dyslexie te ontwikkelen. De huidige thesis heeft hieraan bijgedragen door: (1) het testen van de causaliteitsclaims van de veel gesteunde fonologische tekortkomingshypothese van dyslexie, in kinderen met én zonder een verhoogd familierisico, voordat ze leren lezen (hoofdstuk 2), (2) het onderzoeken of fonologisch bewustzijn (PA), letter-klank koppelingsvaardigheden (LS) en het snel kunnen benoemen van bekende visuele objecten (RAN) in de kleuterklas en in groep 3 (dus voor én na de start van de formele leesinstructie) voorspellende indicatoren zijn voor latere leesvaardigheid van kinderen met én zonder familierisico (hoofdstuk 3), en (3) verder te onderzoeken of het mogelijk is om binnen een grote groep kinderen met ernstige leesproblemen in groep 4 tot 6, meer homogene cognitieve profielen te identificeren, op basis van de hierboven genoemde cognitieve dyslexiemarkers (PA, LS en RAN) en werkgeheugen, woordenschat en IQ. We vonden geen steun voor de aangenomen, maar nog niet bewezen claim, dat een fonologisch bewustzijnsprobleem voorafgaat aan, of de aanleiding is voor, de ontwikkeling van een leesstoornis. Meer specifiek, slechts een klein deel van de kinderen met een familierisico had voorafgaand aan het lezen fonologische verwerkingsproblemen, en slechts een deel van deze kinderen ontwikkelde later een leesprobleem. Daarnaast vonden we dat $80 \%$ van de kinderen die een leesprobleem ontwikkelden na 1 jaar leesinstructie, gewoon normaal presteerden op fonologische taken in de kleuterklas. Bij de kleine groep kinderen die wel fonologische problemen hadden in de kleuterklas vonden we geen samenhang met mogelijke letter-klank koppelingsproblemen. Wel was er een kleine kerngroep kinderen met een familierisico voor dyslexie die in de kleuterklas moeite hadden met het leren van letter-klank koppelingen ondanks een speciaal ontwikkelde training. Dit was echter niet gekoppeld aan een later leesprobleem. Een fonologisch bewustzijnstekort ontwikkelde pas na aanvang van het formele leesonderwijs in groep 3 en was gerelateerd aan ontwikkelende leesmoeilijkheden. Ons predictieonderzoek liet zien dat LS in de kleuterklas de 
belangrijkste predictor was voor leesvaardigheid van kinderen met én zonder risico voor dyslexie in groep 3. Daarnaast was RAN in risico kinderen ook gekoppeld aan hun leesvaardigheid in groep 4. Na de aanvang van de formele leesinstructie in groep 3 bleef LS de belangrijkste predictor in risico kinderen. Foneem bewustzijn bleek de belangrijkste voorspeller van later lezen op dat moment in kinderen zonder een familierisico. We interpreteerden deze gezamenlijke bevinden als een indicatie dat er meer symmetrie lijkt te bestaan tussen de proximale oorzaken van succesvolle en vermoeilijkte leesontwikkeling dan tussen de distale oorzaken. De aard van dit tekort en de impact die het kan hebben op multi-sensorische verwerking in het hele leesnetwerk, vormt een belangrijke uitdaging voor toekomstig lees- en dyslexieonderzoek. Tenslotte lieten onze resultaten zien dat het mogelijk is om meer homogene cognitieve profielen te identificeren in een grote groep slechte lezers met behulp van een data gedreven clustering: (1) een profiel met alleen een leesprobleem, normale spellingsvaardigheden en zonder onderliggende lees-gerelateerde moeilijkheden, (2) een profiel met moeilijkheden op alle lees en lees-gerelateerde vaardigheden, (3) een specifiek profiel met LS problemen naast een PA deficit, en (4) een specifiek profiel met RAN problemen naast een PA deficit. In andere woorden, alle drie de profielen met onderliggende lees-gerelateerde moeilijkheden, deelden een PA deficit en werden onderscheiden door hun prestatie op de andere lees-gerelateerde vaardigheden. Interessant genoeg waren de eerste drie cognitieve profielen meer gekenmerkt door meer negatieve omgevingsinvloeden, terwijl het vierde profiel een sterk verhoogt familiair risico liet zien. Meer in detail over dit laatste profiel, een RAN deficit (in combinatie met een PA deficit) komt vooral voor bij kinderen met een sterk familierisico, en zorgt bij deze kinderen voor een leesprobleem ondanks gemiddeld of hoger dan gemiddeld IQ en gunstigere omgevingsfactoren. Het zou interessant zijn om met toekomstig onderzoek te bepalen of deze verschillende cognitieve profielen ook anders reageren op interventie. Het is bijvoorbeeld bekend dat leesproblemen die sterker beïnvloed worden door genetische invloeden, meer intensieve behandeling vereisen (Wadsworth et al., 2010). De mogelijkheid om in de toekomst diagnostiek en interventies voor leesproblematiek, meer specifiek te ontwerpen voor mogelijke, meer homogene cognitieve profielen, zou een veelbelovende stap vooruit zijn voor mensen die een vermoeilijkte leesontwikkeling laten zien. 


\section{ACKNOWLEDGMENTS}

"Rivers know this: there is no hurry. We shall get there some day." Winnie-the-Pooh

The road I chose was longer than normal, with detours and obstacles, but looking back, I am happy I stuck to it and was able to bring this journey to a successful end. I acknowledge this fortune to many special people who accompanied me along the way. In the end, it was your company that will never make me forget, or regret, starting and continuing this journey. The lessons I learned from setting and pursuing this goal might just have been as important as achieving the goal itself.

Firstly, and most importantly, I want to thank my wonderful family. I love you guys. Mom and dad, knowing you are proud of me and having your unconditional support makes me feel confident and loved. Inge, my 'big sis', I still catch you trying to take care of me. I admire your smart, funny and honest nature that is at times still endearingly naïve. Together with Robert you make me feel at home and give great advice. Thanks for making me auntie to our little rock stars Sam and Finn. Special thanks to Robert for designing my thesis, because a shiny appearance does matter. Mijn lieve, hippe omaatje van 91, ook al begrijp je niet alles van al dat Engels, ik weet dat je me begrijpt als we samen kletsen en lachen. Ik hoop dat je nog heel lang bij ons bent en dat ik in je voetstappen mag treden.

Now, a special thanks to my 'second family'. My scientific family. Anniek, kind-hearted and strong. Dries, brave and untamed. Petra, creative and light (a perfect paranimph). Teresa, vivacious and funny. Noël, warm and talented. Anniek, I am especially and forever grateful to you, for all the time you took to guide me and keep me on the righteous path of academia (finally formalized after many years as my co-promotor). I am lucky to know you all and perhaps my biggest accomplishment resulting from being a PhD candidate is our friendship. Numerous other $\mathrm{CN}$ colleagues, you contributed to a productive and creative work environment. Special thanks to Bernadette and Stelios for joining Anniek as my promotor and co-promotor. Your useful feedback and advice were critical and together you created the necessary conditions for me to graduate. Arie, my fellow 'team building' enthusiast, thanks for reviewing parts of my thesis and Marin for reminding me that nothing beats a good 'coffee-brainstorming' combo.

Finally, I am blessed with amazing friends. Thanks for believing in me. Malu (my bestie and second paranimph), Kika, Eveline, Ellen, Esje, Hanne, Zoë, Jean-Paul, Joyce, Floor, Bryan, Carla, Peter, Esther, Joep, Rachelle L, Willem, Paul, Alex, Stijn, Joey, Jeanette, Gommaar, Iris, Ellen, Tanja, Rachelle, Tamara, Marlies, Nadine, my TEDx friends from Maastricht and abroad and UM colleagues Aisha, Celine, Wendy, Iris, Esther, Pascal, Gerhard and Marie-Lou. I look forward to many more adventures. 


\section{CURRICULUM VITAE}

Gonny Willems was born October 24th 1981 in Hoensbroek, The Netherlands. She attended Bernardinus College in Heerlen and obtained her VWO diploma in 1999. That year, she started studying Psychology at the Faculty of Psychology and Neuroscience at Maastricht University. During her studies, she worked as a student research assistant at the Open University Heerlen assisting in data collection and interpretation in a research project investigating expert versus novice learning strategies (2002). Subsequently, she joined a research project at Maastricht University, developing the 3DM Differential Diagnostic Test Battery for the cognitive analysis of reading and spelling in primary school education (2004). In parallel, she worked as a student lab assistant in the Event-Related Potential (ERP) lab, providing ERP training to students on data acquisition procedures (2004). She completed a clinical internship on diagnostics of dyslexia at the Regional Institute for Dyslexia (RID) and subsequently received the NIP certificate of psycho-diagnostic assessment (2004). In December 2004, she obtained her Master of Science degree in Biological Psychology with a specialization in Developmental Psychology. After graduation, she continued her work as research assistant, studying the cognitive dynamics of reading and spelling together with $\mathrm{dr}$. Anniek Vaessen and the psychophysical and electrophysiological correlates of letter-speech sound processing in dyslexia together with dr. Dries Froyen. In 2005, Gonny started her PhD candidacy as the Dutch associate on a two-year European Commission Marie Curie Excellence Grant hosted by the University Jyväskylä, Finland and granted to prof. dr. Ulla Richardson. Subsequently, she continued her $\mathrm{PhD}$ research at the Department of Cognitive Neuroscience at Maastricht University, conducting part of the work described in this thesis under the supervision of the late prof. dr. Leo Blomert. Her position transferred to an honorary position from October 2009 onward. She continued her research, next to holding a full-time position as Head of the Student Affairs office at the Department of Data Science and Knowledge Engineering at Maastricht University. In 2015, she became manager of this Department. Gonny is moreover the primary licensee of TEDxMaastricht for which she, together with her team, is organizing TEDx conferences since 2014. Due to the above mentioned professional adventures and to the untimely passing of Leo Blomert late 2012, Gonny paused her scientific activities for some time. In 2015, she continued her research, completing the work described in this thesis, next to her fulltime position as an educational manager. Prof. dr. Bernadette Jansma, dr. Anniek Vaessen and dr. Stylianos Asteriadis were appointed as her new promotor and co-promotors. In February 2017, she started as Head of the Admissions and Registrations Department at Maastricht University's Student Service Centre leading 40 professionals responsible for student affairs, administration and student guidance. 
APPENDIX 1

GRAPHOGAME - A GRAPHEME-PHONEME ASSOCIATION TRAINING 
The GraphoGame programme is a child-friendly, computerized intervention originally designed at the interdisciplinary Agora Human Technology Center of the University of Jyväskylä (Lyytinen, Ronimus, Alanko, Poikkeus, \& Taanila, 2007; Richardson \& Lyytinen, 2014). This computer game was developed to help children to learn the basics of the reading acquisition process in an efficient way, focusing on the learning the connections between spoken and written language. GraphoGame aims to improve two key alphabetical principles important for struggling readers: (a) representations of individual speech sounds, or phoneme awareness, and (b) knowledge on the connections between phonemes and their corresponding speech sounds. Though a series of levels increasing in difficulty, the child gradually becomes able to employ this phonological and letter-speech sound knowledge to construct small simple words and then larger more complex words. This computer-assistant learning environment is suitable to train pre-school children by providing them an intensive learning environment with individualized repetition. It offers play-like features and immediate stimulating rewards to the child making practicing less challenging to persist. Moreover, it incorporates a dynamic element, making it adaptive to the individual performance of a child in several ways. First, before proceeding to a next level, a child has to reach an accuracy criterion of $80 \%$ correct responses per level. Therefore, a poorly performing child will be offered excessive repetition to ensure adequate knowledge of the items before proceeding to new and more difficult items. Second, a child's performance influences the number of orthographic distracters per exercise. The target is initially accompanied by one distracter (i.e. the lowest difficulty rate) up to a maximum of six distracters simultaneously (i.e. the highest difficulty rate) if the child's performance increases. Last, if a child's performance gets better, the speed with which the items are offered increase per exercise, which is in added opportunity to increase fluency, an important aspect of learning to read in a fairly transparent orthography like Dutch. The adaptive nature together with the positive feedback and rewards incorporated in the game is expected to ensure sustained attention and motivation and learning to actually be established. Finally, it neutralizes supervision or instruction problems since the guidance is implicitly implemented in the computer game itself. See the demo pictures below showcasing (a) an active level presenting a target/t/ together with four distractors, (b) a repetition level and (c) a motivational level in which a child can play with the animals they obtained as rewards.
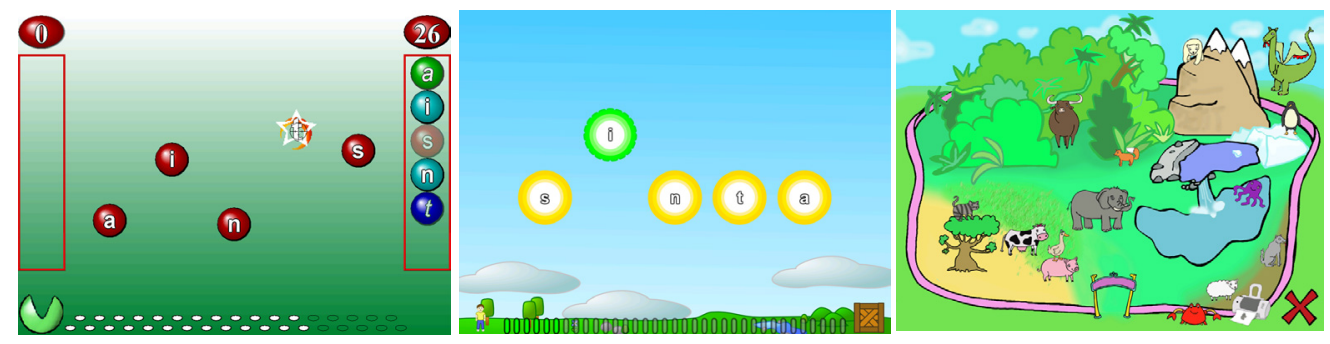


\section{THE DUTCH GRAPHOGAME}

We developed a Dutch version of GraphoGame similar in program but with stimuli representing the characteristics of the Dutch orthography. Dutch GraphoGame was employed in chapter 2 of the present thesis and consisted of 76 levels in total gradually increasing in difficulty. GraphoGame presents the child with a series of levels in which an auditory stimulus (i.e., speech sounds in early levels and syllables or words in later, more difficult levels) is delivered via high quality headphones. Simultaneously, the corresponding orthographic item (e.g. a letter) and a number of orthographic distracter items appear in 'balls' at the top of the screen. The balls start to fall downward on the screen, while the child 'catches' the item correctly corresponding to the auditory presented stimulus by clicking the mouse. Each level contains 7 target items, presented 5 times per level. All exercises are time-constrained and end when the child selects an orthographic item or when the orthographic items reach the bottom of the screen. Selecting the correct ball enables the child to select a reward in the form of a sticker that can be collected in a virtual sticker album. If a child selects the wrong ball (i.e., one of e the distractors) or doesn't make a choice before the balls disappear, the speech sound is repeated and positive feedback is provided by demonstrating which letter correctly corresponded to the speech sound. This item is than repeated in the next trail in a colour-highlighted ball to ensure additional practice. Although the Dutch orthography is considered a fairly transparent orthography (Seymour et al., 2003), it has, compared to the highly transparent Finnish orthography, several deviations from the one-to-one correspondences between letters and speech sound. Moreover, a prominent characteristic of the Dutch orthography is the use of consonant clusters (i.e. a cluster of consecutive consonants at the beginning or end of a word). Therefore, the game was extended with several levels of irregular letter-speech sound learning in addition to extra levels of frequent cluster learning in the context of both words and pseudowords. The letters taught were consonants (i.e., b, c, d, f, g, j, k, l, m, n, p, q, r, s, t, v, w, x, y, z), short vowels (i.e., a, e, i, o, u), long vowels (i.e., aa, ee, oo, uu) in addition to vowel digraphs (i.e., eu, ie, oe, ui, ou, au, ij, ei), consonant digraphs (ie., nk,ng, ch, uw) and multi-letter phonemes (i.e., sch, ooi, aai, oei, eeuw, ieuw, ouw, auw) typical to the Dutch language. The most consistent and frequent vowels and consonants are offered in the most basic levels that not yet included phonological similar (e.g., $d / t / b / p$ ) and visually confusable items (e.g., $\mathrm{m} / \mathrm{n}$ ). Complexity gradually increases by incorporating more infrequent and less consistent items in addition to including visual and phonological similar items within the same level. After the child masters the basic letter-speech sound correspondences, it continues on through a series of levels in which these important letter-speech sound correspondences are incorporated within larger orthographical items on sub-word and word level. The structure of a word in the Dutch language is very 
often based on accumulation of consonant-vowel-consonant, or CVC words (e.g., weerman, /weather man/). These assembled individual CVC compounds together form words that very often have meaning. We therefore choose this word structure for GraphoGame. Finally, the order in which the items are introduced per block was based on the consistency and frequency of the item derived from the whole corpus of the Celex monosyllabic database for the Dutch language (Baayen, Piepenbrock, \& Gulikers, 1995). Below we give an outline of the Dutch version of GraphoGame, presenting an overview of included items per level and providing insight in the training.

\section{Outline of the Dutch GraphoGame}

\begin{tabular}{|c|c|c|c|c|c|}
\hline BLOCK A & Items & & & & \\
\hline \multicolumn{6}{|l|}{ Level } \\
\hline 1 & $n(n)$ & $t(t)$ & a (a) & $r(r)$ & $k(k)$ \\
\hline 2 & at & ak & ar & an & \\
\hline 3 & kan & nat & tak & kat & \\
\hline 4 & rak & $\operatorname{tar}$ & $\tan$ & ran & \\
\hline
\end{tabular}

The first block aimed at implicitly demonstrating the alphabetical principle: the idea that letters represent spoken letters in language that can be combined to form words. As a result, the child will be able to read some simple (pseudo)words immediately, which as an additional advantage can increase motivation. The five items included are all high consistent and frequent letters. Together these letters form four pre-school appropriate words selected from the Dutch target vocabulary list for six-year olds (i.e., 'streeflijst woordenschat voor zesjarigen in Nederland' on which Dutch kindergarten and grade 1 teachers judge if a child knows a word in the context of a simple sentence). Words are included if 90-100\% of children are indicated to know the word. The five items presented in this first block are repeated in Block B together with the other prototypical phonemes. 


\begin{tabular}{|c|c|c|c|c|c|c|c|}
\hline$B L O C K B$ & Items & & & & & & \\
\hline Level & & & & & & & \\
\hline 5 & $n(n)$ & $d(d)$ & a (a) & $r(r)$ & e (e) & $s(s)$ & i (i) \\
\hline 6 & $t(t)$ & $m(m)$ & $z(z)$ & $v(v)$ & $\mathrm{o}(\mathrm{o})$ & h (h) & $k(k)$ \\
\hline 7 & I (I) & e: (ee) & $f(f)$ & $b(b)$ & \}$(u)$ & $\mathrm{a}:(\mathrm{aa})$ & \\
\hline 8 & $w(w)$ & $p(p)$ & o: (oo) & $\mathrm{j}(\mathrm{j})$ & $x(g)$ & $y:$ (uu) & \\
\hline 9 & $\mathrm{u}$ : (oe) & 9l (ui) & 2: (eu) & $\mathrm{Au}(\mathrm{ou})$ & $\mathrm{Ei}(\mathrm{ij})$ & i: (ie) & \\
\hline
\end{tabular}

The most prototypical phonemes (i.e., most consistent and frequent items) are presented in this block. Phonological similar and visually confusing items are not included in the same level when possible. Note, the phonemes are presented in Sam-pa code, the graphemes are shown in parenthesis.

Irregularities in Stream 2

- Vowels in monosyllabic words usually follow a consistent rule: in a long phoneme (a: e: o: $y:$ ) the sound is long and in a short phoneme $(a, e, o, i\}$,$) the sound is short. These 'short' and 'long' vowels are both$ prototypical phonemes introduced in traditional teaching methods. There is one irregularity or exception to this rule and that is the phoneme $y$ : (i.e., grapheme $/ u /$ ) since the most prototypical phoneme for the grapheme $/ u /$ is not the short sound but the long sound (e.g. in the word/nu/). To avoid confusion, this exception will be presented later in whole word context in the exception stream.

- Other short vowels (e.g., o, a) can also be long vowels in monosyllabic words (e.g., in the words /na/ and $/ z 0 /)$, but these phonemes are the less prototypical phonemes for a grapheme and will be presented only in whole word level together with other less prototypical phonemes.

- The phoneme @ (i.e., in the word/de/: 'stomme e') will only be presented in whole word context to avoid confusion with the most prototypical phoneme e (i.e., short/e/ in the word/pet/).

- Two-letter phonemes: /ou/ and /au/ as well as /ij/ and /ei/ are written differently but are the same phoneme (i.e., Au and El, respectively). The less prototypical phonemes /au/ and /ei/ are moved to the exception block in which they are presented in whole word context.

- Consonants: the consonant $/ g /$ has the same phoneme as consonant digraph $/ \mathrm{ch} /$, namely $/ x /$. The less prototypical one /ch/ is also moved to the exception block.

- The two-letter phonemes $/ \mathrm{nk} /, \mathrm{lng} /$ and $/ \mathrm{uw} /$ and the multiple-letter phonemes are very difficult and highly confusable for young children. Based on the traditional Dutch teaching methods these phonemes are introduced at a later level, but before the exception and consonant cluster blocks.

- Multiple-letter phonemes: the ouw/auw are the same phoneme /Auw/. The less prototypical multiletter phoneme /auw/ is again moved to the exception block. 


\begin{tabular}{rr|ccccccc}
\hline BLOCK C & Items & & & & & & \\
\hline Level & & & & & & & \\
10 & pot & put & pit & pet & bos & bes & bus \\
11 & baan & been & boon & raak & rook & boos & baas \\
12 & teen & tuin & zuur & vuur & muur & lieg & leeg \\
13 & vies & vis & zon & zoon & kus & kaas & kies \\
14 & nat & niet & noot & zus & zes & ziek & zak \\
15 & boek & boef & boer & doek & doel & doen & hoek \\
16 & neus & reus & roos & huis & muis & ruik & buik \\
17 & fout & lijn & zien & juf & soep & zien & weg \\
18 & jas & vijf & hout & zeep & poes & kan & kok \\
\hline
\end{tabular}

CVC words used in this block. These CVC words have meaning making learning easier for the child. The complexity of these CVC words increase per level. The words chosen are included since they are known by 90-100\% of pre-school children according to the Dutch target vocabulary list mentioned above. The $r$ and I after /ee/ and /oo/, cause a sound change in words, therefore not used)

\begin{tabular}{rr|ccccccc}
\hline BLOCKD & Items & & & & & & \\
\hline & Level & & & & & & & \\
19 & vaa & raa & faa & zaa & daa & taa & saa \\
20 & bee & wee & gee & pee & lee & hee & kee \\
21 & mui & jui & nui & sui & tui & kui & zui \\
22 & soe & sou & seu & loe & lie & leu & lij \\
23 & soo & see & sie & saa & suu & sij & seu \\
24 & fui & foe & fou & foo & feu & fuu & faa \\
25 & guu & lee & fie & poo & wui & zeu & kaa \\
\hline
\end{tabular}

All short, long and two-letter phonemes are presented with a consonant. Level 29 does not consist of items with one consonant and a short vowel due to the fact that this combination is inconsistent in the Dutch language (i.e., could either be pronounced as a long or short vowel. (e.g. va or za) 


\begin{tabular}{rr|ccccccc}
\hline BLOCKE & Items & & & & & & \\
\hline 26 & ef & ep & et & em & eg & es & ek \\
27 & uuf & uul & uun & uug & uut & uus & uup \\
28 & eun & eur & eum & eup & euk & eus & eul \\
29 & ijm & oum & iem & uim & ouf & ijf & uif \\
30 & et & it & aat & ot & uut & ijt & oet \\
31 & us & ees & ies & ak & oos & ous & uis \\
32 & euf & ief & oem & uip & iet & ijp & ouk \\
\hline
\end{tabular}

All consonants are presented combined with a short, long and two-letter phoneme. Exception: the consonant $/ \mathrm{j} /$ is not presented in a VC context in Dutch. Phonological and visual similar items will be presented together across levels. Graphemes $w, v, z$ are not used since they do not occur at the end of words in the Dutch language. Moreover, graphemes $b$ and $d$ are not used since they are not consistent at end of words in the Dutch language (i.e., could either be $b / p$ or $d / t$ ).

\begin{tabular}{|c|c|c|c|c|c|c|c|}
\hline BLOCK F & Items & & & & & & \\
\hline Level & & & & & & & \\
\hline 33 & bam & bem & bim & bum & kor & ker & kur \\
\hline 34 & fook & fuuk & feek & gaam & geem & goom & guum \\
\hline 35 & miek & meek & mook & kaam & wiem & poem & teem \\
\hline 36 & fien & fuim & pir & par & joug & juug & jeug \\
\hline 37 & zap & ziep & zijp & gem & geem & bik & biek \\
\hline 38 & dijn & dijg & dijs & dijf & dijt & dijp & dijm \\
\hline 39 & souk & seuk & foun & fuin & diel & riel & miel \\
\hline 40 & soer & rijf & suim & goun & keem & zief & veuk \\
\hline 41 & wuil & biem & paam & geup & boes & reul & kum \\
\hline
\end{tabular}




\begin{tabular}{rr|lccc}
\hline \multicolumn{1}{l|}{ BLOCK G } & Items & & & & \\
\hline Level & & & & & \\
42 & $N$ (ng) & sx (sch) & o:j (ooi) & Nk (nk) & y:w (uw) \\
43 & e:w (eeuw) & u:j (oei) & i:w (ieuw) & a:j (aai) & Auw (ouw) \\
\hline
\end{tabular}

In this Block we continue with offering more difficult prototypical two-letter and multiple-letter phonemes (following the more prototypical phonemes already offered in Block B. Offering these more difficult but still prototypical phonemes at a later stage in development is consistent with the later introduction time of these items in the traditional teaching methods followed in the Netherlands. Note, the phonemes are presented in Sam-pa code, the graphemes are shown in parenthesis.

\begin{tabular}{rr|ccccccc}
\hline BLOCKH & & Items & & & & & & \\
\hline 44 & Level & & & & & & & \\
45 & bank & pink & gang & ring & lang & tong & wang \\
46 & mooi & nieuw & touw & haai & leeuw & loei & duw \\
47 & scher & schuup & schom & schien & schir & schaat & schul \\
48 & pank & zeng & fink & wong & zunk & geng & vank \\
49 & fouw & faai & fieuw & zuw & pooi & peeuw & puw \\
50 & raai & poei & deeuw & wooi & tuw & souw & dieuw \\
\hline
\end{tabular}

Introduction of the new two-letter and multiple-letter phonemes in short CVC words and pseudowords. 


\begin{tabular}{|c|c|c|c|c|c|c|c|}
\hline BLOCK I & Items & & & & & & \\
\hline Level & & & & & & & \\
\hline 51 & st & $\mathrm{vr}$ & sl & bl & $\mathrm{pl}$ & $\mathrm{pr}$ & $z w$ \\
\hline 52 & $\mathrm{vl}$ & $\mathrm{kn}$ & $\operatorname{tr}$ & sn & gl & str & schr \\
\hline 53 & vlag & vraag & vrouw & vlek & pret & knoop & knie \\
\hline 54 & schreeuw & schrijf & trui & traan & straat & snel & slee \\
\hline 55 & slak & stad & stier & sneeuw & strik & zwaan & zwaar \\
\hline 56 & glas & glad & plek & plat & prijs & blok & bloem \\
\hline 57 & snur & staai & schraf & stooi & $\underline{\text { stroei }}$ & knees & knes \\
\hline 58 & gles & gluin & blaan & plouw & strom & sleeuw & bluup \\
\hline 59 & treg & trup & zwijs & trijl & snom & schrif & sloek \\
\hline 60 & vruuk & vrook & vluw & vleur & prieuw & plaas & preul \\
\hline
\end{tabular}

Introduction of consonant clusters at the beginning of words. We selected 12 simple and 2 more complex clusters (i.e., /str/ and /schr/) common in the Dutch language. All consonant clusters were presented four times, two times in real word context (i.e., simple nouns known by $90-100 \%$ of pre-school children according to the Dutch target vocabulary mentioned above) and two times in pseudoword context.

\begin{tabular}{|c|c|c|c|c|c|c|c|}
\hline BLOCKJ & Items & & & & & & \\
\hline Level & & & & & & & \\
\hline 61 & st & Is & ns & If & rk & rs & $\mathrm{rg}$ \\
\hline 62 & cht & Im & $\mathrm{rp}$ & ts & $\mathrm{rm}$ & $\mathrm{rt}$ & $\mathrm{rd}$ \\
\hline 63 & kerk & kers & kort & hals & helm & licht & film \\
\hline 64 & mens & muts & gans & dorp & erg & scherp & schaats \\
\hline 65 & lacht & laars & berg & beest & zalf & zwart & zwaard \\
\hline 66 & pols & park & rijst & woord & wolf & warm & worm \\
\hline 67 & kelm & kuirs & pijst & purk & peets & zarm & zeulf \\
\hline 68 & faars & funs & bijcht & belm & birk & darp & veerp \\
\hline 69 & riets & germ & lork & larg & lort & werg & nuist \\
\hline 70 & weuns & wilf & warg & voorp & vicht & scherk & schurt \\
\hline
\end{tabular}

Introduction of consonant clusters at the end of words. We selected 12 simple and 2 more complex clusters (i.e., /cht/ and/ts/) common in the Dutch language. All consonant clusters were presented four times, two times in real word context (i.e., simple nouns known by $90-100 \%$ of pre-school children according to the Dutch target vocabulary mentioned above) and two times in pseudoword context. 


\begin{tabular}{|c|c|c|c|c|c|c|c|}
\hline BLOCK K & Items & & & & & & \\
\hline Level & & & & & & & \\
\hline 71 & g-ch $(x)$ & ij-ei (El) & $\begin{array}{l}\text { ouw-auw } \\
\text { (Auw) }\end{array}$ & $o u-a u(A u)$ & $p-b(p)$ & $t-d(t)$ & \\
\hline 72 & pech & pauw & prei & gauw & geit & goed & flauw \\
\hline 73 & tijd & trein & toch & blauw & reis & heb & hand \\
\hline 74 & hoofd & saus & klei & mand & lach & web & zeil \\
\hline
\end{tabular}

Introduction of exception homophones (i.e., one phoneme for two or more graphemes):

- The phoneme/Au/for the graphemes/ou/ and /au/

- The phoneme /El/for the graphemes/ij/ and/ei/

- The phoneme $/ x /$ for the graphemes $/ \mathrm{g} /$ and $/ \mathrm{ch} /$

- The phoneme /Auw/for the graphemes/ouw/and/auw/

- The phoneme /o:/for the graphemes/oo/ and /o/

- The phoneme / $y$ :/ for the graphemes/uu/ and /u/

- The phoneme /a:/for the graphemes /aa/ and /a/

- The phoneme/t/for the grapheme/t/and/d/(e.g./had/)

- The phoneme $/ p /$ for the graphemes $/ p /$ and $/ b /$

All homophone and homograph pairs will be presented together in a clustered ball that falls down the screen. The most prototypical item, that has already been introduces in stream 2, will physically be larger compared to the less prototypical item. After presenting the pairs they will be introduced in whole word context (i.e., simple nouns known by $80-100 \%$ of pre-school children according to the Dutch target vocabulary mentioned above).

\begin{tabular}{r|cccccc}
\hline \multicolumn{1}{|l|}{ BLOCK L } & Items & & & & \\
\hline Level & e-ĕ (@) & u-uu (y:) & o-oo (o:) & a-aa (a:) & & \\
75 & ja & zo & we & stro & vla & de \\
76 & me & je & ma & te & sla & nu \\
\hline
\end{tabular}

Introduction of exception homographs (i.e., one grapheme for two or more phonemes):

- The grapheme/e/for the phoneme/E/ and/@/(e.g./den/ and/de/)

Homographs are presented with a short instruction. Then, it is presented in whole word context (i.e., simple nouns known by $80-100 \%$ of pre-school children according to the Dutch target vocabulary mentioned above). 


\section{REFERENCES}

Baayen, R. H., Piepenbrock, R., \& Gulikers, L. (1995). The CELEX lexical database (CD-ROM). Philadelphia, PA: Linguistic Data Consortium, University of Pennsylvania.

Lyytinen, H., Ronimus, M., Alanko, A., Poikkeus, A.-M., \& Taanila, M. (2007). Early identification of dyslexia and the use of computer game-based practice to support reading acquisition. Nordic Psychology, 59(2), 109.

Richardson, U., \& Lyytinen, H. (2014). The GraphoGame method: The theoretical and methodological background of the technology-enhanced learning environment for learning to read. Human Technology: An Interdisciplinary Journal on Humans in ICT Environments, 10(1), 39-60. 